NUREG/CR-6341

INEL-95/0215

\title{
Microbial Degradation of
}

Low-Level Radioactive Waste

Final Report

FrCERED

JUL 05 彳996

OSTI

Prepared by

R. D. Rogers, M. A. Hamilton, R. H. Veeh,

J. W. McConnell, Jr.

Idaho National Engineering Laboratory

Lockheed Idaho Technologies Company

Prepared for

U.S. Nuclear Regulatory Commission 


\section{AVAILABILITY NOTICE}

Availability of Reference Materials Cited in NRC Publications

Most documents cited in NRC publications will be available from one of the following sources:

1. The NRC Public Document Room, 2120 L Street, NW., Lower Level, Washington, DC 20555-0001

2. The Superintendent of Documents, U.S. Government Printing Office, P. O. Box 37082, Washington, DC 20402-9328

3. The National Technical Information Service, Springfield, VA 22161-0002

Although the listing that follows represents the majority of documents cited in NRC publications, it is not intended to be exhaustive.

Referenced documents available for inspection and copying for a fee from the NRC Public Document Room include NRC correspondence and internal NRC memoranda: NRC bulletins, circulars, information notices, inspection and investigation notices; licensee event reports; vendor reports and correspondence; Commission papers; and applicant and licensee documents and correspondence.

The following documents in the NUREG series are available for purchase from the Government Printing Office: formal NRC staff and contractor reports, NRC-sponsored conference proceedings, international agreement reports, grantee reports, and NRC booklets and brochures. Also available are regulatory guides, NRC regulatlons in the Code of Federal Regulations, and Nuclear Regulatory Commission Issuances.

Documents avallable from the National Technical information Service include NUREG-series reports and technical reports prepared by other Federal agencies and reports prepared by the Atomic Energy Commission, forerunner agency to the Nuclear Regulatory Commission.

Documents available from public and special technical libraries include all open literature items, such as books. journal articles, and transactions. Federal Register notices. Federal and State legislation, and congressional reports can usually be obtained from these libraries.

Documents such as theses, dissertations, foreign reports and translations, and non-NRC conference proceedings are available for purchase from the organization sponsoring the publication cited.

Single coples of NRC draft reports are available free, to the extent of supply. upon written request to the Office of Administration, Distribution and Mail Services Section, U.S. Nuclear Regulatory Commission. Washington. DC 20555-0001.

Coples of industry codes and standards used in a substantive manner in the NRC regulatory process are maintalned at the NRC Library. Two White Flint North, 11545 Rockville Pike, Rockville. MD 20852-2738, for use by the public. Codes and standards are usually copyrighted and may be purchased from the originating organization or, if they are American National Standards. from the American National Standards Institute, 1430 Broadway, New York, NY 10018-3308.

\section{DISCLAIMER NOTICE}

This report was prepared as an account of work sponsored by an agency of the United States Government. Neither the United States Government norany agency thereof, nor any of their employees, makes any warranty, expressed or implied, or assumes any legal liability or responsibility for any third party's use, or the results of such use, of any information, apparatus, product, or process disclosed in this report, or represents that its use by such third party would not infringe privately owned rights. 


\section{Microbial Degradation of \\ Low-Level Radioactive Waste}

\section{Final Report}

Manuscript Completed: March 1996

Date Published: June 1996

Prepared by

R. D. Rogers, M. A. Hamilton, R. H. Veeh,

J. W. McConnell, Jr.

Idaho National Engineering Laboratory

Lockheed Idaho Technologies Company

Idaho Falls, ID 83415

P. Reed, NRC Project Manager

Prepared for

Division of Regulatory Applications

Office of Nuclear Regulatory Research

U.S. Nuclear Regulatory Commission

Washington, DC 20555-0001

NRC Job Code L1807 


\section{DISCLAIMER}

NUREG/CR-6341 is not a substitute for NRC regulations and compliance is not required. The approaches and/or methods described in this NUREG/CR are provided for information only. Publication of this report does not necessarily constitute NRC approval or agreement with the information contained herein. 


\begin{abstract}
The Nuclear Regulatory Commission stipulates in 10 CFR 61 that disposed lowlevel radioactive waste (LLW) be stabilized. To provide guidance to disposal vendors and nuclear station waste generators for implementing those requirements, the NRC developed the Technical Position on Waste Form, Revision 1. That document details a specified set of recommended testing procedures and criteria, including several tests for determining the biodegradation properties of waste forms. Information has been presented by a number of researchers, which indicated that those tests may be inappropriate for examining microbial degradation of cementsolidified LLW. Cement has been widely used to solidify LLW; however, the resulting waste forms are sometimes susceptible to failure due to the actions of waste constituents, stress, and environment. The purpose of this research program was to develop modified microbial degradation test procedures that would be more appropriate than the existing procedures for evaluation of the effects of microbiologically influenced chemical attack on cement-solidified LLW. The procedures that have been developed in this work are presented and discussed. Groups of microorganisms indigenous to LLW disposal sites were employed that can metabolically convert organic and inorganic substrates into organic and mineral acids. Such acids aggressively react with cement and can ultimately lead to structural failure. Results on the application of mechanisms inherent in microbially influenced degradation of cement-based material are the focus of this final report. Datavalidated evidence of the potential for microbially influenced deterioration of cement-solidified LLW and subsequent release of radionuclides developed during this study are presented.
\end{abstract}

Job Code L1807-Microbial Degradation of Low-Level Waste 


\section{CONTENTS}

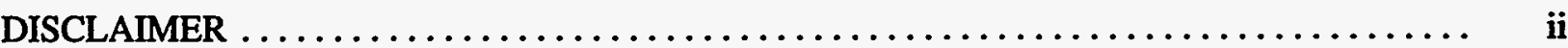

ABSTRACT $\ldots \ldots \ldots \ldots \ldots \ldots \ldots \ldots \ldots \ldots \ldots \ldots \ldots \ldots \ldots \ldots \ldots \ldots \ldots \ldots \ldots \ldots \ldots \ldots \ldots$

LIST OF FIGURES $\ldots \ldots \ldots \ldots \ldots \ldots \ldots \ldots \ldots \ldots \ldots \ldots \ldots \ldots \ldots \ldots \ldots \ldots \ldots$

LIST OF TABLES $\ldots \ldots \ldots \ldots \ldots \ldots \ldots \ldots \ldots \ldots \ldots \ldots \ldots \ldots \ldots \ldots \ldots \ldots \ldots \ldots \ldots$

INTRODUCTION $\ldots \ldots \ldots \ldots \ldots \ldots \ldots \ldots \ldots \ldots \ldots \ldots \ldots \ldots \ldots \ldots \ldots \ldots \ldots$

Regulatory Background $\ldots \ldots \ldots \ldots \ldots \ldots \ldots \ldots \ldots \ldots \ldots \ldots \ldots \ldots \ldots \ldots \ldots \ldots$

Technical Background $\ldots \ldots \ldots \ldots \ldots \ldots \ldots \ldots \ldots \ldots \ldots \ldots \ldots \ldots \ldots \ldots \ldots \ldots$

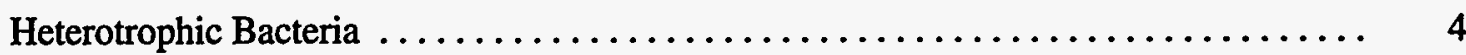

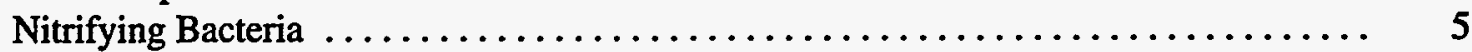

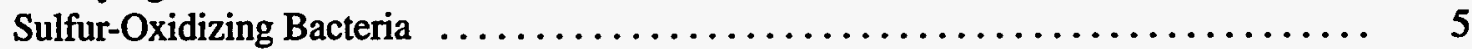

MATERIALS AND METHODS $\ldots \ldots \ldots \ldots \ldots \ldots \ldots \ldots \ldots \ldots \ldots \ldots \ldots \ldots \ldots$

Development of Microbial Culture Collection $\ldots \ldots \ldots \ldots \ldots \ldots \ldots \ldots \ldots \ldots \ldots$

Soil Sample Collection $\ldots \ldots \ldots \ldots \ldots \ldots \ldots \ldots \ldots \ldots \ldots \ldots \ldots \ldots \ldots \ldots \ldots \ldots \ldots \ldots \ldots$

Isolation of Microbes from Soils $\ldots \ldots \ldots \ldots \ldots \ldots \ldots \ldots \ldots \ldots \ldots \ldots \ldots \ldots \ldots$

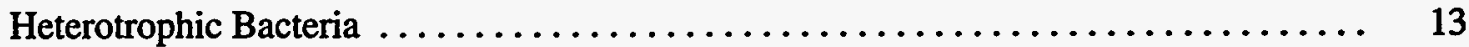

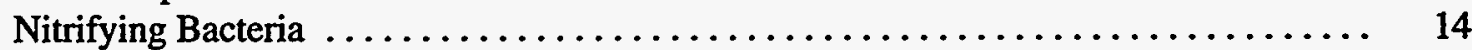

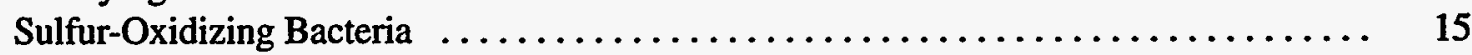

Development of Procedures for Growing Candidate Microorganisms $\ldots \ldots \ldots \ldots \ldots \ldots$

Determination of Microorganisms Capable of Cement Degradation $\ldots \ldots \ldots \ldots \ldots \ldots \ldots$

Development of Criteria for Evaluation of Test Effects $\ldots \ldots \ldots \ldots \ldots \ldots \ldots \ldots \ldots$

EXPERIMENTAL RESULTS $\ldots \ldots \ldots \ldots \ldots \ldots \ldots \ldots \ldots \ldots \ldots \ldots \ldots \ldots \ldots \ldots \ldots \ldots$

Microorganism Availability $\ldots \ldots \ldots \ldots \ldots \ldots \ldots \ldots \ldots \ldots \ldots \ldots \ldots \ldots \ldots$

Development of Testing Methodology $\ldots \ldots \ldots \ldots \ldots \ldots \ldots \ldots \ldots \ldots \ldots \ldots \ldots \ldots \ldots$

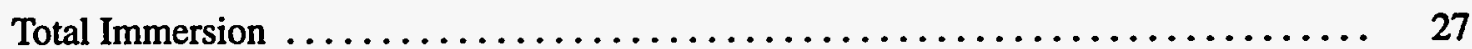

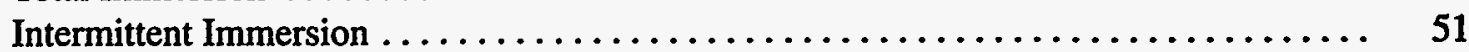

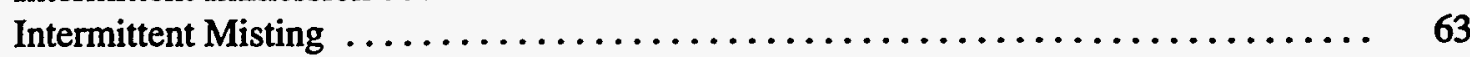

Testing of Actual Waste Forms $\ldots \ldots \ldots \ldots \ldots \ldots \ldots \ldots \ldots \ldots \ldots \ldots \ldots \ldots \ldots \ldots$

SUMMARY $\ldots \ldots \ldots \ldots \ldots \ldots \ldots \ldots \ldots \ldots \ldots \ldots \ldots \ldots \ldots \ldots \ldots \ldots \ldots \ldots \ldots$ 
CONCLUSIONS

REFERENCES

Appendix A - Task 8: Intermittent Emersion Test Procedure

A-1

Appendix B - Task 7: Development of Criteria for Evaluation of Test Effects

B-1 


\section{LIST OF FIGURES}

1. Development of microbial culture collection $\ldots \ldots \ldots \ldots \ldots \ldots \ldots \ldots \ldots \ldots \ldots \ldots$

2. U.S. Ecology Low-Level Waste Facility, Beatty, NV ................... 8

3. Proposed U.S. Ecology Low-Level Waste Site, Ward Valley, CA .............. 8

4. Disassembled soil coring equipment $\ldots \ldots \ldots \ldots \ldots \ldots \ldots \ldots \ldots \ldots \ldots \ldots \ldots \ldots \ldots$

5. Assembled soil core retriever (extension rods are afixed for retrieving cores at depth) $\ldots \ldots \quad 10$

6. Soil auger with attached extension rods for coring at depth $\ldots \ldots \ldots \ldots \ldots \ldots \ldots \ldots$

7. Capped stainless steel core liner and casing device $\ldots \ldots \ldots \ldots \ldots \ldots \ldots \ldots \ldots \ldots \ldots$

8. Twisting the coring device into the soil $\ldots \ldots \ldots \ldots \ldots \ldots \ldots \ldots \ldots \ldots \ldots \ldots \ldots \ldots \ldots \ldots \ldots$

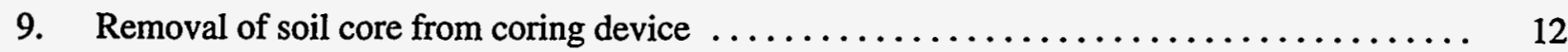

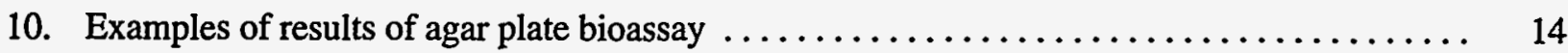

11. Schematic of methods used for selecting candidate microorganisms $\ldots \ldots \ldots \ldots \ldots \ldots \ldots$

12. Development of procedures for growth and preservation of selected microbes $\ldots \ldots \ldots \ldots \quad 17$

13. Schematic of proposed methods for testing the effects of MID on cement waste forms $\ldots \ldots \quad 22$

14. Examples of possible composition of simulated low-level waste forms $\ldots \ldots \ldots \ldots \ldots$

15. Matrix for testing simulated low-level waste forms $\ldots \ldots \ldots \ldots \ldots \ldots \ldots \ldots \ldots \ldots$

16. ASTM control waste-form specimens after being immersed for 66 days in (a) sterile nitrifier

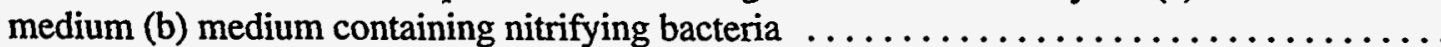

17. INEL-supplied simulated evaporator bottoms waste-form specimen after being immersed for 66 days in (a) sterile nitrifier medium (b) medium containing nitrifying bacteria .......

18. INEL-supplied simulated ion-exchange resin waste-form specimen after being immersed for 66 days in (a) sterile nitrifier medium (b) medium containing nitrifying bacteria . . . . . .

19. ESEM photograph of ASTM control waste-form specimens after exposure to (a) sterile

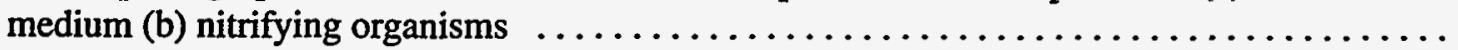

20. ESEM photograph of INEL-supplied simulated evaporator bottoms waste-form specimens after exposure to (a) sterile medium (b) nitrifying organisms $\ldots \ldots \ldots \ldots \ldots \ldots \ldots$

21. ESEM photograph of INEL-supplied simulated exchange resin waste-form specimen after

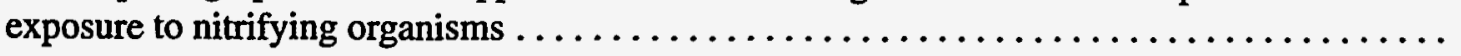

22. Biofilm staining of INEL-supplied simulated waste-form specimen after exposure to nitrifying organisms (a) stained blue to demonstrate presence of biofilm EPS material and (b) fluorescent orange stain demonstrating presence of viable cells $\ldots \ldots \ldots \ldots \ldots$

23. Quantities of Ca leached from INEL-supplied simulated waste forms after $\mathbf{6 0}$ days of total immersion (nitrifying organisms) 
24. Nitrite content over time of media containing nitrifying bacteria and vendor-supplied

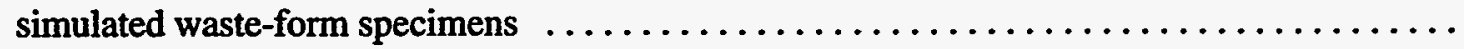

25. $\mathrm{pH}$ over time of media containing nitrifying bacteria and vendor-supplied simulated

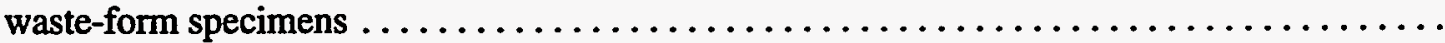

26. Cumulative Ca released from vendor-supplied simulated waste-form specimens exposed

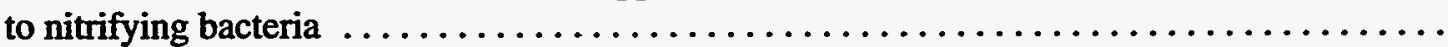

27. Total Ca released from vendor-supplied simulated waste-form specimen over a period of

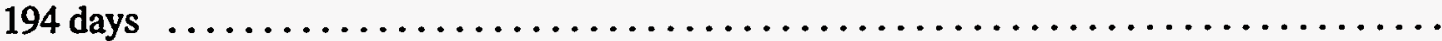

28. Electron micrographs of ASTM and vendor-supplied simulated waste-form specimens after 26 days of exposure to nitrifying bacteria (a) ASTM treatment (b) ASTM treatment

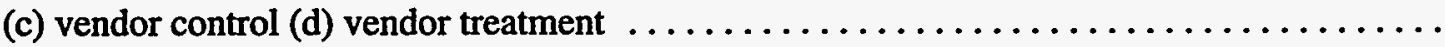

29. Electron micrographs of vendor-supplied simulated waste-form specimens after 61 days exposure to nitrifying bacteria (a) vendor treatment (b) PWR treatment $\ldots \ldots \ldots \ldots \ldots \ldots$

30. Electron micrographs of ASTM and vendor-supplied simulated waste-form specimens after 113 days exposure to nitrifying bacteria (a) ASTM treatment (b) vendor treatment

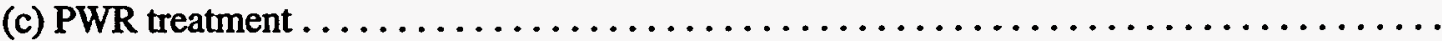

31. ASTM control waste-form specimens after being immersed for 60 days in (a) sterile

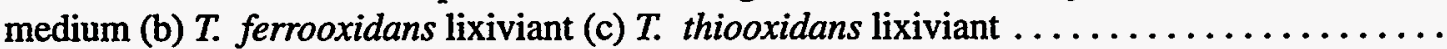

32. INEL-supplied simulated evaporator bottoms waste-form specimens after being immersed for 60 days in (a) sterile medium (b) $T$. ferrooxidans lixiviant (c) T. thiooxidans lixiviant ...

33. INEL-supplied simulated ion-exchange resin waste-form specimens after being immersed for 60 days in (a) sterile medium (b) $T$. ferrooxidans lixiviant (c) $T$. thiooxidans lixiviant ...

34. Quantities of $\mathrm{Ca}$ leached from INEL-supplied simulated waste-form specimens after 60 days of total immersion

35. $\mathrm{pH}$ of lixiviants after exposure to INEL-supplied simulated waste-form specimens during

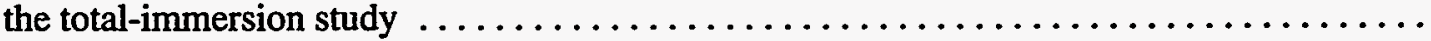

36. Vendor-supplied simulated evaporator bottoms waste-form specimens after being immersed for 30 days in (a) sterile medium (b) $T$. ferrooxidans lixiviant (c) $T$. thiooxidans lixiviant ...

37. Vendor-supplied simulated ion-exchange resin waste-form specimens after being immersed for 30 days in (a) sterile medium (b) $T$. ferrooxidans lixiviant (c) $T$. thiooxidans lixiviant ...

38. Quantities of Ca leached from vendor-supplied simulated waste-form specimens after 30 days of total immersion

39. Quantities of $\mathrm{Al}$ leached from vendor-supplied simulated waste-form specimens after

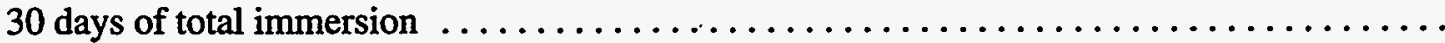

40. Quantities of Si leached from vendor-supplied simulated waste-form specimens after 30 days of total immersion

41. Quantities of Fe leached from vendor-supplied simulated waste-form specimens after 30 days of total immersion 
42. Quantities of $\mathrm{Mg}$ leached from vendor-supplied simulated waste-form specimens after 30 days of total immersion

43. $\mathrm{pH}$ of lixiviants after exposure to vendor-supplied simulated waste-form specimens during the total-immersion study

44. ESEM photograph of ASTM control waste-form specimen after exposure to sulfuroxidizing organisms

45. ESEM photograph of INEL-supplied simulated evaporator bottoms waste-form specimen

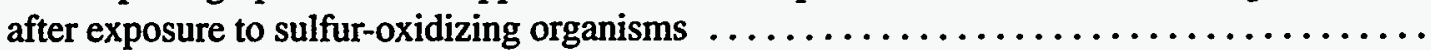

46. Biofilm staining of INEL-supplied simulated waste-form specimen after exposure to sulfur-oxidizing organisms (a) stained blue to demonstrate presence of biofilm EPS material and (b) fluorescent orange stain demonstrating presence of viable cells .........

47. Vessels (Soxhlet extractors) used to intermittently expose simulated waste-form specimens to lixiviants

48. ASTM control waste-form specimens after being intermittently immersed for 60 days in (a) sterile medium (b) $T$. ferrooxidans lixiviant (c) $T$. thiooxidans lixiviant . . . . . . .

49. INEL-supplied simulated evaporator bottoms waste-form specimens after being intermittently immersed for 60 days in (a) sterile medium (b) $T$. ferrooxidans lixiviant

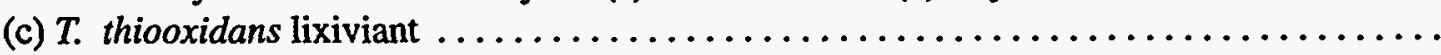

50. INEL-supplied simulated ion-exchange resin waste-form specimens after being intermittently immersed for 60 days in (a) sterile medium (b) $T$. ferrooxidans lixiviant (c) $T$. thiooxidans lixiviant

51. Vendor-supplied simulated evaporator bottoms waste-form specimens after being intermittently immersed for 60 days in (a) sterile medium (b) $T$. ferrooxidans lixiviant (c) T. thiooxidans lixiviant

52. Vendor-supplied simulated ion-exchange resin waste-form specimens after being intermittently immersed for 60 days in (a) sterile medium (b) $T$. ferrooxidans lixiviant (c) $T$. thiooxidans lixiviant

53. Quantities of $\mathrm{Ca}$ leached from vendor-supplied waste-form specimens after 60 days of

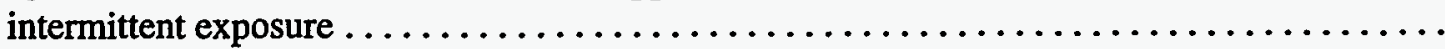

54. Quantities of $\mathrm{Al}$ leached from vendor-supplied waste-form specimens after 60 days of

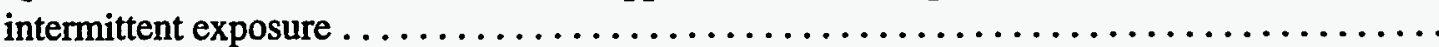

55. Quantities of Si leached from vendor-supplied waste-form specimens after 60 days of

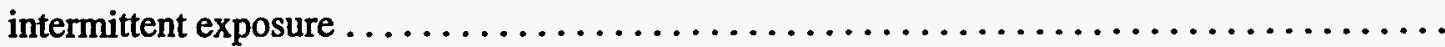

56. Quantities of Fe leached from vendor-supplied waste-form specimens after 60 days of intermittent exposure

57. Quantities of $\mathrm{Mg}$ leached from vendor-supplied waste-form specimens after 60 days of intermittent exposure. 
58. Cumulative quantities of $\mathrm{Ca}$ leached from vendor-supplied evaporator bottoms waste-form specimens during the intermittent-exposure study $\ldots \ldots \ldots \ldots \ldots \ldots \ldots \ldots \ldots \ldots$

59. Cumulative quantities of $\mathrm{Al}$ leached from vendor-supplied evaporator bottoms waste-form

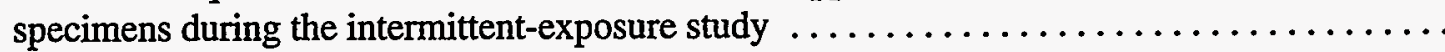

60. Cumulative quantities of $\mathrm{Si}$ leached from vendor-supplied evaporator bottoms waste-form specimens during the intermittent-exposure study $\ldots \ldots \ldots \ldots \ldots \ldots \ldots \ldots \ldots \ldots \ldots$

61. Cumulative quantities of $\mathrm{Ca}$ leached from vendor-supplied ion-exchange resin waste-form specimens during the intermittent-exposure study $\ldots \ldots \ldots \ldots \ldots \ldots \ldots \ldots \ldots \ldots$

62. Cumulative quantities of $\mathrm{Al}$ leached from vendor-supplied ion-exchange resin waste-form specimens during the intermittent-exposure study $\ldots \ldots \ldots \ldots \ldots \ldots \ldots \ldots \ldots \ldots$

63. Cumulative quantities of $\mathrm{Si}$ leached from vendor-supplied ion-exchange resin waste-form specimens during the intermittent-exposure study $\ldots \ldots \ldots \ldots \ldots \ldots \ldots \ldots \ldots \ldots$

64. $\mathrm{pH}$ of lixiviants after exposure to vendor-supplied waste-form specimens during the intermittent-immersion study

65. Prototype for intermittent-misting chamber

66. Waste-form specimen placement in misting chamber

67. ASTM control waste-form specimens after being intermittently misted for 60 days with (a) sterile medium (b) $T$. ferrooxidans lixiviant (c) $T$. thiooxidans lixiviant $\ldots \ldots \ldots \ldots \ldots$

68. Vendor-supplied simulated evaporator bottoms waste-form specimens after being intermittently misted for 60 days with (a) sterile medium (b) $T$. ferrooxidans lixiviant

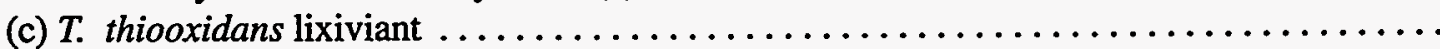

69. Vendor-supplied simulated ion-exchange resin waste-form specimens after being intermittently misted for 60 days with (a) sterile medium (b) $T$. ferrooxidans lixiviant (c) T. thiooxidans lixiviant

70. ESEM photograph of vendor-supplied simulated evaporator bottoms waste-form specimens after exposure to (a) $T$. ferrooxidans (b) $T$. thiooxidans $\ldots \ldots \ldots \ldots \ldots \ldots \ldots \ldots \ldots \ldots$

71. ESEM photograph of vendor-supplied simulated ion-exchange resin waste-form specimen

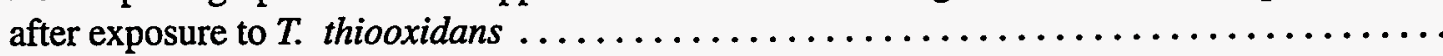

72. ESEM photograph of vendor-supplied simulated ion-exchange resin waste-form specimen after exposure to sterile medium.$\ldots \ldots \ldots \ldots \ldots \ldots \ldots \ldots \ldots \ldots \ldots \ldots \ldots$.

73. Setup for intermittent-immersion testing of actual vendor-supplied waste-form specimens ...

74. ASTM control waste-form specimens exposed over time to sterile medium (a) ASTM duplicate 1 at day 20 (b) ASTM duplicate 2 at day 20 (c) ASTM duplicate 1 at day 30 (d) ASTM duplicate 2 at day 30 (e) ASTM duplicate 1 at day 60 (f) ASTM duplicate 2 at day 60 
75. ASTM control waste-form specimens exposed over time to thiobacilli lixiviant (a) ASTM duplicate 1 at day 20 (b) ASTM duplicate 2 at day 20 (c) ASTM duplicate 1 at day 30

(d) ASTM duplicate 2 at day 30 (e) ASTM duplicate 1 at day 60 (f) ASTM duplicate 2

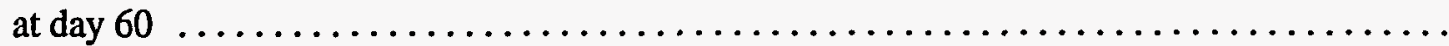

76. Vendor-supplied waste-form specimens exposed over time to sterile medium (a) Peach Bottom duplicate 1 at day 20 (b) Peach Bottom duplicate 2 at day 20 (c) Peach Bottom duplicate 1 at day 30 (d) Peach Bottom duplicate 2 at day 30 (e) Peach Bottom duplicate 1 at day 60

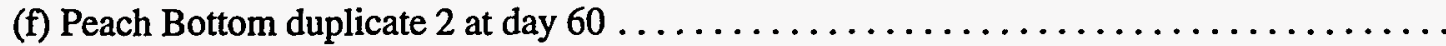

77. Vendor-supplied waste-form specimens exposed over time to thiobacilli lixiviant (a) Peach Bottom duplicate 1 at day 20 (b) Peach Bottom duplicate 2 at day 20 (c) Peach Bottom duplicate 1 at day 30 (d) Peach Bottom duplicate 2 at day 30 (e) Peach Bottom duplicate 1 at day 60 (f) Peach Bottom duplicate 2 at day $60 \ldots \ldots \ldots \ldots \ldots \ldots \ldots \ldots \ldots \ldots$

78. Vendor-supplied waste-form specimens exposed over time to sterile medium (a) Nine Mile Point duplicate 1 at day 20 (b) Nine Mile Point duplicate 2 at day 20 (c) Nine Mile Point duplicate 1 at day 30 (d) Nine Mile Point duplicate 2 at day 30 (e) Nine Mile Point duplicate 1 at day 60 (f) Nine Mile Point duplicate 2 at day 60

79. Vendor-supplied waste-form specimens exposed over time to thiobacilli lixiviant (a) Nine Mile Point duplicate 1 at day 20 (b) Nine Mile Point duplicate 2 at day 20 (c) Nine Mile Point duplicate 1 at day 30 (d) Nine Mile Point duplicate 2 at day 30 (e) Nine Mile Point duplicate 1 at day 60 (f) Nine Mile Point duplicate 2 at day 60

80. Recovered vendor-supplied Peach Bottom waste-form specimens (a) before exposure (b) duplicate 1 after 60-day exposure to sterile medium (c) duplicate 2 after 60-day exposure to sterile medium (d) duplicate 1 after 60-day exposure to thiobacilli lixiviant (e) duplicate 2 after 60 -day exposure to thiobacilli lixiviant $\ldots \ldots \ldots \ldots \ldots \ldots \ldots \ldots$

81. Recovered vendor-supplied Nine Mile Point waste-form specimens (a) before exposure (b) duplicate 1 after 60-day exposure to sterile medium (c) duplicate 2 after 60-day exposure to sterile medium (d) duplicate 1 after 60-day exposure to thiobacilli lixiviant (e) duplicate 2 after 60 -day exposure to thiobacilli lixiviant $\ldots \ldots \ldots \ldots \ldots \ldots \ldots$

82. Cumulative Co-60 leached over time from Peach Bottom waste-form specimens exposed to either sterile medium or thiobacilli lixiviant $\ldots \ldots \ldots \ldots \ldots \ldots \ldots \ldots \ldots \ldots \ldots \ldots$

83. Cumulative Cs-137 leached over time from Peach Bottom waste-form specimens exposed

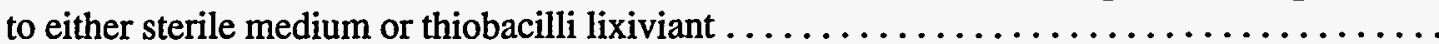

84. Cumulative $\mathrm{Co}-60$ leached over time from Nine Mile Point waste-form specimens exposed to either sterile medium or thiobacilli lixiviant $\ldots \ldots \ldots \ldots \ldots \ldots \ldots \ldots \ldots \ldots \ldots \ldots$

85. Cumulative Cs-137 leached over time from Nine Mile Point waste-form specimens exposed to either sterile medium or thiobacilli lixiviant

86. Cumulative Cs-134 leached over time from Nine Mile Point waste-form specimens exposed to either sterile medium or thiobacilli lixiviant . 


\section{LIST OF TABLES}

1. Physical description and $\mathrm{pH}$ of soils collected from the proximity of $\mathrm{LWW}$ and proposed

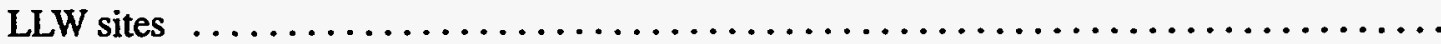

2. Types and numbers of microorganisms isolated from the proximity of LLW and proposed LLW sites

3. Typical formulations of waste types from BWR and PWR reactor sites with listed $\mathrm{pH}$ and

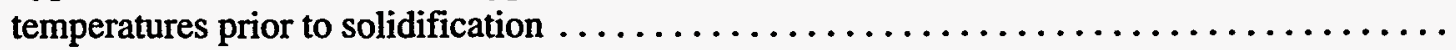

4. Formulation of heterotrophic bacteria medium $\ldots \ldots \ldots \ldots \ldots \ldots \ldots \ldots \ldots \ldots$

5. Formulation of ammonia-oxidizer medium for Nitrosomonas and Nitrosovibrio

6. Results of most probable number enumeration of pellet surfaces $\ldots \ldots \ldots \ldots \ldots \ldots \ldots$

7. Formulation of sulfur-oxidizing bacteria medium $\ldots \ldots \ldots \ldots \ldots \ldots \ldots \ldots \ldots$

8. Surface $\mathrm{pH}$ of INEL-supplied simulated cement waste-form specimens before and after immersion for 60 days in sterile medium or microbially produced lixiviant $\ldots \ldots \ldots \ldots \ldots$

9. Surface $\mathrm{pH}$ of vendor-supplied, simulated cement waste-form specimens, before and after immersion for 30 days in sterile medium or microbially produced lixiviant $\ldots \ldots \ldots \ldots \ldots$

10. Surface $\mathrm{pH}$ of INEL waste-form specimens exposed to lixiviant during intermittent immersion

11. Surface $\mathrm{pH}$ of vendor-supplied waste-form specimens exposed to lixiviant during intermittent immersion

12. Summary of data collected from waste-form specimens exposed to intermittent misting .....

13. Peach Bottom and Nine Mile Point waste stream analysis $\ldots \ldots \ldots \ldots \ldots \ldots \ldots \ldots$

14. Quantities of Co-60, Cs-137, and Cs-134 leached over time from Peach Bottom cementsolidified low-level waste-form specimens as a result of the accelerated biotest . . . . . . . .

15. Quantities of Co-60, Cs-137, and Cs-134 leached over time from Nine Mile Point cementsolidified low-level waste-form specimens as a result of the accelerated biotest . . . . . . . .

16. Total quantity of C-14, Tc-99, and Sr-90 leached over 8 weeks from Peach Bottom and Nine Mile Point cement-solidified low-level waste-form specimens as a result of the accelerated biotest 


\section{Microbial Degradation of Low-Level Radioactive Waste Final Report}

\section{INTRODUCTION}

\section{Regulatory Background}

Microorganisms have been isolated in samples taken from low-level radioactive waste (LLW) environments (Francis et al. 1980). This realization, combined with scientific data that demonstrate the existence of microorganisms under hostile conditions once thought to exclude them, have raised the concerns that microbial activity at LLW disposal sites could affect the long-term stability of the disposed waste. Due to apprehension over possible microbial effects, the United States Nuclear Regulatory Commission (NRC) requires that microbial activity be addressed as one of the requirements for determining the stability of Class B and C LLW [10 CFR 61.56(b)(1)]. This methodology is needed to ensure that these radioactive wastes can be disposed of safely for 300 to 500 years. The NRC developed the Technical Position on Waste Form, Revision 1 (NRC 1991), to provide guidance to disposal vendors and nuclear station waste generators to implement the stability requirements of 10 CFR 61 (NRC 1987). That document details a specified set of required testing procedures and criteria, including several tests for determining the biodegradation properties of waste forms.

Concerns were voiced over the appropriateness of the Technical Position tests for microbial degradation of cement containing LLW at the NRCsponsored "Proceedings of the Workshop on Cement Stabilization of Low-Level Radioactive Waste" (Tokar 1989). It became apparent during the deliberations that improved tests would be required if meaningful information were to be obtained from biodegradation studies on cement wastes. A major difficulty identified was that current testing procedures did not adequately determine the bioeffects on cementitious materials because the microorganisms used for the accelerated testing were not associated with cement degradation. Further, it was pointed out that there were literature references that identified specific microorganisms as the causative agents of cement degradation. The conclusions reached by the workshop were that "there appeared to be a clear need to specify more appropriate microbes for such [Technical Position] tests" and that "this [need] might require a substantial research effort" (Tokar 1989).

Researchers familiar with the required Technical Position biodegradation tests, American Society for Testing and Materials (ASTM) G21 and G22 (ASTM 1981a; 1981b), have not found them to be applicable for use with cementsolidified LLW. Doubts raised concerning the tests included (a) the lack of demonstrable evidence that specific microorganisms, required by the ASTM standard tests, could promote degradation of cement waste forms under any test conditions, (b) the lack of flexibility in determining the duration of time required for test completion, and (c) the lack of flexibility in determining test specimen size and preparation (Rogers and McConnell 1988).

The NRC's Advisory Committee on Nuclear Waste has also raised concerns about biodegradation testing of LLW. In a letter to the Commission, dated September 6, 1990, the Committee indicated that biodegradation testing should be specified for cementitious waste matrices, using bacteria that are likely to affect cement and any organic component exposed during the degradative process.

Based on the NRC needs, the objectives of the program have been to (a) develop biodegradation test procedures to determine cement waste stability, (b) test the developed procedures on simulated nonradioactive waste and, if successful, continue with actual solidified LLW, (c) recommend modified test procedures for consideration as revisions to the Technical Position, based on the best procedures developed, 
(d) investigate the environment of LLW sites to determine if microorganisms capable of degrading waste-form materials are present, and (e) determine if microbial action can promote the release of radionuclides from LLW and solidified LLW.

The research conducted for this program provided data, information, and recommendations, which the NRC can use as a basis for (a) the implementation of 10 CFR 61 requirements that deal with the stability of cementitious LLW specimens when challenged by known cementdegrading microorganisms under optimal conditions for cement degradation, (b) modifications to the Technical Position testing procedures to more realistically determine microbial effects on cement-solidified LLW, (c) guidance to licensees concerning a determination of the susceptibility of cement-stabilized LLW to biodegradation, and (d) the determination of microorganism-related radionuclide releases. This work provided a basis for including microbial-degradation potential in predicting overall safety and performance of new LLW disposal facilities.

The following tasks were identified as requirements to reach the objectives stated above. The status of each task is also given.

Task 1: Literature Review-A literature review was conducted to provide information on test sophistication, methods, and materials. Information was gathered on the impact that biological organisms have on cement. This included information on conditions that promote deterioration and what organisms are responsible. Information on the occurrence and extent of microbial populations at LLW disposal sites together with the prevalent type of microorganism was investigated. This task resulted in the preparation of NUREG/CR-5987 (Rogers et al. 1993). This task is complete.

Task 2: Develop Program Plan-A program plan was written that contains detailed program requirements, including a test plan, testing procedures, required equipment and facilities, waste form composition (cement and type of LLW to be used), identification of microbial species, and a bibliography. Input for the plan came from past experience, the literature review, and involvement with recognized peers. This task resulted in a letter report. This task is complete.

Task 3: Develop Microbial Culture Collection-A collection of microbial cultures was initiated. The intent of this activity is to obtain organisms that are expected to interact with the selected cement-solidified waste material(s). Microorganisms were obtained from other culture collections (commercial and private) as well as from environments where there is evidence of natural degradation of solidification materials. Pure cultures of promising microorganisms were developed and are being maintained. This task resulted in a letter report. This task is complete.

Task 4: Determine Microorganisms Capable of Cement Degradation-Work was conducted to determine which microorganisms from the culture collection of Task 3 were capable of degrading cement. This task required an in-depth study of the biodegradation potential of the individual microbial species. Growth of the test microorganisms was monitored, and analysis was conducted to detect the presence of microbially produced metabolites, which could affect the test material. Different methodologies that integrate exposure time and microbial activity were evaluated. Microbial isolates were classified that were determined by the screening procedures to be potential candidates for degradation studies. A knowledge of the types of microorganisms that promote degradation was useful for comparison with microorganisms endemic to existing and proposed LLW disposal sites. Cement-degrading microorganisms were determined and documented in a letter report. This task is complete.

Task 5: Develop Procedures for Growing Candidate Microorganisms-Media necessary for the promotion of active growth of the candidate microorganisms from Task 4 were obtained or developed. This involved determining the appropriate energy and carbon source, mineral nutrients, $\mathrm{pH}$ range, and temperature range. Methods were developed for incubation and preservation of the candidate 
microorganisms. Procedures such as freeze drying, low-temperature freezing of liquid cultures, or storage on solid media were evaluated. Procedures for growing candidate microbes were developed and are documented in a letter report. This task is complete.

Task 6: Develop Initial Test Methodology for Assessing Biodegradation-It has been suggested by researchers at the INEL and Brookhaven National Laboratory that standard biodegradation tests (such as ASTM G21 and G22) are not applicable for use with some materials used to solidify LLW. Concerns raised over these tests included specimen size and preparation, the lack of demonstrable evidence that the microorganisms required by the standard tests stated above could promote degradation of the materials in question, and lack of flexibility in determining the duration of time required for test completion. Cement testing methodology was developed to answer the above concerns. Such methods included exposure of cement to a wide range of microbial species (especially to those known to affect cement); determination of the appropriate size for test specimens; use of alternative energy sources (carbon and non-carbon) to provide opportunity for assessing the effects of co-metabolism or biologically produced chemicals on specimen structure; and adequate time for a reasonable interaction between the microbial component and the test specimen. Testing of vendor-supplied simulated waste forms exposed to three species of bacteria is completed. Testing of vendor-supplied actual radioactive waste forms with a select bacterial species is completed. Analysis of samples of test lixiviant for radioactive content from that test has been completed. This task resulted in a letter report and is complete.

Task 7: Develop Criteria for Evaluation of Test Effects-It was necessary to designate some occurrence as a measurable endpoint for the cement specimen testing. Both biological and physical parameters were investigated. For example, effects on cement could be determined directly by measuring metabolic activity such as by-product production $\left(\mathrm{CO}_{2}\right.$, acid, etc.) or use of consumables (oxygen, carbon, inorganic, etc.). Some physical parameters such as specimen weight loss or visual deterioration will also be used. Work is being conducted on evaluation of methods that will determine to what extent biofilms develop on the surface of the waste forms. It is thought that the detection of biofilm development can be used as an indicator of the potential onset of cement degradation. Direct observation of biofilm development is continuing with scanning electron microscopy and light microscopy with selective straining methodology. This task resulted in a preliminary test eyaluation method, which was documented in a letter report. This task is complete.

Task 8: Apply Biodegradation Test to Actual LLW-The testing method developed in Task 6 was evaluated on actual cement solidification LLW samples containing different types of waste, including decontamination ion-exchange resins, evaporator concentrates, and filter sludges. Testing Thiobacillus thiooxidans using sections of actual LLW waste forms (Peach Bottom and Nine Mile Point) for 8 weeks has been completed. Visual observation indicate that these waste forms performed similarly to the simulated waste forms in prototype testing, that is, they were in various stages of disintegration. Photographs of the operation were taken on day 30 and again on day 60 . Radiochemical analysis of lixiviant recovered from the test has been completed. Effects were reported by letter. This task is complete.

Task 9: Apply Current Technical Position (Rev. 1) to LLW Containing Decontamination Radwaste - The effect of decontamination solutions on the integrity of LLW containing them was to be evaluated. Under current regulations, these wastes need to be tested for biodegradation. Selected cement-solidified wastes and decontamination LLW corresponding to those tested in Task 8 were to be examined using the current Technical Position method of ASTM G21 and G22. The results of that testing were to be compared to those obtained from the newly developed tests (Task 8). These comparisons could then be used by the NRC to judge the effectiveness of the new test protocol. This task was cancelled as being unnecessary. 
Task 10: Determine Radionuclide Releases from LLW by Microbial Action-Studies are being performed to determine the releases of radionuclides from actual stabilized cement LLW containing ion-exchange resins, and activated LLW materials by microorganisms. The investigations involve Class B low-level radioactive waste obtained from operating nuclear power stations (Peach Bottom and Nine Mile Point). The ion-exchange resins used in this task were those typically used in LLW applications at the nuclear stations and focused on decontamination waste containing chelating agents. Analytical results from Task 8 were presented in NUREG/CR-6188, Vol. 2 (Rogers et al. 1995). This task is complete.

\section{Technical Background}

Microbially influenced degradation (MID) of concrete has been reviewed elsewhere (Rogers et al. 1993). MID is thought to occur when microorganisms present in the environment produce mineral or organic acids that dissolve or disintegrate the cement matrix. The rate of degradation cannot be determined by measuring the generation of metabolically produced gases because the microorganisms are not metabolizing the cement matrix. The particular mechanisms of biological acid attack are consistent with those that have been associated with chemical attack.

A knowledge of the types of microorganisms that promote cement degradation is useful for selecting appropriate candidate organisms. Preliminary data (Rogers et al. 1993, 1994) suggest that the activity of three different genera of bacteria must be understood to provide a comprehensive evaluation of microbial degradation of selected cement-solidified waste materials. These include organic acid-producing heterotrophic bacteria, nitrifying bacteria, and sulfur-oxidizing bacteria. For the purposes of the work, suitable sources, from which these microorganisms have been isolated, include samples from sites with natural microbial activity, actual or proposed LLW locations, and use of inocula from existing culture collections.
While the literature suggests that the above microorganisms are ubiquitous in the environment, it was important in this study to demonstrate their presence in soils representative of present and proposed commercial LLW sites. The sources of microorganisms, with steps for confirming their viability in selective environments, were discussed previously (Rogers et al. 1994). However, by way of review, data on the isolation as well as the activity and significance of MID bacteria are provided.

Because of the number of individual bacterial isolates and the complexity of the testing procedures, it was necessary to use only representatives of the three main species of microorganisms in the actual testing procedure. It was assumed that the action of a representative species would be indicative of the activity of others in the group. This premise was shown to apply for the mineral acid-producing bacteria (nitrifying and thiobacilli species), but not for the heterotrophs. This was because organic acid production is not limited to a single genera of heterotrophs. Therefore, for this study, a known, aggressive heterotrophic bacterium (Pseudomonas cepacia) was selected. Strength of acid production was determined by the $\mathrm{pH}$ change of the solution in which the organism was being cultivated.

Heterotrophic Bacteria. A diverse group of microorganisms that degrade concrete are included with the heterotrophic bacteria. Heterotrophic microorganisms, capable of producing organic acids through the assimilation of organic carbon compounds, can be found everywhere. Organic acids such as lactic, citric, gluconic, malic, and many others are by-products of their metabolism. Several organic acids are produced on an industrial scale through the metabolic activity of these microbes. In addition, several types of these organisms, collected from a wide range of environments, are known to use an organic acid mechanism for the active extraction of phosphate from phosphate ores (Rogers and Wolfram 1992). They are known to promote acidic conditions that can be less than $\mathrm{pH} 3$.

In work conducted to determine the microbiological parameters associated with the English 
nuclear waste disposal effort (Dunk 1991), wide diversities of heterotrophic microorganisms were isolated from simulated, cement-solidified, plutonium-contaminated materials. Many cultured microbes could grow in alkaline conditions ( $\mathrm{pH} 11)$ common on the surface of concrete. Unfortunately, the studies were not carried out over a sufficient time to determine if growth of the organisms influenced the integrity of the concrete. Studies on the effects of heterotrophic degradation of cement-solidified LLW have also been conducted by the French ( $N$. Langomazino, personal communication 1990, Libert et al. 1993). They used a microbial growth medium containing concrete powder and common soil (the initial source of microbes). Several species of microbes were isolated by this method and maintained good growth in an alkaline medium ( $\mathrm{pH} 9$ ). Also, these microbes grew well in the presence of cement and produced organic acids. A fungus and the bacterium $P$. cepacia were selected for the concrete degradation studies. Their data showed that by 7 months, porosity had increased $11 \%$ in the samples, and at the end of 11 months, there had been a 50 to $85 \%$ loss of $\mathrm{Ca}(\mathrm{OH})_{2}$ in the treated concrete samples, resulting in an $80 \%$ loss of compressive strength. Further results, from a 2-year study, demonstrated that the organic acidproducing fungi were responsible for a significant loss of calcium from a defined leach layer of $0.2 \mathrm{~cm}$.

Though several heterotrophic bacterial species were isolated from the collected soil samples, it was possible to select only one as the candidate heterotrophic bacterium for use in the testing protocol. The selection was made after several isolates were screened to determine which could produce organic acids. This was accomplished using a bioassay that could detect bacteria capable of dissolving calcium compounds. Only one or two of the isolates exhibited the ability for extreme dissolution of calcium compounds. Of these, $P$. cepacia was selected for application in the waste form work.

Nitrifying Bacteria. The second group of microorganisms known to promote concrete degradation are the nitrifying bacteria. These bacteria (e.g.,
Nitrosomonas and Nitrobacter) are chemoautotrophs. They obtain energy through the oxidation of inorganic nitrogen compounds and have been isolated from a variety of soils. Growth of nitrifying organisms on concrete is not sequential as observed for the sulfur-oxidizing bacteria. However, in controlled experiments (using a simulation chamber), it was found that mixed cultures of Nitrosomonas and Nitrobacter inoculated on concrete blocks produced about $14 \mathrm{~mL}$ of $65 \%$ nitric acid per block per year (Mansch and Bock 1992). This was sufficient acid to dissolve the concrete and produce the breakdown product calcium nitrate. Thus, the relationship between ammoniaoxidizing and nitrite-oxidizing bacteria is mutualistic rather than antagonistic.

There was evidence from a soil sampling study that representative soil samples from all sampled locations contained a nitrifying bacterial population. These data show that both ammonia oxidizers and nitrite oxidizers were present in soils from all eight of the sampling sites (Rogers et al. 1994). It was significant that nitrifying bacteria were found in all of the surface soils and most of the subsurface samples. Populations of ammonia oxidizers were confirmed in at least one soil sample from each geographic location. The number of ammonia oxidizers ranged from $10^{1}$ to $10^{3}$ per gram of soil (wet weight) in the 17 soil samples that hosted them. The presence of nitrite oxidizers was confirmed at all depths for all but one soil location. The number of these microbes ranged from $10^{1}$ to $10^{4}$ per gram of soil (wet weight) in the 21 soil samples in which they were found.

A representative of Nitrosomonas was used as a culture for testing the effects of nitrifying bacteria. Although species of the nitrite-oxidizing genus Nitrobacter convert nitrite to nitrate as the second step in nitrification, this is merely an oxidation step. The acidification step of ammonia oxidation to nitrite by Nitrosomonas and other ammonia-oxidizing genera is thought to constitute the step resulting in cement-based material solubilization.

Sulfur-Oxidizing Bacteria. Sulfur-oxidizing bacteria (genus Thiobacillus) are the microorganisms most often associated with the biological 
degradation of concrete structures. These organisms were responsible for the catastrophic, biogenic sulfuric-acid attack of the Hamburg sewer system (Sand and Bock 1988) and are now recognized as the causative factor in degradation of concrete sewer pipe elsewhere (Islander et al. 1991; Mori et al. 1992). Thiobacilli are chemoautotrophs that obtain energy by oxidizing reduced, inorganic sulfur sources such as elemental sulfur, thiosulfate, and polythionates, while assimilating $\mathrm{CO}_{2}$ as their sole carbon source.

Literature data suggest that, regardless of the initial populations of the various species of thiobacilli in soils, once the process of sulfur oxidation begins, $T$. thiooxidans or $T$. ferrooxidans will eventually become the dominate organisms (Rogers et al. 1993). Although dominance depends on the environmental conditions, both species appear to be appropriate choices for use in
MID evaluations. Our work (Rogers et al. 1994) showed that soil from all LLW sampling locations had the presence of sulfur oxidizers in at least one of the soil profiles sampled. It appeared that these bacteria numbered approximately $10^{2}$ to $10^{3}$ per gram of soil.

As has been discussed, sulfur oxidation under conditions conducive for cement degradation (production of sulfuric acid) suggested that $T$. thiooxidans and $T$. ferrooxidans were the sulfur-oxidizing organisms of choice for use in developing part of a standardized test. Accordingly, an effort was made to selectively isolate these particular sulfur-oxidizing organisms from the collected environmental samples. Isolates from the various environmental samples were cultured under conditions conducive to long-term maintenance of pure cultures. 


\section{MATERIALS AND METHODS}

Development of Microbial Culture Collection

Preliminary data (Rogers et al. 1993) suggest that three different genera of bacteria are required to provide a comprehensive evaluation of microbial degradation of selected cement-solidified waste materials. These include organic acidproducing heterotrophic bacteria, nitrifying bacteria, and sulfur-oxidizing bacteria. Possible sources from which the microorganisms could be isolated include samples from sites with natural microbial activity, actual or proposed LLW locations, or existing culture collections. While the literature suggests that the three types of microorganisms considered for this study are ubiquitous in the environment, it was important to demonstrate their presence in soils representative of present and proposed commercial LLW sites. The sources of microorganisms together with steps for confirming their viability in selective environments are detailed in Figure 1.

The main criteria for LLW sample sites was their location within the geographic area of com- mercial disposal facilities or proposed state or state compact sites. At the time of collection, licensed disposal sites included Beatty, Nevada; Barnwell, South Carolina; and Hanford, Washington. Host states for proposed compact sites included Pennsylvania, Appalachian Compact; Nebraska, and Ohio, Midwest Interstate Compact; Connecticut and New Jersey, Northeast Interstate Compact; Washington, Northwest Interstate Compact; Nevada, Rocky Mountain Compact; South Carolina/North Carolina, Southeast Compact; California, Southwestern Compact; Nebraska, Central Interstate Compact; Texas and New York, Unaffiliated States (ANS 1992).

To aid in a rational selection, the collection sites should also include at least four climatologically diverse environments: warm humid, cool humid, warm dry, and cool dry. Furthermore, selected sites needed to be within compacts that had reached maturity in the site selection process. When these conditions were overlain with the main criteria for sample sites and host locations, it is seen that candidate sites could be selected from

\section{Proposed source for microorganisms}

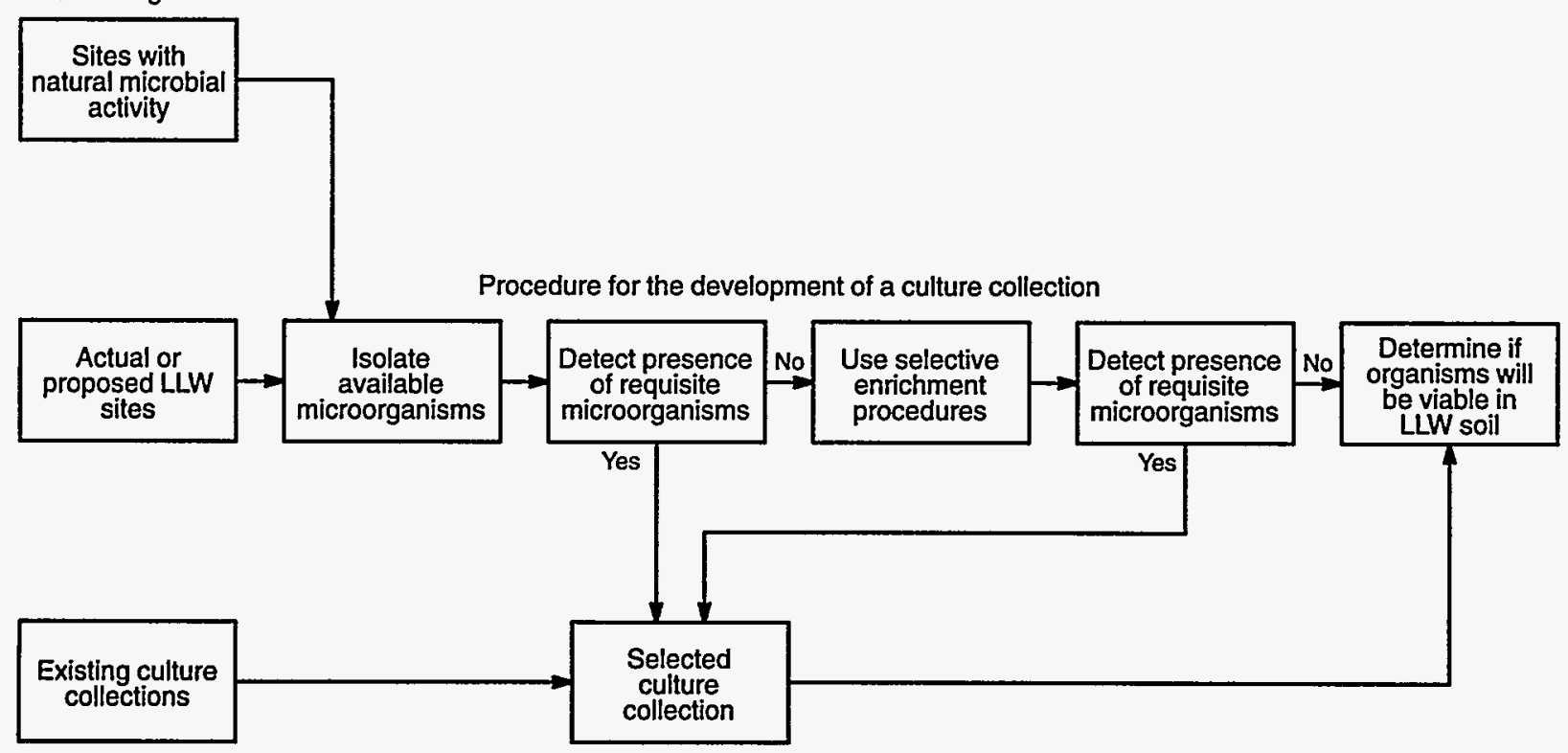

LF95 0053

Figure 1. Development of microbial culture collection. 
the following compacts: Central Midwest: Illinois or Central Interstate, Nebraska (cool humid); Northeast: New Jersey or New York (cool humid); Southeast: South Carolina/North Carolina (warm humid); Northwest: Washington (cool dry); Southwestern: California or Rocky Mountain Nevada (warm dry); and Texas (warm dry). The final selections were Argonne and Urbana, Illinois; Richland, Washington; Beatty, Nevada; Ward Valley, California; El Paso, Texas; Barnwell, South Carolina; and New York State.
Figures 2 and 3 are pictures of the Beatty and Ward Valley locations.

As an overview, soils were collected from several locations (dependent on opportunity and availability) at each sampling site. At each location, a sufficient quantity of soil was retrieved with sterile implements and placed into specially prepared sterile collection bags and sealed. These bags were placed into an ice chest and sent to the laboratory for processing.

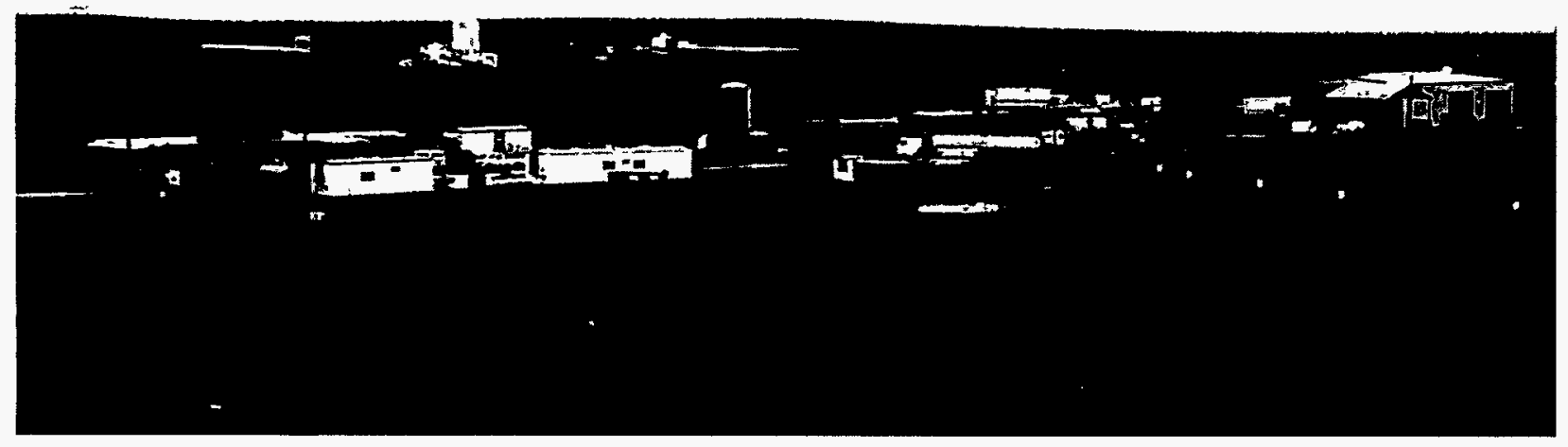

Figure 2. U.S. Ecology Low-Level Waste Facility, Beatty, NV.

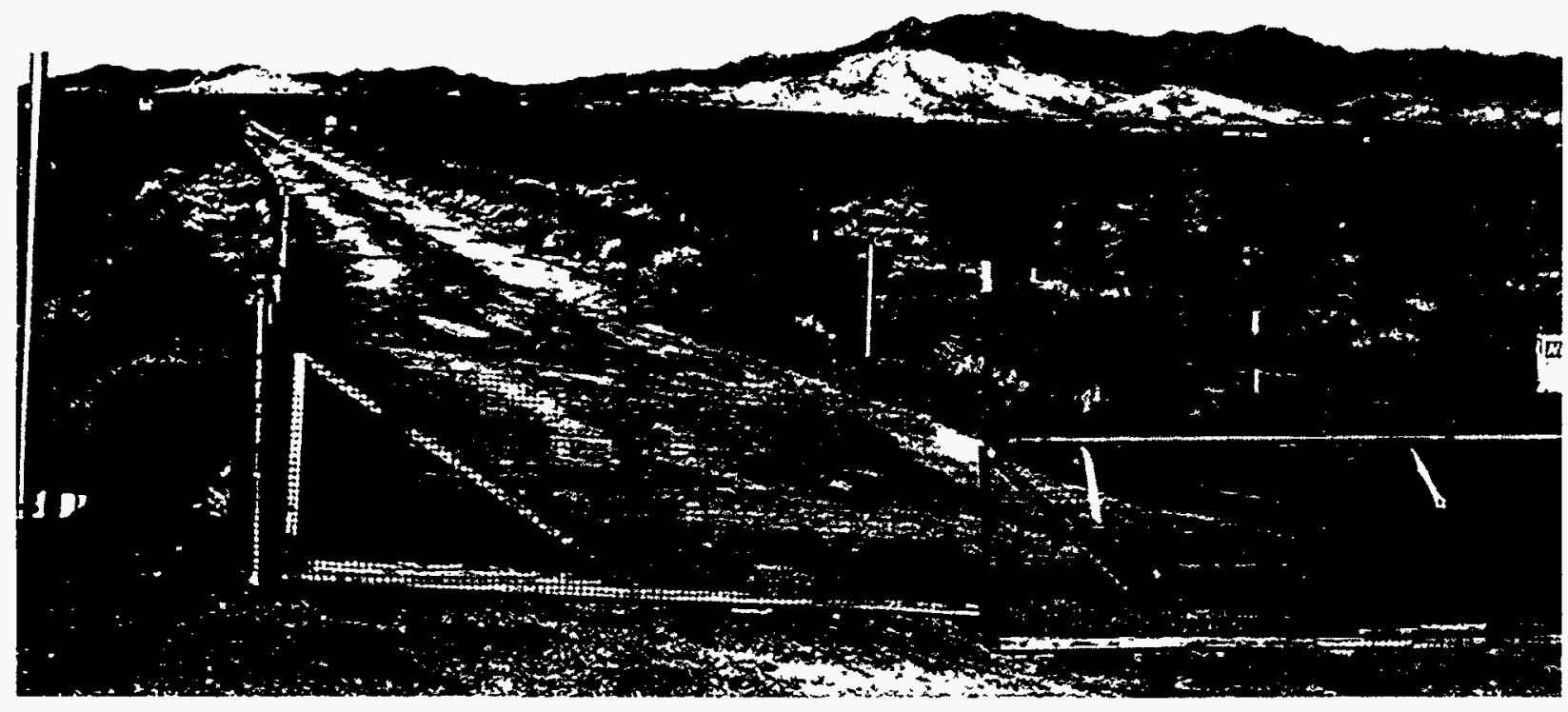

Figure 3. Proposed U.S. Ecology Low-Level Waste Site, Ward Valley, CA. 


\section{Soil Sample Collection}

Specific methods for soil collection were as follows:

1. Select an area from which a sample was to be obtained at a designated sampling site.

2. Clear the area of loose soil and debris with a trowel.

3. Assemble the soil coring device (see Figures 4,5 , and 6 ). If a core was to be retrieved from the soil surface, the following procedures were used:

a. Remove adhering soil (with a kimwipe or brush) from the inside of the auger coring device.

b. Wash the interior of the auger with ethyl alcohol.

c. Select a sterilized, capped, stainless steel core liner and remove one of the caps (Figure 7).

d. Hold the liner by the remaining capped end and insert it uncapped end first into the auger coring device.

e. Remove the remaining liner cap and finish assembling the coring device by attaching the solid end plug.

4. Twist the coring device into the soil (Figure 8).

5. Remove the coring device when it is full.

6. Disassemble the coring device and expose the soil core by removing the solid end of the coring device (Figure 9).

7. Wash the liner retrieving hook with ethyl alcohol.

8. Place the end of the hook into the hole in the end of the liner and retrieve the liner.
9. As the liner is removed from the auger, immediately place a cap (blue cap on the end with hole for retrieval) with a sterile stainless steel insert on the exposed ends of the liner.

10. Place the capped and sealed liner in a cooler.

11. Reassemble the coring device using the open-ended cap.

12. Using chalk, place a mark indicating the depth of the corer to the next sample on the rod connecting the coring device with the handle.

13. Put the coring device back into the started hole and twist until it has moved into the soil to the depth matching the chalk mark and the surface of the surrounding soil.

14. Retrieve the coring device from the hole and remove and dispose of the soil plug.

15. Continue moving the coring device into the soil profile to the depth of the next designated core.

16. Follow steps 3 through 10 to obtain the next soil core.

17. Record the depth of core retrieval by measuring the length of the rod submerged into the soil profile.

The collected soils were processed in the following manner:

1. Process soil cores in a sterile work area such as a laminar flow hood.

2. Remove caps from the core liner.

3. Insert an extrusion tool into the liner on the lower end of the core (end opposite the extraction hole).

4. Extrude the first $2 \mathrm{~cm}$ of the soil core with a sterile spatula and discard that section.

5. Extrude the rest of the core into a sterile tray. 


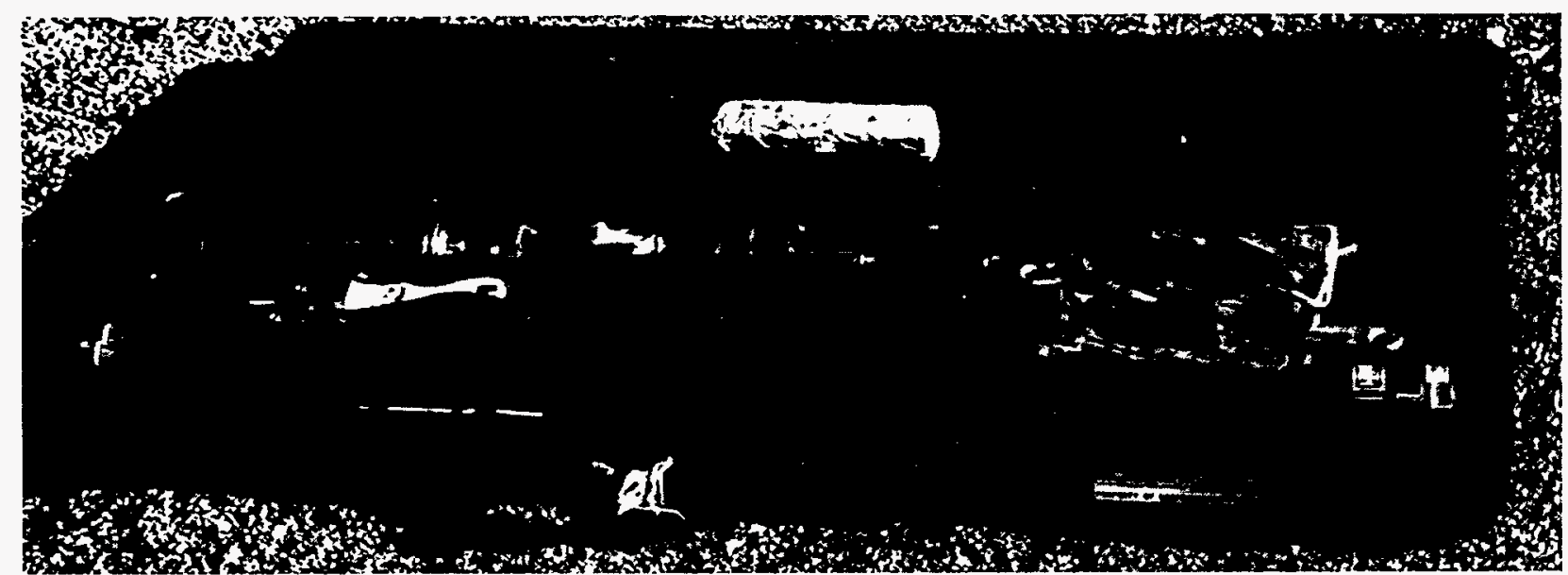

Figure 4. Disassembled soil coring equipment.

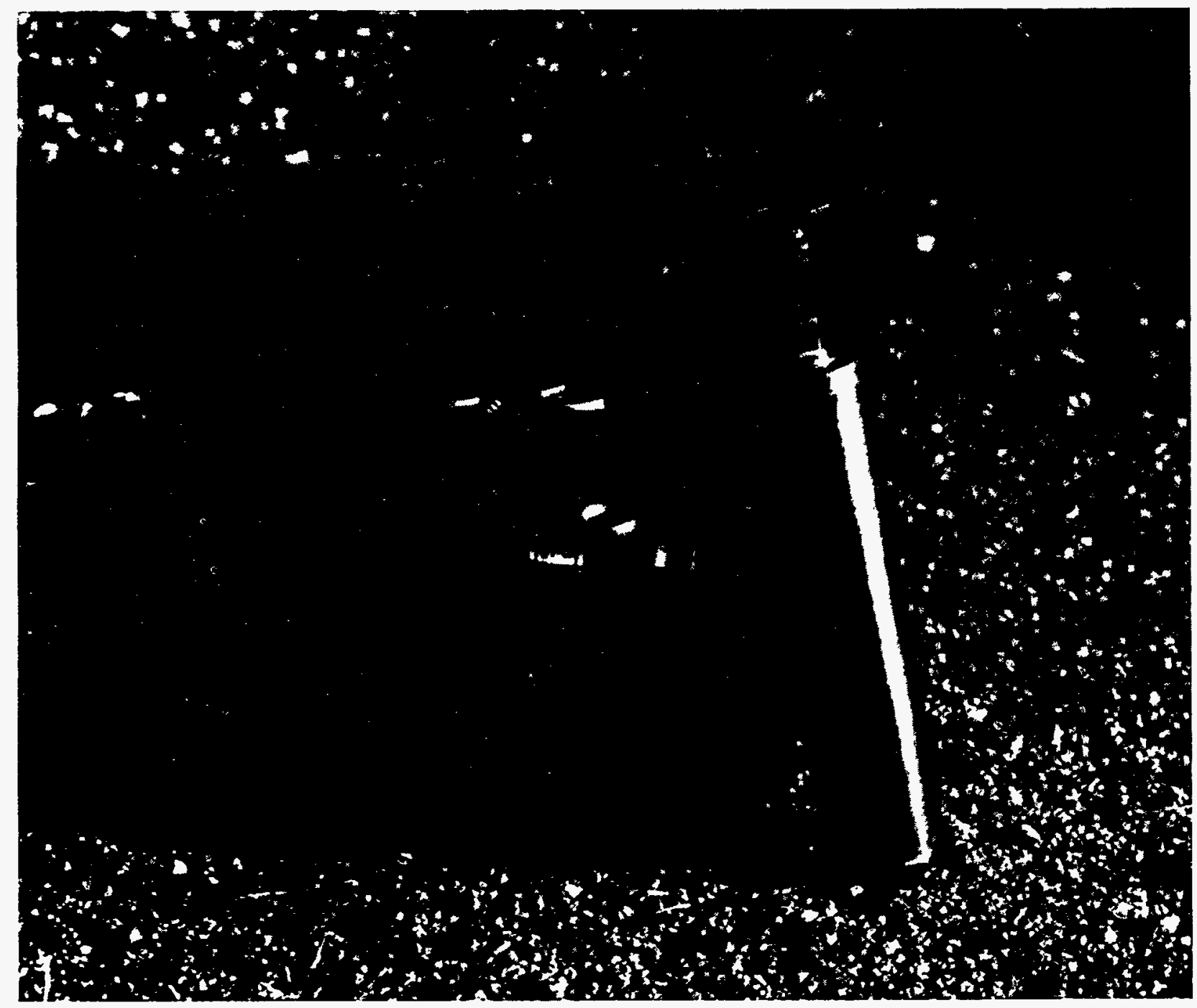

Figure 5. Assembled soil core retriever (extension rods are afixed for retrieving cores at depth). 


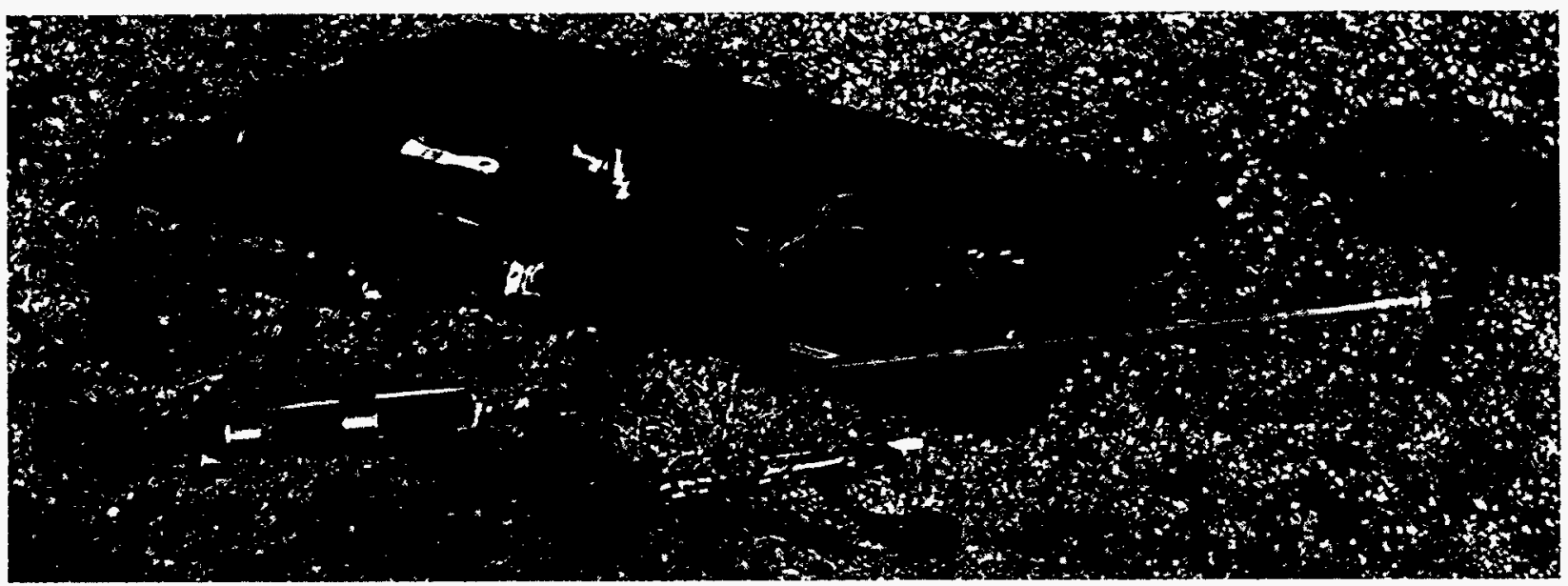

Figure 6. Soil auger with attached extension rods for coring at depth.



Figure 7. Capped stainless steel core liner and casing device. 


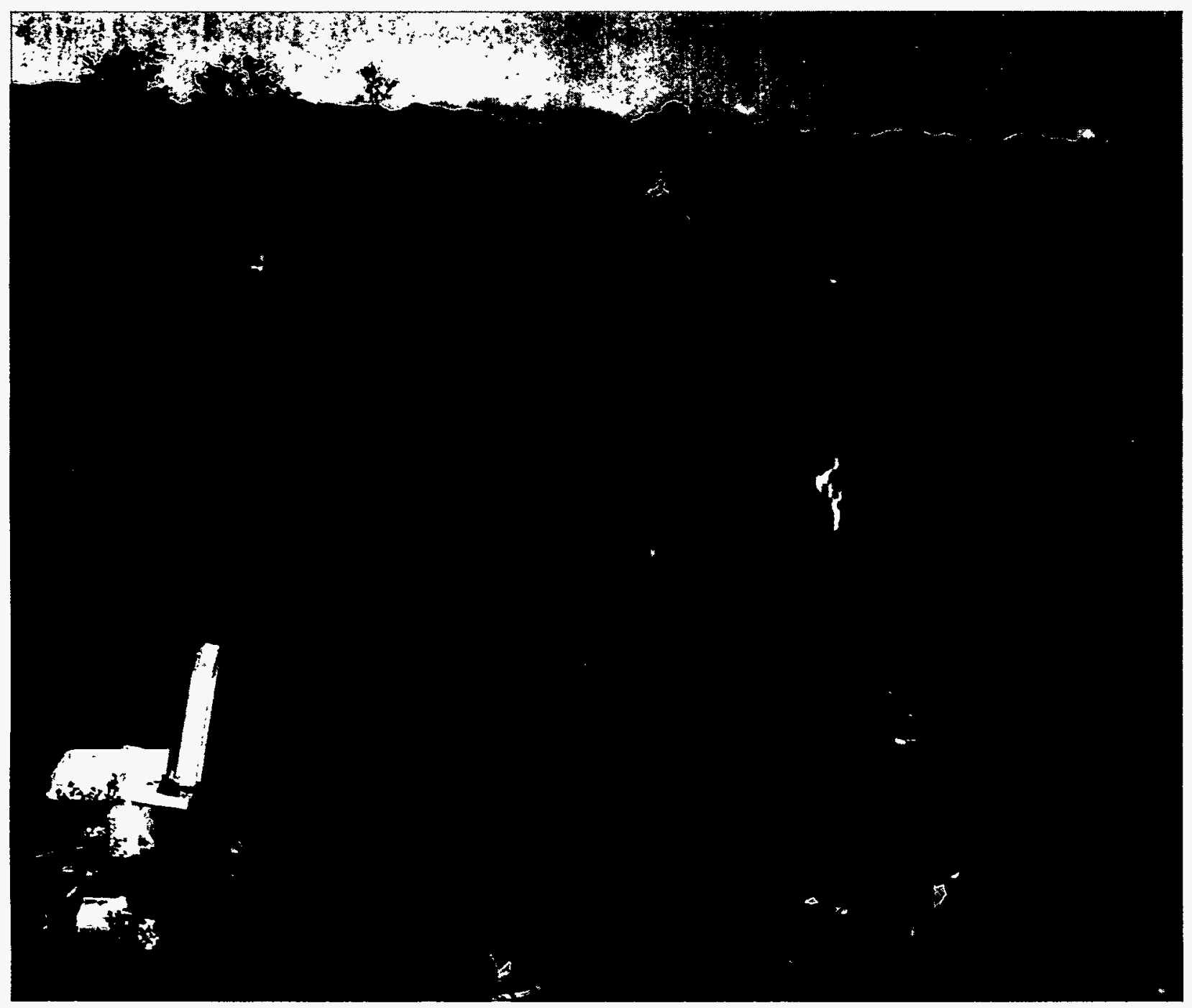

Figure 8. Twisting the coring device into the soil.

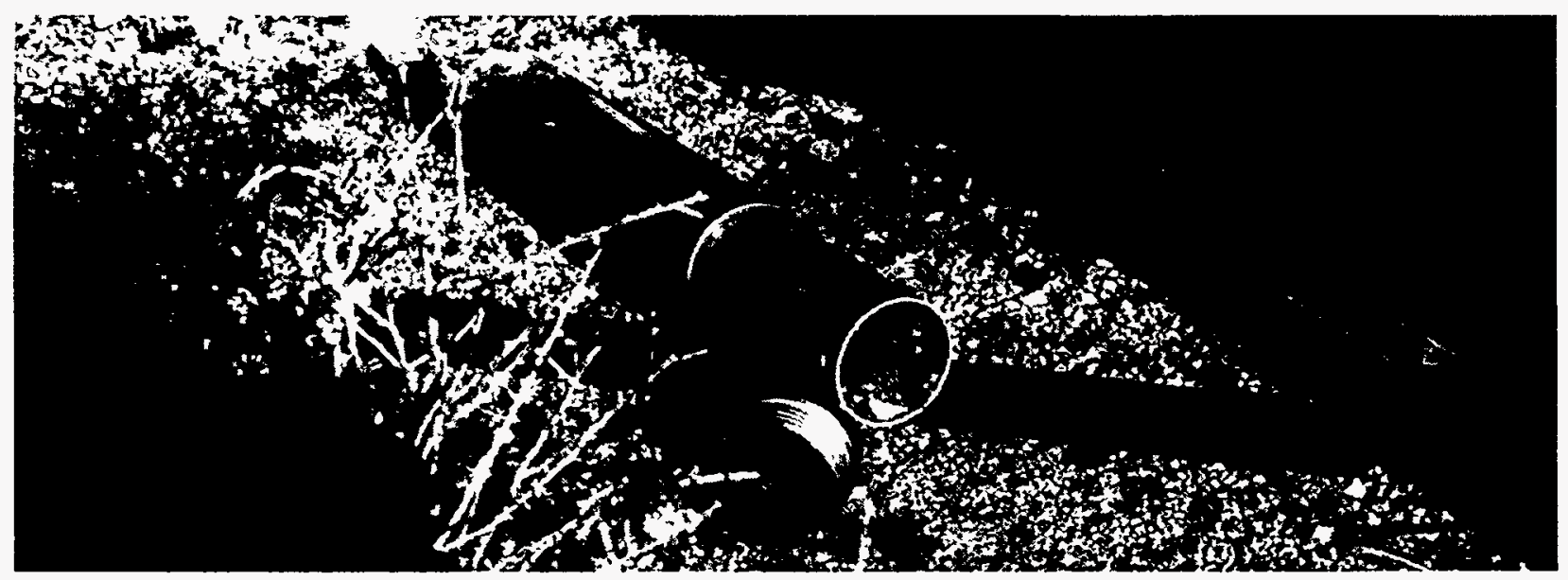

Figure 9. Removal of soil core from coring device. 
6. If more than one core was taken at the same depth (within the same site), extrude them also and place them in the tray together.

7. Homogenize these similar samples with repeated cutting and blending.

8. Place processed cores into sterile, tared bags.

9. Determine the sample weight.

10. Remove a 5-g sample of the soil to determine the percent moisture on a dry-weight basis.

11. Using an additional 5-g sample of the soil, prepare saturated paste to determine $\mathrm{pH}$.

12. Finally, use a minimum amount of soil necessary for microbiological examination.

13. Place the remaining soil into refrigerated storage $\left(\sim 4^{\circ} \mathrm{C}\right)$.

\section{Isolation of Microbes from Soils}

Standard methods were used to isolate microbes from the soils. These are described in more detail later. These methods used bioassay methodologies to select those isolates that fell into the three genera of interest. Candidate organisms from this screening were isolated into pure cultures and saved as part of a culture collection for later evaluation.

In those soils in which a specific desired type of organism was not isolated on the first attempt (e.g., sulfur oxidizers), further processing steps included enrichment of the soils (baiting with substrates of interest such as reduced sulfur compounds and inorganic nitrogen compounds) followed by use of microbe-specific methods to isolate the microbes of interest. The protocol indicated that if a specific type of organism was not found after enrichment in soils from a LLW location, then samples of those soils could be inoculated with the bacteria of interest and a determination could be made of whether the soil had the potential to support the desired bacteria. Such an evaluation would be necessary since experience has shown that once soils contain the required substrates, they invariably become contaminated with microorganisms able to exploit the favorable conditions. This work also provided much needed information on the activity of candidate organisms under field conditions.

The above steps are consistent with environmental microbiology procedure, and similar protocols have been followed by the Canadians (Mayfield and Barker 1982), the French (Langomazino, personal communication, 1990) and the English (Dunk 1991) in their work with microbial involvement in various aspects of LLW disposal.

Heterotrophic Bacteria. Methods used to isolate the various genera of microorganisms differed depending on the type of microbe. Heterotrophic organisms of interest tended to be readily isolated on selective media without the necessity of further enrichment. Isolates were obtained by first diluting $1-\mathrm{g}$ quantities of each of the collected soils $10^{2}$ to $10^{6}$ times with sterile water. After dilution, $0.1 \mathrm{~mL}$ of each solution was spread on the solid surface of trypticase soy agar (TSA) with dextrose (40 g TSA, $5 \mathrm{~g}$ dextrose/L DI $\mathrm{H}_{2} \mathrm{O}$ ) contained in petri plates. The inoculated plates were then incubated 48 hours at a temperature of $28^{\circ} \mathrm{C}$. Those plates on which 30 to 300 colonies of microorganisms were subsequently found to be growing were retained.

Morphologically different colonies were then evaluated with an agar plate assay (Katznelson and Bose 1959) for their ability to produce organic acid in sufficient quantities to effect the solubilization of an insoluble calcium phosphate compound. The assay was carried out by spotting the isolates on the surface of agar, which has been made opaque by the formation of insoluble dicalcium phosphate. Those isolates that were capable of solubilizing the insoluble compound form a clear zone or halo (see Figure 10). Microorganisms found by the test to be positive for organic acid production were retained in a culture collection. 


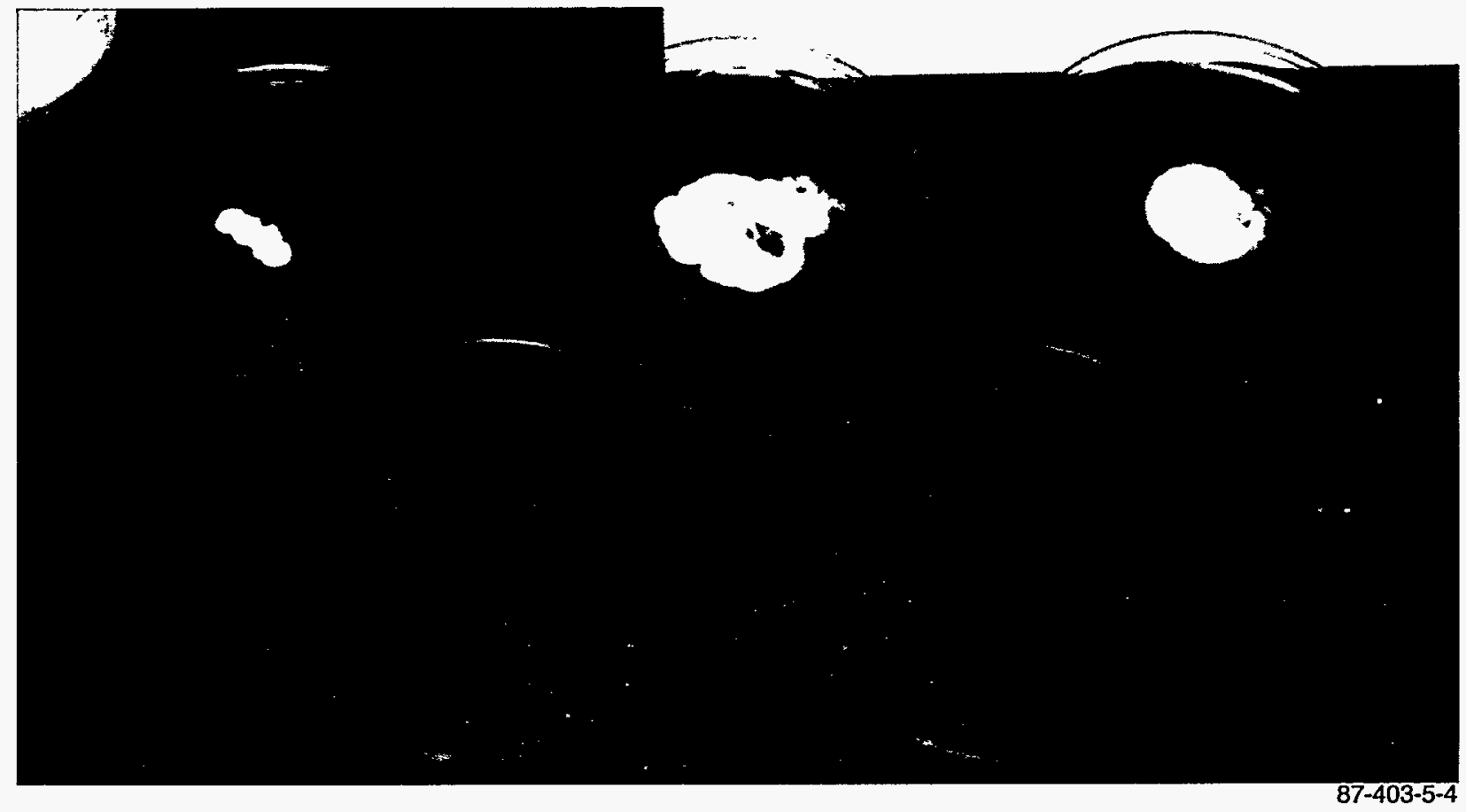

Figure 10. Examples of results of agar plate bioassay.

Nitrifying Bacteria. Nitrifying bacteria grow extremely slow compared to heterotrophs. Their doubling time is typically 24 to 48 hours compared to a few hours for other microorganisms. Dilution techniques described in the above section could not be used to ascertain the presence and approximate numbers of these bacteria in soils. However, rather than a direct application of diluted samples onto an agar plate, a most-probable-number method described by Alexander (1982) was used. The specific mostprobable-number method modified for nitrifier enumeration was that developed by Schmidt and Belser (1982). The most-probable-number method permitted a statistical estimation of the bacterial population without an actual, physical count of single cells or colonies. This method was based on an analysis of the presence or absence of the microorganism of interest in five replicates of each of three serial dilutions of candidate soils. A prerequisite for the technique was that the microorganism, whose population is to be determined, must be able to produce an easily recognizable transformation (e.g., a chemical change) in the medium into which it was inoculated. Because nitrifying bacteria carry out a two-step sequential chemical process of oxidizing ammonium to nitrite and then nitrate, it was necessary to use two different enumeration media to detect the formation of these compounds.

On the basis of probability theory, it was possible to calculate the most probable number of microorganisms in the various serial dilutions from the number of positive and negative occurrences of nitrite or nitrate. Using these combined data, a single value was obtained as the estimate of the most probable number of nitrifying bacteria present in the original environmental sample.

The procedure used for the enumeration of nitrifying bacteria was as follows. Stock solutions of appropriate nitrifier media were prepared according to Schmidt and Belser (1982). Next, 5-g quantities of unprocessed soil from each collection site were then transferred into large culture tubes. Sterile phosphate buffer $(45 \mathrm{~mL})$ was added, and the mixture of soil and buffer was shaken vigorously for 1 minute. Subsequently, five 10-fold dilutions of the soil buffer mixture were carried out ( 1 to 9 -mL sterile buffer) so that, eventually, a final sample dilution of $10^{6}$ was achieved. One-mL aliquots of liquid from the five highest serial dilutions were then transferred to each of five replicate culture tubes containing 
$4 \mathrm{~mL}$ of the nitrifier medium. The inoculated tubes were incubated in the dark for a period of 6 to 7 weeks. At the completion of the incubation period, the presence of ammonia oxidizers was determined by confirming the formation of nitrite by use of a spot test. This test used a $0.1-\mathrm{mL}$ aliquot of tube contents mixed with one drop of diazotizing reagent (sulfanilamide) and one drop of coupling reagent [N-(1-naphthyl)-ethylenediamine dihydrochloride]. A resulting pink to red color was recorded as a positive for the presence of ammonia oxidizers. The accumulation of nitrate, a presumptive indication of the presence of nitrite oxidizers, was determined by ion chromatography. The contents of those tubes shown to lack nitrite were further tested by a diphenylamine spot test for the presence of nitrate. This was done in the event that nitrite had been microbially oxidized to nitrate. In addition to the spot tests, subsamples of the tube contents were diluted and analyzed by ion chromatography to confirm nitrite and nitrate content.

Sulfur-Oxidizing Bacteria. Thiobacilli, like nitrifying bacteria, are very slow-growing bacteria. Their doubling time is typically 3 to 4 days. The slow growth rate necessitates incubation and enrichment techniques that are unique to sulfur oxidizers. Therefore, these techniques precluded enumeration by direct isolation or mostprobable-number techniques. Also, obtaining pure isolates of these bacteria involves enrichment procedures rather than direct isolation. Enrichment procedures encourage growth and improve accurate assessment because of the increase in number. Many times, this procedure is the method of choice for reliable identification of sulfur oxidizers in soils that have a wide range of characteristics and microbial communities.

The various methods used for the isolation of thiobacilli included liquid culture, enrichment culture, and solid media. For liquid culture isolations, previously collected soil samples were inoculated into a sterile liquid medium selective for culturing sulfur-oxidizing microbes. Two medium formulations were used for liquid culture of thiobacilli: Medium S and Medium B. Medium $\mathrm{S}$ contained the salts ammonium sulfate, potas- sium phosphate, calcium chloride, and magnesium sulfate, and trace amounts of EDTA and metal salts, zinc sulfate, calcium chloride, manganese chloride, iron sulfate, ammonium molybdate, copper sulfate, and cobalt chloride. After sterilizing this solution in an autoclave, previously steam-sterilized elemental sulfur was added at a concentration of $10 \mathrm{~g} / \mathrm{L}$. Medium B contained the salts ammonium chloride, potassium phosphate, magnesium chloride, and calcium chloride. Sodium thiosulfate was added at a concentration of $5 \mathrm{~g} / \mathrm{L}$, and the solution was sterilized in an autoclave. Both media were especially formulated without a carbon source. Each medium was dispensed in $50-\mathrm{mL}$ portions into 125-mL erlenmeyer flasks. 1-g quantities of the respective soils were placed into flasks containing either Medium S or B. The inoculated flasks were then incubated on a shaker at $30^{\circ} \mathrm{C}$ for 2 to 3 weeks or until evidence of microbial growth was observed either by turbidity or through microscopic examination.

After incubation, 5-mL aliquots of the growing cultures were transferred into other flasks containing $50 \mathrm{~mL}$ of fresh, sterile medium of the same formulation previously used. Incubation then occurs as previously described. Two additional transfers using the above methodology were made for each soil culture when evidence of growth was observed. Three successive transfers of each culture were sufficient to ensure that metabolism by the isolated microbes was dependent on the reduced form of sulfur. This procedure ensured that the microbes present in the final culture were not species capable of utilizing residual energy sources (such as organic carbon) derived from the original soil sample. Thus, this method was very selective for isolation of only sulfur-oxidizing microorganisms.

When sulfur-oxidizing organisms were not readily isolated from a particular soil, enrichment procedures were used. To do this, a 5-g aliquot of each soil sample was weighed and aseptically transferred into a sterile 125 -mL erlenmeyer flask. A solution of $20 \mathrm{~g}$ of sodium thiosulfate in $200 \mathrm{~mL}$ of deionized water was prepared and sterilized in an autoclave. $10 \mathrm{~mL}$ of this solution was added to each of the soils, resulting in $1 \mathrm{~g}$ of 
sodium thiosulfate per $5 \mathrm{~g}$ of soil. The soils were incubated at $30^{\circ} \mathrm{C}$ for 2 to 3 weeks. For each of these "enriched" soils, 1-g aliquots were removed and inoculated into $50 \mathrm{~mL}$ of Medium B and 50 $\mathrm{mL}$ of Medium S, respectively. These liquid cultures then underwent the same incubation and transfer according to the procedure described above.

Organisms selected from or enriched from soil in the liquid cultures were subsequently grown on solid medium selective for Thiobacillus. The medium was prepared using the same formulation as liquid Medium B with $5 \mathrm{~g} / \mathrm{L}$ gelrite added as the solidification agent. For each liquid culture from Medium S and Medium B, a 0.1-mL aliquot was spread onto a solid medium plate and incubated for 2 to 3 weeks at $30^{\circ} \mathrm{C}$. Growth of organisms was monitored during this period of time.

Work was conducted to determine if microorganisms from selected existing culture collections had the potential to degrade cement-solidified LLW. Microbes were obtained and grown. Growth of the test microorganisms on selected media was monitored. Analytical methodology was used to detect the presence of microbially produced metabolites (mineral or organic acids), which have been reported to degrade concrete structures. Microbial isolates that were determined by the screening procedures to be potential candidates were identified and placed in a permanent culture collection. The process of selection is outlined in Figure 11.

\section{Development of Procedures for Growing Candidate Microorganisms}

Media necessary for the promotion and maintenance of active growth of the candidate microorganisms were obtained from the literature or developed. This involved determination of the appropriate energy and carbon source, mineral nutrients, $\mathrm{pH}$ range, and range of incubation temperatures. Methods were developed for incubation and preservation of the candidate microorganisms. Procedures such as freeze drying, low-temperature freezing of liquid cultures, or storage on solid media were considered. Efforts for this task are detailed in Figure 12.

\section{Determination of \\ Microorganisms Capable of Cement Degradation}

A knowledge of the types of microorganisms that promote cement degradation is useful for selecting appropriate candidate organisms. There was no one prime candidate for a genera of heterotrophic bacteria used in the testing protocol.

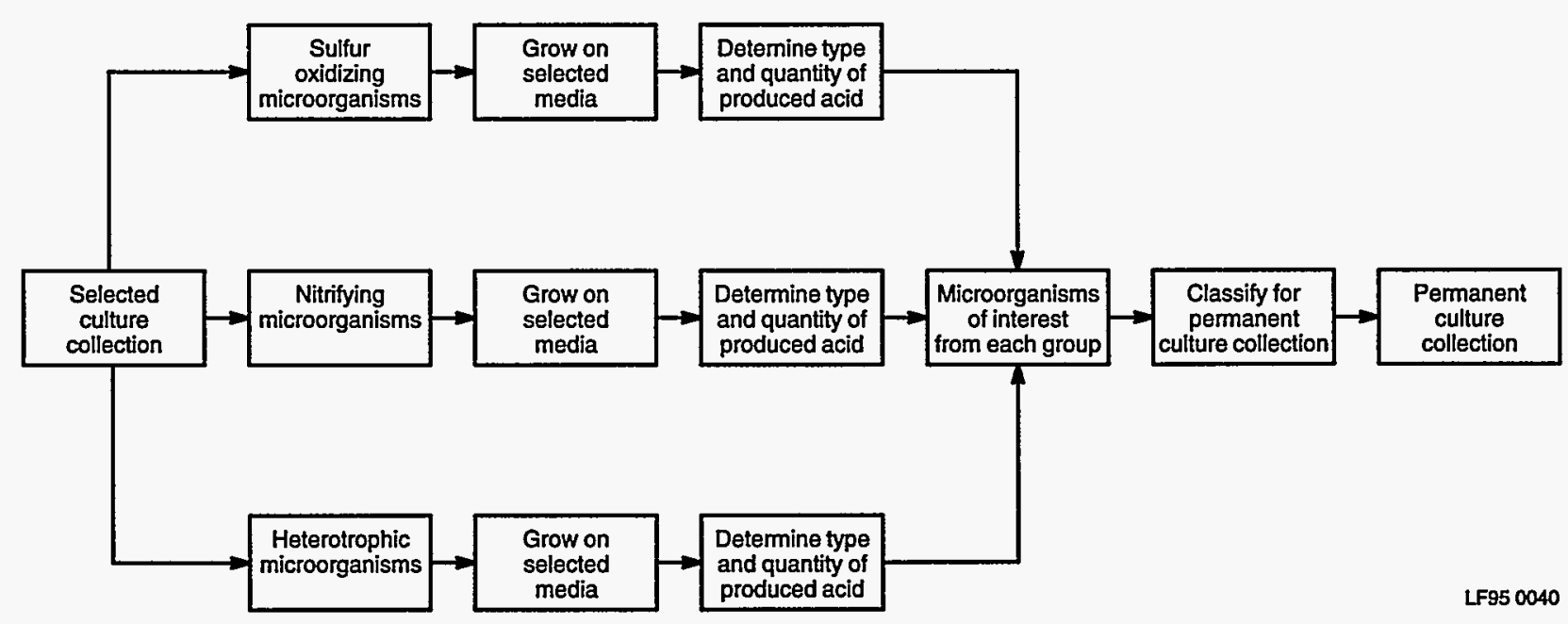

Figure 11. Schematic of methods used for selecting candidate microorganisms. 


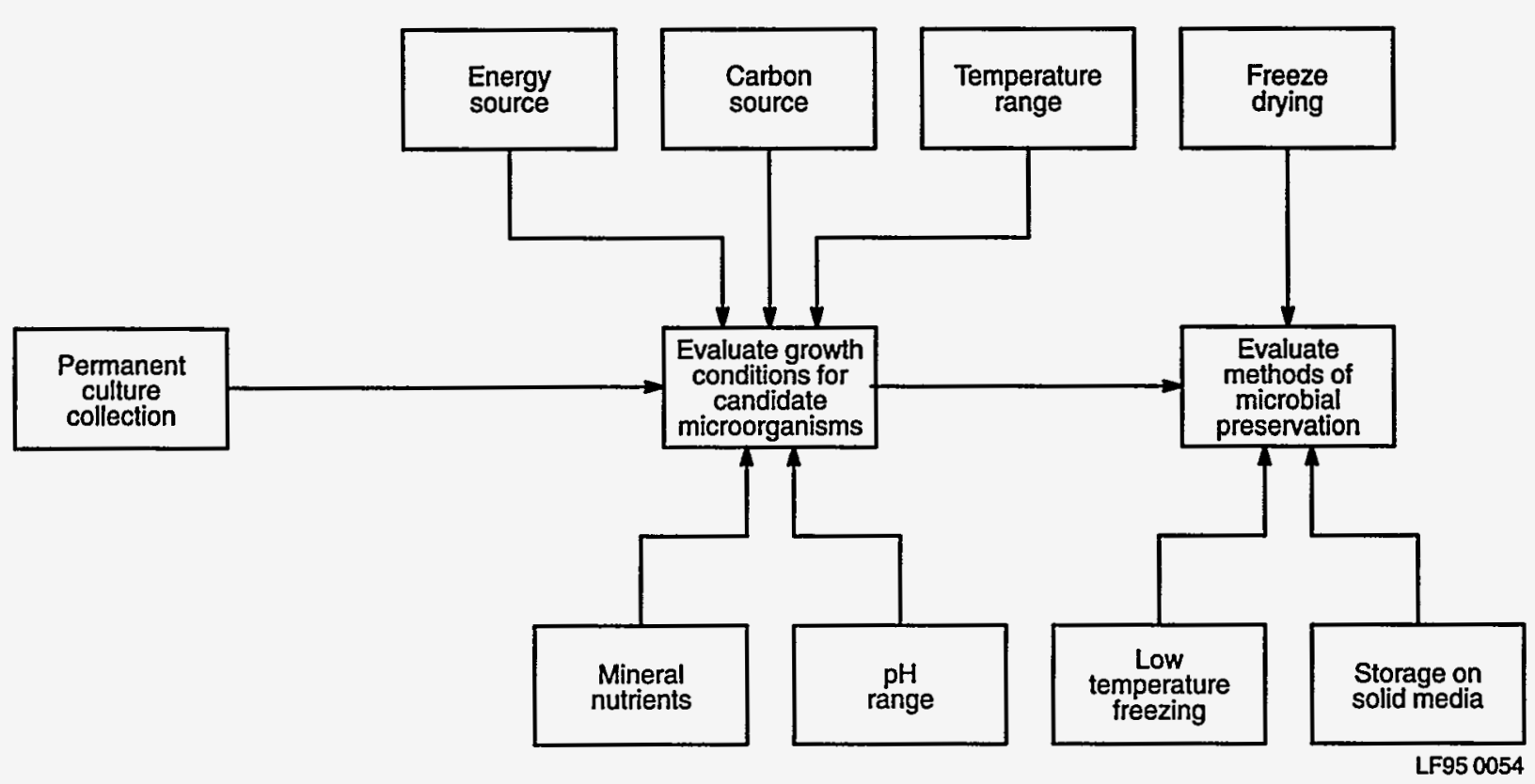

Figure 12. Development of procedures for growth and preservation of selected microbes.

Several groups were determined capable of producing organic acids. A bioassay that was sensitive to detect bacteria capable of dissolving calcium compounds was used to select candidate organisms. Only one or two species exhibiting extreme dissolution of calcium compounds were selected for additional studies.

A representative of Nitrosomonas was used as a culture for testing the effects of nitrifying bacteria. Although species of the nitrite-oxidizing genus Nitrobacter convert nitrite to nitrate as the second step in nitrification, this is merely an oxidation step. The acidification step of ammonia oxidation to nitrite by Nitrosomonas and other ammonia-oxidizing genera is thought to constitute the step resulting in cement-based material solubilization.

As discussed in the introduction, sulfur oxidation under conditions conducive for cement degradation (i.e., production of sulfuric acid) suggested that $T$. thiooxidans was the sulfur-oxidizing organism of choice for use in developing part of a standardized test. Accordingly, an effort was made to selectively isolate this particular sulfur-oxidizing organism from the collected environmental media samples. Isolates from the various environmental samples were cultured under conditions conducive to long-term maintenance of pure cultures.

Acid production was used as the criterion for a final selection of both mineral acid and organic acid-producing bacteria. Strength of acid production was determined by the $\mathrm{pH}$ change of the solution in which the organism was being cultivated. Analytical methods were used to determine the amount of sulfate and nitrite production. In the case of mineral acids, the concentration of these anions could be related to the initial amount of available substrate.

\section{Development of Criteria for Evaluation of Test Effects}

It was necessary to designate some occurrence or change as failure criteria for the cement specimens. Physical, chemical, and biological parameters are being investigated. Before specimens were tested, their dry weight and physical dimensions were determined. In addition, a total chemical analysis was performed on the INEL-fabricated and vendor-supplied simulated waste forms. Total quantities of $\mathrm{Ca}, \mathrm{Al}$, and $\mathrm{Si}$ were obtained so that the percentages of these elements leached from the waste forms 
during the evaluation could be determined. Also, the physical effects (i.e. color change, swelling, spalling, crumbling etc.) were documented with photographs. Other possibilities that could be examined include biological parameters measured directly as a metabolic activity such as byproduct production (acid, etc.) or by use of consumables (oxygen, carbon, inorganic materials, etc.). These data could provide information on the activity of the microorganisms. 


\section{EXPERIMENTAL RESULTS}

\section{Microorganism Availability}

While the literature suggests that the three types of microorganisms considered for the study (sulfur-oxidizing, nitrifying, and organic acidproducing bacteria) are ubiquitous in the environment, it was important to demonstrate that such types either be isolated from or tolerant to soils representative of present and proposed commercial LLW sites.

During this program, soils were collected from a total of six locations. These included the University of Illinois, Urbana, and Argonne National Laboratory, Chicago, IL; Savannah River National Laboratory, Aiken, SC; U.S. Ecology, Hanford, WA; U.S. Ecology, Beatty, NV; U.S. Ecology, Ward Valley, CA; regional, EI Paso, TX.
Additional information concerning sampling depths and $\mathrm{pH}$ values at each location are presented in Table 1. It should be noted that these samples represent a wide diversity of soil types. For example, soil $\mathrm{pH}$ values (obtained from 1:1 soil water paste) ranged from an acidic 4.2 to an alkaline 8.5.

Various methods were used to isolate candidate microorganisms from these soils. The types and, where possible, the numbers of bacteria isolated from the soils are listed in Table 2. Testing for the presence of heterotrophs was conducted selectively on soils from five of the eight collection sites. The evaluated soils were representative of all of the geographical locations that were sampled. Not surprisingly, heterotrophic microbes were isolated from all 15 soil samples collected at the five locations. Numbers of viable

Table 1. Physical description and $\mathrm{pH}$ of soils collected from the proximity of LLW and proposed LLW sites.

\begin{tabular}{|c|c|c|c|}
\hline Location & Physical description & $\begin{array}{l}\text { Depth } \\
\text { (cm) }\end{array}$ & $\mathrm{pH}$ \\
\hline Urbana, IL & Moderately drained crop land & $\begin{array}{r}0-17.8 \\
91.4-111.8 \\
172.7-193.0\end{array}$ & $\begin{array}{l}4.5 \\
5.6 \\
6.8\end{array}$ \\
\hline Argonne, IL & Lysimeter site cut profile & $\begin{array}{r}0-15.2 \\
91-111.8 \\
116.8-147.3\end{array}$ & $\begin{array}{l}6.6 \\
7.3 \\
7.5\end{array}$ \\
\hline Barnwell, SC & Disturbed soil underlying gravel & $\begin{array}{r}0-20.3 \\
91-111.8 \\
116.8-147.3\end{array}$ & $\begin{array}{l}4.2 \\
7.0 \\
5.1\end{array}$ \\
\hline Hanford, WA & Undisturbed native vegetation & $\begin{array}{r}0-20.3 \\
121.9-142.2 \\
172.7-203.2\end{array}$ & $\begin{array}{l}7.3 \\
8.2 \\
8.3\end{array}$ \\
\hline El Paso, TX 1 & Crop land & $\begin{array}{r}0-20.3 \\
121.9-142.2 \\
182.9-203.2\end{array}$ & $\begin{array}{l}8.2 \\
7.8 \\
7.8\end{array}$ \\
\hline El Paso, TX 2 & Undisturbed underlying caliche & $\begin{array}{r}0-20.3 \\
81.3-101.6\end{array}$ & $\begin{array}{l}7.6 \\
7.7\end{array}$ \\
\hline Beatty, NV & Undisturbed desert pavement & $\begin{array}{r}0-10.2 \\
25.4-35.6 \\
\text { Stockpile }\end{array}$ & $\begin{array}{l}8.2 \\
8.4 \\
8.0\end{array}$ \\
\hline Ward Valley, CA & Undisturbed desert pavement & $\begin{array}{r}0-20.3 \\
91.4-111.8\end{array}$ & $\begin{array}{l}8.3 \\
8.5\end{array}$ \\
\hline
\end{tabular}


Experimental Results

Table 2. Types and numbers of microorganisms isolated from the proximity of LLW and proposed LLW sites.

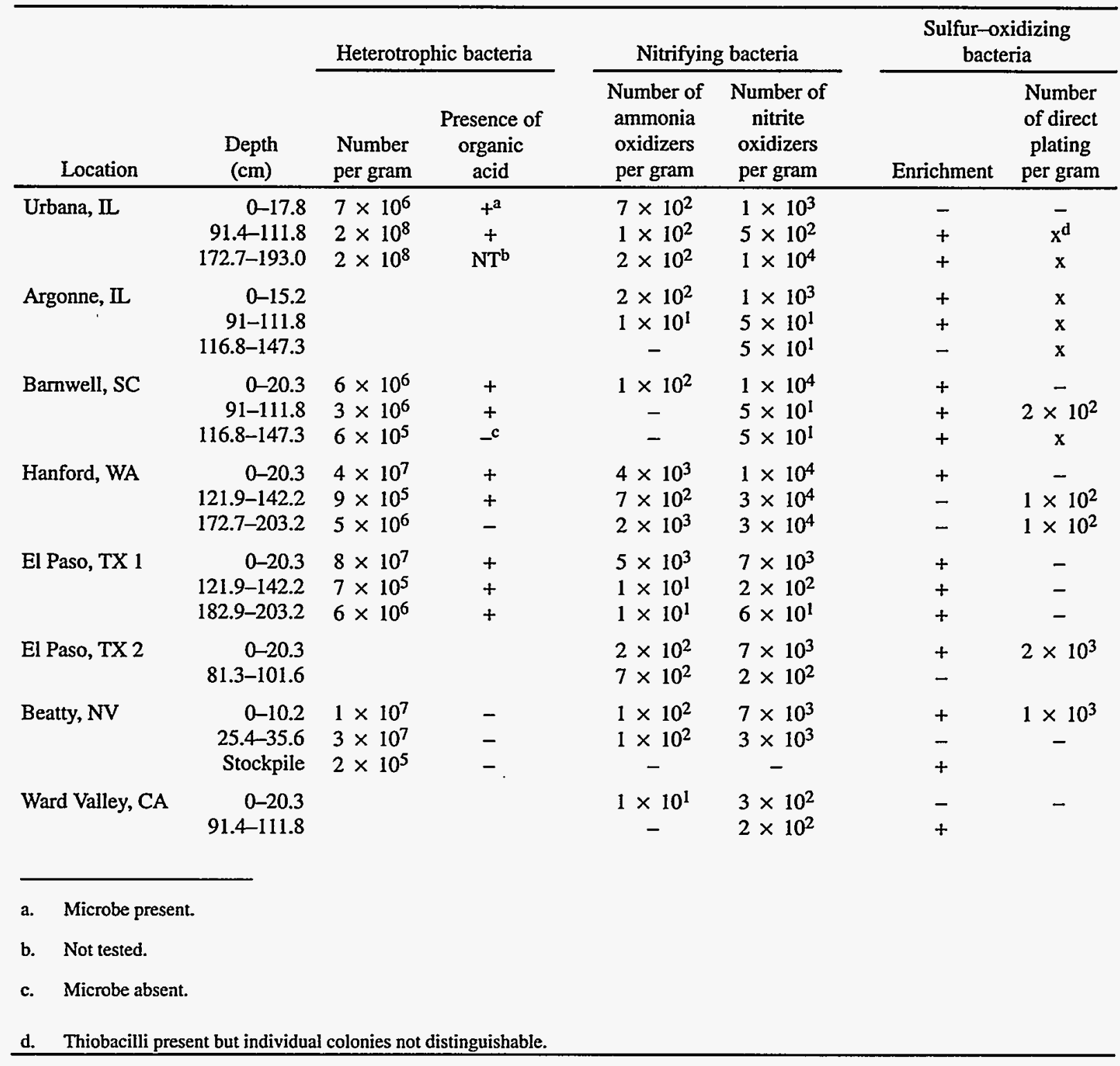

microbes ranged from $10^{5}$ to $10^{8}$ per gram of soil (wet weight). Further, of these isolates, there were apparent organic acid-producing organisms obtained from four of the five locations evaluated.

There was evidence that representative soil samples from all locations contained a nitrifying bacterial population. The results of the enumeration studies for these bacteria using the mostprobable-number method are presented in Table 2. These data show that both ammonia oxidizers and nitrite oxidizers were present in soils from all the sampling sites. It was significant that nitrifying bacteria were found in all of the surface soils and most of the subsurface samples. Populations of ammonia oxidizers were confirmed in at least one soil sample from each geographic location. At two of these locations, there was occurrence at only one depth, two locations had the bacteria at two depths, while the remaining four showed activity at all depths. The numbers of ammonia oxidizers ranged from $10^{1}$ to $10^{3}$ per gram of soil (wet weight) in the 17 soil sample that hosted them. The presence of nitrite oxidizers was confirmed at all depths for all but one soil 
location. The numbers of these microbes ranged from $10^{1}$ to $10^{4}$ per gram of soil (wet weight) in the 21 soil samples in which they were found.

Isolation and quantification of thiobacilli was more difficult. Using an enrichment technique, soil from all eight sampling locations had the presence of sulfur oxidizers confirmed in at least one of the soil profiles sampled. At three of the locations, the bacteria were present in at least two profiles, while another three locations had them occurring at all three depths. Data from a direct plating method confirmed the presence of thiobacilli in six of the eight soils. It appears that these bacteria could number approximately $10^{2}$ to $10^{3}$ per gram of soil. Perhaps more importantly, these data prove that given the required environmental conditions, these microbes will proliferate.

Because of the numbers of individual bacterial isolates and the complexity of the testing procedures, it was necessary to use only representatives of the three main species of microorganisms in the actual testing procedure. It was assumed that the action of a representative species would be indicative of the activity of others in that group. This has been true for the nitrifying and thiobacilli species but not necessarily for the heterotrophic organisms. This was due to the large number of microbes capable of producing organic acids. In this case, a known, aggressive bacterium was selected.

\section{Development of Testing Methodology}

It has been determined that standard biodegradation tests (such as ASTM G21 and G22) are not applicable for use with some materials used to solidify LLW. Therefore, testing methods were devised and evaluated for a selected microorganism from each of the three different genera known to degrade concrete. The evaluation was designed using the optimum conditions of growth, exposure to the test specimen, and reaction time to promote degradation of simulated, cement-solidified LLW. Such an approach will provide the necessary flexibility to be able to conduct an evaluation of micro- bial activity, exposure methodology, specimen size, and test duration. The developed tests were intended to be very conservative. That is, they were to determine if microbial activity can affect the integrity of cement-solidified waste forms rather than speculate on whether degradation will occur under natural conditions.

A conservative method was developed that provided candidate organisms with optimum growth conditions as well as providing necessary exposure time for the waste forms. This was accomplished by using a microbial propagation system coupled with a specimen exposure chamber (Figure 13). The candidate microorganisms were intended to be introduced to the test specimens in several ways, including continual perfusion in which specimens were completely immersed in a continual flow of solution as well as intermittent immersion and intermittent misting.

During this phase of the study, it was necessary to conduct evaluations on cement specimens that were simulated waste forms. This provided the opportunity to determine how candidate organisms might react to actual solidified LLW. The type of cement that could be used as well as the type of simulated waste solidified were subjects for discussion.

Portland type I, II, and III cements had been reported as being used as binders for the solidification of both liquid radioactive wastes (materials that are soluble in water, such as salts) and solid radioactive wastes (materials that are insoluble in water, such as nuclear-grade ion-exchange resins). Portland type I cement has been the generalpurpose cement commonly used for construction applications in which sulfate attack from soil or water is minimal and where the heat generated during curing will not cause a critical rise in temperature. Portland type II cement has been modified to have a lower heat of hydration than type I and improved resistance to sulfate attack. Portland type III cement has high initial strength and has been used when high strengths are desirable in relatively short times (from 1 to 3 days). 


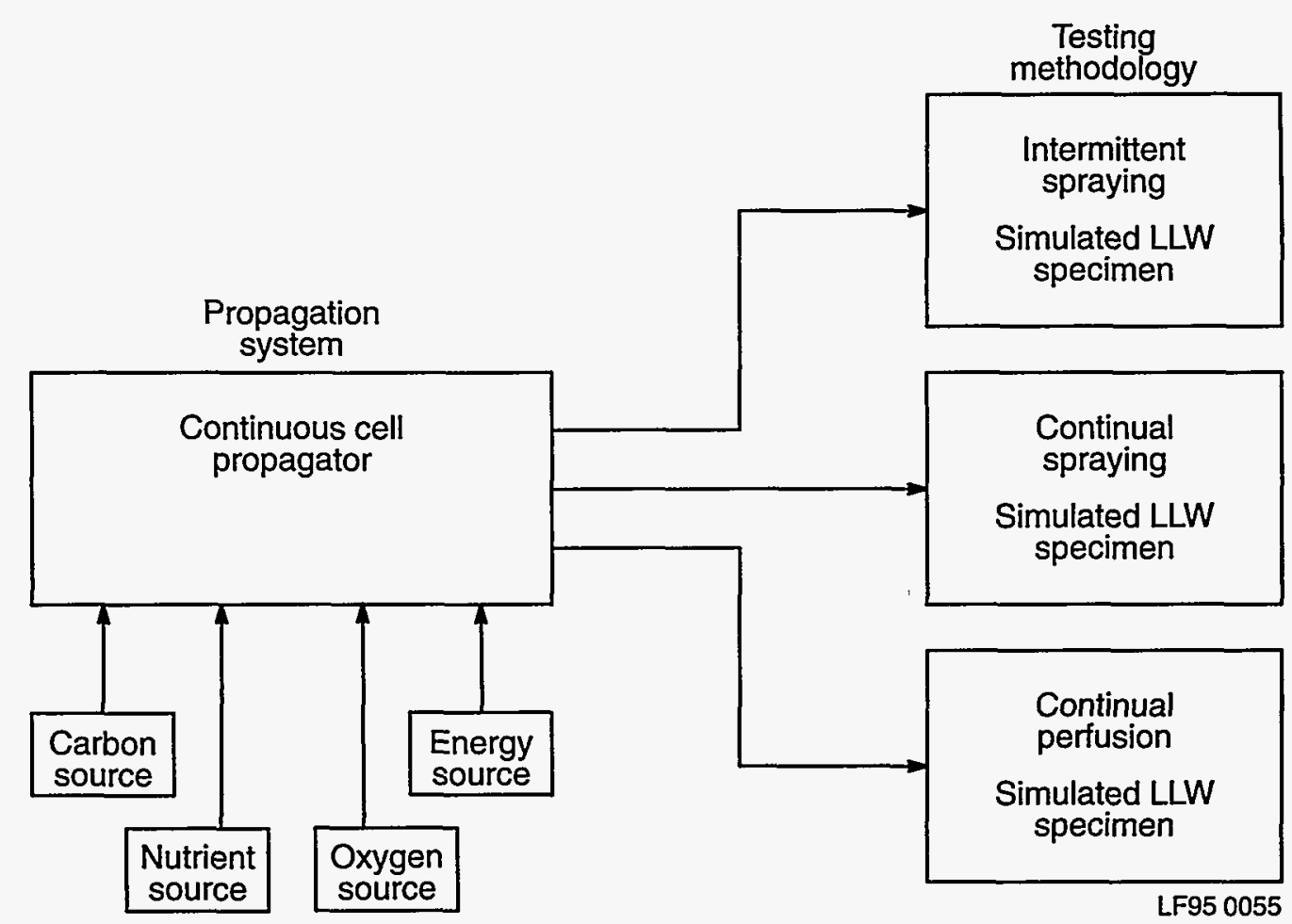

Figure 13. Schematic of proposed methods for testing the effects of MID on cement waste forms.

Colombo and Neilson (1979) stated that the type of Portland cement chosen for waste solidification probably depends more on availability and cost, thus favoring the selection of type I cement. It has been common practice for additives to be mixed in proprietary quantities with types I and II cement prior to its use as a solidification agent. The formulation of the cement binder used for this study, type II, was determined after a careful review of the available cementitious binders.

Comprehensive lists of waste formulations from boiling water reactors (BWRs) and pressure water reactors (PWRs) have been difficult to obtain. Colombo and Neilson (1979) compiled such a list over a decade ago. Because most operating power reactors were in operation at the time that their list was developed, it was reasonable to assume that it was representative of many presentday waste streams. Their data showed that reactor operations produced a variety of solid and liquid wastes that were compatible with cement solidification technology. Table 3 provides a listing of those materials. It appeared that for this program, the use of both a simulated solid waste (containing ion-exchange resin) and liquid waste (containing soluble salts) would provide a representative sample of LLW waste. The solid waste could be composed of ion-exchange resins in a formulation similar to $1 \mathrm{~b}$ as listed in Table 1 , while that of the liquid might be similar to $3 \mathrm{~b}$ without the "crud." However, because of the difficulty in obtaining up-to-date formulations of LLW waste as well as cement solidification formulations, it was advisable to obtain simulated cement waste forms directly from interested vendors.

Representative formulations for the INELfabricated simulated waste forms, together with a cement mortar control waste form, are found in Figure 14. The formulations for the waste forms were similar to those listed by Colombo and Neilson (1979). The formulation of the control cement mortar was as specified in "Standard Test Methods of Compressive Strength of Hydraulic Cement Mortars" (ASTM 1990) and included Portland type II cement, quartz sand, and water mixed at a 1:2.75:0.5 ratio. For the waste contain-. ing salts, the formulation includes sodium sulfate, ammonium sulfate, and sodium chloride in 
Table 3. Typical formulations of waste types from BWR and PWR reactor sites with listed pH and temperatures prior to solidification (Colombo and Neilson 1979).

\begin{tabular}{|c|c|c|}
\hline & Material & Weight percent \\
\hline la. & $\begin{array}{l}\text { Bead resin waste (slurry) } \\
\text { Water } \\
\text { Bead resin (IRN-150) } \\
\text { Temperature } \\
\text { pH }\end{array}$ & $\begin{array}{l}50.0 \\
50.0 \\
70^{\circ} \mathrm{F} \\
7\end{array}$ \\
\hline lb. & $\begin{array}{l}\text { Bead resin waste (dewatered) } \\
\text { Water } \\
\text { Bead resin }(\text { IRN-150)(a) } \\
\text { Temperature } \\
\text { pH }\end{array}$ & $\begin{array}{l}35.0 \\
65.0 \\
70^{\circ} \mathrm{F} \\
7 \\
\text { Weight percent in } \\
\quad \text { filter cake } \\
\end{array}$ \\
\hline $2 \mathrm{a}(1)$. & $\begin{array}{l}\text { BWR precoat filter cake with powdered resin (slurry) } \\
\text { Water } \\
\text { Anion powdered resin }(\mathrm{PAO})^{(\mathrm{b})} \\
\text { Cation powdered resin }(\mathrm{PCH})^{(\mathrm{b})} \\
\text { Crud }{ }^{(\mathrm{c})} \\
\text { Sodium chloride } \\
\text { Temperature } \\
\text { pH }\end{array}$ & $\begin{array}{l}50.0 \\
20.0 \\
20.0 \\
5.0 \\
5.0 \\
70^{\circ} \mathrm{F} \\
7\end{array}$ \\
\hline $2 a(2)$. & $\begin{array}{l}\text { BWR precoat filter cake with powdered resin (dewatered) } \\
\text { Water } \\
\text { Anion powdered resin }(\mathrm{PAO})^{(\mathrm{b})} \\
{\text { Cation powdered resin }(\mathrm{PCH})^{(\mathrm{b})}}_{\text {Crud }^{(\mathrm{c})}} \\
\text { Sodium chloride } \\
\text { Temperature } \\
\text { pH }\end{array}$ & $\begin{array}{l}32.0 \\
30.0 \\
30.0 \\
6.0 \\
2.0 \\
70^{\circ} \mathrm{F} \\
7\end{array}$ \\
\hline $2 b(1)$ & $\begin{array}{l}\text { BWR precoat filter cake with diatomaceous earth (slurry) } \\
\text { Water } \\
\text { Diatomaceous earth } \\
\text { Crud(c) } \\
\text { Temperature } \\
\text { pH }\end{array}$ & $\begin{array}{l}75.0 \\
20.0 \\
5.0 \\
70^{\circ} \mathrm{F} \\
7\end{array}$ \\
\hline $2 b(2)$. & $\begin{array}{l}\text { BWR precoat filter cake with diatomaceous earth (dewatered) } \\
\text { Water } \\
\text { Diatomaceous earth } \\
\text { Crud(c) } \\
\text { Temperature } \\
\text { pH }\end{array}$ & $\begin{array}{l}60.0 \\
30.0 \\
10.0 \\
170^{\circ} \mathrm{F} \\
7\end{array}$ \\
\hline
\end{tabular}


Table 3. (continued).

3a. BWR chemical regenerative waste of a forced recirculation evaporator

$\begin{array}{ll}\text { Water } & 75.0 \\ \text { Sodium sulfate } & 22.9 \\ \text { Sodium chloride } & 2.0 \\ \text { Crud(c) } & 0.1 \\ \text { Temperature } & 170^{\circ} \mathrm{F} \\ \text { pH } & 6\end{array}$

3b. PWR chemical regenerative waste of a forced recirculation Evaporator

\begin{tabular}{ll}
\hline Water & 73.4 \\
Sodium sulfate & 14.9 \\
Ammonium sulfate & 9.6 \\
Sodium chloride & 2.0 \\
Crud(c) & 0.1 \\
Temperature & $170^{\circ} \mathrm{F}$ \\
pH & 2.5 to 4.0
\end{tabular}

3c. Boric acid waste of a forced recirculation evaporator

\begin{tabular}{ll}
\hline Water & 87.9 \\
Boric acid & 12.0 \\
Crud(c) & 0.1 \\
Temperature & $170^{\circ} \mathrm{F}$ \\
pH & 3.5
\end{tabular}

3d. Decontamination waste of a forced recirculation evaporator

Water

80.0

Nutek NT-700(d) $\quad 9.4$

EDTA $\quad 5.0$

Citric Acid $\quad 5.0$

$\begin{array}{ll}\text { Crud }^{(c)} & 0.2\end{array}$

Hydraulic oil No. $2 \quad 0.2$

Lubricating oil No. $20 \quad 0.2$

Temperature $\quad 170^{\circ} \mathrm{F}$

$\mathrm{pH}-5$

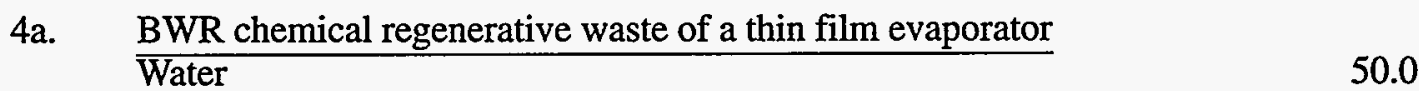

$\begin{array}{ll}\text { Sodium sulfate } & 45.8\end{array}$

Sodium chloride $\quad 4.0$

$\begin{array}{ll}\text { Crud (c) } & 0.2\end{array}$

Temperature $\quad 150$ to $250^{\circ} \mathrm{F}$

$\mathrm{pH}$

6 
Table 3. (continued).

Material

4b. PWR chemical regenerative waste of a thin film evaporator

Water

Sodium sulfate

Ammonium sulfate

Sodium chloride

Crud (c)

Temperature

$\mathrm{pH}$

4c. Boric acid waste of a thin film evaporator

Water

Boric acid

Crud(c)

Temperature

$\mathrm{pH}$
Weight percent in

evaporator bottoms

50.0

29.0

16.8

4.0

0.2

150 to $250^{\circ} \mathrm{F}$

1.8 to 4.0

50.0

49.8

0.2

150 to $250^{\circ} \mathrm{F}$

2.5 to 3.5

4d. Decontamination waste of a thin film evaporator

Water

Nutek NT-700(d)

50.0

20.0

EDTA

9.8

Citric acid

Crud(c)

19.0

Hydraulic oil No. 2

Lubricating oil No. 20

Temperature

$\mathrm{pH}$

0.2

0.5

0.5

150 to $250^{\circ} \mathrm{F}$

5

a. Rohm and Haas Co., Philadelphia, PA 19105.

b. Ecodyne Corp., Union, NJ 07083.

c. Fine air cleaner test dust no. 1543094, AC Spark Plug Division, General Motors Corp. Flint, MI 48556.

d. Nuclear Technology Corp., Amston, CT 06231.

water mixed at a ratio of $1: 1$ Portland type II cement to waste. The simulated ion-exchange resin waste contained ion-exchange resin and water mixed at a 1:1.5 ratio of Portland type II cement to waste. Vendor-supplied simulated waste forms were obtained. They included both resin and boric acid salts formulations.

All of the simulated waste-form specimens (including the ASTM formulation) manufactured at the INEL were molded as cylinders $1.8 \mathrm{~cm}$ in diameter $\times 2.2 \mathrm{~cm}$ long. The vendor's process and formulations for waste form production are proprietary; however, it is known that the formulation includes a pozzolanic cement mixture. The vendor used its methods to produce both simulated, solidified ion-exchange resin and evaporator bottoms wastes forms molded into cylinders $5 \times 10.2 \mathrm{~cm}$. Before use, these waste forms were cut into pie-shaped specimens $3 \mathrm{~cm}$ wide, $2.5 \mathrm{~cm}$ long, and $1 \mathrm{~cm}$ thick. These vendor-supplied simulated waste forms were then tested in a manner similar to the INEL-supplied simulated waste forms using the testing matrix described in Figure 15. The two types of simulated waste forms and the control cement mortar were exposed to 
Formulation of waste containing resin (solid)

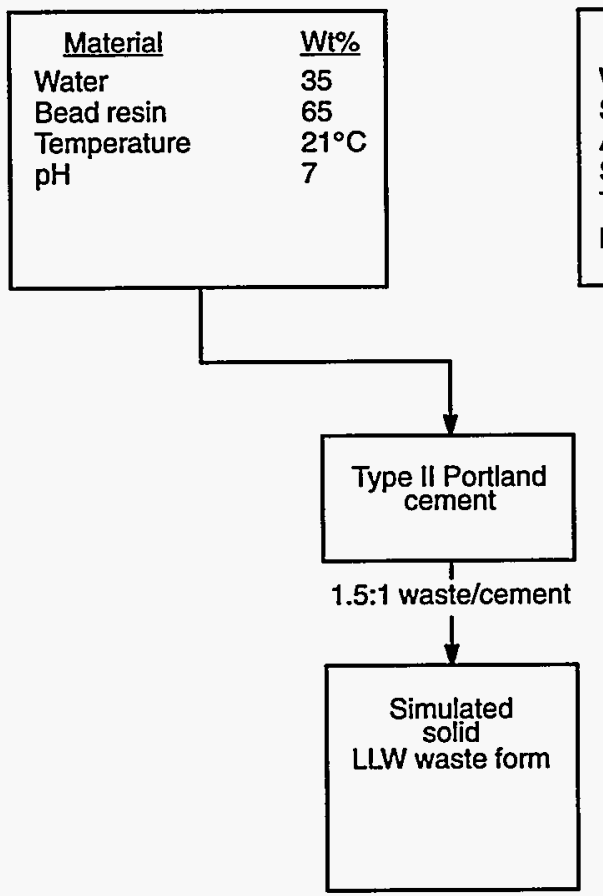

Formulation of waste containing salt (liquid)

\begin{tabular}{|ll|}
\hline \multicolumn{1}{|c|}{ Material } & Wt\% \\
Water & 73.4 \\
Sodium sulfate & 15.0 \\
Ammonium sulfate & 9.6 \\
Sodium chloride & 2.0 \\
Temperature & $77^{\circ} \mathrm{C}$ \\
pH & 4
\end{tabular}

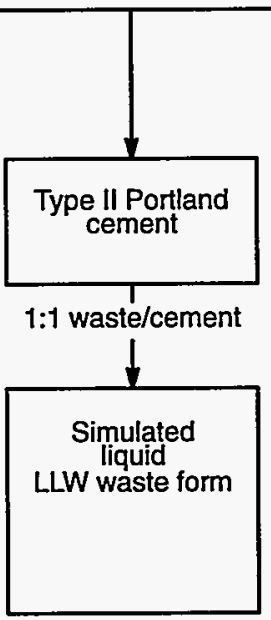

Control formulation

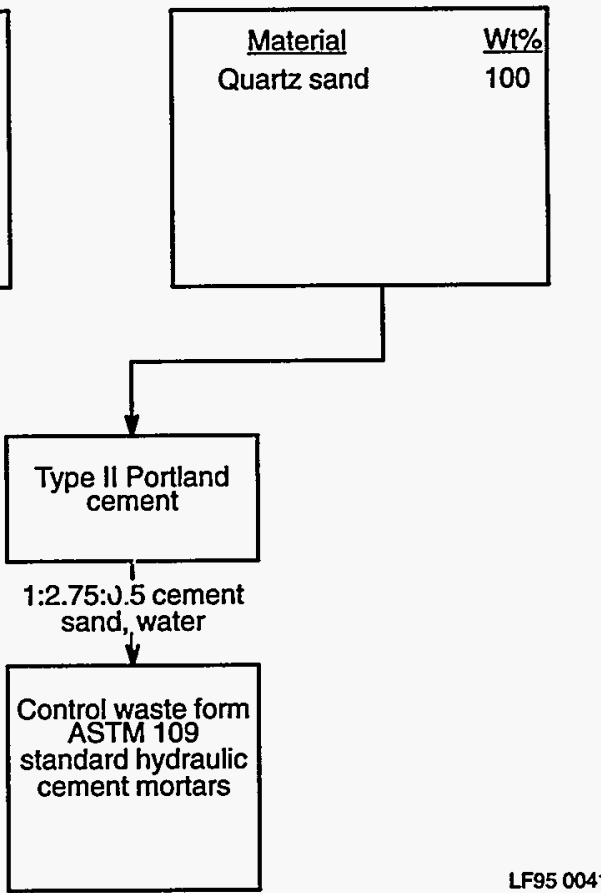

Figure 14. Examples of possible composition of simulated low-level waste forms.

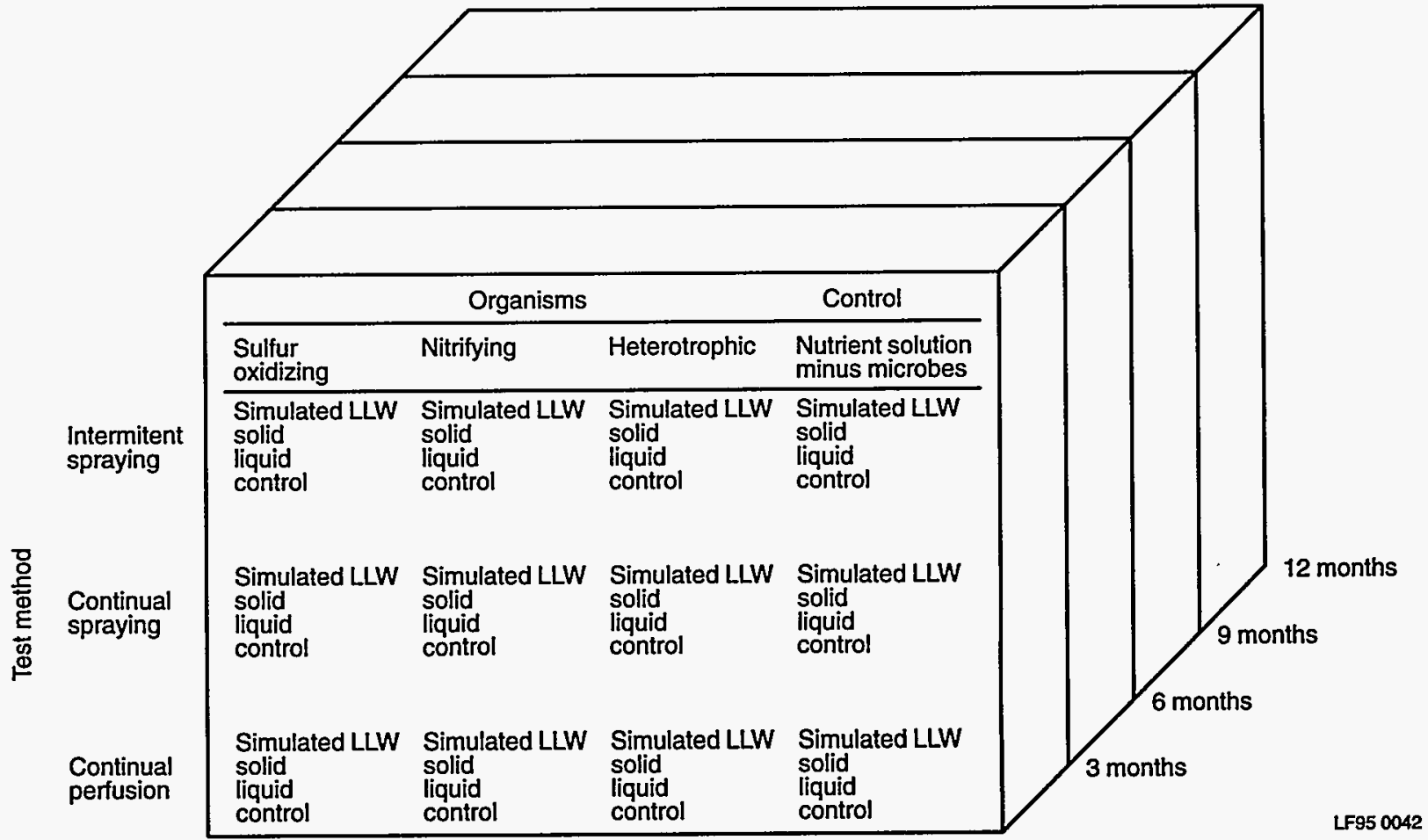

Figure 15. Matrix for testing simulated low-level waste forms. 
each of the three genera of selected microorganisms. Control solutions of sterile nutrient feed were also used for each set of experiments. Because the time requirement for observable effects was not known, exposure times had to be determined for each testing scenario.

In a final test, radioactive waste-form specimens from two actual commercial nuclear power plant waste forms were evaluated. Those wasteform specimens, $5.1 \mathrm{~cm}$ in diameter $\times 10.2 \mathrm{~cm}$ high, were obtained by INEL personnel during solidification of the plant wastes. The first waste form was composed of decontamination ion-exchange resin in a proprietary formulation of pozzolanic cement from Peach Bottom Atomic Power Station Unit 3. The second consisted of filter sludge in a proprietary pozzolanic cement mixture from Nine Mile Point Nuclear Plant Unit 1. Before use, the waste forms were cut into pie-shaped specimens $4 \mathrm{~cm}$ wide, $2.5 \mathrm{~cm}$ on edge, and $0.6 \mathrm{~cm}$ thick.

\section{Total Immersion.}

Heterotrophic Bacteria. Preliminary work has been conducted with the continual perfusion method using lixiviant produced by representatives of the three types of candidate microorganisms. A strain of Pseudomonas cepacia was selected as representative of the organic acid-producing heterotrophs. This organism was selected because previous work demonstrated its capabil- ity for promoting the degradation of rock phosphate ore (Rogers and Wolfram 1992). The formulation of media used to grow the microorganisms is found in Table 4. The effect of this microbe on the integrity of both INEL and vendor waste forms appeared to be minimal. After 60 days of complete immersion in Pseudomonas lixiviant, the surface $\mathrm{pH}$ of the vendor-supplied simulated waste forms were not significantly different from those immersed in the sterile, neutral $\mathrm{pH}$ growth medium. The resin formulation after lixiviant immersion had a surface $\mathrm{pH}$ of 9 compared to $\mathrm{pH} 10$ after immersion in the sterile medium, and the surface $\mathrm{pH}$ of the evaporator bottoms formulation was 9 after lixiviant immersion compared to $\mathrm{pH} 9.5$ after immersion in the sterile medium. The surface $\mathrm{pH}$ of the ASTM control cement formulation was slightly lower after immersion in the Pseudomonas lixiviant, $\mathrm{pH} 6$ compared to $\mathrm{pH} 9$ after immersion in the sterile medium.

Percent calcium leached from the resin, evaporator bottoms, and the ASTM formulations were $16.6 \%, 9.8 \%$, and $24.7 \%$, respectively, after immersion in Pseudomonas lixiviant. These results suggest that over the period of the test, the buffering capacity of the cement formulations is sufficient to resist chemical attack from the organic acids produced by Pseudomonas. Therefore, no further testing was conducted with the heterotrophic species.

Table 4. Formulation of heterotrophic bacteria medium.

\begin{tabular}{lc}
\hline Chemical compound & $\begin{array}{c}\text { Amount per liter } \\
\text { doubly deionized water } \\
(\mathrm{g})\end{array}$ \\
\hline$\left(\mathrm{NH}_{4}\right)_{2} \mathrm{SO}_{4}$ & 2.0 \\
$\mathrm{MgCl}_{2} \cdot 6 \mathrm{H}_{2} \mathrm{O}$ & 0.3 \\
$\mathrm{MnCl}_{2} \cdot 4 \mathrm{H}_{2} \mathrm{O}$ & 0.001 \\
$\mathrm{FeSO}_{4} \cdot 7 \mathrm{H}_{2} \mathrm{O}$ & 0.0006 \\
$\mathrm{NaMoO}_{4} \cdot 2 \mathrm{H}_{2} \mathrm{O}$ & 0.026 \\
$\mathrm{KH}_{2} \mathrm{PO}_{4}$ & 1.0 \\
$\mathrm{Glucose}$ & 10.0 \\
\hline
\end{tabular}


Nitrifying Bacteria. Although nitrifying bacteria produce acidity through their metabolic activity, it is known that most of these bacteria grow optimally in buffered systems in which the $\mathrm{pH}$ is maintained between 7.5 and 8.5 (Schmidt and Belser 1982). The necessary buffering capacity in the case of natural sandstone is supplied by the continuous dissolution of the calcareous binding matrix (Mansch and Bock 1992). Unlike thiobacilli whose metabolic activity results in overwhelming the buffering capacity of cementderived calcium hydroxide, nitric acid formation by nitrifying bacteria is continuously being neutralized by the loss of the calcium constituent.

The continuous flow reactor system was evaluated (as described in the previous section) for application to the nitrifying bacteria using mixed cultures of Nitrosomonas and Nitrobacter (Rogers et al. 1994). Data from this work showed that the continuous flow reactor system was not suitable for optimum growth of these bacteria. Also, it was determined that mixed cultures of the ammonia-oxidizing and nitrite-oxidizing bacteria were not necessary to achieve optimum mineral acid production. In addition, the growth of these bacteria under continuous flow bioreactor conditions required the addition of a buffer to maintain slightly alkaline growth conditions. Therefore, the use of the continuous flow design for waste form exposure was discontinued for these microorganisms, and another design was evaluated. This necessitated a complete redesign and evaluation of the exposure system to make it more amenable for the growth and subsequent application of the nitrifying bacteria to the waste forms. Efforts to develop and test the modified exposure system are explained in this section. In addition, some sophisticated methods to determine how MID bacteria interact with the surface of the cement test specimens were evaluated during this phase of testing. Those methods were then applied to testing with other bacteria in this program. Results of this work are also reported.

A bioreactor design used successfully by other researchers to grow nitrifying bacteria was known to be based on a fed batch design. It has been demonstrated that fed batch reactor systems are particularly suited to the growth and monitoring of slow-growing microorganisms (Grady and Lim 1980; Bailey and Ollis 1986). They combine the desirable aspects of both continuous flow and batch reactor systems. An evaluation of the fed batch system was initiated to determine if it satisfied program needs. The process was initiated by inoculating nutrient solutions (see Table 5 for content) containing the test specimens (simulated waste forms) with a pure culture of the ammoniaoxidizing bacteria Nitrosomonas europea. Preliminary work with the method was encouraging. It was possible to monitor the solution concentrations of ammonia and nitrite, thus providing a quantitative assessment of acid production. Also, the concentration of $\mathrm{Ca}$ in exposed media was monitored to determine the quantity of cementbased $\mathrm{Ca}$ that was solubilized. The results of the evaluation were sufficiently encouraging to warrant further studies.

Waste forms used in the initial fed batch study were the INEL simulated resin and salts and the ASTM control. The study was designed so that one each of the simulated waste forms was exposed to both the biotreatment and a sterile medium control. To accomplish this, sterilized waste forms (ethylene oxide treatment) were placed into individual $250-\mathrm{mL}$ flasks (six in all). Sterile medium $(\sim 100 \mathrm{~mL})$ inoculated with $N$. europea (with a final concentration of $1 \times 10^{7}$ cells $/ \mathrm{mL}$ ) was added to flasks containing representative samples of either the two waste forms or the ASTM control (treatments). Sterile medium without inocula was added to the remaining three flasks (sterile controls). All the flasks were sealed with sterile rubber stoppers modified to accept influent and effluent tubes for the exchange of media. Prepared flasks were then placed into a covered, insulated water bath and incubated at $28^{\circ} \mathrm{C}$ in the dark. Every 48 hours, the liquid in all flasks was removed and replaced with fresh sterile media (these media were automatically inoculated in those flasks containing the microbial treatment). The $\mathrm{pH}$ of the collected effluent was recorded, followed by quantitative determination of the nitrite concentration. A decrease in solution $\mathrm{pH}$ with a concomitant increase in the 
Table 5. Formulation of ammonia-oxidizer medium for Nitrosomonas and Nitrosovibrio.

\begin{tabular}{|c|c|}
\hline Chemical compound & $\begin{array}{c}\text { Amount } \\
(\mathrm{g})\end{array}$ \\
\hline \multicolumn{2}{|l|}{ Primary stock solution } \\
\hline $\mathrm{KH}_{2} \mathrm{PO}_{4}$ & 1.08 \\
\hline $\mathrm{KCl}$ & 1.48 \\
\hline $\mathrm{MgSO}_{4} \cdot 7 \mathrm{H}_{2} \mathrm{O}$ & 0.98 \\
\hline $\mathrm{CaCl}_{2} \cdot 2 \mathrm{H}_{2} \mathrm{O}$ & 2.94 \\
\hline $\mathrm{NaCl}$ & 11.78 \\
\hline \multicolumn{2}{|c|}{ Trace element stock solution per liter $0.025 \mathrm{~N} \mathrm{HCl}$} \\
\hline $\mathrm{MnSO}_{4} \cdot \mathrm{H}_{2} \mathrm{O}$ & 0.034 \\
\hline $\mathrm{H}_{3} \mathrm{BO}_{3}$ & 0.049 \\
\hline $\mathrm{ZnSO}_{4} \cdot 7 \mathrm{H}_{2} \mathrm{O}$ & 0.043 \\
\hline$\left(\mathrm{NH}_{4}\right)_{6} \mathrm{Mo}_{7} \mathrm{O}_{24} \cdot 4 \mathrm{H}_{2} \mathrm{O}$ & 0.037 \\
\hline $\mathrm{FeSO}_{4} \cdot 7 \mathrm{H}_{2} \mathrm{O}$ & 0.973 \\
\hline $\mathrm{CuSO}_{4}$ & 0.016 \\
\hline \multicolumn{2}{|l|}{ Cresol Red solution } \\
\hline \multicolumn{2}{|c|}{ 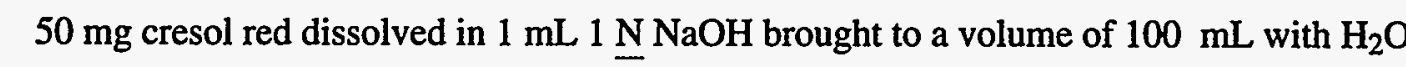 } \\
\hline \multicolumn{2}{|c|}{ Autotrophic medium for Nitrosomonas and Nitrosovibrio (per liter $\mathrm{H}_{2} \mathrm{O}$ ) } \\
\hline \multicolumn{2}{|l|}{$0.535 \mathrm{~g} \mathrm{NH}_{4} \mathrm{Cl}(10 \mathrm{mmol})$} \\
\hline \multicolumn{2}{|l|}{$50 \mathrm{~mL}$ primary stock solution } \\
\hline \multicolumn{2}{|l|}{$1 \mathrm{~mL}$ trace element stock solution } \\
\hline \multicolumn{2}{|l|}{$1 \mathrm{~mL}$ cresol red solution } \\
\hline \multicolumn{2}{|c|}{ Adjust to $\mathrm{pH} 7.8-8.2$ with sterilized $10 \% \mathrm{Na}_{2} \mathrm{CO}_{3}$ after autoclaving } \\
\hline
\end{tabular}

concentration of nitrite were used as an indication of metabolic activity by the bacteria. Confirmation of bacterial growth was obtained by direct counts of planktonic cells (unattached) using light microscopy.

Results from the first week of an initial test indicated that the bacteria were not active. There had been no increase in nitrite content, solution $\mathrm{pH}$ had not decreased from an initial high of between 11 and 12, and direct counts showed that cell numbers were decreasing. The apparent reason for the lack of microbial viability was an alkaline solution $\mathrm{pH}(>9)$. Nitrosomonas are known to prefer a pH range between 7.5 and 8.5 (Bock, personal communication, 1993). However, there were data from the literature (Diercks et al. 1991; Mansch and Bock 1992) that indicate these bacteria do grow on the surface of concrete under natural and laboratory conditions. The question of how to initiate growth on fresh concrete was answered by Bock (personal communication, 1993). He pointed out that before growth occurs on fresh concrete test specimens, it is necessary to condition the exposed concrete surfaces to duplicate the natural process of carbonization (carbonate formation) that results in a decrease of surface $\mathrm{pH}$. The conditioning process has been carried out by Bock in test chambers by allowing media to percolate over specimens for several weeks before attempting inoculation. We elected to accelerate conditioning by immersing specimens 
in sterile water fortified with weak carbonic acid that was generated by bubbling with carbon dioxide. It was found that a 1 to 2 -week treatment (depending on waste formulation) in the resulting solution was sufficient to duplicate the natural process that reduces surface $\mathrm{pH}$ to near 8.5. Conditioned specimens were then used in subsequent studies.

Results 48 hours after initiation of the second study using conditioned simulated waste-form specimens indicated that the $N$. europea bacteria were able to tolerate the presence of the test specimens. By day 12 , the $\mathrm{pH}$ of the inoculated solutions had decreased to $6.0,8.5,7.1$, respectively, for the ASTM control, resin, and salts waste forms. In addition, nitrite concentrations had increased to 6,5 , and $6 \mathrm{mM}$ respectively. Results at the end of the 66-day study clearly demonstrated a relationship between $\mathrm{pH}$ and nitrite production. It was seen that as $\mathrm{pH}$ decreased, the concentration of nitrite increased (an inverse relationship). The $\mathrm{pH}$ during the course of the study fluctuated, but the average remained close to the day-12 values. A total of $5.5,1.8$, and $4.9 \mathrm{mM}$ of nitrite were produced in the ASTM, resin, and salts waste-form specimen treatments, respectively. This corresponded to $0.34,0.11$, and 0.31 $\mathrm{mL}$ of concentrated nitric acid. The continued production of relatively stable amounts of nitrite showed that bacterial activity was maintained each time after media replacement.

It was noted in this study that after 2 weeks of incubation, the treated waste-form specimens had become contaminated with an additional microbial species. Biochemical tests identified the contaminant as Pseudomonas fluorescence. This is a heterotrophic bacteria that is capable of growth using only minute quantities of organic carbon. Initially, there was concern that these microbes could affect the activity of the $N$. europea. However, the contamination of the simulated wasteform specimens in the sterile medium (after 45 days) showed that the presence of $P$. fluorescence had no effect on solution $\mathrm{pH}$ or on the production of nitrite. Sterile cotton swabs were used to obtain surface samples of all the waste-form specimens to determine if colonization by with either species of bacteria had occurred. Results from spreading on a heterotrophic medium and incubation of inoculated sterile nitrifier medium showed that both species of bacteria had successfully colonized the surface of the specimens.

At the end of 66 days, the waste-form specimens were retrieved and prepared for analysis. Their physical appearance can be seen in Figures 16 through 18. The ASTM controls and salts formulations of both treatment and controls remained intact while the resin waste-form specimens disintegrated. Those specimens exposed to the microbial treatment showed some color change as well. A small portion of each specimen was taken for image analysis using environmental scanning electron microscopy (ESEM). Using a sterile spatula, surface scrapings were taken from these portions for further study using appropriate staining techniques. The remainder of each portion was rinsed in sterile water to remove planktonic cells. This was followed by sonication of the solids in sterile phosphate buffer to remove attached biofilm and/or individual bacterial cells. Aliquots of those solutions were incubated in the nitrifier medium to confirm the presence of nitrifying bacteria adhering to the waste form surface. The surface scrapings were subjected to a combined staining procedure designed to detect both the presences of biofilm exopolysaccheride (EPS) and bacterial cells. Alcian blue stain was used to highlight the presence of biofilm EPS, while acridine orange stain was used to show the presence of viable bacteria imbedded in the biofilm. Examination of the stained material was conducted with both light and fluorescence microscopy. In addition, the surface $\mathrm{pH}$ of each waste-form specimen was determined.

Examination with the ESEM showed the presence of an amorphous material on the surface of all waste-form specimens (both treatment and sterile control) (Figures 19 through 21). Experts familiar with biofilm formation identified this material as an organic-mineral matrix consistent with biofilm formation. The presence of some individual bacterial cells was also detected, but it was assumed that most of them were immersed in the biofilm. Confirmation of these observations 

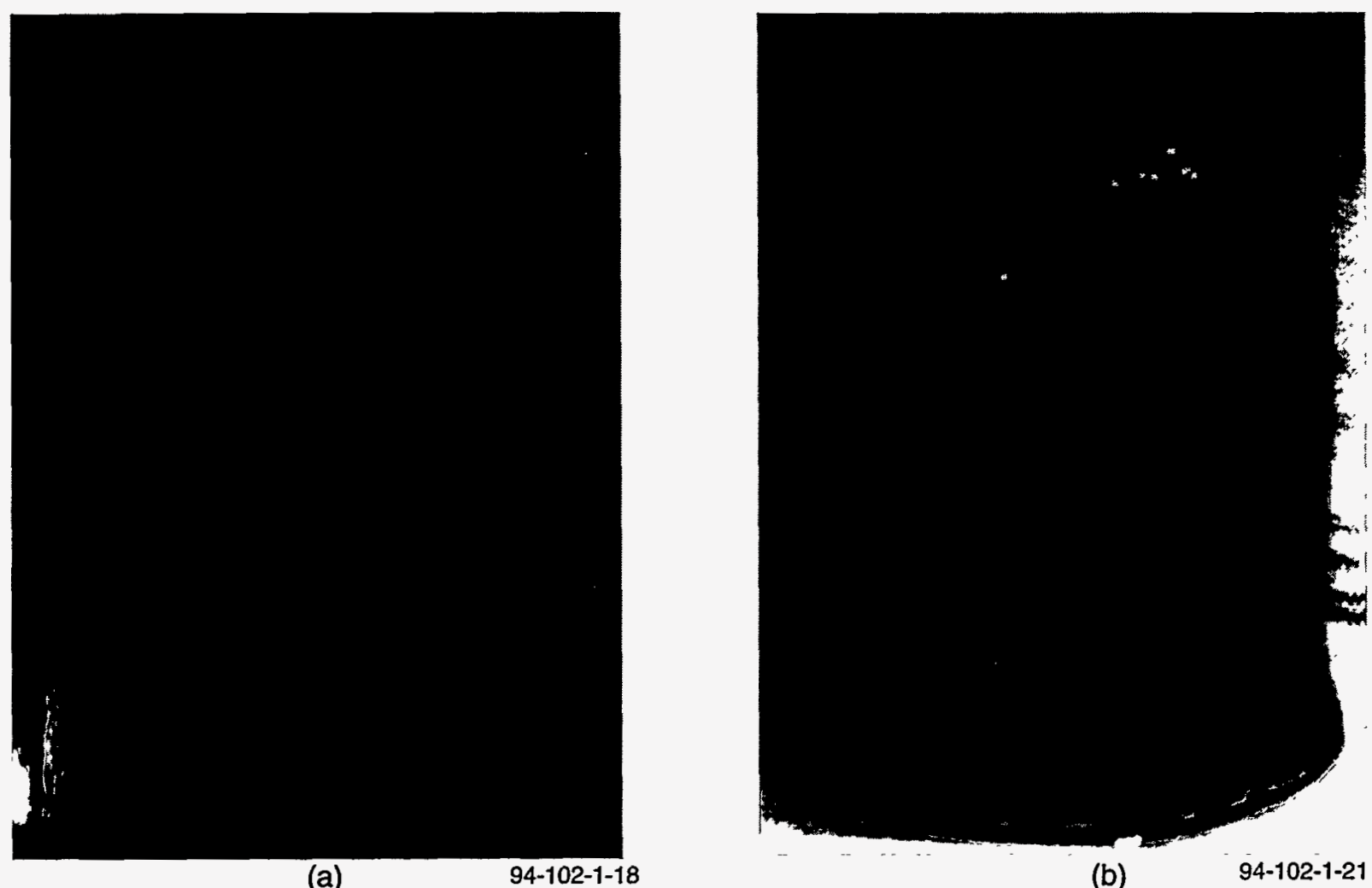

(b)

Figure 16. ASTM control waste-form specimens after being immersed for 66 days in (a) sterile nitrifier medium (b) medium containing nitrifying bacteria.
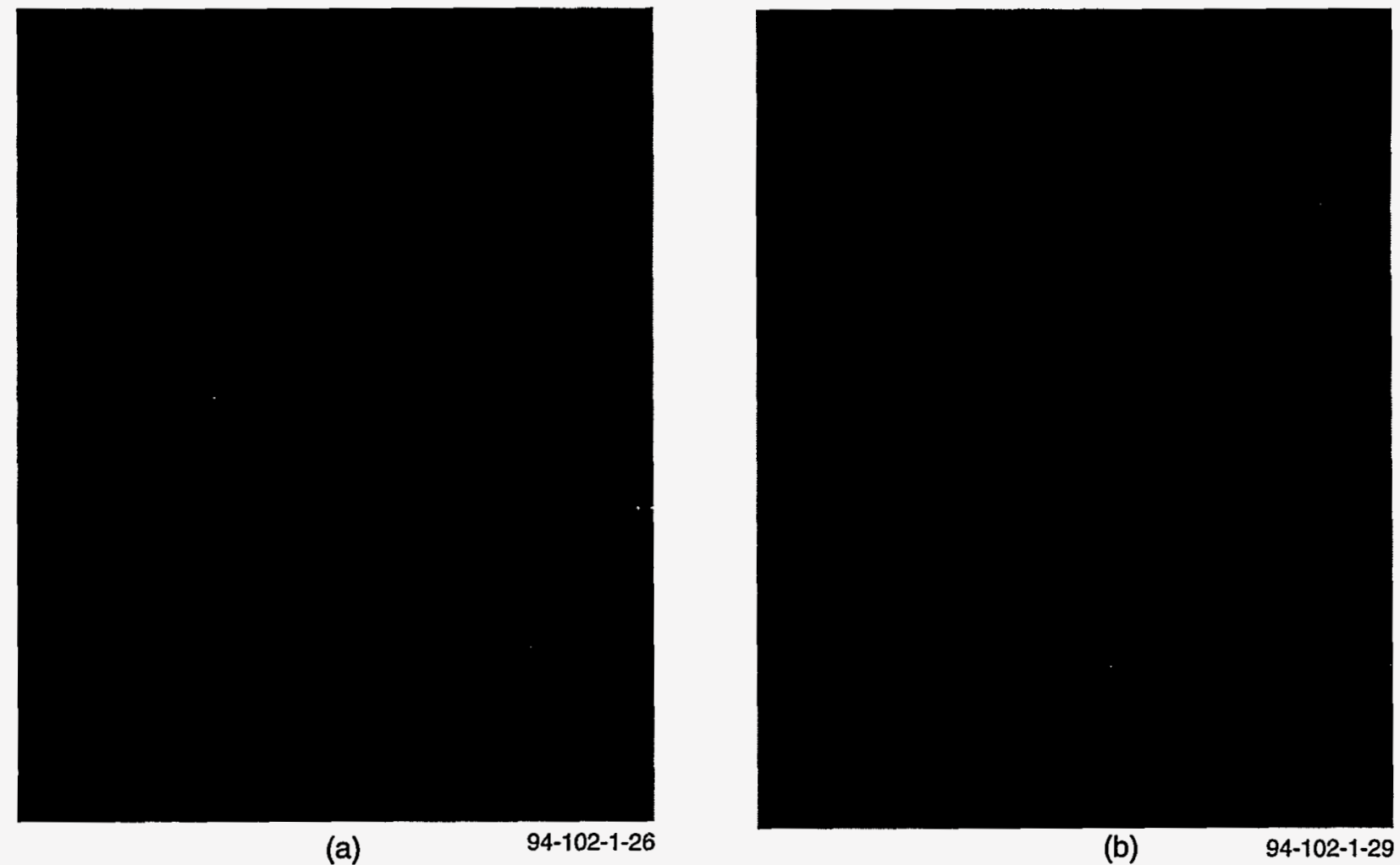

Figure 17. INEL-supplied simulated evaporator bottoms waste-form specimen after being immersed for 66 days in (a) sterile nitrifier medium (b) medium containing nitrifying bacteria. 


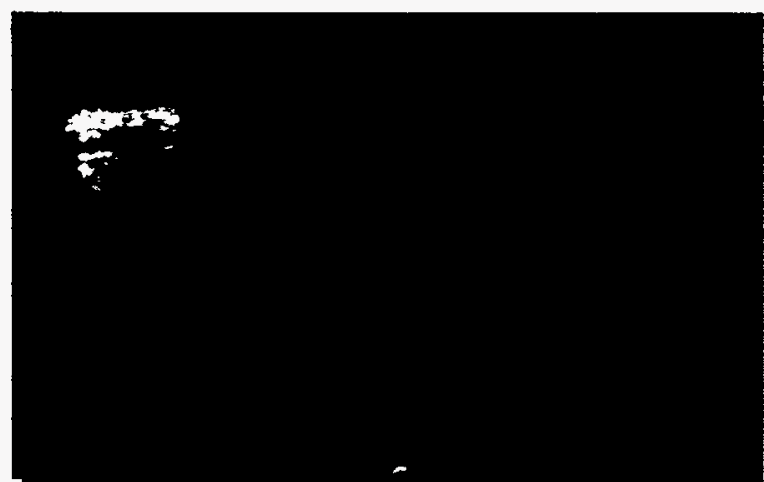

(a)
$94-102-1-22$

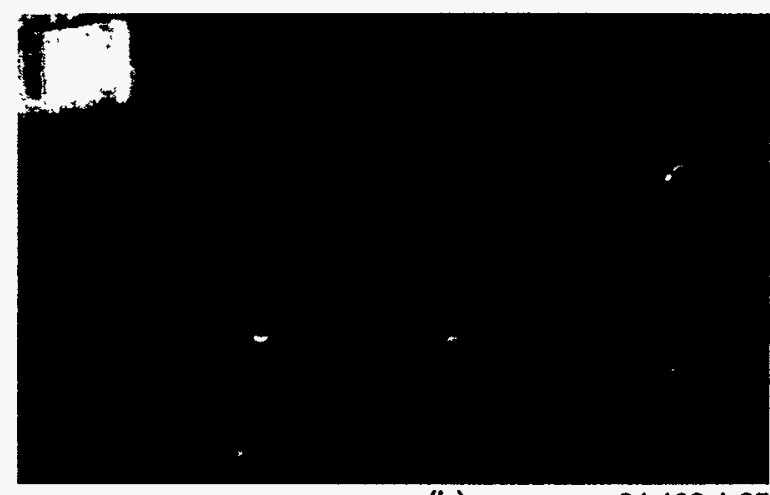

(b)

$94-102-1-25$

Figure 18. INEL-supplied simulated ion-exchange resin waste-form specimen after being immersed for 66 days in (a) sterile nitrifier medium (b) medium containing nitrifying bacteria.

was obtained from the staining procedure (Figure 22). Note that the presence of the background blue color confirms the presence of biofilm EPS material (Figure 22a) while the bright, fluorescing orange oval shapes indicate the presence of viable cells associated with the biofilm matrix (Figure 22b). Results from plating of the surface scrapings confirmed the earlier findings obtained from swabbing the surfaces of the waste-form specimens. $P$. fluorescence was present on the surface of all waste form specimens, and in addition, $N$. europea was identified by most-probable-number analysis (Schmidt and Belser 1982) as a co-colonizer of the treated waste-form specimens. All of the data clearly demonstrate that bacteria were capable of colonizing the surface of the simulated cement waste-form specimens.

The colonization by the $N$. europea resulted in the beginning of an MID attack. This is confirmed by the increased loss of $\mathrm{Ca}$ in the treated samples. The percent loss of $\mathrm{Ca}$ from the INEL-supplied simulated waste-form specimens exposed to $N$. europea is summarized in Figure 23. The ASTM standard and the evaporator bottoms waste-form specimen each had a greater loss of $\mathrm{Ca}$ due to the nitrifying microbe $(\sim 12$ and $6 \%$, respectively) than they did from the sterile medium $(\sim 3 \%)$. The ion-exchange resin waste-form specimens exposed to the biotreatment and the sterile medium both lost comparable quantities of $\mathrm{Ca}$ $(\sim 17 \%)$. The increased loss of $\mathrm{Ca}$ demonstrates that the activity of the nitrifying bacteria was beginning to affect the chemical integrity of two of the test specimens. It is apparent, however, that a more thorough evaluation of the effects of $N$. europea will require a test period longer than 60 days.

In the next study, the vendor-supplied simulated ion-exchange resin and the evaporator bottoms waste-form formulations were used. In addition, the ASTM formulation was included as the control waste form. Before use, the simulated waste forms and control were sliced into pellets approximately $0.5 \mathrm{~cm}$ thick. For the vendor-supplied waste forms, this resulted in pie-shaped pellets approximately $0.5 \mathrm{~cm}$ thick with $0.9 \mathrm{~cm} \times 0.9$ $\mathrm{cm} \times 1.3 \mathrm{~cm}$ side dimensions, with a bisecting groove cut nearly to the depth of pellet thickness. Before the pellets were used, they were exposed to the carbonization process (as described for the previous study) and then sterilized with ethylene oxide. Sterilized pellets were then transferred aseptically into 250-mL Erlenmeyer flasks (five each), which were subsequently immersed in the $28^{\circ} \mathrm{C}$ water bath, and the cover was replaced. Following that, each of the treatment flasks (a total of three) was inoculated through the inlet tube with approximately $100 \mathrm{~mL}$ of an $N$. europea solution (strain "freitag" $1 \times 10^{7}$ cells $/ \mathrm{mL}$ ), which entirely immersed the pellets in culture solution. The pellets in the three control flasks were immersed in sterile medium. The $N$. europea strain had been cultured in the dark before pellet inoculation in $500 \mathrm{~mL}$ of ammonia-oxidizer growth medium (Schmidt and Belser 1982). 


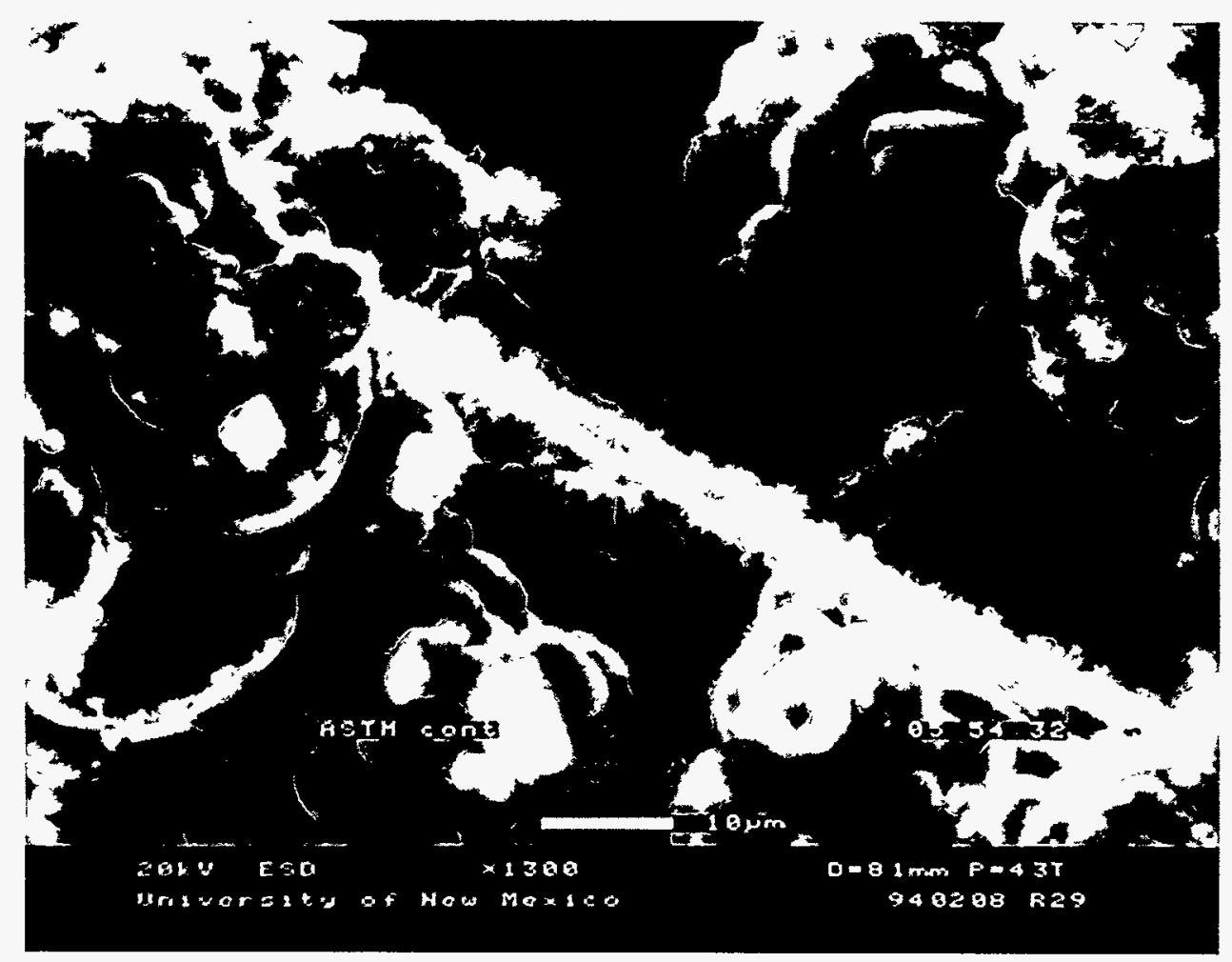

(a)

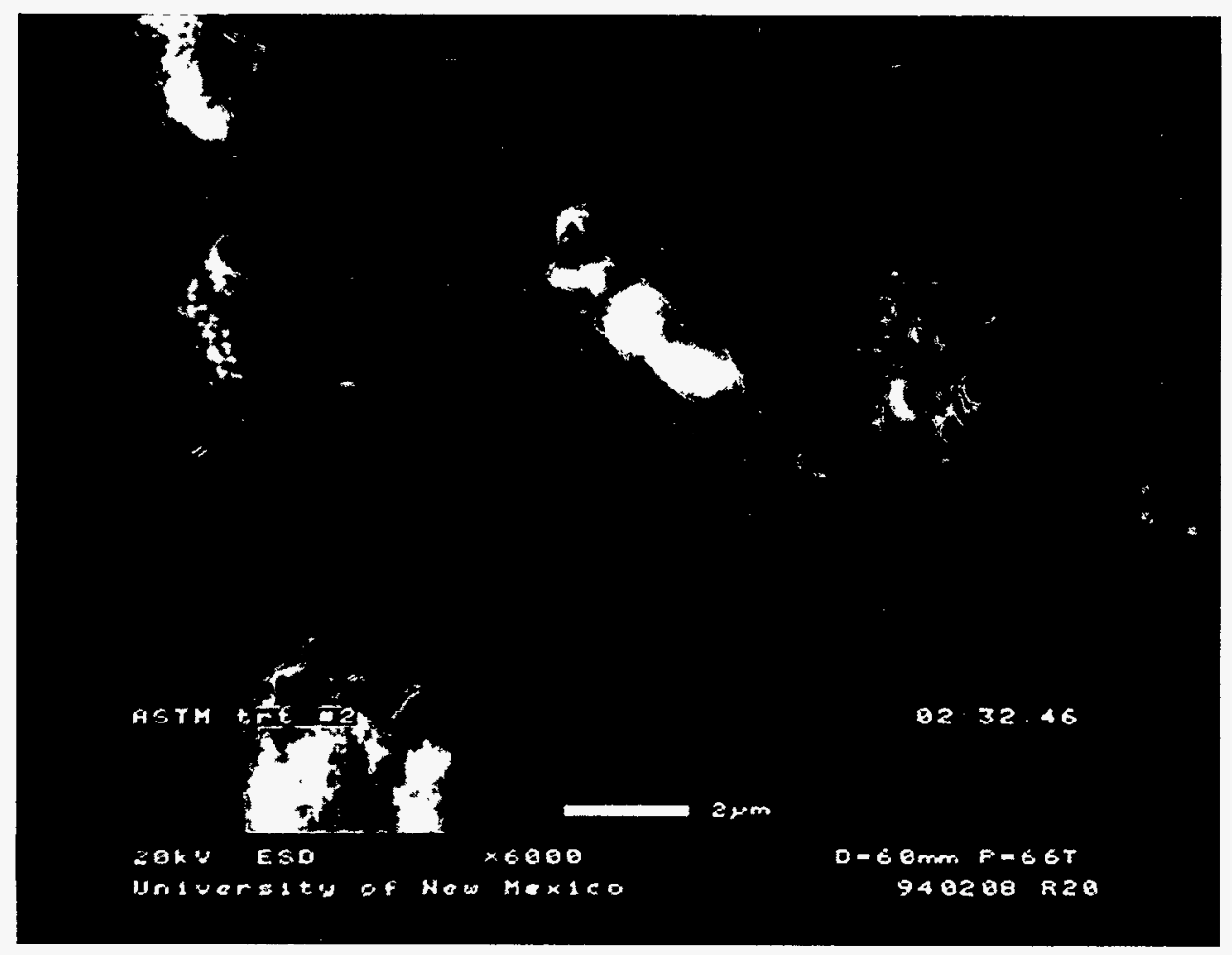

(b)

Figure 19. ESEM photograph of ASTM control waste-form specimens after exposure to (a) sterile medium (b) nitrifying organisms. 


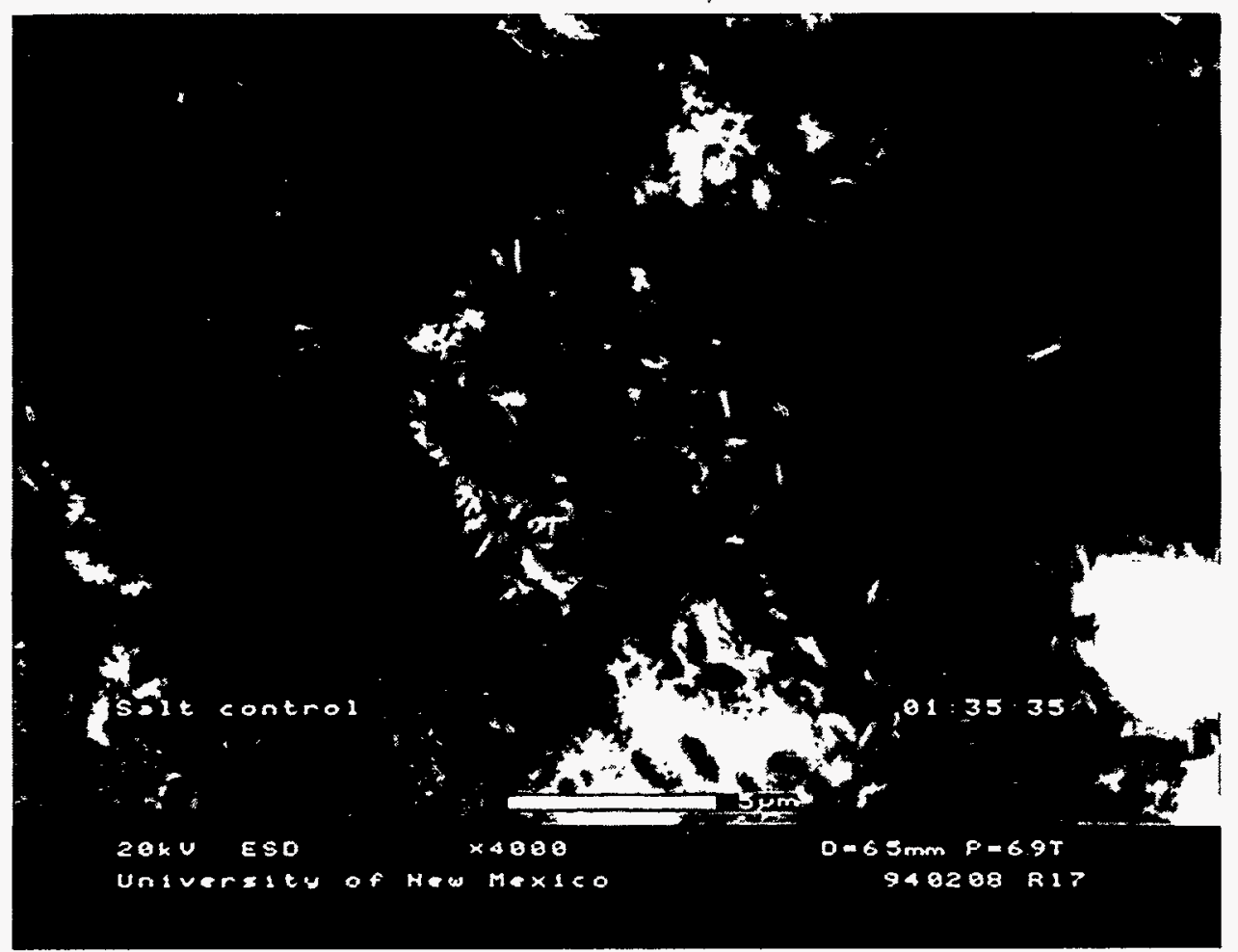

(a)

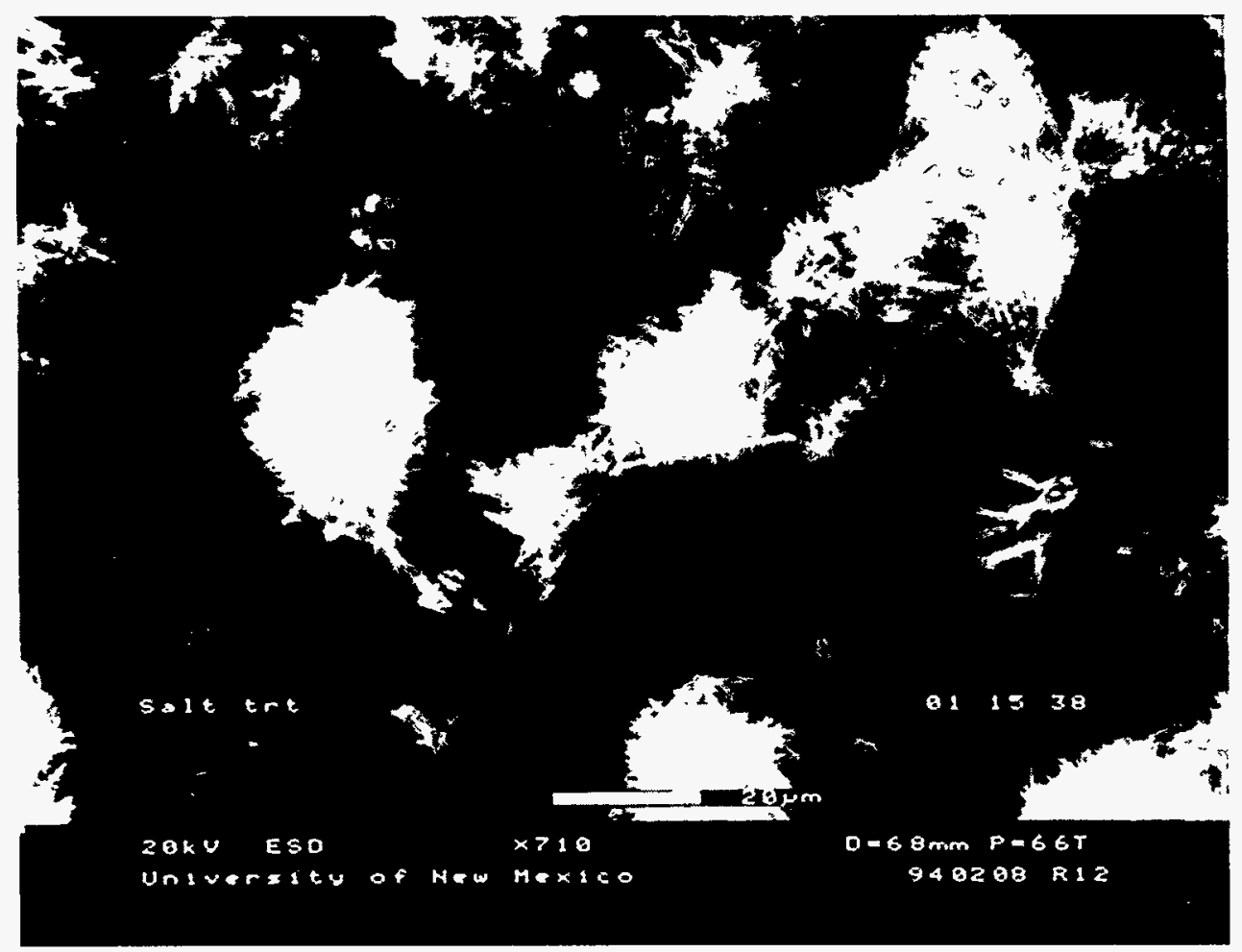

(b)

Figure 20. ESEM photograph of INEL-supplied simulated evaporator bottoms waste-form specimens after exposure to (a) sterile medium (b) nitrifying organisms. 


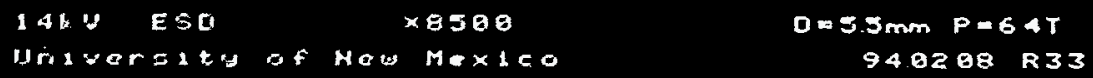

Figure 21. ESEM photograph of INEL-supplied simulated exchange resin waste-form specimen after exposure to nitrifying organisms.

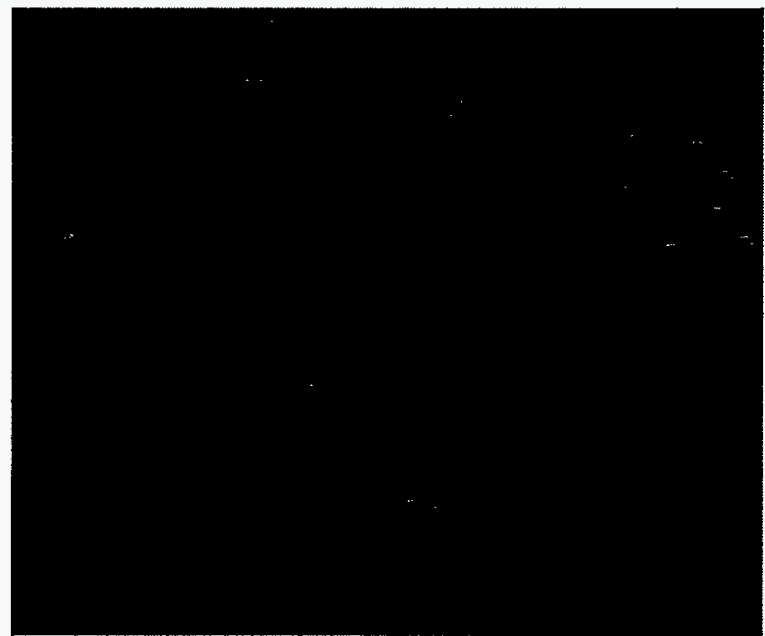

(a)

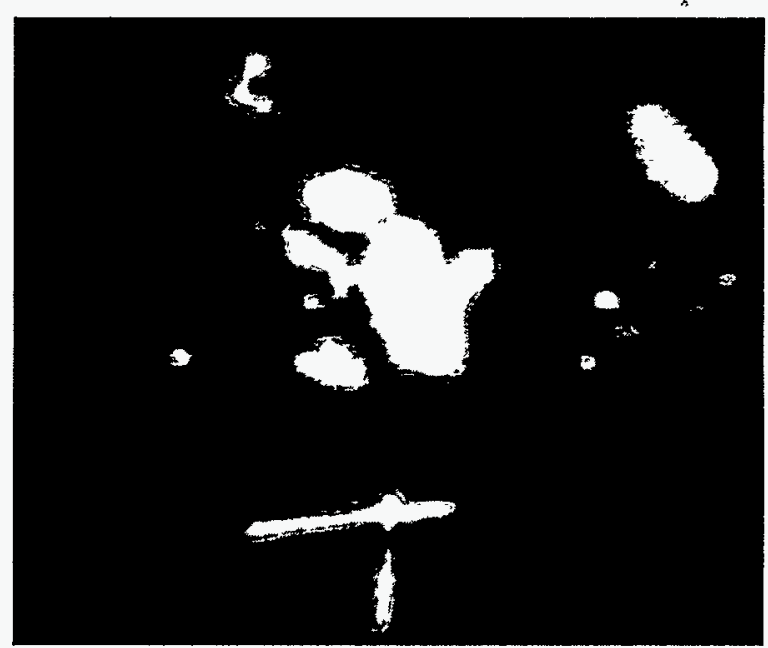

(b)

Figure 22. Biofilm staining of INEL-supplied simulated waste-form specimen after exposure to nitrifying organisms (a) stained blue to demonstrate presence of biofilm EPS material and (b) fluorescent orange stain demonstrating presence of viable cells. 


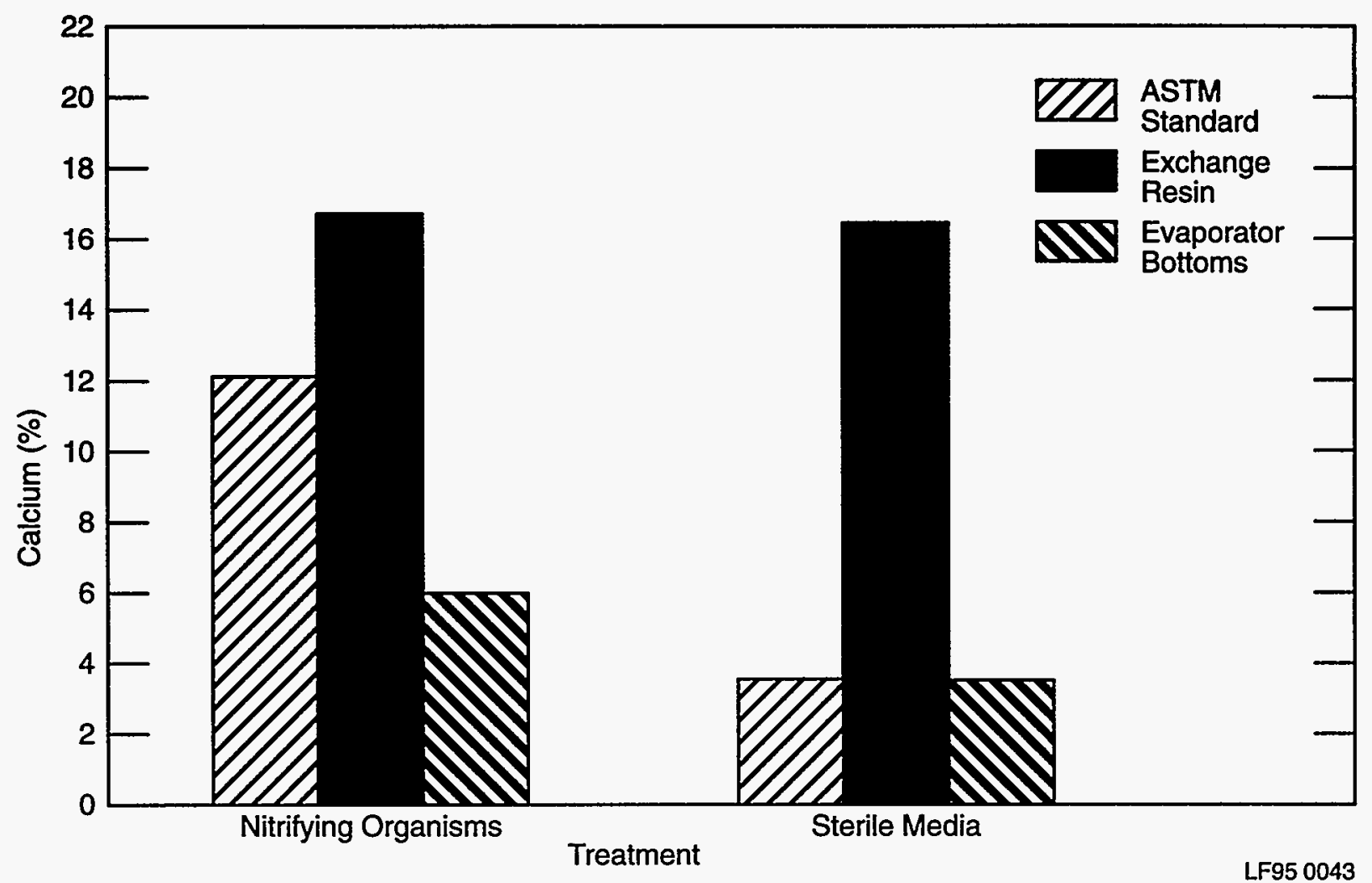

Figure 23. Quantities of $\mathrm{Ca}$ leached from INEL-supplied simulated waste forms after 60 days of total immersion (nitrifying organisms).

After 2 days to allow for pellet colonization, the solution from both inoculated and control reactor flasks was removed and replaced with fresh ammonia-oxidizer growth medium. After the specimens were incubated for an additional 17 days (day 17), there was a second 3-day period of colonization following the procedures described above. For the duration of the study, a regime was established of growth medium removal and replacement every 3 to 10 days.

Growth medium removed from both inoculated and control reactor flasks was analyzed for nitrite and $\mathrm{Ca}$ concentrations, $\mathrm{pH}$, and microbial number. Solution concentrations of nitrite were quantitatively determined using a form of the GreissIlosvay colorimetric test (Garret and Nason 1969) in which nitrite diazotizes sulfanilamide followed by coupling to $\mathrm{N}$-(1-naphthyl)-ethylenediamine dihydrochloride. Microbial numbers were obtained by direct counting using a Hausser Scien- tific brightline hemacytometer with $400 \times$ phase contrast microscopy.

Besides periodic analysis of the liquid, one of the original five pellets was removed from each treatment and one from the control reactor (for a total of six samples) on days 26,61 , and 113 . A sterilized chisel was inserted into the bisecting groove in each pellet to effect separation into two, approximately equal subsamples. After rinsing one subsample with sterile phosphate buffer to remove planktonic cells, the surface was scraped and then scrapings and pellet subsamples were sonicated for 5 minutes in $10 \mathrm{~mL}$ of phosphate buffer. A most-probable-number method (Schmidt and Belser 1982) was then used to enumerate ammonia-oxidizing bacteria present in the buffer solution. The second pellet subsample was prepared for viewing with a scanning electron microscope (SEM). This was accomplished by fixing it in $10 \mathrm{~mL}$ of $2 \%$ glutaraldehyde aqueous solution for 1 hour, followed by successive 15-20 
minute treatments in $10 \mathrm{~mL}$ of $10 \%, 25 \%, 50 \%$, and $75 \%$ ethanol in aqueous solution. The subsamples were air-dried and then sputter-coated with $30 \mathrm{~nm}$ of Au-Pd under high vacuum. Then, the SEM was used to inspect pellet subsample surfaces for the presence of nitrifying bacteria.

Figures 24 through 27 summarize data collected over 194 days. Figure 24 displays nitrite accumulation in inoculated and control reactor flasks. These data show that no nitrite was produced in any of the control reactors, whereas inoculated reactors had a very consistent accumulation of 1-2 mM nitrite between sampling events from about day 40 onward. This suggested that there was stable activity of $N$. europea in the inoculated reactors. A total of 5.9, 5.6, and 5.1 $\mathrm{mM}$ of nitrite were produced in the inoculated ASTM control, resin, and salts waste-form reactors, respectively. This corresponded to 0.37 , 0.35 , and $0.31 \mathrm{~mL}$ of concentrated nitric acid. These data are similar to day 66 and show little increase in the nitrite content. One possible explanation for this is that nitrite under prolonged exposure to conditions of low $\mathrm{pH}(<\mathrm{pH} 5)$ can undergo chemical oxidation and be lost.

Figure 24 also shows the effect of reinoculation of the treated salts waste-form specimen. Nitrite production in this reactor had decreased to nearly nondetectable levels by day 19 . The apparent reason for the lack of continued bacterial activity in this reactor was the initial high $\mathrm{pH}$ values, usually above 8.5 and some as high as 9.3 (Figure 25). The elevated $\mathrm{pH}$ was due to insufficient carbonization of the waste-form specimens. The inoculated reactor $\mathrm{pH}$ values ranged from 5.6 to 6.4 for most of the experimental period, whereas uninoculated controls were generally about $2.5 \mathrm{pH}$ units higher. Results at day 194 clearly show the same correlation between $\mathrm{pH}$ and nitrite production mentioned at the beginning of this section.

A comparison of the data for cumulative $\mathrm{Ca}$ solubilized in inoculated reactors to the data for the uninoculated controls shows that there was microbial influence (lower $\mathrm{pH}$ and high nitrite) responsible for an increase in Ca solubilization (Figures 26 and 27). This was particularly appar- ent for the ASTM and resin-containing pellet reactors. However, for the reactors containing the salts waste-form specimens, the control remained continually higher in cumulative solubilized $\mathrm{Ca}$ until about day 120, when levels began to decrease. Conversely, cumulative solubilized $\mathrm{Ca}$ continued to steadily increase throughout the study in the reactor that contained the inoculated salts waste-form specimen, finally overtaking the control at about day 135 (Figure 26).

The direct-count results that were used to detect microbial numbers in solution showed that the initial number of $1 \times 10^{7}$ cells $/ \mathrm{mL}$ had dropped to $\sim 1 \times 10^{4}$. However, the three most-probablenumber enumerations that were conducted on pellet samples removed on day 26,61 , and 113 showed the treated pellets to be heavily inoculated with nitrifiers. These results are shown in Table 6. The respective " $>$ and $<$ " numbers associated with two of the data points for the inoculated resin and with the controls reflect the statistical nature of the most-probable-number enumeration method. Absolute numbers are not expressed because serial dilutions were not carried out past the $10^{-6}$ dilution and because the $10^{-1}$ dilutions were not sampled for enumeration. For all intents and purposes, an actual value of zero was assumed for the controls since no nitrite production was ever detected in any of the reactors. It can be concluded from the data that the $N$. europea strain had colonized the pellet surfaces of the inoculated simulated waste-form specimens and the ASTM control by day 26. Day 61 bacterial numbers reflect a relatively stable surface population, which had already been established by day 26 , although a 2.5 -fold increase is indicated for the ASTM reactor. It is somewhat surprising that day 113 values indicate a general tenfold decrease in the surface population for all of the inoculated reactors. This magnitude of surface population decrease is not supported by the nitrite production data (Figure 24), which indicate relatively stable amounts of nitrite production in all inoculated reactors during days 61 through 113 . It is possible that a systematic error involved with surface scraping or sonication effectiveness was responsible. This type of error would occur, for example, if bacterial "sticking efficiency" as a function of EPS or biofilm formation increased. 


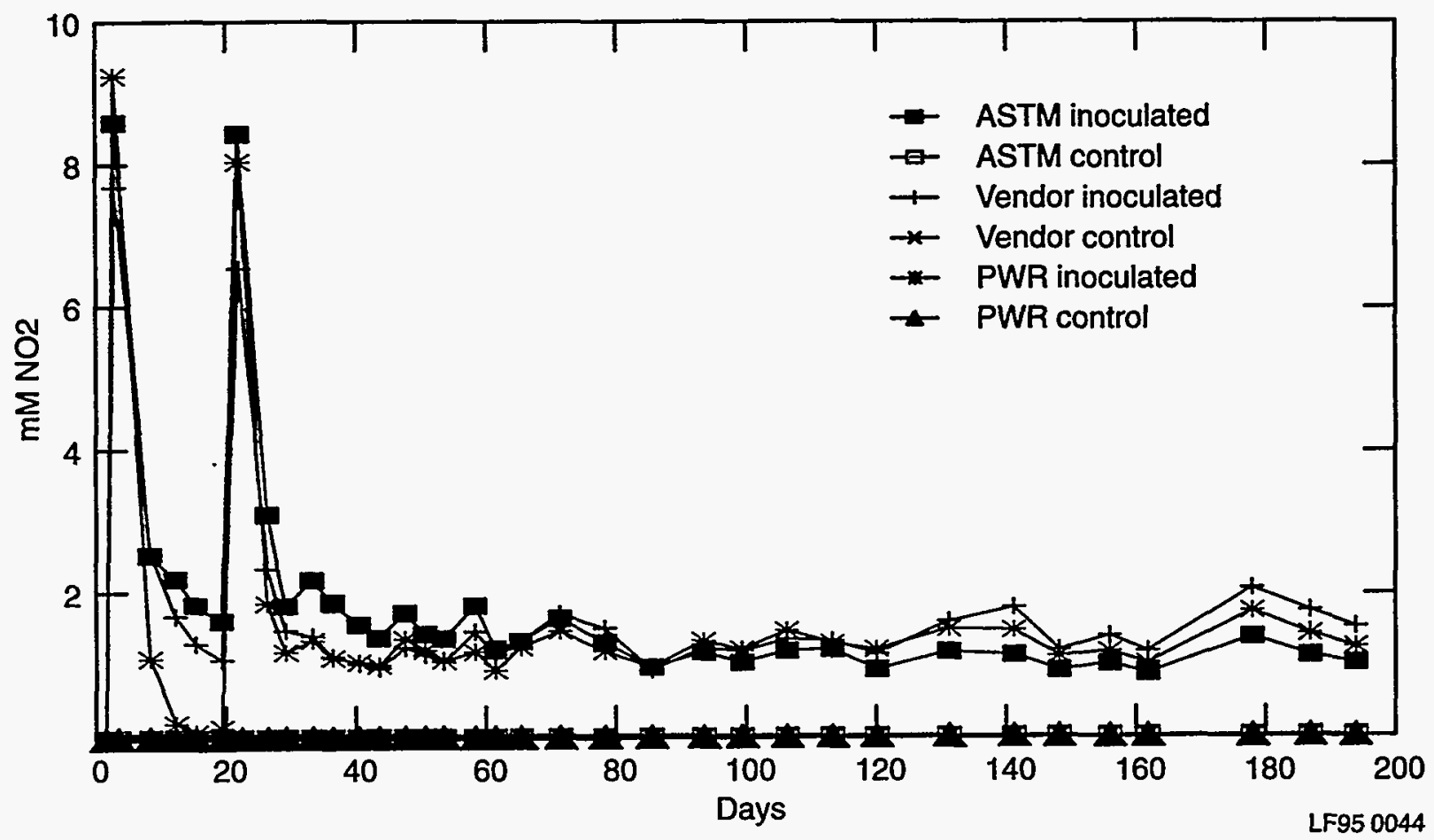

Figure 24. Nitrite content over time of media containing nitrifying bacteria and vendor-supplied simulated waste-form specimens.

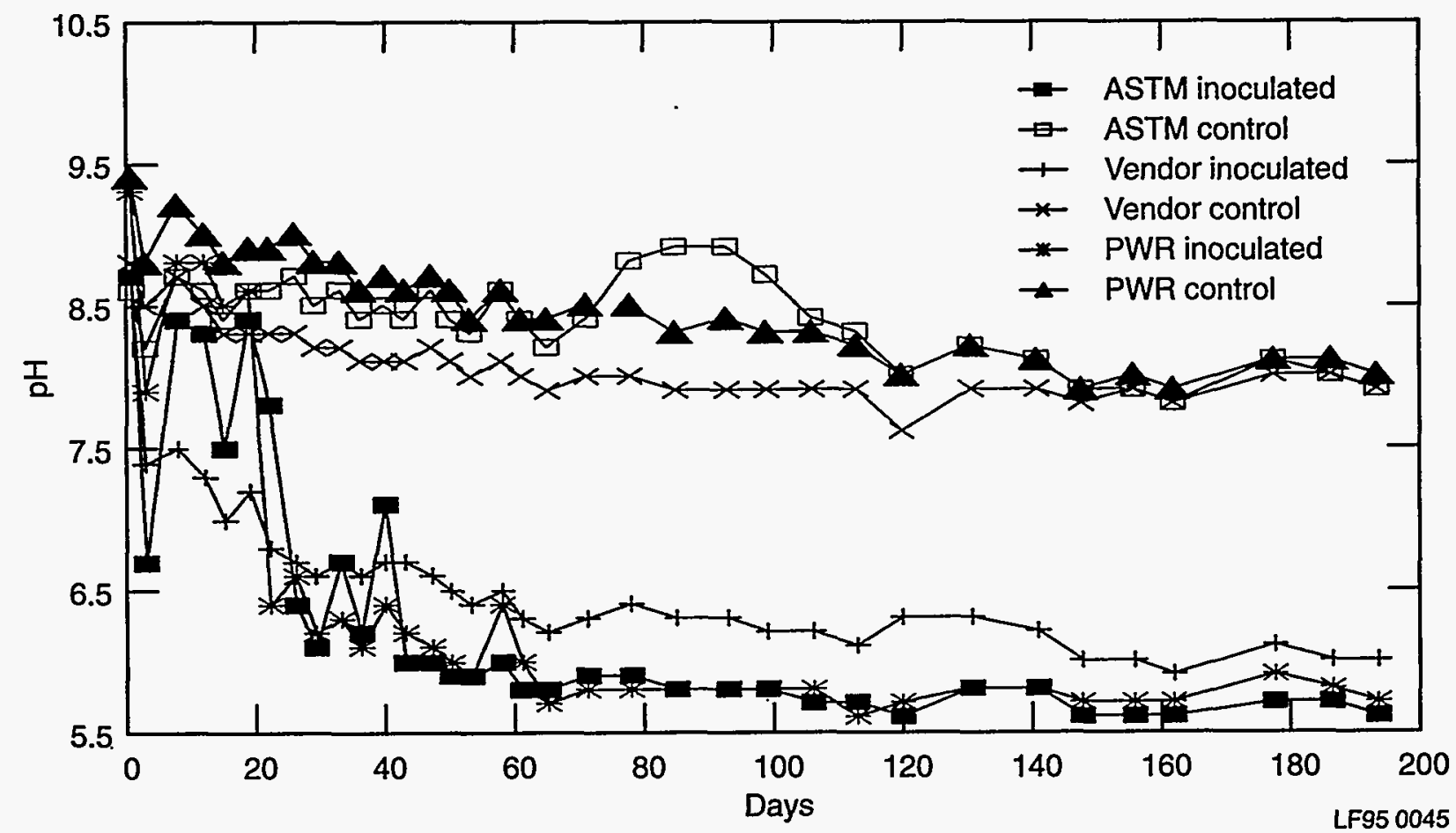

Figure 25. $\mathrm{pH}$ over time of media containing nitrifying bacteria and vendor-supplied simulated wasteform specimens. 


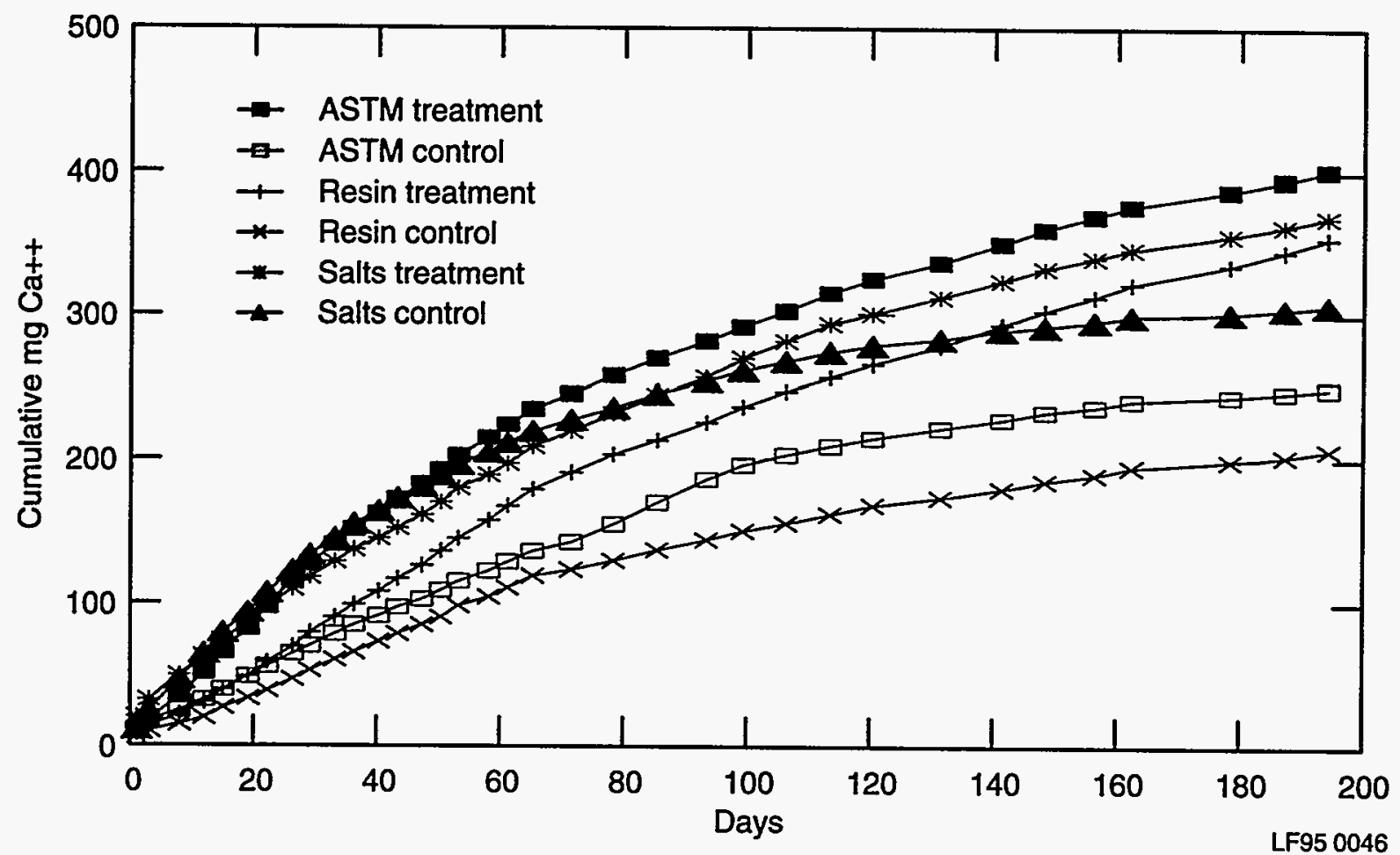

Figure 26. Cumulative Ca released from vendor-supplied simulated waste-form specimens exposed to nitrifying bacteria.

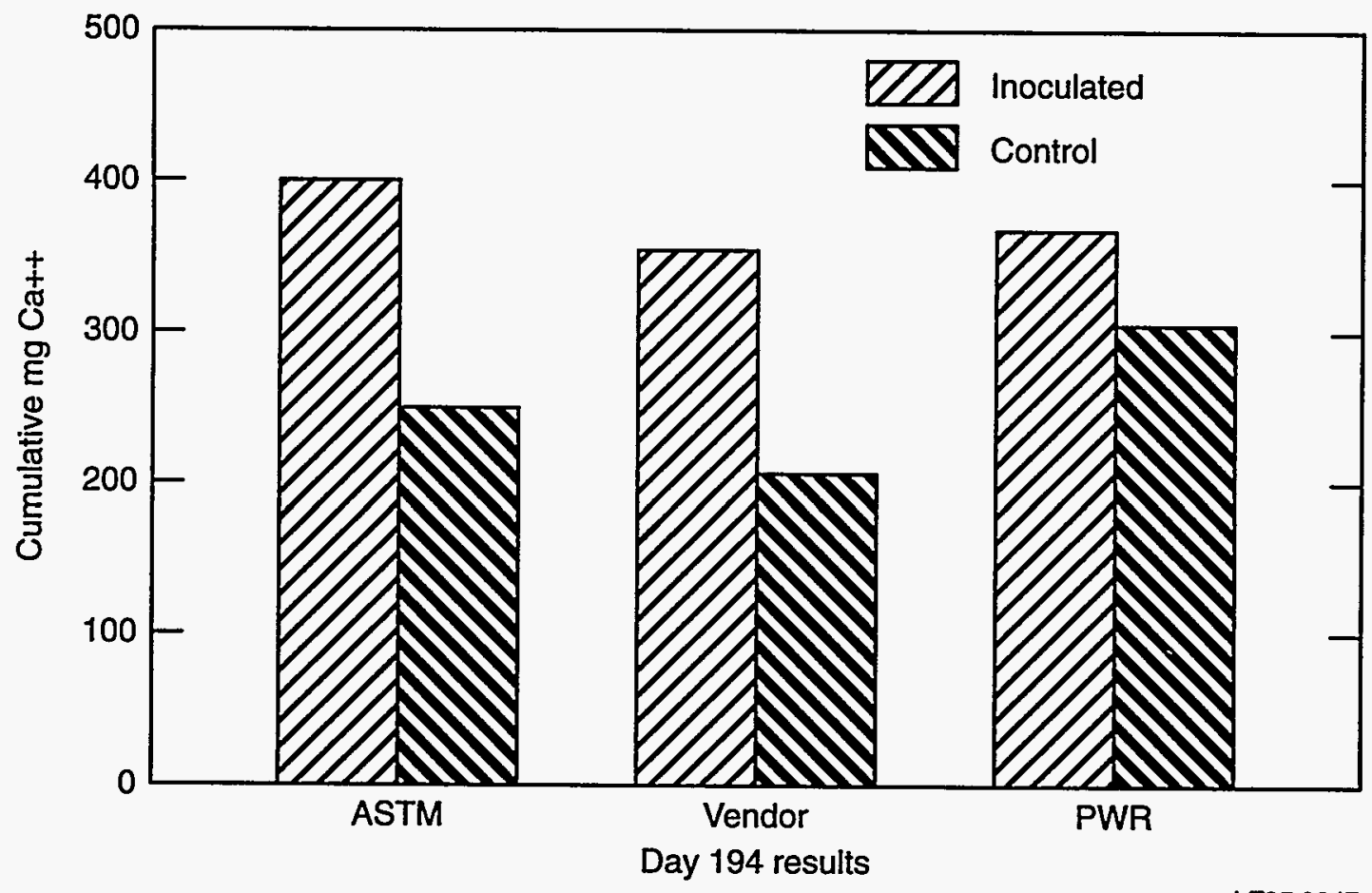

Figure 27. Total Ca released from vendor-supplied simulated waste-form specimen over a period of 194 days. 
Table 6. Results of most probable number enumeration of pellet surfaces.

\begin{tabular}{lcccccc}
\hline & \multicolumn{6}{c}{ Number of cells per $\mathrm{cm}^{2}$} \\
\cline { 2 - 7 } Sampling Day & $\begin{array}{c}\text { ASTM } \\
\text { inoculated }\end{array}$ & $\begin{array}{c}\text { Vendor } \\
\text { inoculated }\end{array}$ & $\begin{array}{c}\text { PWR } \\
\text { inoculated }\end{array}$ & $\begin{array}{c}\text { ASTM } \\
\text { control }\end{array}$ & $\begin{array}{c}\text { Vendor } \\
\text { control }\end{array}$ & $\begin{array}{c}\text { PWR } \\
\text { control }\end{array}$ \\
\hline Day 26 & $8.5 \times 10^{4}$ & $>1.2 \times 10^{6}$ & $8.0 \times 10^{5}$ & $<12$ & $<12$ & $<12$ \\
Day 61 & $2.2 \times 10^{5}$ & $>1.2 \times 10^{6}$ & $8.0 \times 10^{5}$ & $<12$ & $<12$ & $<12$ \\
Day 113 & $4.8 \times 10^{4}$ & $9.0 \times 10^{4}$ & $3.2 \times 10^{4}$ & $<12$ & $<12$ & $<12$ \\
& & & & & & \\
\hline PWR = INEL-supplied specimens. & & & & & \\
\hline
\end{tabular}

SEM imaging of respective complementary pellet subsamples also does not support a decrease in the surface bacterial population between days 61 and 113 . These images áre presented in Figures 28 through 30 and represent selected examples of SEM micrographs from the three respective chronological sampling times: days 26, 61, and 113 . Because the SEM images represent only a very small area of the total pellet subsample surface and of the total surface area actually scanned and viewed by the SEM operator, subjective impressions of the operator become important and can provide useful insights in interpreting other relevant data. It should be noted that the ease of locating areas on all pellet surfaces suitably populated with bacteria for imaging increased steadily over the sampling period. For instance, at the first sampling time, it was difficult to find bacteria on the surface of the salts waste-form specimen. However, by day 61 , bacteria were apparent, and by day 113 , they seemed to be ubiquitous on the pellet subsample surface.

Figure 28a shows an inoculated ASTM pellet and is a $3 \times$ magnified image of Figure $28 \mathrm{~b}$. In both images, the "pockmarks" and the presence of bacteria is unmistakable. It seems highly likely that a relationship exists between bacteria and pits because of their similar size $(\sim 1 \mu \mathrm{m})$. These images are similar to others obtained using ESEM imaging of ASTM pellets examined after our initial fed-batch experiment. Figure $28 \mathrm{c}$ shows the appearance after 26 days of an uninoculated vendor-supplied resin waste-form specimen. In an image $250 \times$ the magnification of Figure 28c, Fig- ure $28 \mathrm{~d}$ shows a well-colonized resin bead from an inoculated vendor-supplied waste form specimen. Many cells in this image appear to be dividing, suggesting cell viability and growth. Figure 29 shows the surfaces of pellet subsamples removed at day 61 . Figure 29a clearly shows a colonization pattern on a resin bead surface, defined by a line from near the upper left corner to the lower right corner of the image. The bead surface is well colonized below this line, but bacteria are not present above it. It appears that a mineral deposit (not present below the line) may be preventing colonization of the upper area of the resin bead surface. Although bacteria were also observed on the cement matrix between resin beads, colonization was not as extensive. Figure $29 \mathrm{~b}$ shows the type of general colonization pattern observed on the PWR salts waste-form pellet. Figure 30 shows SEM images of the surface of pellet subsamples removed from the three respective inoculated reactors on day 113. Figure 30 a shows a similar bacterial colonization pattern for the ASTM pellet subsample surface as observed in Figure 28b, indicating a relatively stable surface population from days 26 to 113 . It should be noted that the resin waste form cement matrix between resin beads appeared to be much more heavily colonized than previously observed, bacterial colonies usually being associated with pits or depressions in the matrix surface.

Sulfur-Oxidizing Bacteria. A test was devised in which evaporator bottoms and ionexchange resin specimens from the INEL and vendor formulations of simulated waste forms 


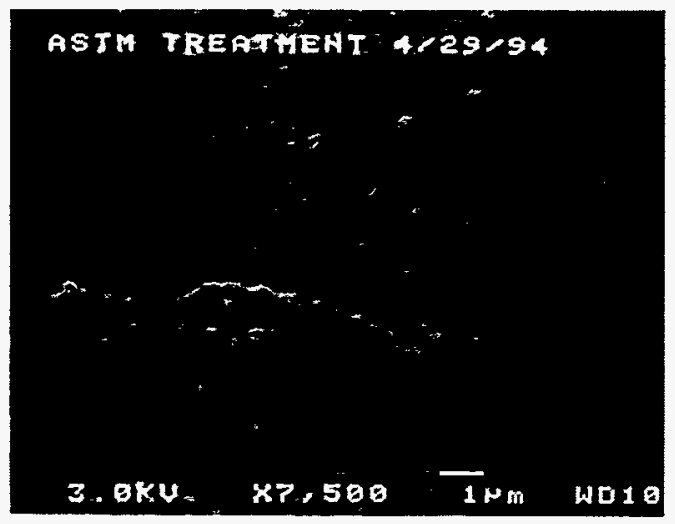

(a)

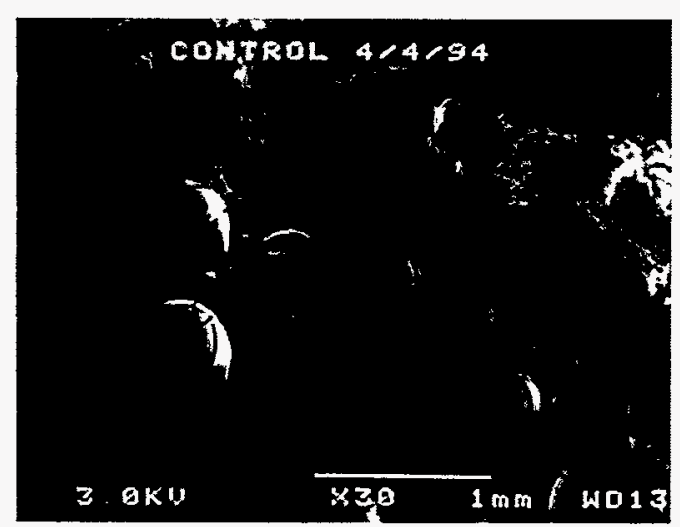

(c)

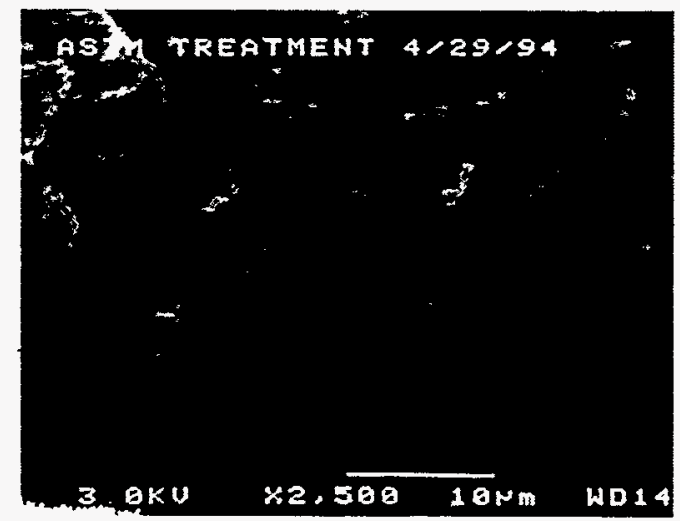

(b)

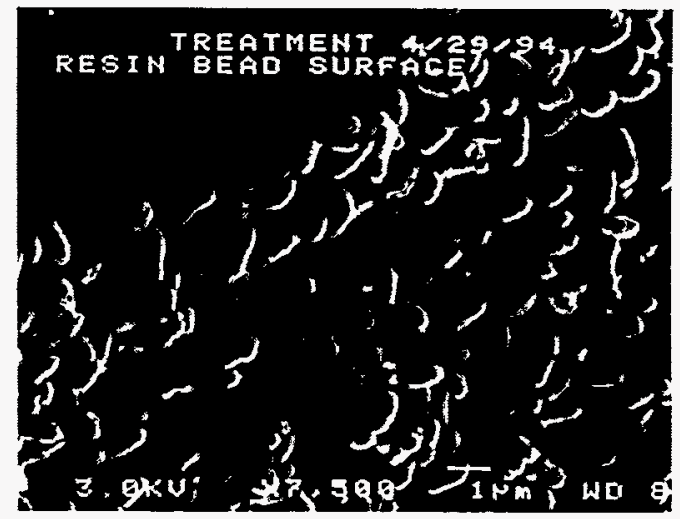

(d)

Figure 28. Electron micrographs of ASTM and vendor-supplied simulated waste-form specimens after 26 days of exposure to nitrifying bacteria (a) ASTM treatment (b) ASTM treatment (c) vendor control (d) vendor treatment.

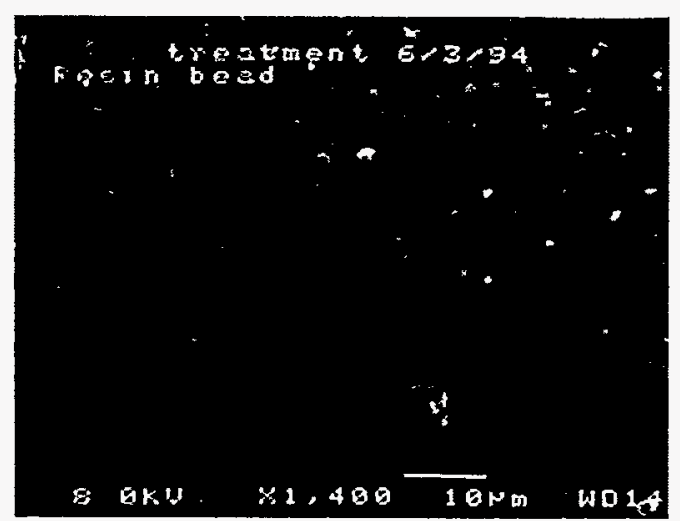

(a)

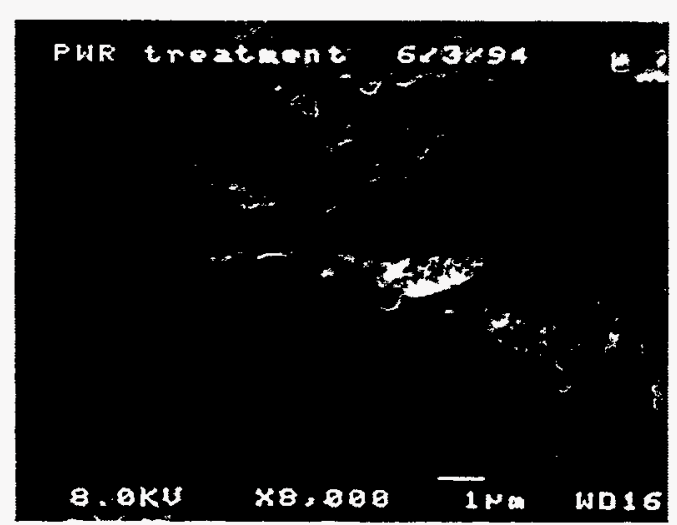

(b)

Figure 29. Electron micrographs of vendor-supplied simulated waste-form specimens after 61 days exposure to nitrifying bacteria (a) vendor treatment (b) PWR treatment. 


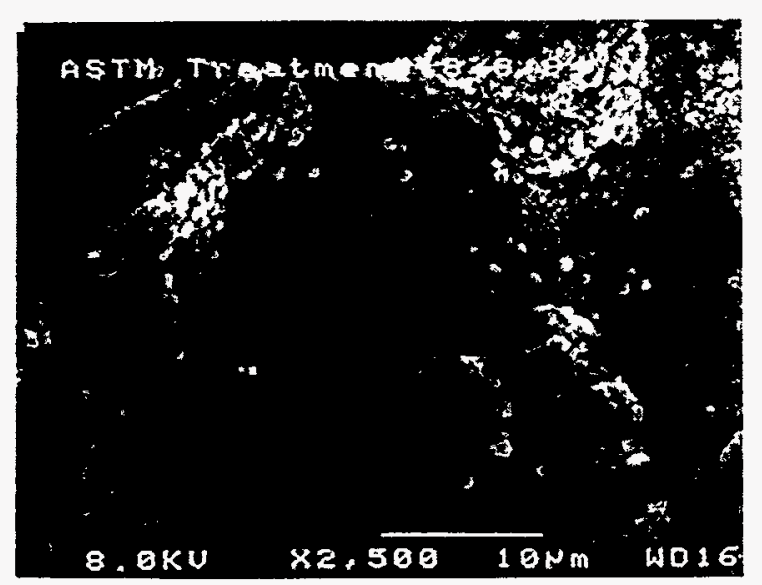

(a)

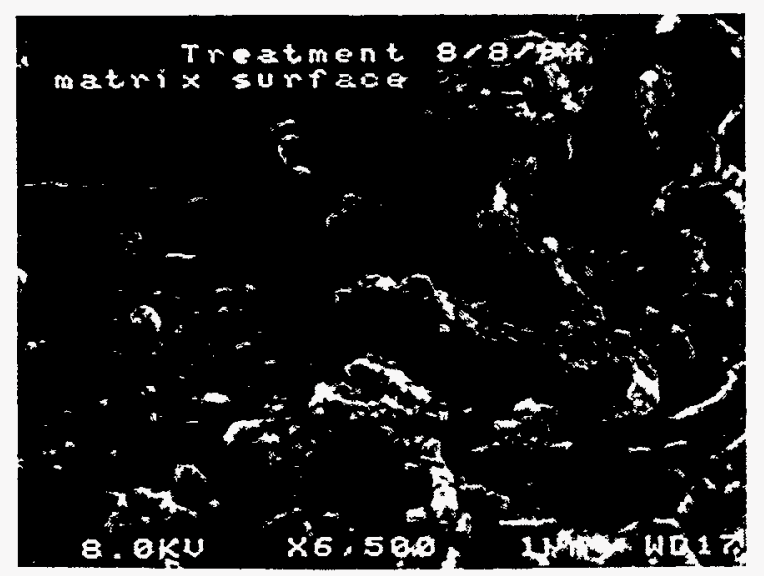

(b)

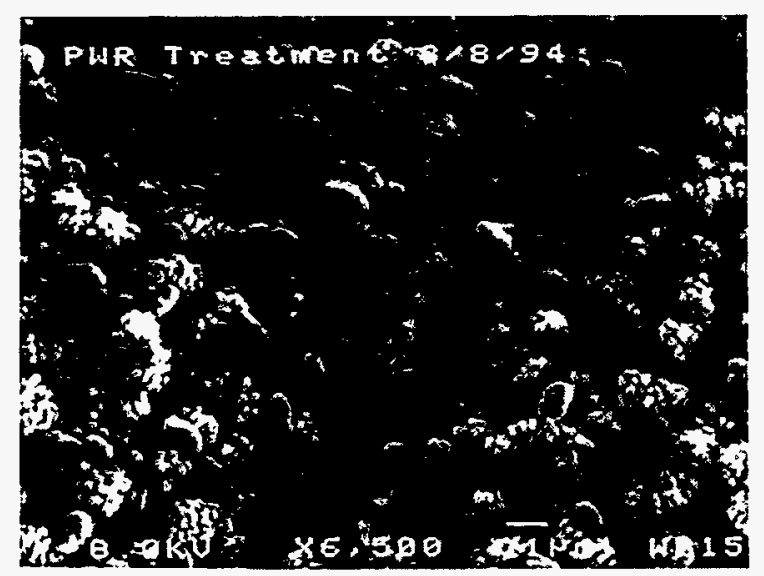

(c)

Figure 30. Electron micrographs of ASTM and vendor-supplied simulated waste-form specimens after 113 days exposure to nitrifying bacteria (a) ASTM treatment (b) vendor treatment (c) PWR treatment. and the ASTM control waste-form specimens were exposed to lixiviant produced by $\mathrm{T}$. thiooxidans and $T$. ferrooxidans isolates grown in separate continuous flow bioreactors. For formulation of growth medium, see Table 7. In addition to the thiobacilli lixiviants, replicate specimens were exposed to a continual supply of the bacteria-free (sterile) medium used to support microbial growth. The intended duration of this continuous exposure test was 60 days. However, the vendor's waste forms were exposed for only 30 days. During the test, sampies of the liquid (effluent) that had come in contact with the INEL-supplied simulated waste forms were collected and analyzed by inductively coupled plasma for $\mathrm{Ca}$ content and $\mathrm{pH}$. In the case of the vendor's simulated waste forms, the effluent was analyzed for $\mathrm{Ca}, \mathrm{Fe}, \mathrm{Al}$, $\mathrm{Mg}$, and Si. At the conclusion of the test, the waste forms were collected for physical examination to determine the extent of MID, and using methods developed for nitrifying bacteria (detailed in the previous section), an effort was made to determine the interaction of bacterial cells with the waste form surface.

The ASTM control immersed for 60 days in the sterile medium is shown in Figure 31a. The extent of MID affecting the ASTM control specimens after 60 days of exposure to thiobacilli lixiviant can be seen in Figure $31 \mathrm{~b}$ ( $T$. ferrooxidans lixiviant) and Figure 31c ( $T$. thiooxidans lixiviant). The same sequence is followed in Figures 32 and 33 for the INEL-supplied simulated evaporator bottoms and ion-exchange resin specimens, respectively. There was little or no apparent physical damage to the ASTM control and evaporator bottoms specimens exposed to the sterile medium (Figures $31 \mathrm{a}$ and $32 \mathrm{a}$ ), while those specimens that were in contact with the thiobacilli lixiviants (Figures $31 \mathrm{~b}, 31 \mathrm{c}, 32 \mathrm{~b}$, and $32 \mathrm{c}$ ) had extensive damage in the form of spalling, material loss, and lighting of color. In the case of the ion-exchange waste forms (Figure 33), physical damage is seen with all the specimens. It is not uncommon for these types of specimens to disintegrate, even in distilled water, due to swelling of the resin beads. However, as can be seen in Figure $33 \mathrm{a}$, the waste form exposed to the sterile medium still retains a cement matrix in which 
Table 7. Formulation of sulfur-oxidizing bacteria medium.

\begin{tabular}{lc}
\hline & $\begin{array}{c}\text { Amount per liter } \\
\text { doubly deionized water } \\
\text { (g) }\end{array}$ \\
\hline $\mathrm{MgSO}_{4} \cdot 7 \mathrm{H}_{2} \mathrm{O}$ & 0.4 \\
$\left(\mathrm{NH}_{4}\right)_{2} \mathrm{SO}_{4}$ & 0.5 \\
$\mathrm{CaCl}_{2}$ & 0.25 \\
$\mathrm{KH}_{2} \mathrm{PO}_{4}$ & 03.0 \\
$\mathrm{FeSO}_{4}$ & 0.01 \\
$\mathrm{~K}_{2} \mathrm{~S}_{4} \mathrm{O}_{6}$ & 3.0 \\
\hline
\end{tabular}

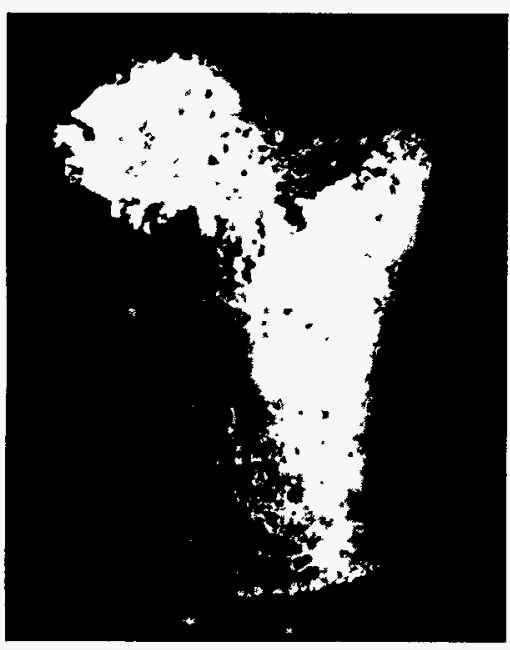

(a)

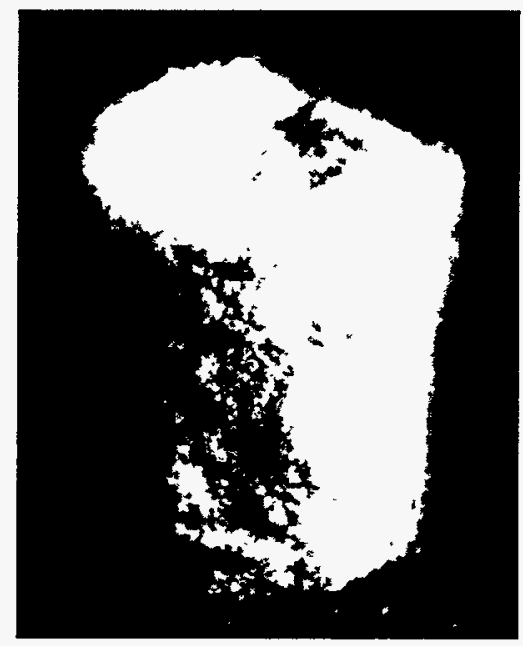

(b)

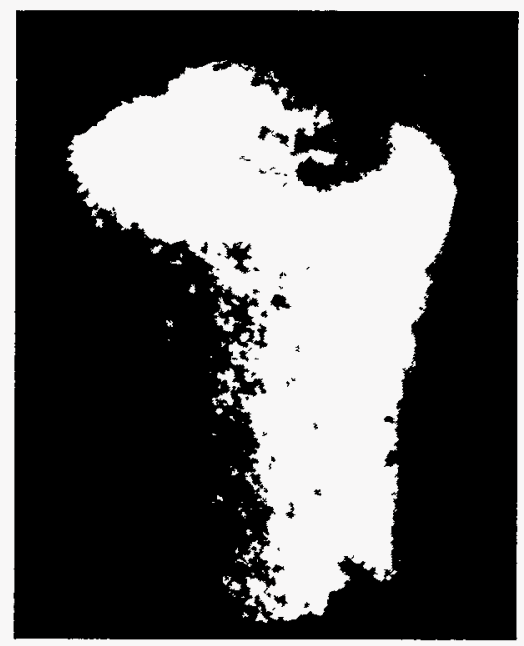

(c)

$92-474-4-2$

Figure 31. ASTM control waste-form specimens after being immersed for 60 days in (a) sterile medium (b) T. ferrooxidans lixiviant (c) T. thiooxidans lixiviant.

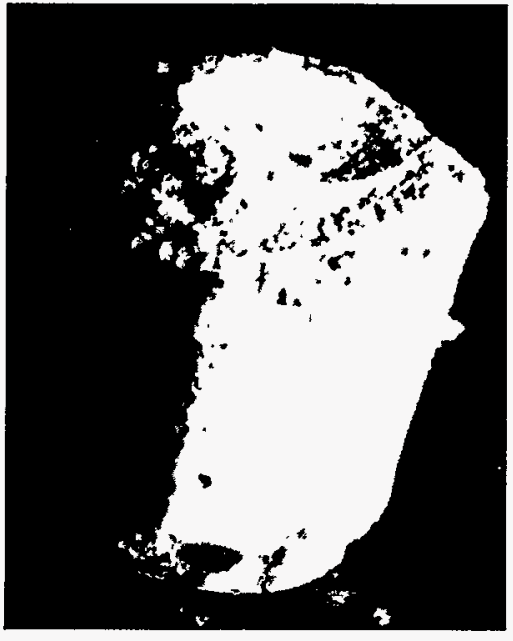

(a)

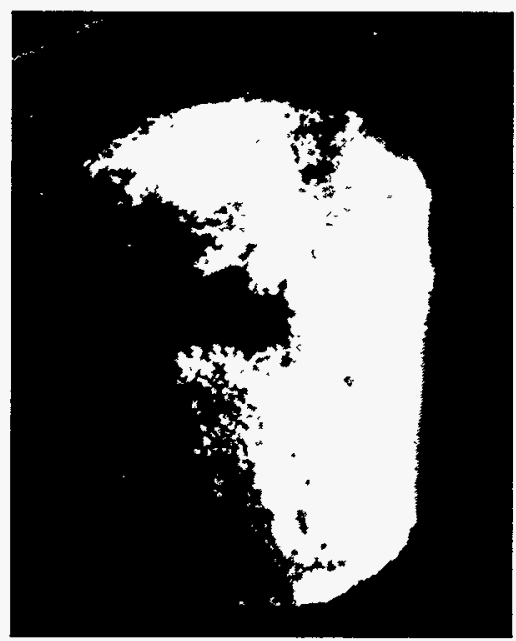

(b)

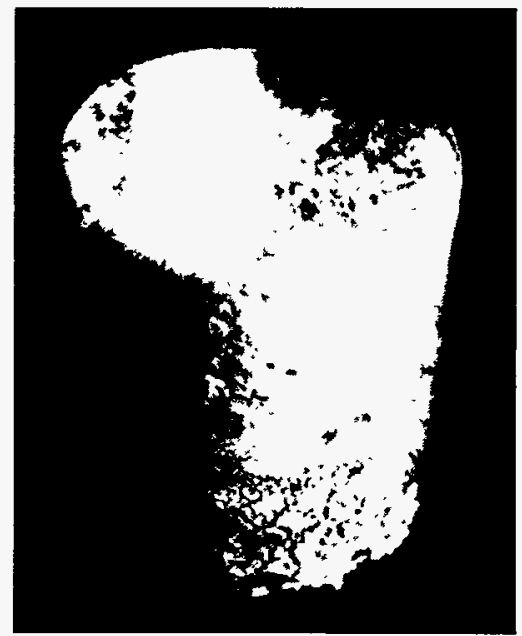

(c)

$92-474-3-3$

Figure 32. INEL-supplied simulated evaporator bottoms waste-form specimens after being immersed for 60 days in (a) sterile medium (b) $T$. ferrooxidans lixiviant (c) $T$. thiooxidans lixiviant. 


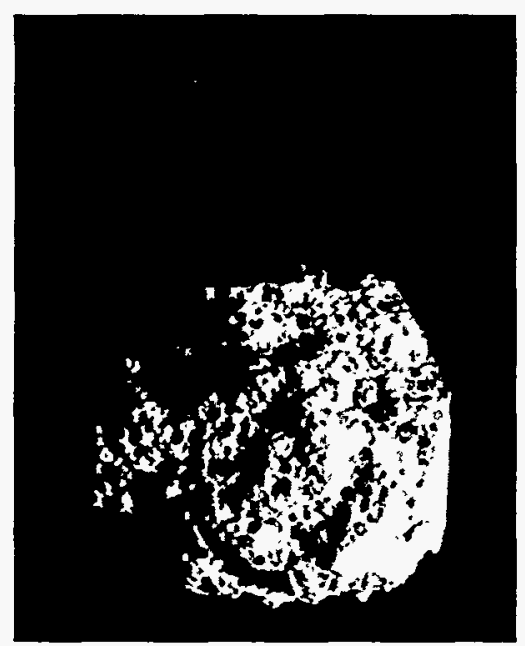

(a)

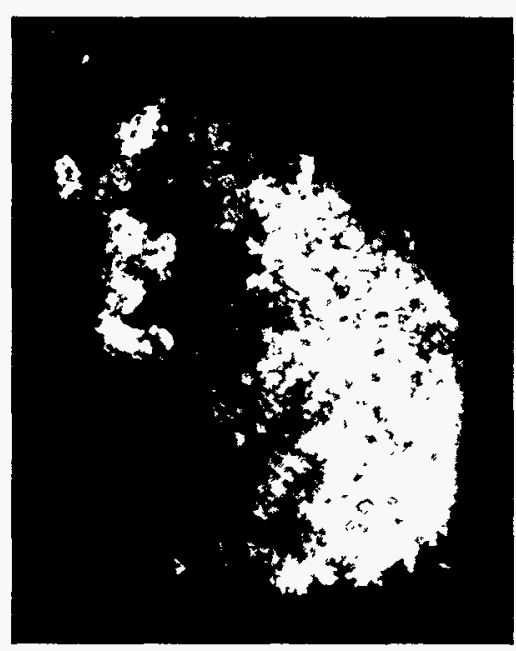

(b)

92-474-2-1

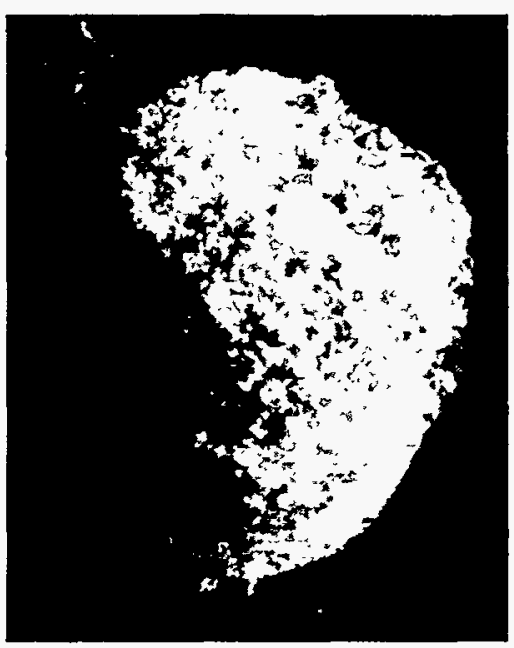

(c)

$92-474-2-3$

Figure 33. INEL-supplied simulated ion-exchange resin waste-form specimens after being immersed for 60 days in (a) sterile medium (b) $T$. ferrooxidans lixiviant (c) $T$. thiooxidans lixiviant.

resin beads are firmly imbedded. Conversely, the other two waste forms lost their cement matrix as indicated by the presence of loose resin beads (Figures 33b and 33c).

Chemical evidence for the effect of MID includes the extensive loss of $\mathrm{Ca}$ from the INELsupplied simulated waste forms exposed to thiobacilli lixiviant. The quantities of Ca removed during exposure to the two lixiviants and the sterile medium can be seen in Figure 34. The Ca lost from the specimens exposed to $T$. ferrooxidans lixiviant ranged from $30 \%$ for the ASTM control to 99\% for the ion-exchange waste form. For the T. thiooxidans lixiviant and sterile medium, the corresponding values were 20 to $59 \%$ and 20 to $12 \%$, respectively. These data support the assumption that loss of the cement matrix contributed to the deterioration of the simulated waste forms. The $\mathrm{pH}$ of the INEL waste form effluent was determined. These data show that the waste forms had little effect on moderating the acid environment supplied by the two lixiviants (Figure 35). The $\mathrm{pH}$ of the effluent was consistently 2 or lower during the test. On the other hand, considerable buffering was noted for the sterile medium effluent. The initial effluent $\mathrm{pH}$ was as high as 9 and then decreased over time to about 3.2 , which was the $\mathrm{pH}$ of the fresh, sterile medium. The effect of a continual supply of low-pH, biologically produced lixi- viants can be seen in the resulting surface $\mathrm{pH}$ (as determined by $\mathrm{pH}$-sensitive paper strips) of the test specimens (Table 8). Note that those specimens in contact with a lixiviant had very low values of surface $\mathrm{pH}$ as compared to the sterile medium-treated or untreated specimens. Low $\mathrm{pH}$ values in these ranges cause damage to cement materials.

As was mentioned earlier, the duration of the second study using the vendor-supplied simulated waste forms was limited to 30 days. Neither of the specimens exposed to the sterile medium appeared to have any damage (Figures 36a and 37a). However, the simulated evaporator bottoms waste form immersed in $T$. ferrooxidans lixiviant appeared to have swelled and was extensively damaged (Figure $36 \mathrm{~b}$ ). Also, exposure of the same type of waste form to the $T$. thiooxidans lixiviant caused similar swelling, with most of the damage appearing on the specimen's edges (Figure 36c). Both of the vendor-supplied simulated ion-exchange resin waste forms were extensively damaged by the bacteria lixiviants (Figures $37 \mathrm{~b}$ and $37 \mathrm{c}$ ). In comparison, these results were similar to those obtained from the evaluation of the INEL-supplied simulated waste forms. That is, the specimens appeared to have lost much of their cement matrix, which resulted in the resin beads being loosely attached to the eroded surface. 


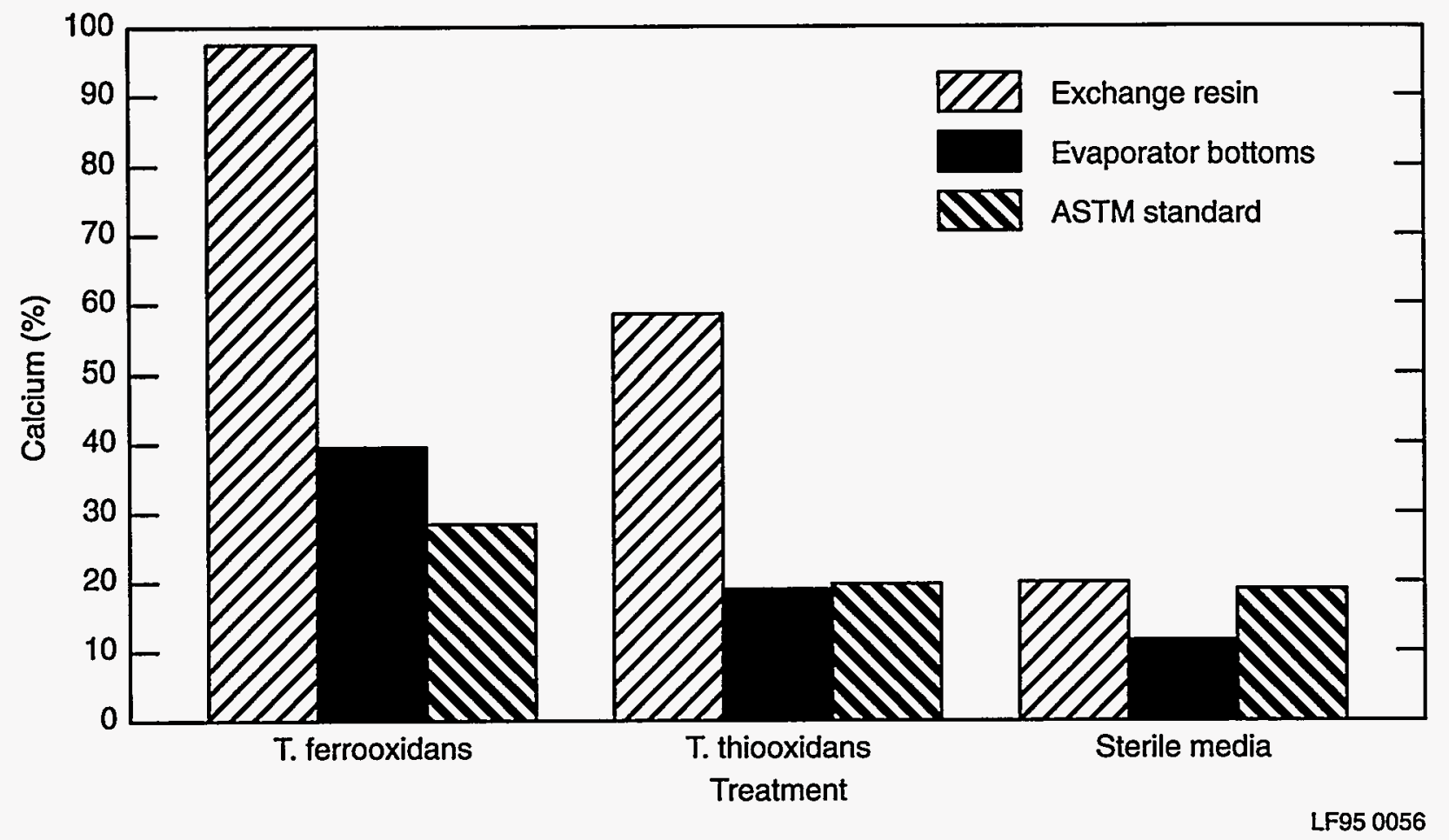

Figure 34. Quantities of Ca leached from INEL-supplied simulated waste-form specimens after 60 days of total immersion.

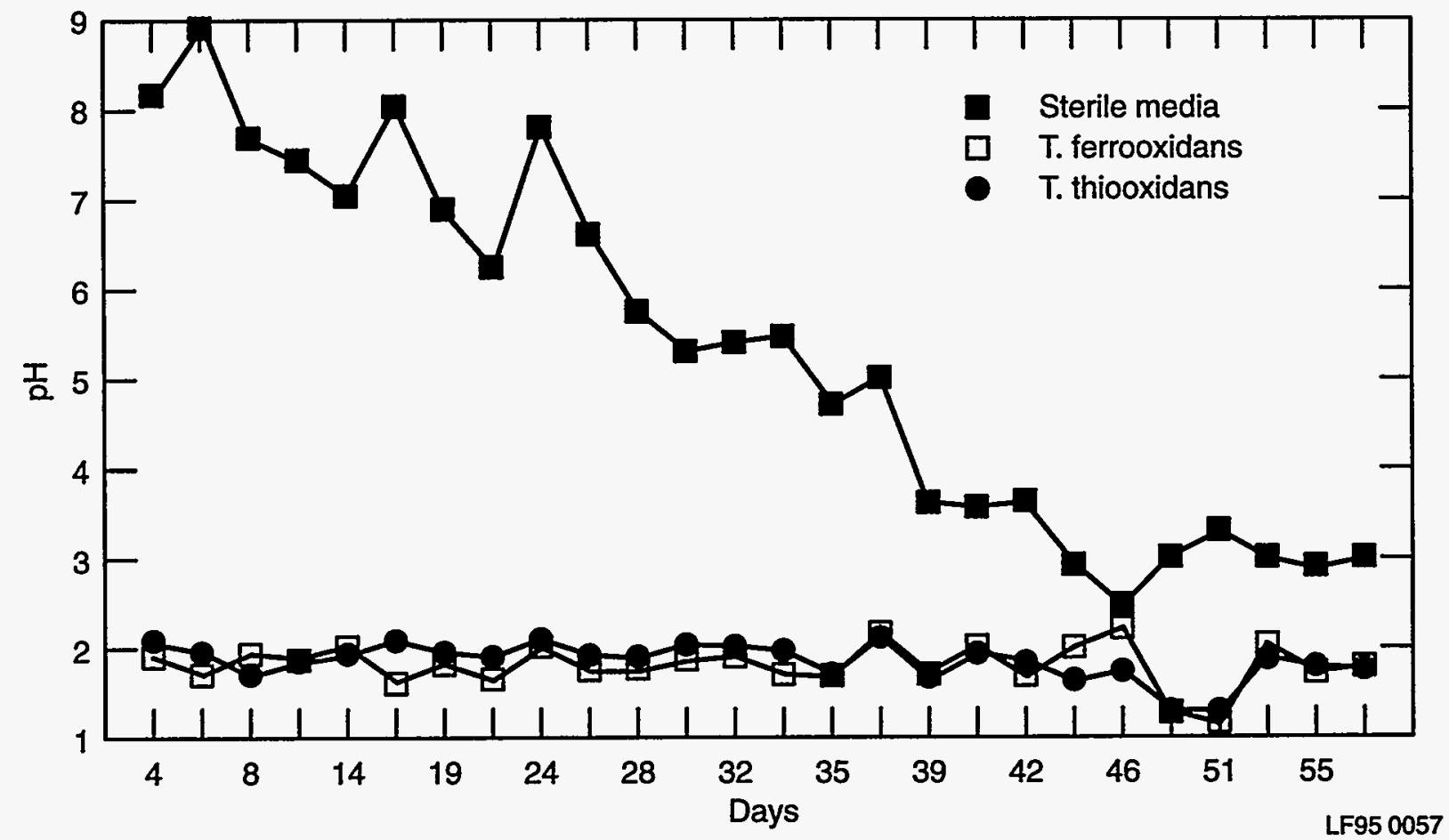

Figure 35. $\mathrm{pH}$ of lixiviants after exposure to INEL-supplied simulated waste-form specimens during the total-immersion study. 
Table 8. Surface pH of INEL-supplied simulated cement waste-form specimens before and after immersion for 60 days in sterile medium or microbially produced lixiviant.

\begin{tabular}{lccc}
\hline & \multicolumn{3}{c}{ Simulated cement waste forms } \\
\cline { 2 - 4 } \multicolumn{1}{c}{ Treatment } & $\begin{array}{c}\text { Exchange resin } \\
(\mathrm{pH})\end{array}$ & $\begin{array}{c}\text { Evaporator bottoms } \\
(\mathrm{pH})\end{array}$ & $\begin{array}{c}\text { ASTM standard } \\
(\mathrm{pH})\end{array}$ \\
\hline Untreated & 9 & 13 & 11.5 \\
Sterile medium & 10 & 10 & 7 \\
T. ferrooxidans & 0.5 & 4.5 & 3.0 \\
T. thiooxidans & 1.0 & 1.5 & 3.0 \\
\hline
\end{tabular}

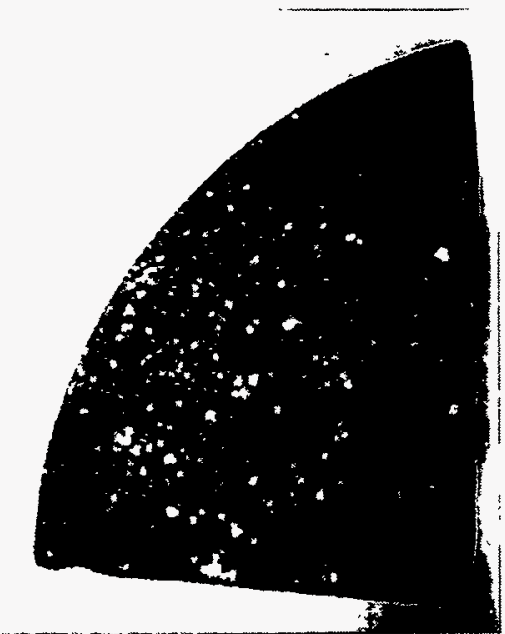

(a)

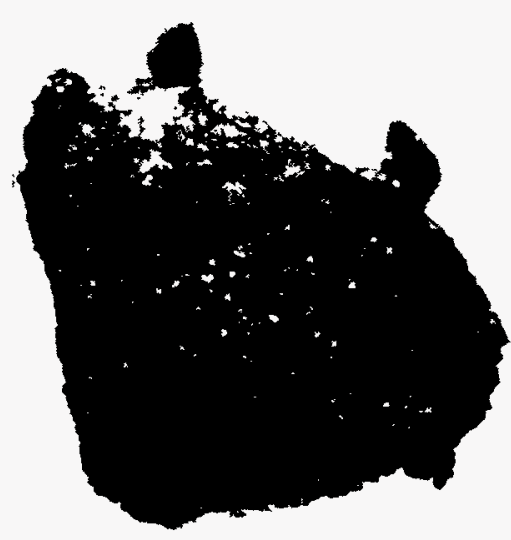

(b)

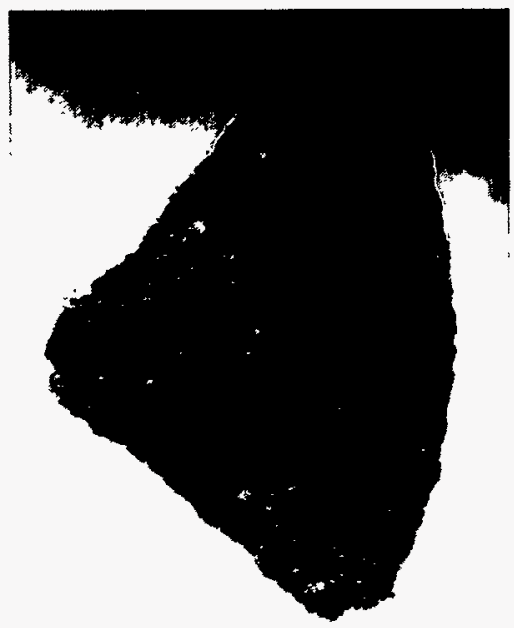

(c)

Figure 36. Vendor-supplied simulated evaporator bottoms waste-form specimens after being immersed for 30 days in (a) sterile medium (b) $T$. ferrooxidans lixiviant (c) T. thiooxidans lixiviant.

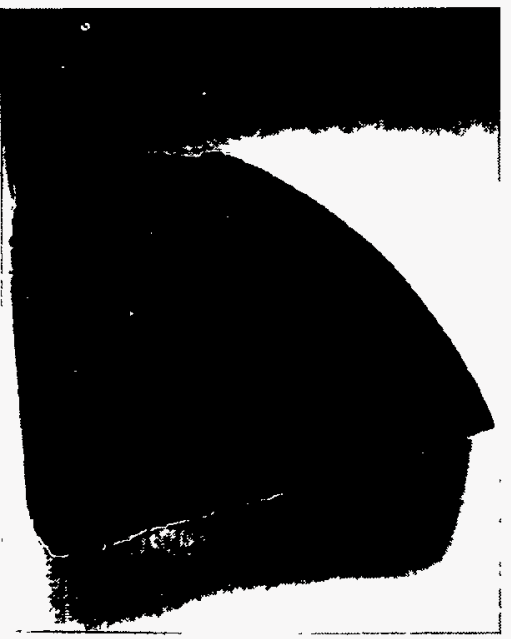

(a)

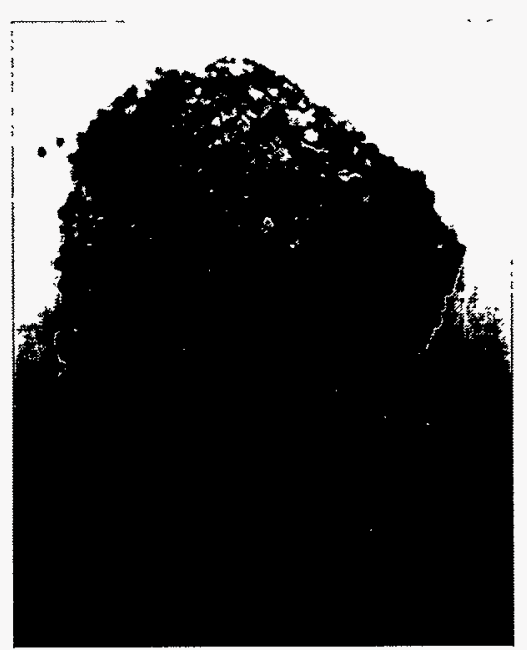

(b)

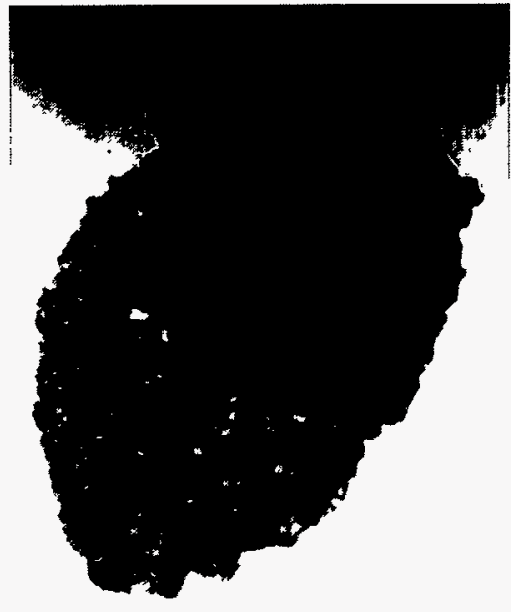

(c)

Figure 37. Vendor-supplied simulated ion-exchange resin waste-form specimens after being immersed for 30 days in (a) sterile medium (b) T. ferrooxidans lixiviant (c) T. thiooxidans lixiviant. 
As previously mentioned, effluent from this study was analyzed for the presence of $\mathrm{Ca}, \mathrm{Al}, \mathrm{Si}$, $\mathrm{Fe}$, and $\mathrm{Mg}$. As observed for the INEL-fabricated waste forms, $\mathrm{Ca}$ was leached from the vendor waste forms as a result of exposure to the various liquids (Figure 38). The amount of $\mathrm{Ca}$ leached from the ion-exchange resin waste forms ranged from 17 to $46 \%$ with 7 to $29 \%$ loss for the evaporator bottoms specimens. Once again, those waste forms exposed to the bacterial lixiviants lost more $\mathrm{Ca}$ than those treated with only the sterile medium. Calcium loss from the waste forms was approximately doubled by the presence of the T. ferrooxidans lixiviant and was more than tripled by the $T$. thiooxidans treatment.

Loss of Al occurred only from those specimens exposed to the thiobacilli lixiviants (Figure 39). Amounts leached from the two types of simulated waste forms were similar within each treatment and ranged from 9 to $14 \%$ for the $T$. ferrooxidans treatment and 19 to $21 \%$ for specimens exposed to $T$. thiooxidans lixiviant. Figure 40 shows that only a minimal amount of $\mathrm{Si}$ (less than $0.2 \%$ ) was removed from specimens regardless of the treatment. While the total initial quantity of $\mathrm{Fe}$ and $\mathrm{Mg}$ was not determined for the vendor-supplied simulated waste forms, these elements were shown to be leached from the specimens (Figures 41 and 42). More Fe was leached by the bacterial lixiviants than by the sterile medium (Figure 41). Simulated waste forms containing ion-exchange resin had a larger quantity of $\mathrm{Fe}$ removed than those containing evaporator bottoms material. Also, leaching was more apparent with the $T$. thiooxidans lixiviant. The $\mathrm{Mg}$ data (Figure 42) were unexpected since it was shown that more of the element, regardless of waste form type, appeared in the sterile effluent than in that of the T. thiooxidans lixiviant. In the case of evaporator bottoms specimens, there appeared to be no $\mathrm{Mg}$ leached from the bacteria-treated waste forms, while $32 \mathrm{mg}$ were removed from the same waste form exposed to the sterile medium. This was a curious finding for which no explanation was apparent.

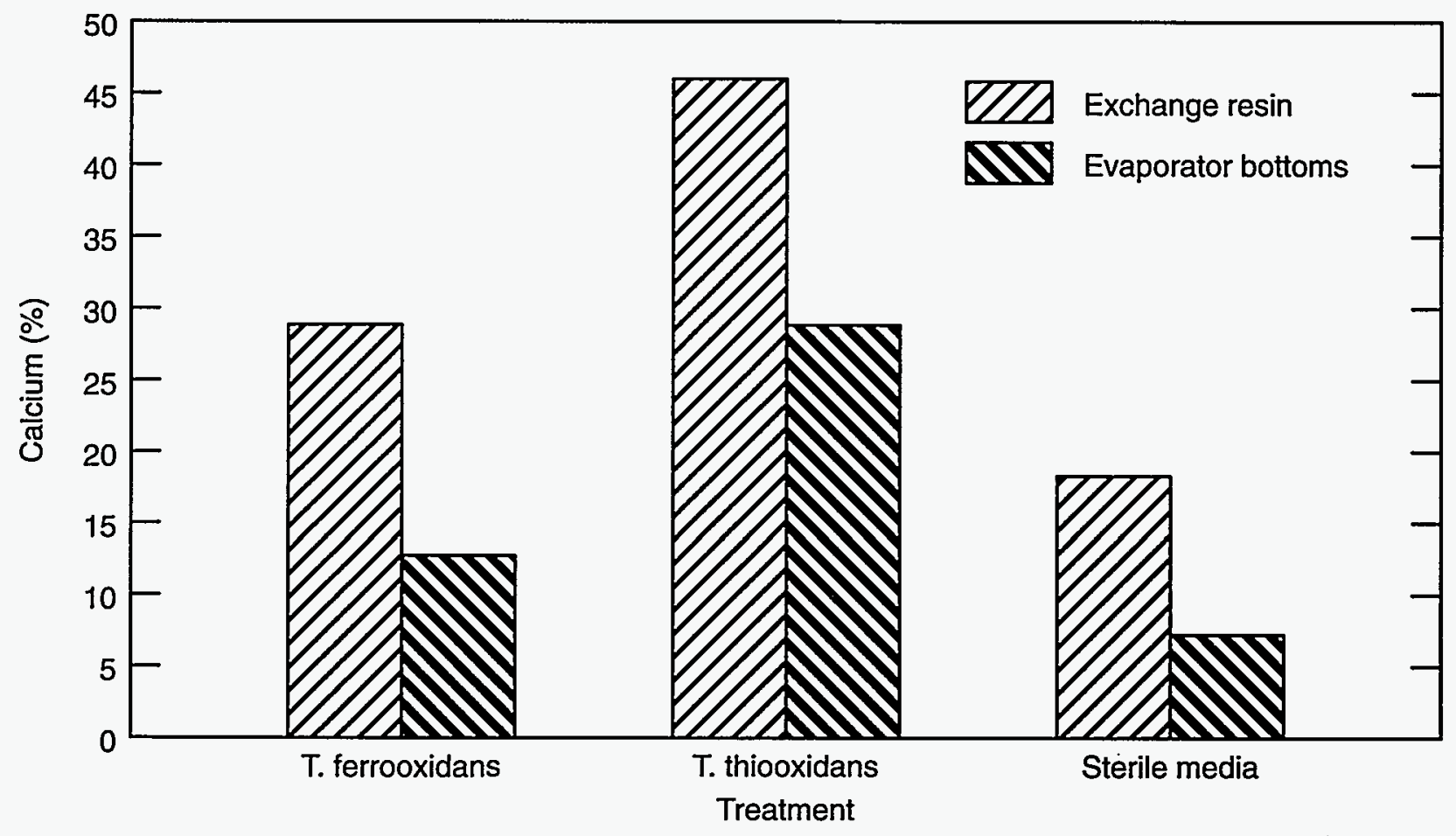

LF95 0058

Figure 38. Quantities of Ca leached from vendor-supplied simulated waste-form specimens after 30 days of total immersion. 


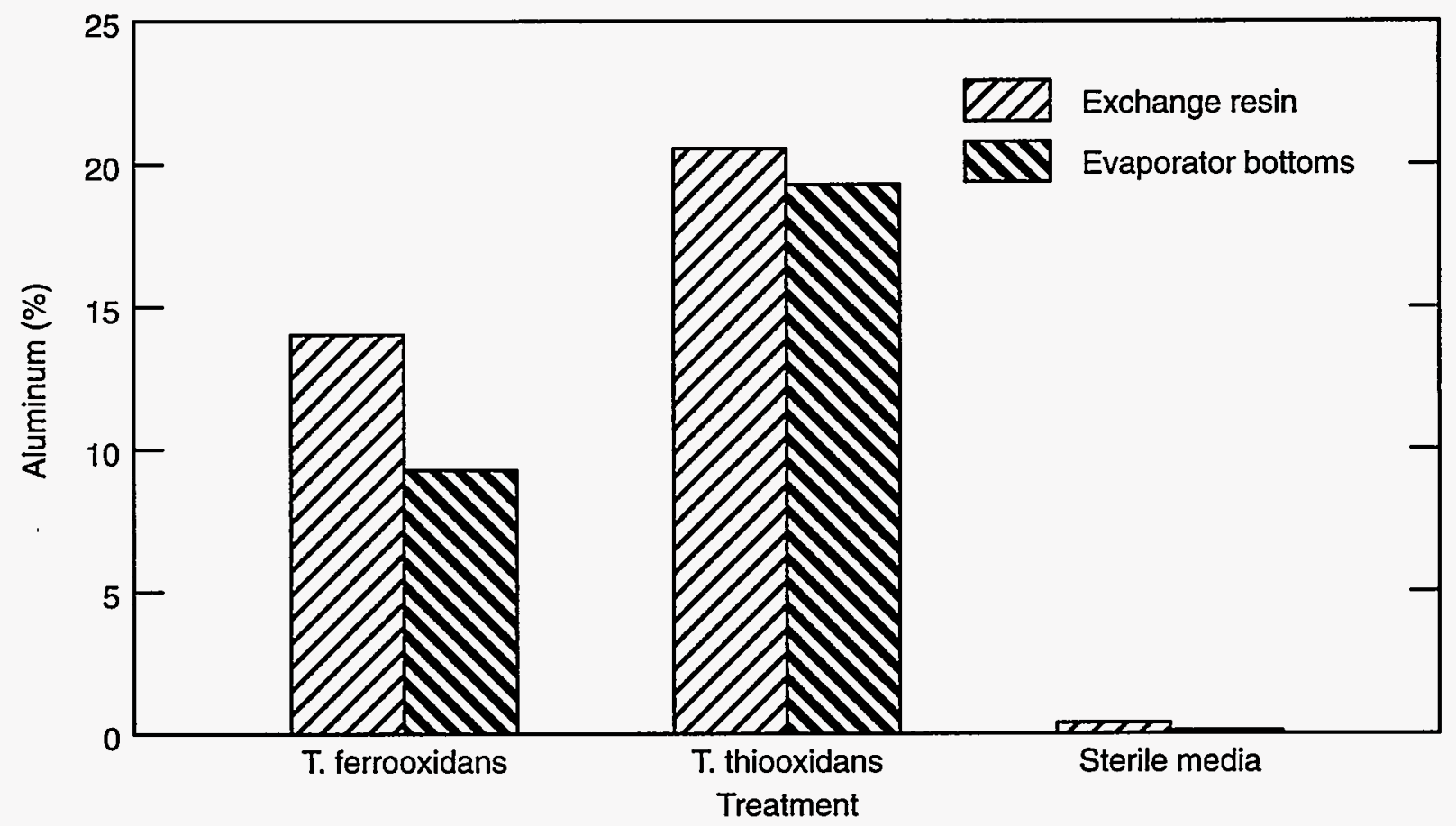

Figure 39. Quantities of $\mathrm{Al}$ leached from vendor-supplied simulated waste-form specimens after 30 days of total immersion.

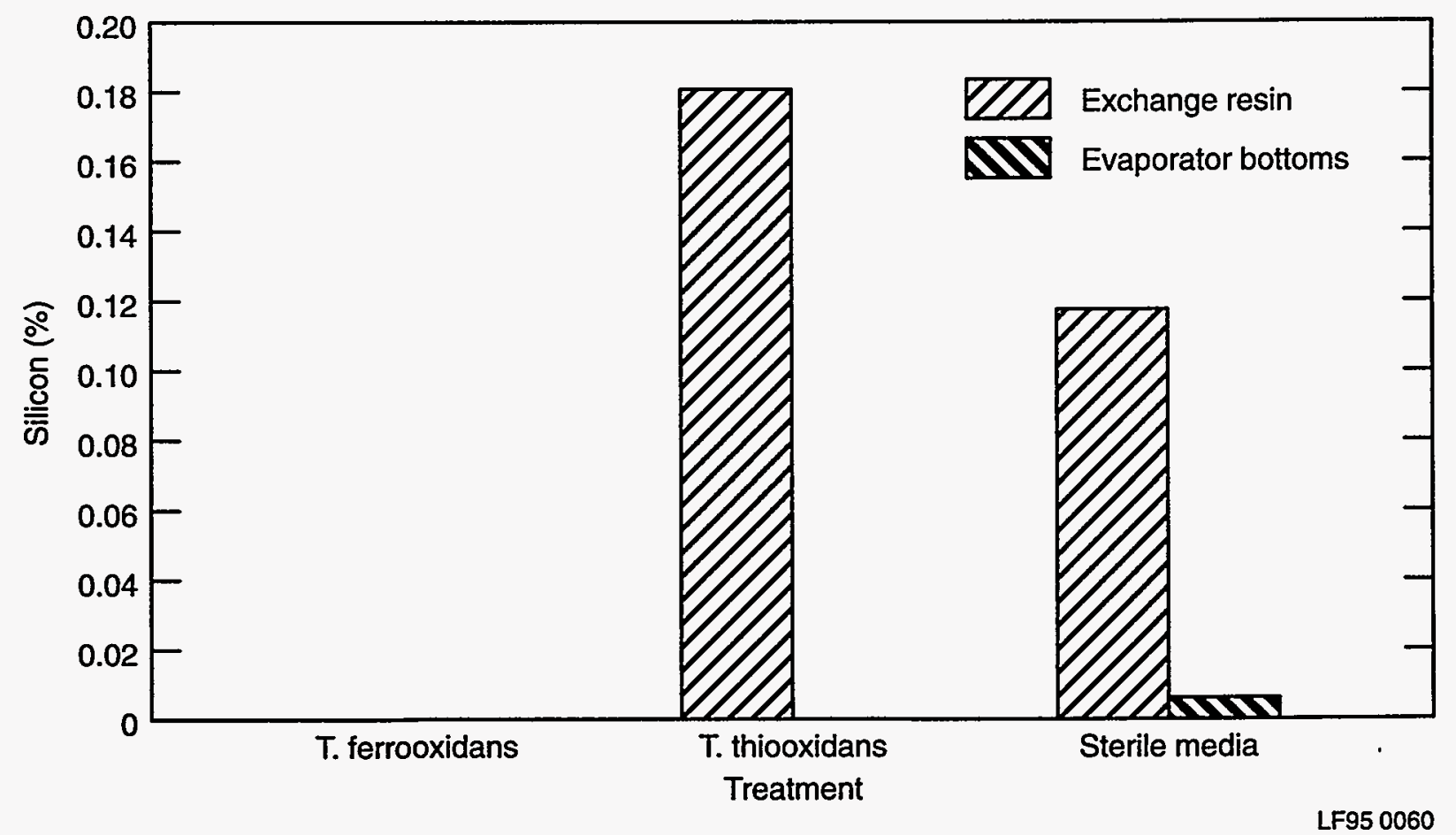

Figure 40. Quantities of Si leached from vendor-supplied simulated waste-form specimens after 30 days of total immersion. 


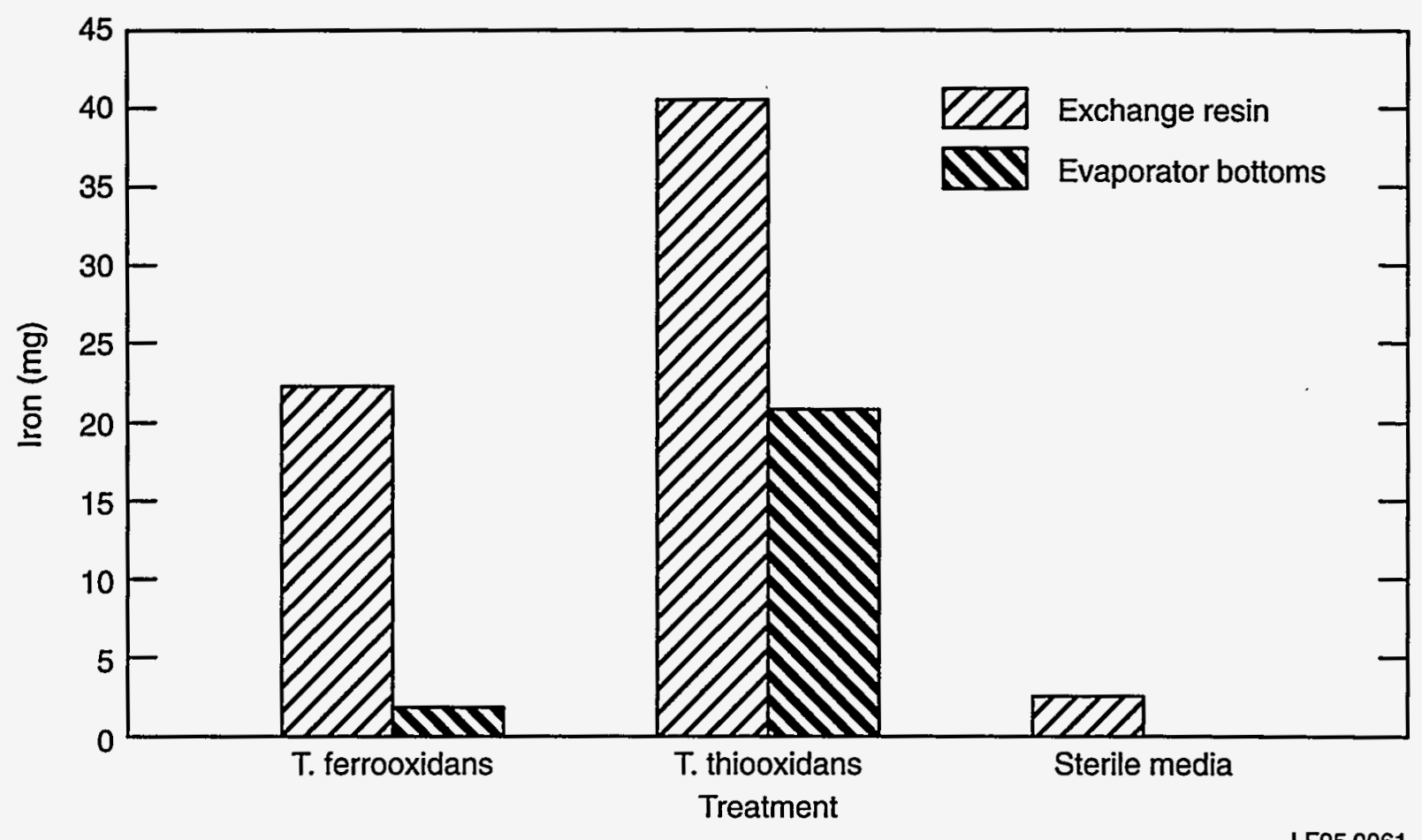

Figure 41. Quantities of Fe leached from vendor-supplied simulated waste-form specimens after 30 days of total immersion.

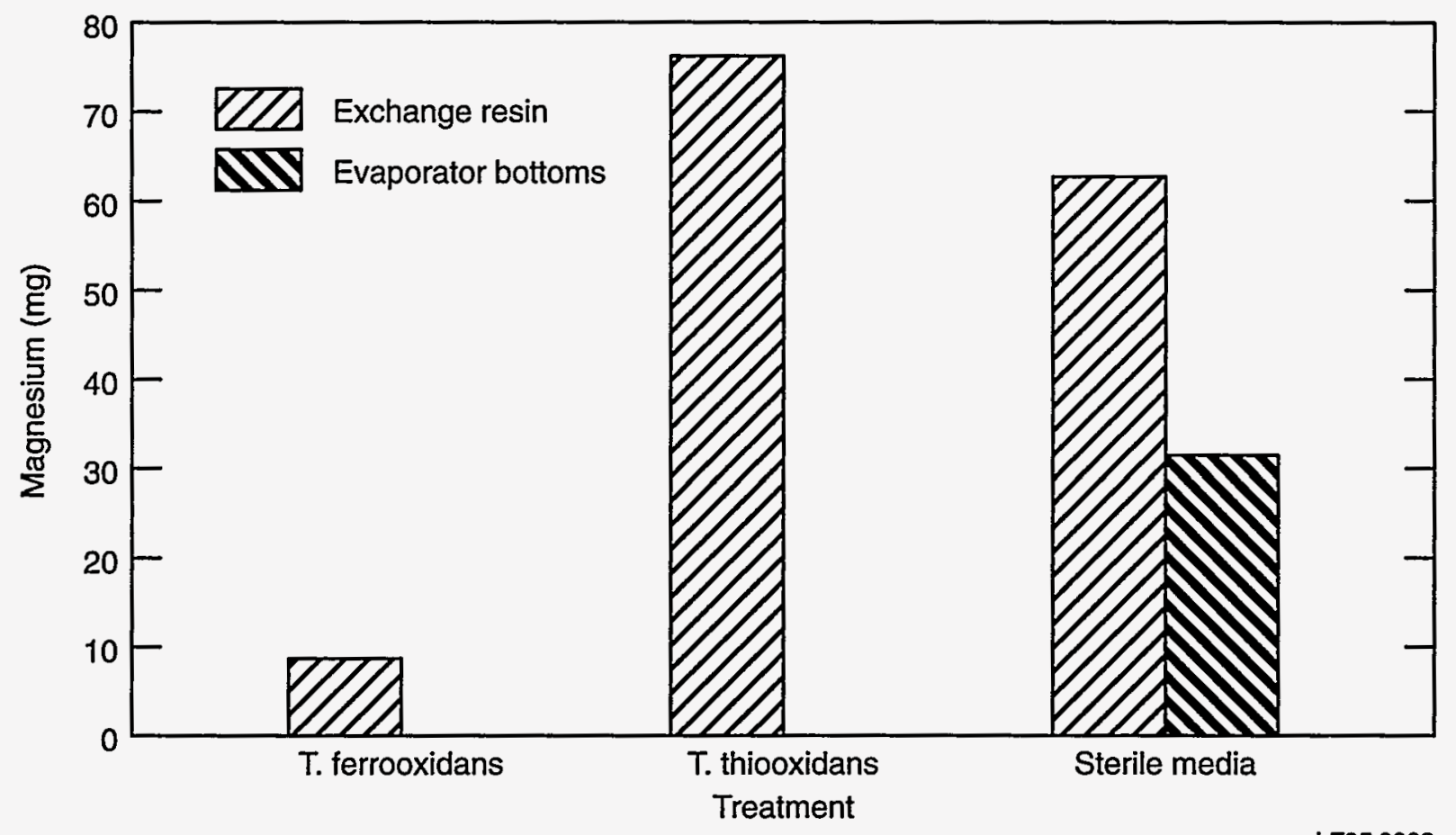

Figure 42. Quantities of $\mathrm{Mg}$ leached from vendor-supplied simulated waste-form specimens after 30 days of total immersion. 
Like the case of the INEL-supplied simulated waste forms, effluent $\mathrm{pH}$ data showed that the specimens had little effect on moderating the acid environment imposed by the thiobacilli lixiviants. Over the course of the study, the average $\mathrm{pH}$ values of the two lixiviants remained near 2 (Figure 43). The $\mathrm{pH}$ of the sterile medium that was exposed to the vendor waste forms remained constant at about 3 during the first 7 days. Subsequently, the $\mathrm{pH}$ began to increase into the $\mathrm{pH} 6$ and 7 range. These data are significantly different from those from the INEL material, which provided an alkaline buffer for a significant period of time (Figure 35). This time, it appears that the vendor waste forms contributed little to the initial buffering of the sterile medium. Why buffering of the sterile medium was delayed in this study was not ascertained.

The continual exposure of waste forms to thiobacilli lixiviants had a marked influence on their final surface $\mathrm{pH}$. Table 9 provides $\mathrm{pH}$ data showing that surface $\mathrm{pH}$ values of the untreated

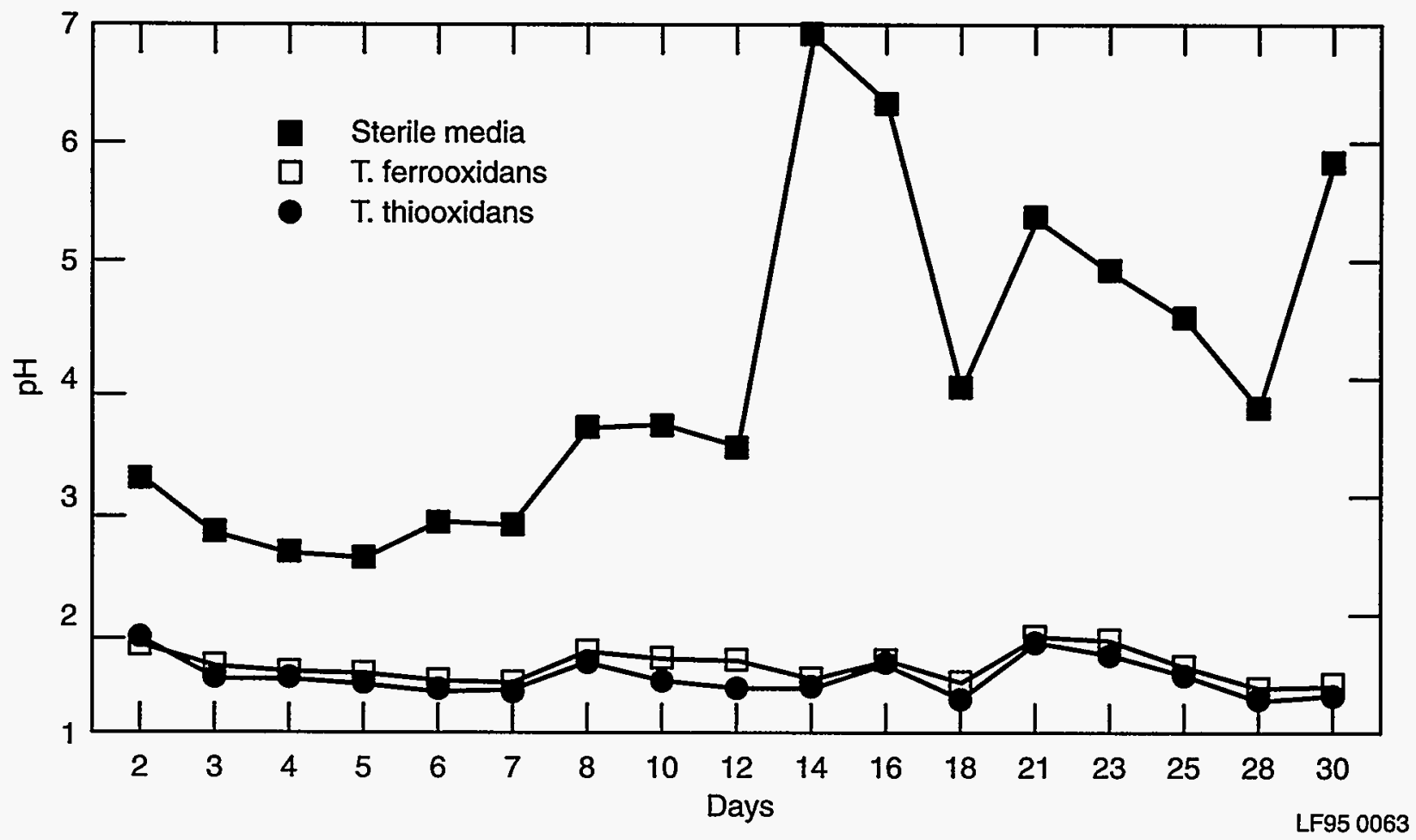

Figure 43. $\mathrm{pH}$ of lixiviants after exposure to vendor-supplied simulated waste-form specimens during the total-immersion study.

Table 9. Surface $\mathrm{pH}$ of vendor-supplied, simulated cement waste-form specimens, before and after immersion for 30 days in sterile medium or microbially produced lixiviant.

\begin{tabular}{lcc}
\hline Treatment & $\begin{array}{c}\text { Exchange resin } \\
(\mathrm{pH})\end{array}$ & $\begin{array}{c}\text { Evaporator bottoms } \\
(\mathrm{pH})\end{array}$ \\
\hline Untreated & 9 & 13 \\
Sterile medium & 9.5 & 8.5 \\
T. ferrooxidans & 1.0 & 3.0 \\
T. thiooxidans & 3.0 & 3.0 \\
\hline
\end{tabular}


vendor-supplied specimens decreased from alkaline ( $\mathrm{pH} 9$ to 13 ) to extremely acidic ( $\mathrm{pH} 1$ to 3 ). Although the sterile medium had some effect, the surface $\mathrm{pH}$ values remained alkaline. These results are similar to those obtained from the INEL materials.

During the final year of the study, an ASTM specimen and a vendor-supplied simulated evaporator bottoms waste-form specimen exposed to T. thiooxidans lixiviant for 30 days were examined for the presence of EPS and bacterial cells. Fragments of both specimens examined by ESEM showed the presence of biofilm (Figures 44 and 45). Scrapings from the ASTM specimens were prepared and stained with alcian blue and acridine orange. The presence of both EPS and bacterial cells was confirmed (Figure 46). Again, the background blue color confirms the presence of biofilm EPS material (Figure 46a) and the bright, fluorescing orange indicates the presence of viable cells associated with the biofilm matrix (Figure 46b).

Intermittent Immersion. A test similar to that described in the section on total immersion was conducted using Thiobacillus. INEL-fabricated and vendor-supplied simulated evaporator bottoms specimens, along with ion-exchange resin waste-form specimens and ASTM controls were exposed to $T$. ferrooxidans and $T$. thiooxidans lixiviants and to the sterile microbial growth medium. This test differed from total immersion in that test specimens were fully immersed in the respective treatment liquid for only 6 hours out of every 12 hours. This was accomplished by using 125-mL Soxhlet extraction columns. Figure 47 shows several of the columns set up, including attachment to effluent collection flasks. Each specimen was placed on top of a plastic pedestal inside an individual Soxhlet column. Filling of the columns was controlled by the influent flow rate. It required 6 hours for a specimen to become immersed. After the liquid level rose to a predetermined height, the column was emptied by the activation of a syphon. Approximately $100 \mathrm{~mL}$ of liquid passed through each column per day. Effluent from each Soxhlet column was collected to determine $\mathrm{pH}$. In addition, effluents from the vendor-supplied waste-form specimens were analyzed for $\mathrm{Ca}, \mathrm{Fe}, \mathrm{Al}, \mathrm{Mg}$, and $\mathrm{Si}$. Chemical analyses were not conducted on the lixiviants from INEL-supplied specimens. At the conclusion of the test, all specimens underwent physical examination, including determination of surface $\mathrm{pH}$, to assess the extent of MID. The duration of the intermittent exposure test was 60 days.

The visual effect of MID on the ASTM control and the INEL-prepared simulated waste forms can be seen in Figures 48 through 50 . The surface $\mathrm{pH}$ of the waste forms exposed to the lixiviant was very low, ranging from 0.5 to 3.0 (Table 10). Those exposed only to the sterile medium were pH 7 or above. Figures $48 \mathrm{a}, 48 \mathrm{~b}$, and $48 \mathrm{c}$ show the ASTM control after exposure to sterile medium, T. ferrooxidans lixiviant, and T. thiooxidans lixiviant, respectively. Figures 49 and 50 are arranged in the same sequence for the INEL-supplied simulated evaporator bottoms and ion-exchange resin waste forms. There is a gradation of effects for those specimens exposed only to the sterile medium. No visible effect is seen on the ASTM control (Figure 48a). Even though the evaporator bottoms specimen exhibited minor swelling and some cracking, the waste form shape is still well defined (Figure 49a). The ionexchange resin specimen, however, was totally crumbled (Figure 50a), similar to the total immersion sample. Even though some of the resin beads were loose, as seen by the craters in the cement debris, most of the resin beads remained firmly embedded. ASTM specimens that were in contact with the two thiobacilli lixiviants were light (white) in color, indicating that extensive leaching of $\mathrm{Ca}$ had taken place (Figures $48 \mathrm{~b}$ and $48 \mathrm{c}$ ). The evaporator bottoms waste forms exposed to the lixiviants (Figures $49 \mathrm{~b}$ and 49c) became very light in color and lost some margin definition. Also, material loss was evident, but no cracking or spalling appeared. Extensive, physical damage was seen in the ion-exchange resin specimens exposed to lixiviants (Figures 50b and 50c). As discussed previously, these specimens lost their cement matrix as indicated by the appearance of loose resin beads. 


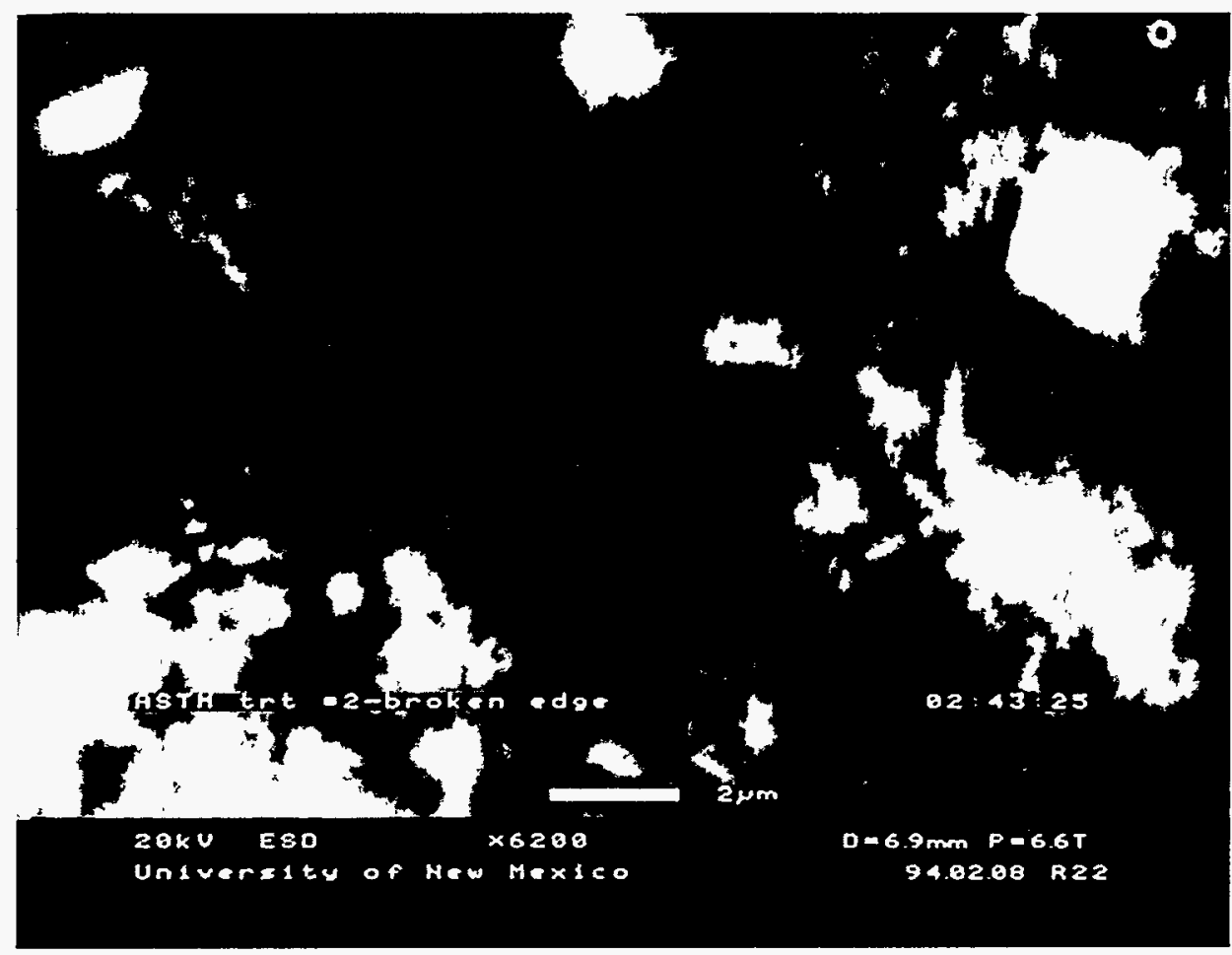

Figure 44. ESEM photograph of ASTM control waste-form specimen after exposure to sulfur-oxidizing organisms.

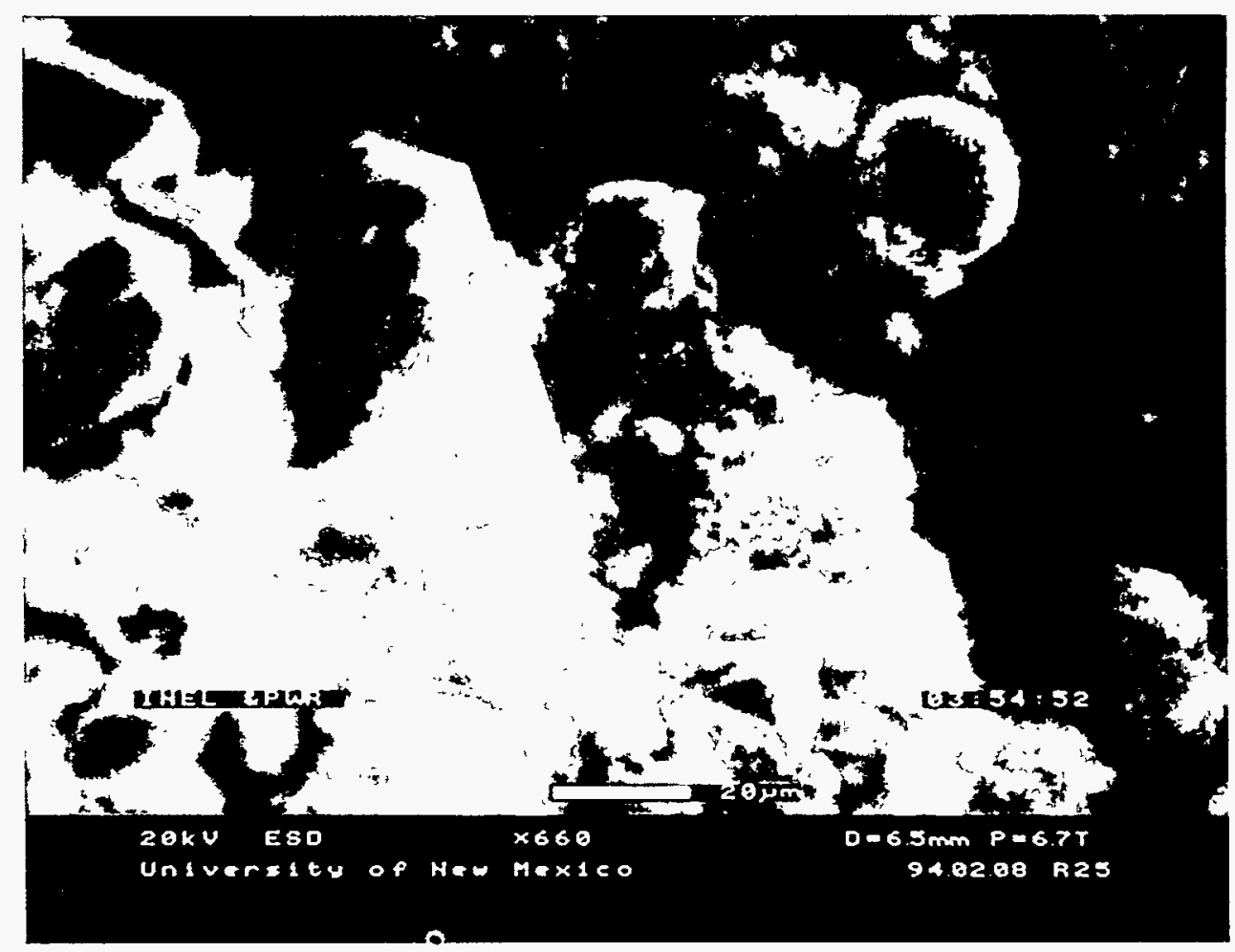

Figure 45. ESEM photograph of INEL-supplied simulated evaporator bottoms waste-form specimen after exposure to sulfur-oxidizing organisms. 


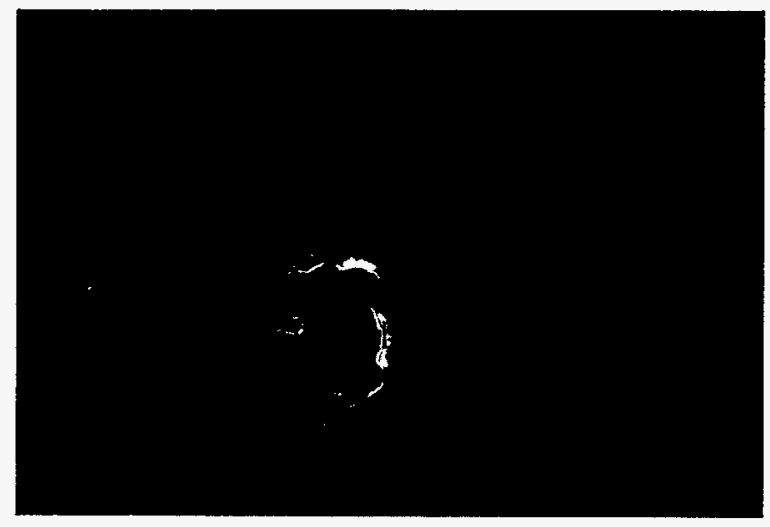

(a)

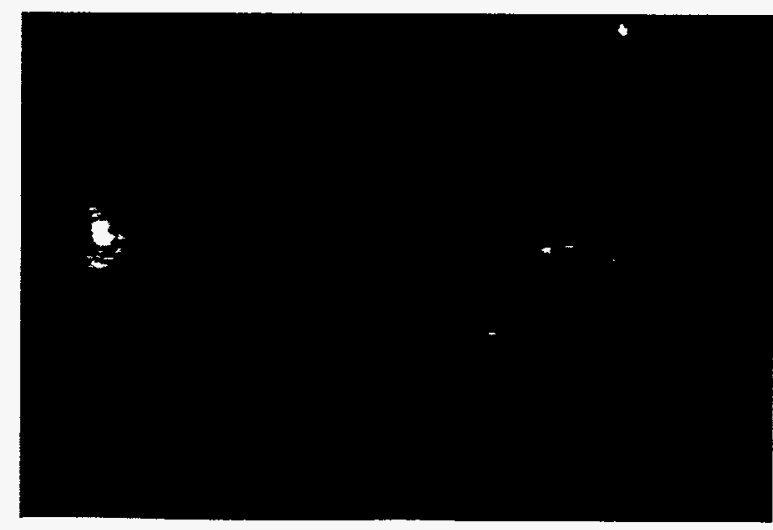

(b)

Figure 46. Biofilm staining of INEL-supplied simulated waste-form specimen after exposure to sulfuroxidizing organisms (a) stained blue to demonstrate presence of biofilm EPS material and (b) fluorescent orange stain demonstrating presence of viable cells.

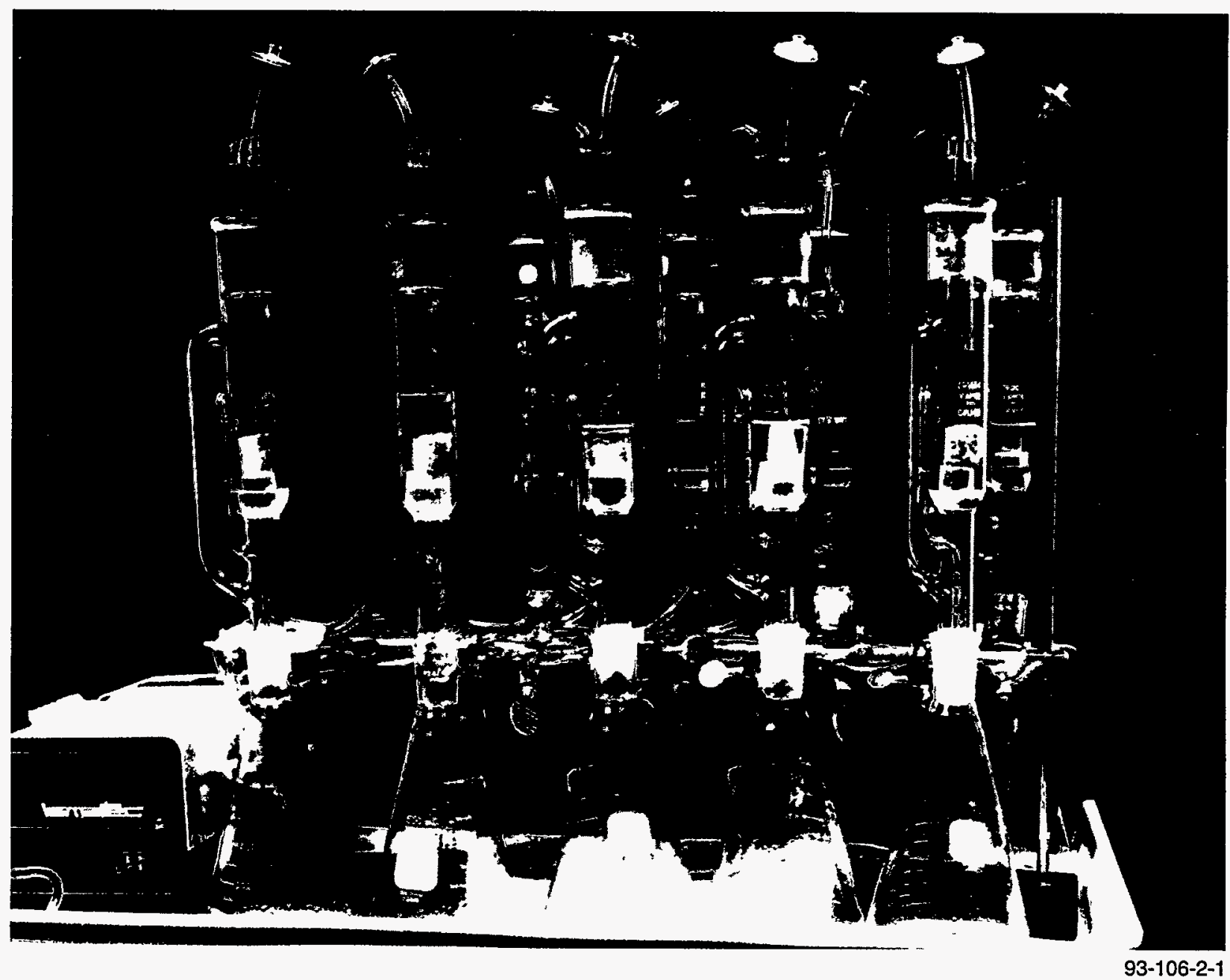

Figure 47. Vessels (Soxhlet extractors) used to intermittently expose simulated waste-form specimens to lixiviants. 


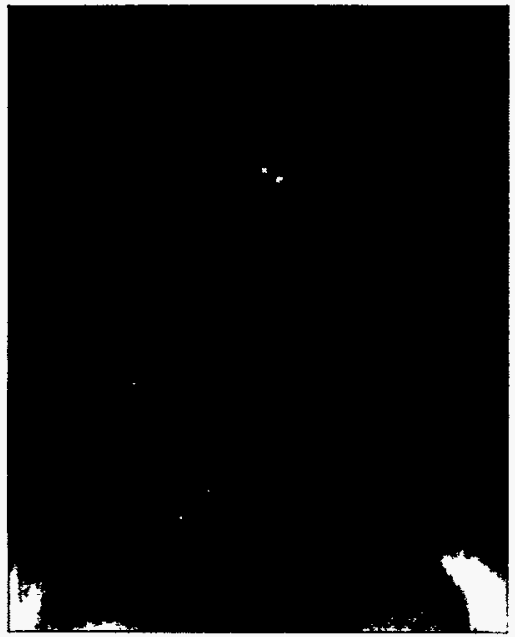

(a)

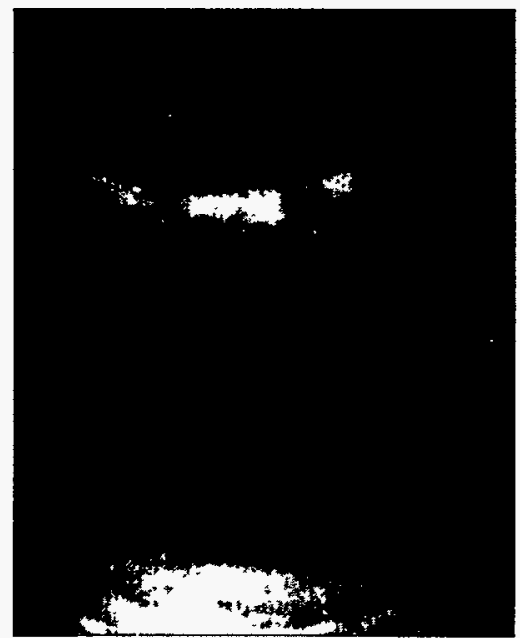

(b)
93-213-1-11

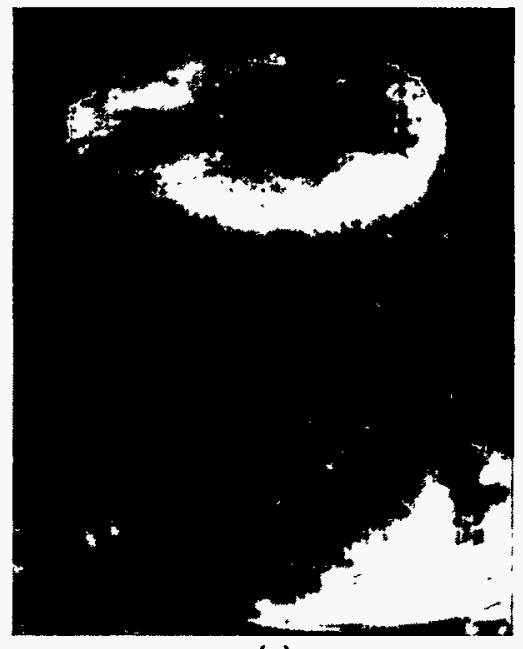

(c)

93-213-2-5

Figure 48. ASTM control waste-form specimens after being intermittently immersed for 60 days in (a) sterile medium (b) $T$. ferrooxidans lixiviant (c) $T$. thiooxidans lixiviant.

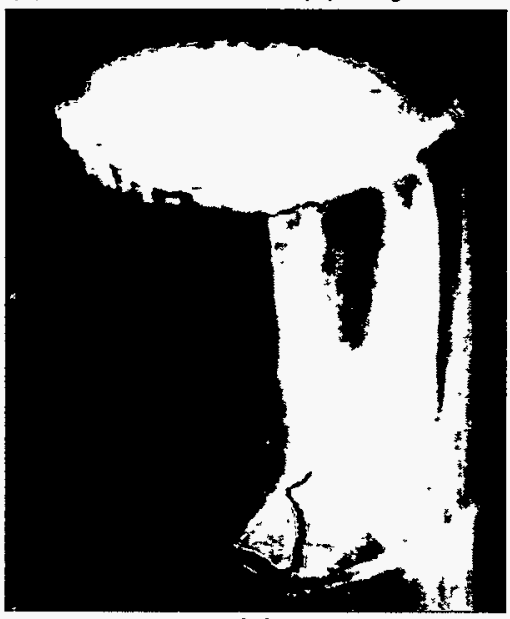

(a)

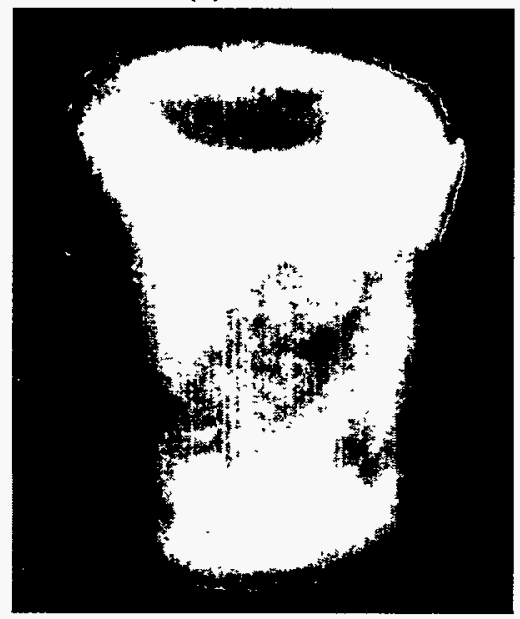

(b)

93-213-2-3

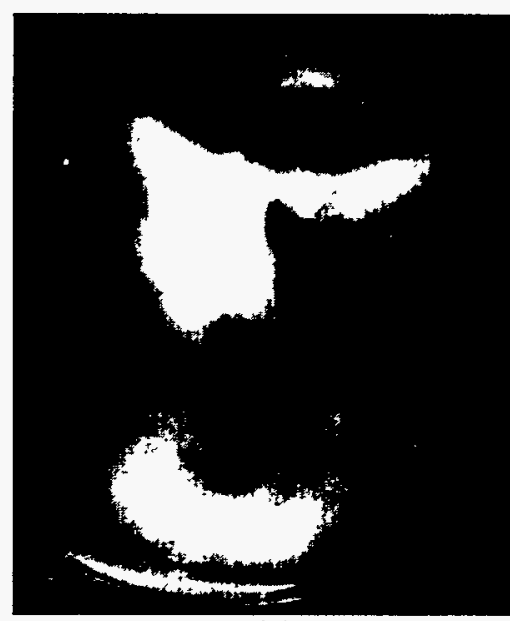

(c)

$93-213-1-9$

Figure 49. INEL-supplied simulated evaporator bottoms waste-form specimens after being intermittently immersed for 60 days in (a) sterile medium (b) $T$. ferrooxidans lixiviant (c) $T$. thiooxidans lixiviant.

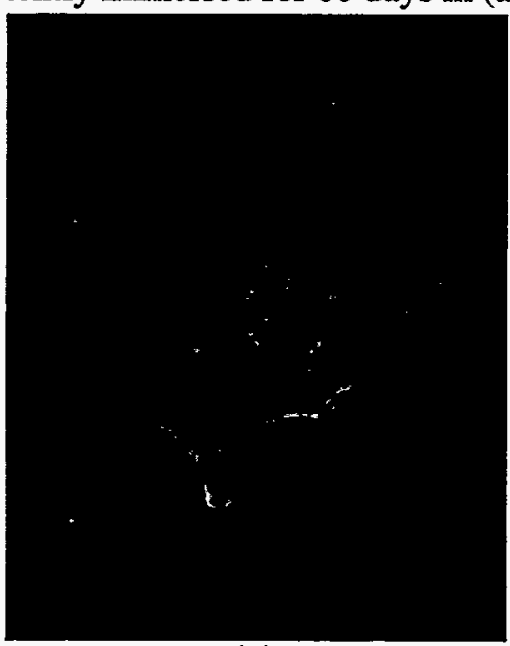

(a)

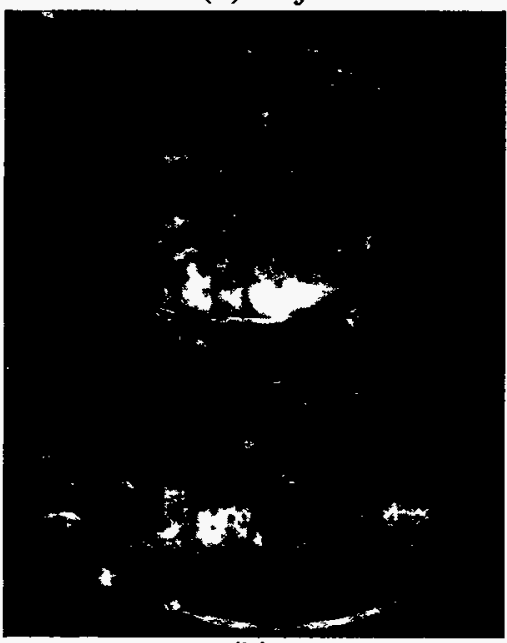

(b)

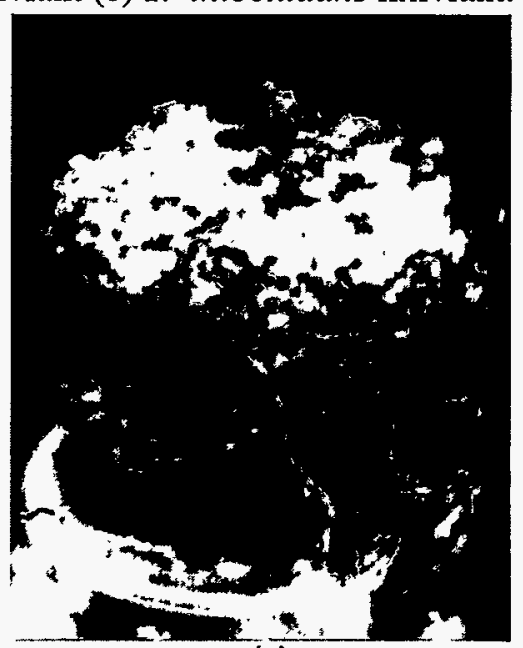

(c)

$93-213-1-8$

Figure 50. INEL-supplied simulated ion-exchange resin waste-form specimens after being intermittently immersed for 60 days in (a) sterile medium (b) $T$. ferrooxidans lixiviant (c) $T$. thiooxidans lixiviant. 
Table 10. Surface $\mathrm{pH}$ of INEL waste-form specimens exposed to lixiviant during intermittent immersion.

\begin{tabular}{lccc}
\hline \multicolumn{1}{c}{ Treatment } & $\begin{array}{c}\text { Exchange resin } \\
(\mathrm{pH})\end{array}$ & $\begin{array}{c}\text { Evaporator bottoms } \\
(\mathrm{pH})\end{array}$ & $\begin{array}{c}\text { ASTM standard } \\
(\mathrm{pH})\end{array}$ \\
\hline Untreated & 9 & 13 & 11.5 \\
Sterile medium & 7 & 8 & 8 \\
T. ferrooxidans & 0.5 & 3.0 & 1.0 \\
T. thiooxidans & 0.5 & 1.5 & 1.5 \\
\hline
\end{tabular}

Results of exposure of the vendor-supplied simulated waste forms to sterile medium and lixiviants are shown in Figures 51 and 52. The evaporator bottoms waste form exposed to the sterile medium was not physically degraded in any way (Figure 51a), while there was some damage to the ion-exchange resin specimen (Figure 52a). There was significant damage, however, to all specimens in contact with the two lixiviants. Swelling with accompanying loss of material was noted for the evaporator bottoms waste forms (Figures $51 \mathrm{~b}$ and 51c). The ion-exchange resin specimens were completely disintegrated, and loose resin beads were evident (Figures 52b and 52c).

Analysis of the effluent from the vendor waste forms indicated that substantial percentages of $\mathrm{Ca}, \mathrm{Al}$, and $\mathrm{Si}$ were removed from specimens exposed to the thiobacilli lixiviants (Figures 53 through 55). Loss of $\mathrm{Ca}$ ranged from 70 to $90 \%$ by the thiobacilli lixiviants compared to about $30 \%$ by the sterile medium control (Figure 53). The percentage of Al lost was 51 to $75 \%$ to the lixiviants and approximately $2 \%$ to the medium control (Figure 54). Silica losses for those specimens exposed to thiobacilli lixiviants ranged from 19 to $28 \%$ and averaged about $13 \%$ for the control (Figure 55). Because initial concentrations of $\mathrm{Fe}$ and $\mathrm{Mg}$ were not available for these waste forms, only total quantities of these elements removed by the leachant are reported (Figures 56 and 57). Iron removal was observed from those waste forms exposed to the lixiviants (29 to $56 \mathrm{mg}$ ), while no loss was detected in the sterile medium (Figure 56). There was active $\mathrm{Mg}$ removal from only those specimens in contact with the $T$. thiooxidans lixiviant (about $58 \mathrm{mg}$ ), with minor amounts to the sterile medium ( 2 to $12 \mathrm{mg}$ ) (Figure 57).
Neither ion-exchange resin nor evaporator bottoms waste-form specimens had a predominant loss of elements. More $\mathrm{Ca}$ and $\mathrm{Fe}$ were removed from the ion-exchange resin specimens, while more Al was leached from the evaporator bottoms specimens. Silica loss was thiobacilli species-dependant. A greater percentage was removed from the evaporator bottoms waste form by exposure to the $T$. ferrooxidans lixiviant, while slightly more $\mathrm{Si}$ was lost from the ion-exchange resin specimen exposed to the $T$. thiooxidans treatment. Release of $\mathrm{Mg}$ was the same from both waste form types.

Data for the cumulative percentage removal of $\mathrm{Ca}, \mathrm{Al}$, and $\mathrm{Si}$ from each waste form type is presented in Figures 58 through 63. Element release rates were variable from the evaporator bottoms samples (Figures 58 through 60). Although the total percent $\mathrm{Ca}$ loss was nearly the same for the two lixiviants (Figure 58), the rate of release was different. A maximum amount of $\mathrm{Ca}$ was removed by the $T$. ferrooxidans lixiviant by day 35 , while levels of $\mathrm{Ca}$ in the $T$. thiooxidans lixiviant were still increasing by day 58 . The rate of leaching of $\mathrm{Al}$ (Figure 59) was approximately the same for both lixiviants until day 40 , when a greater percentage began to be released into the T. thiooxidans lixiviant. This resulted in more total $\mathrm{Al}$ being leached by this treatment. The cumulative data for Si leaching (Figure 60) clearly show large initial release in the $T$. ferrooxidans treatment. This resulted in the total $\mathrm{Si}$ leached by this treatment to be substantially more than that for the $T$. thiooxidans treatment. Figures 61 through 63 show that the rate of release of elements from the ion-exchange resin specimens was nearly the same for the two 


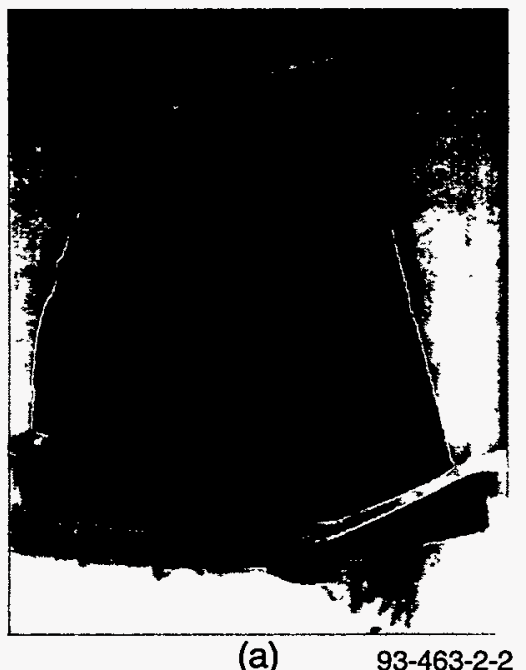

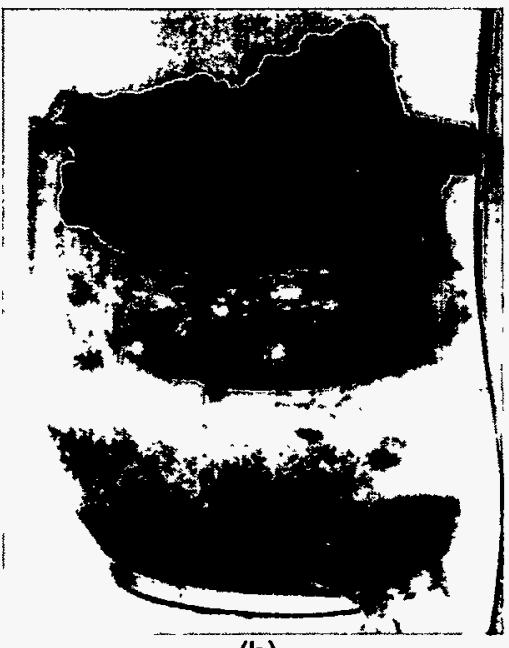

(b) $\quad 93-463-2-3$

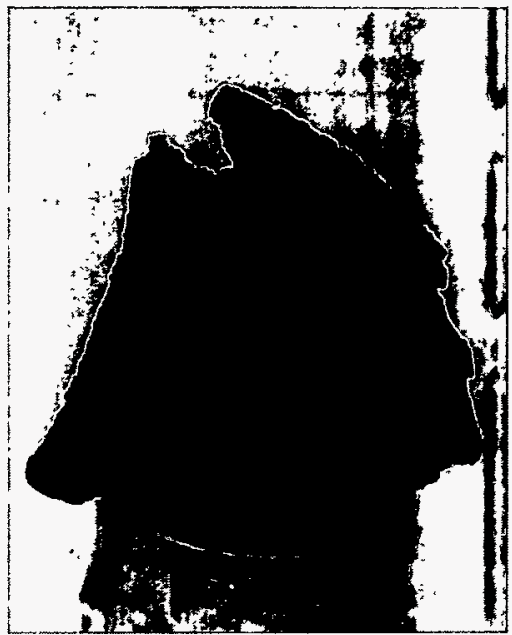

(c)

93463-3-8

Figure 51. Vendor-supplied simulated evaporator bottoms waste-form specimens after being intermittently immersed for 60 days in (a) sterile medium (b) $T$. ferrooxidans lixiviant (c) $T$. thiooxidans lixiviant.

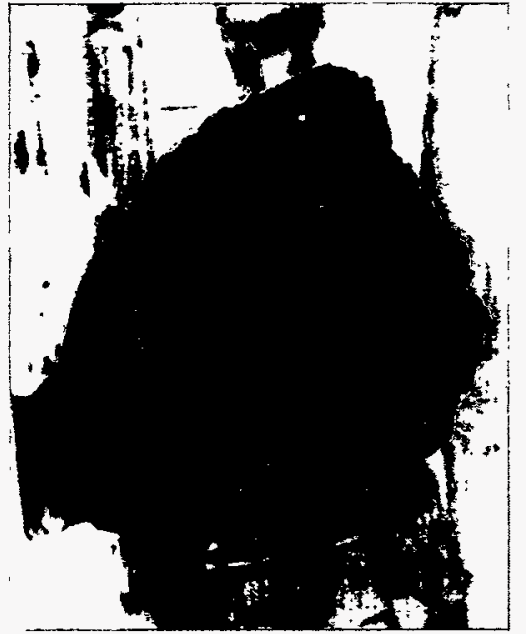

(a)

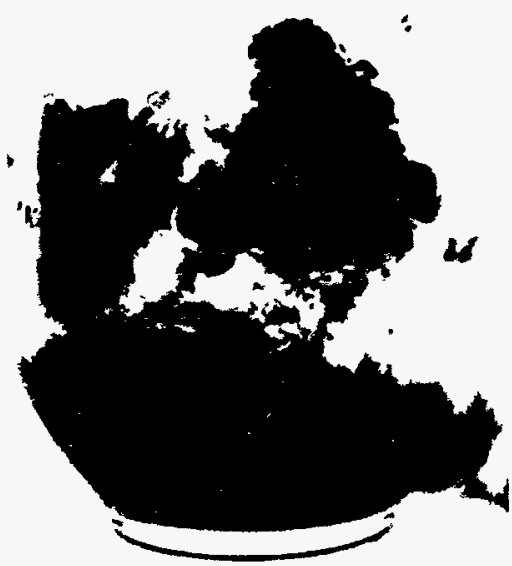

(b)

$93-463-2-6$

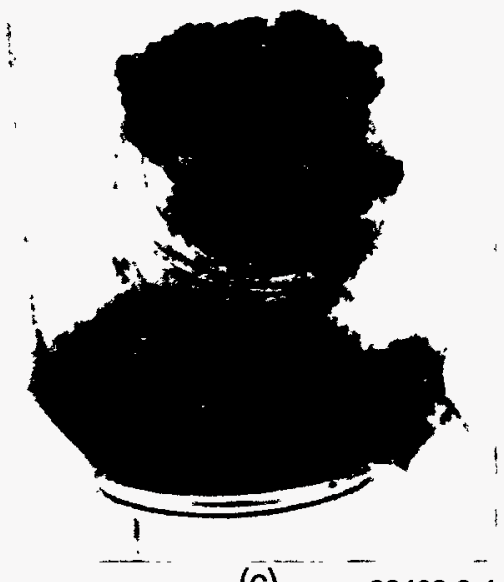

(c) $93463-3-4$

Figure 52. Vendor-supplied simulated ion-exchange resin waste-form specimens after being intermittently immersed for 60 days in (a) sterile medium (b) T. ferrooxidans lixiviant (c) $T$. thiooxidans lixiviant.

thiobacilli treatments. The majority of the $\mathrm{Ca}$ and $\mathrm{Al}$ release occurred during the first 30 days (Figures 61 and 62), while loss of Si was progressive with time (Figure 63). Also, as shown in Figure 61 , until about day 50 , the rate of release by the two lixiviant streams was the same; the final total $\mathrm{Ca}$ released, however, is not representative of the overall rate of leaching.

Average lixiviant $\mathrm{pH}$ for the study period (Figure 64) was similar to that of other studies.
The $\mathrm{pH}$ was less than 2 by day 8 for the lixiviants, and the $\mathrm{pH}$ of the sterile medium gradually decreased and stabilized at the influent $\mathrm{pH}$ by day 31. Final surface $\mathrm{pH}$ values of the vendorsupplied waste forms, ranging from 3 to 4, were not as acidic as the lixiviant to which they had been exposed (Table 11). Surprisingly, the surface $\mathrm{pH}$ of the specimens in contact with the sterile medium were acidic (4 and 5) rather than alkaline. 


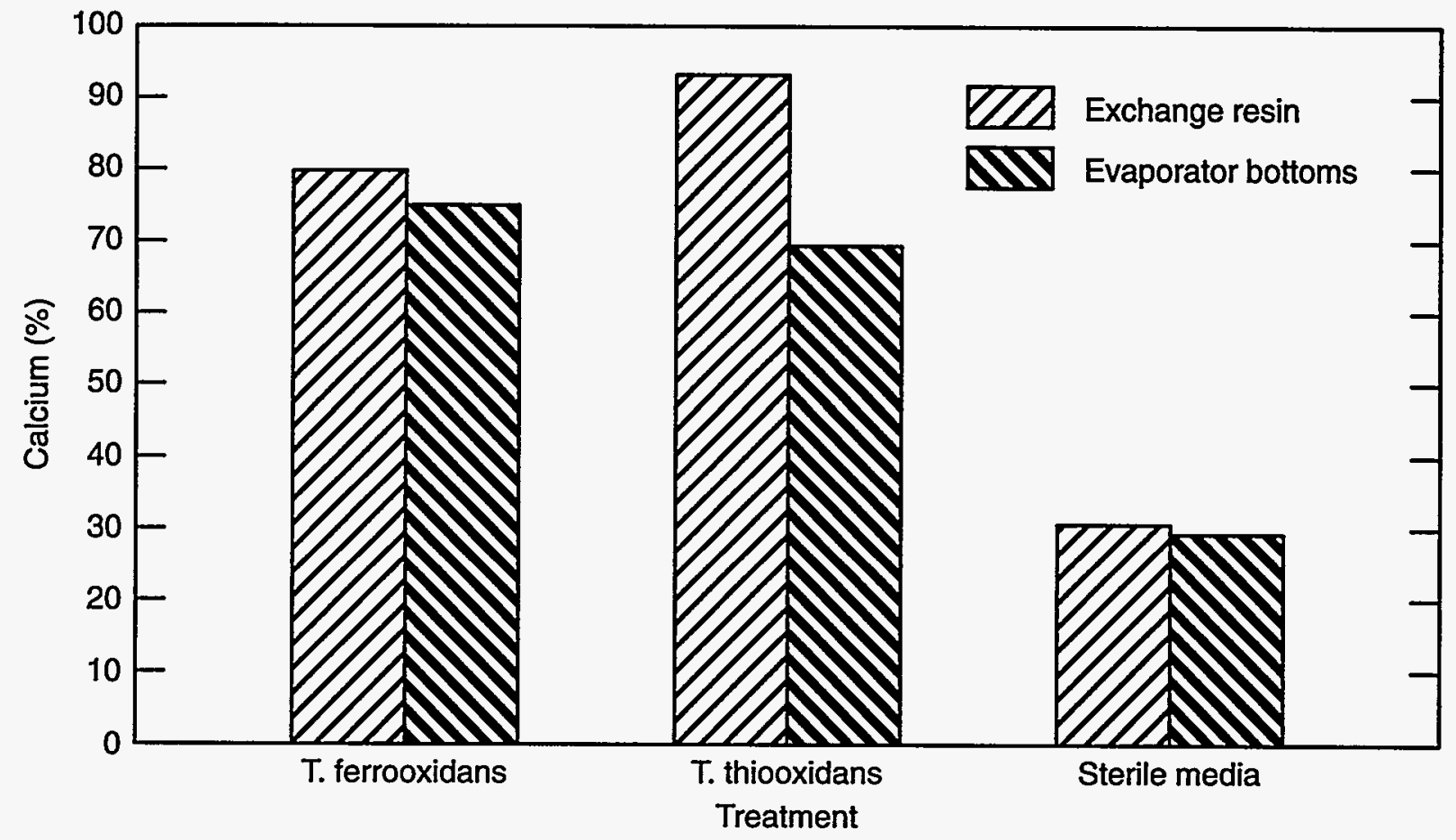

LF95 0064

Figure 53. Quantities of $\mathrm{Ca}$ leached from vendor-supplied waste-form specimens after 60 days of intermittent exposure.

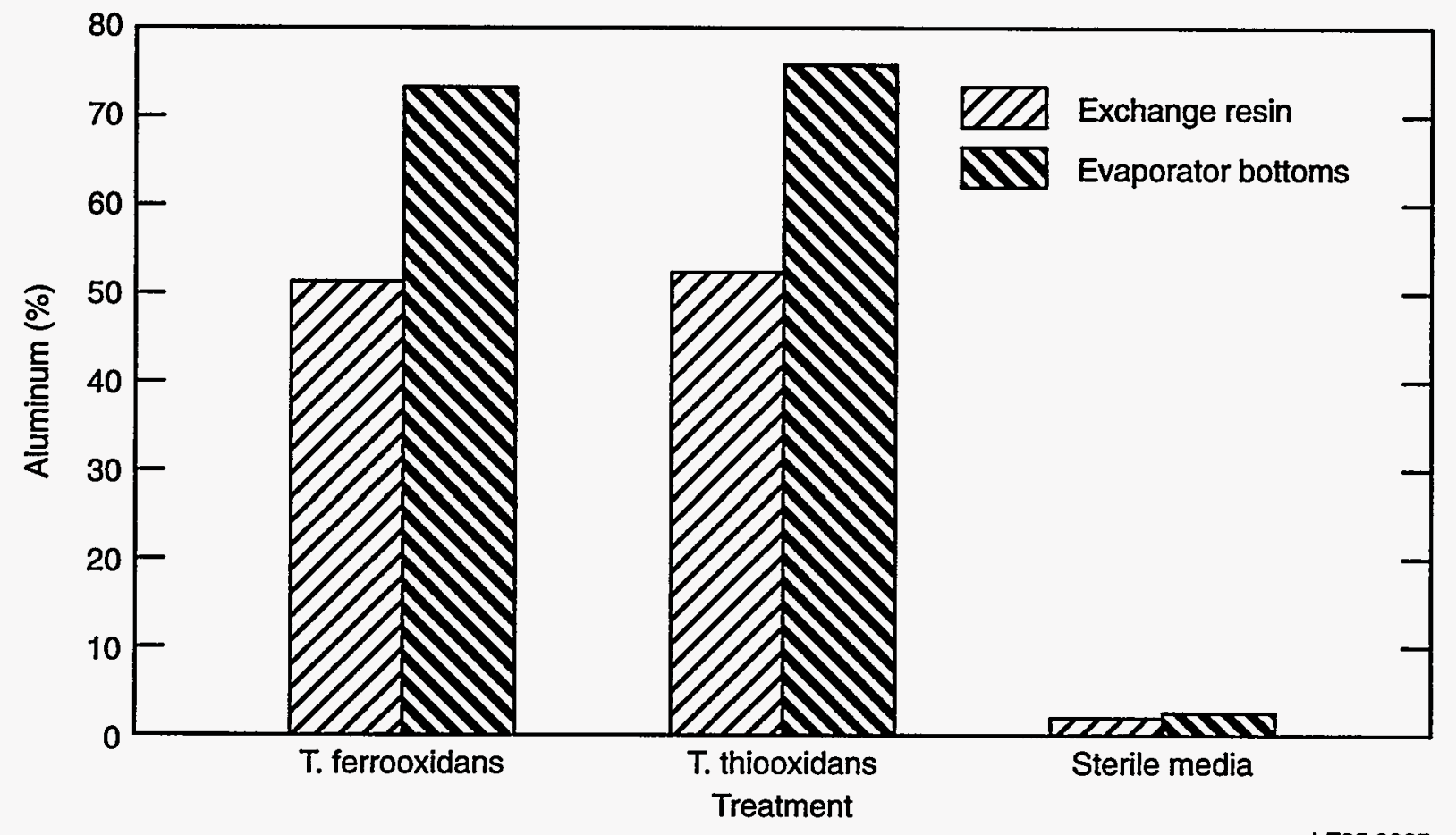

Figure 54. Quantities of Al leached from vendor-supplied waste-form specimens after 60 days of intermittent exposure. 


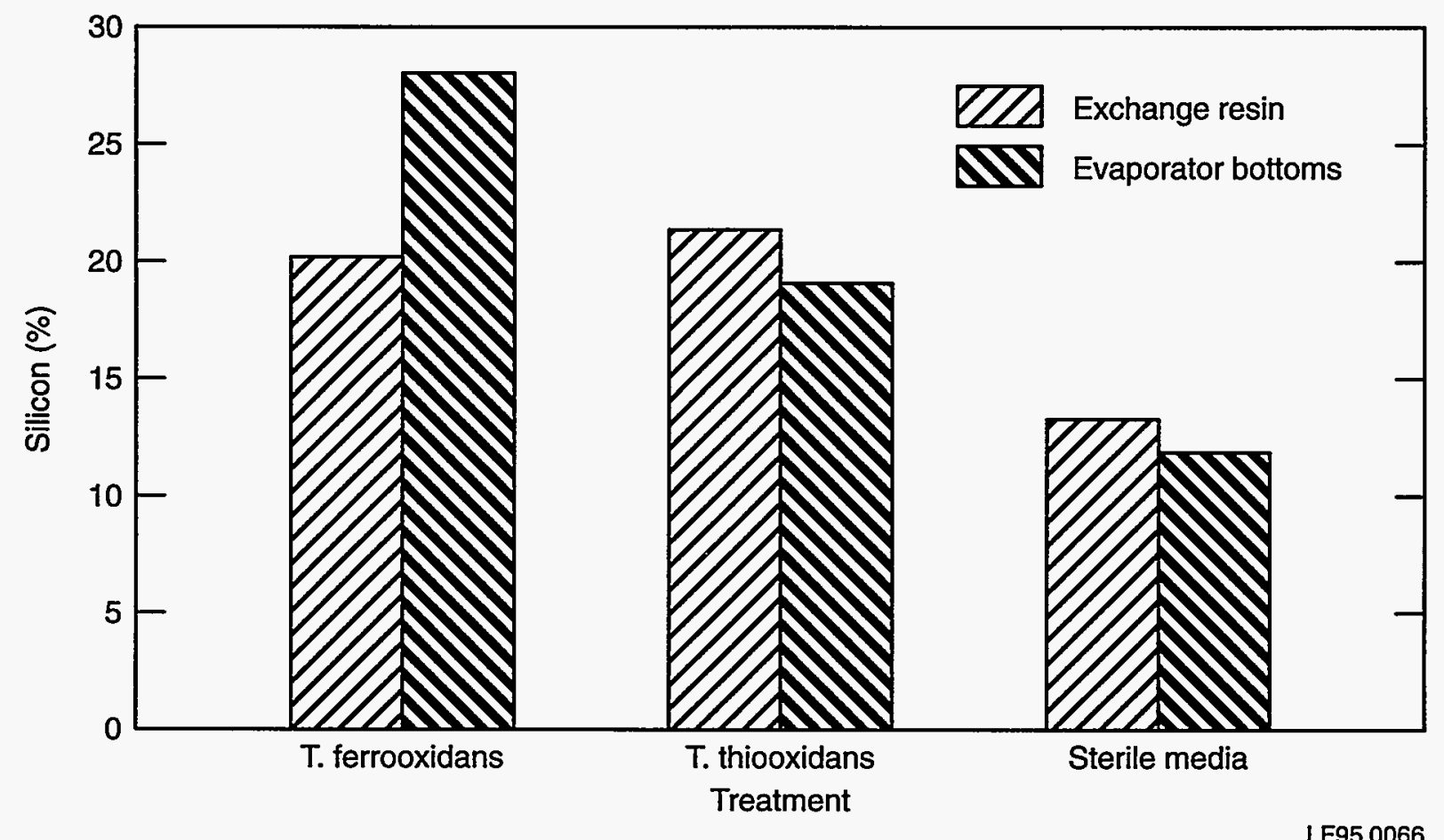

Figure 55. Quantities of Si leached from vendor-supplied waste-form specimens after 60 days of intermittent exposure.

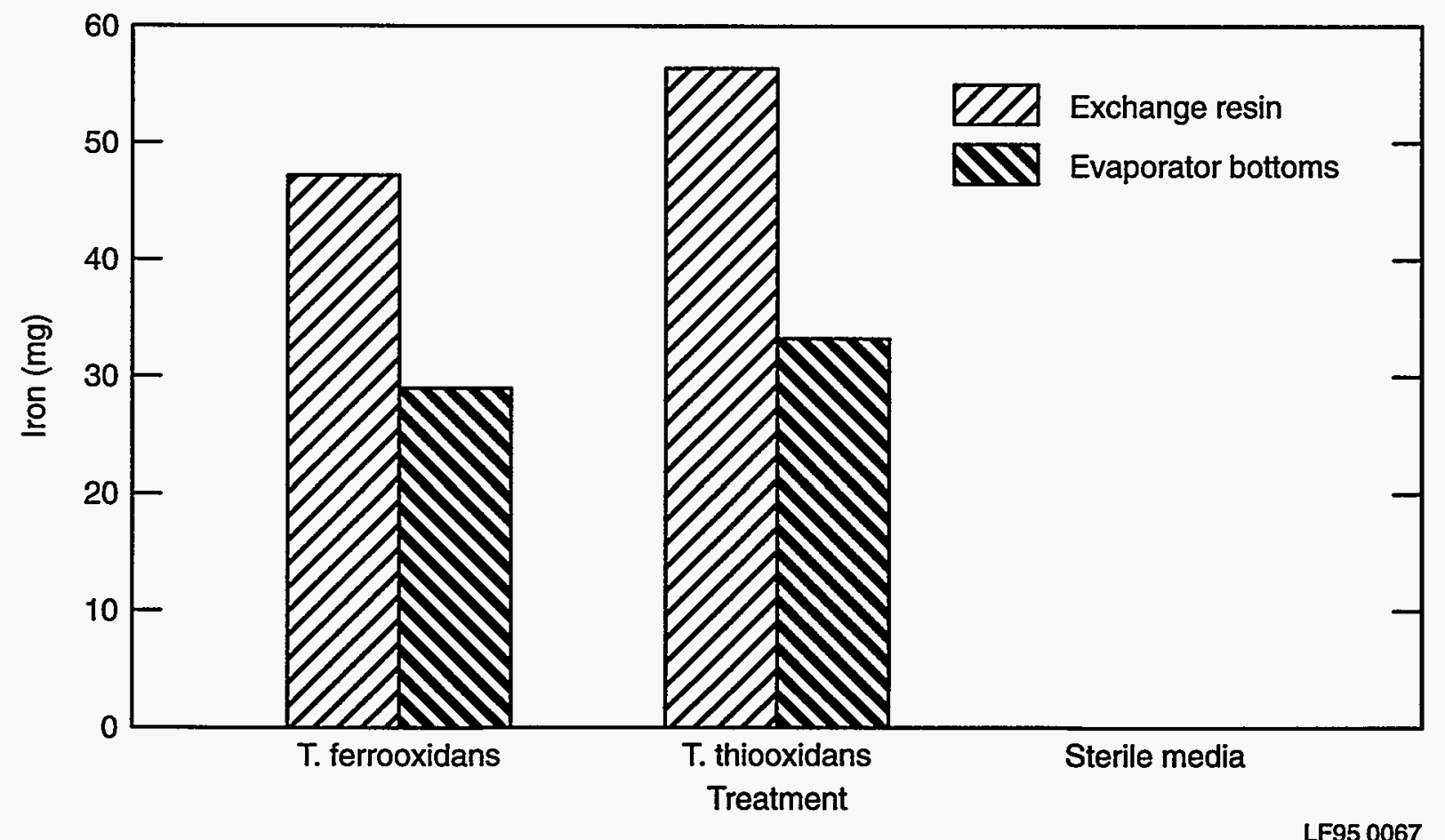

Figure 56. Quantities of Fe leached from vendor-supplied waste-form specimens after 60 days of intermittent exposure. 


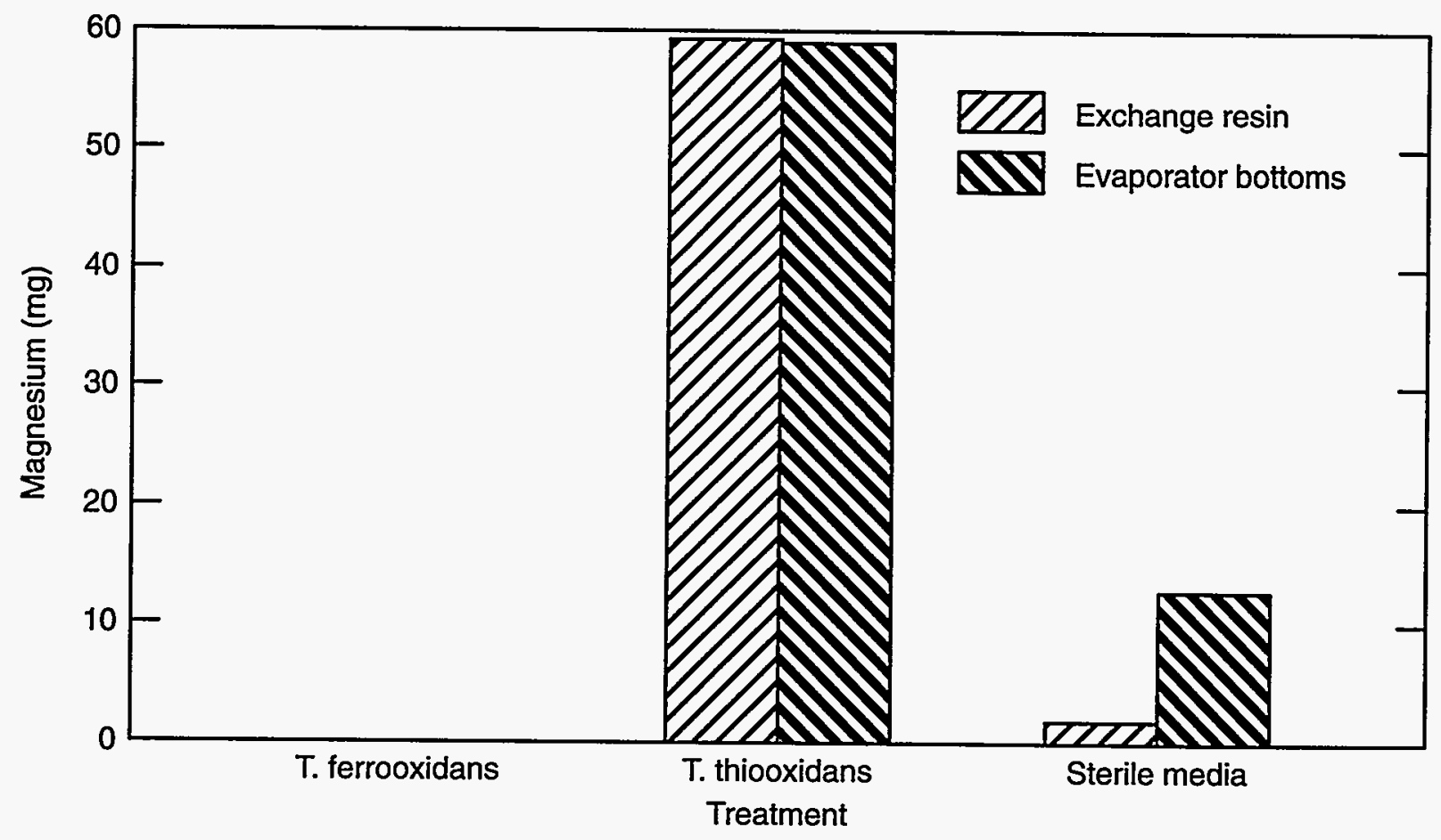

LF95 0068

Figure 57. Quantities of $\mathrm{Mg}$ leached from vendor-supplied waste-form specimens after 60 days of intermittent exposure.

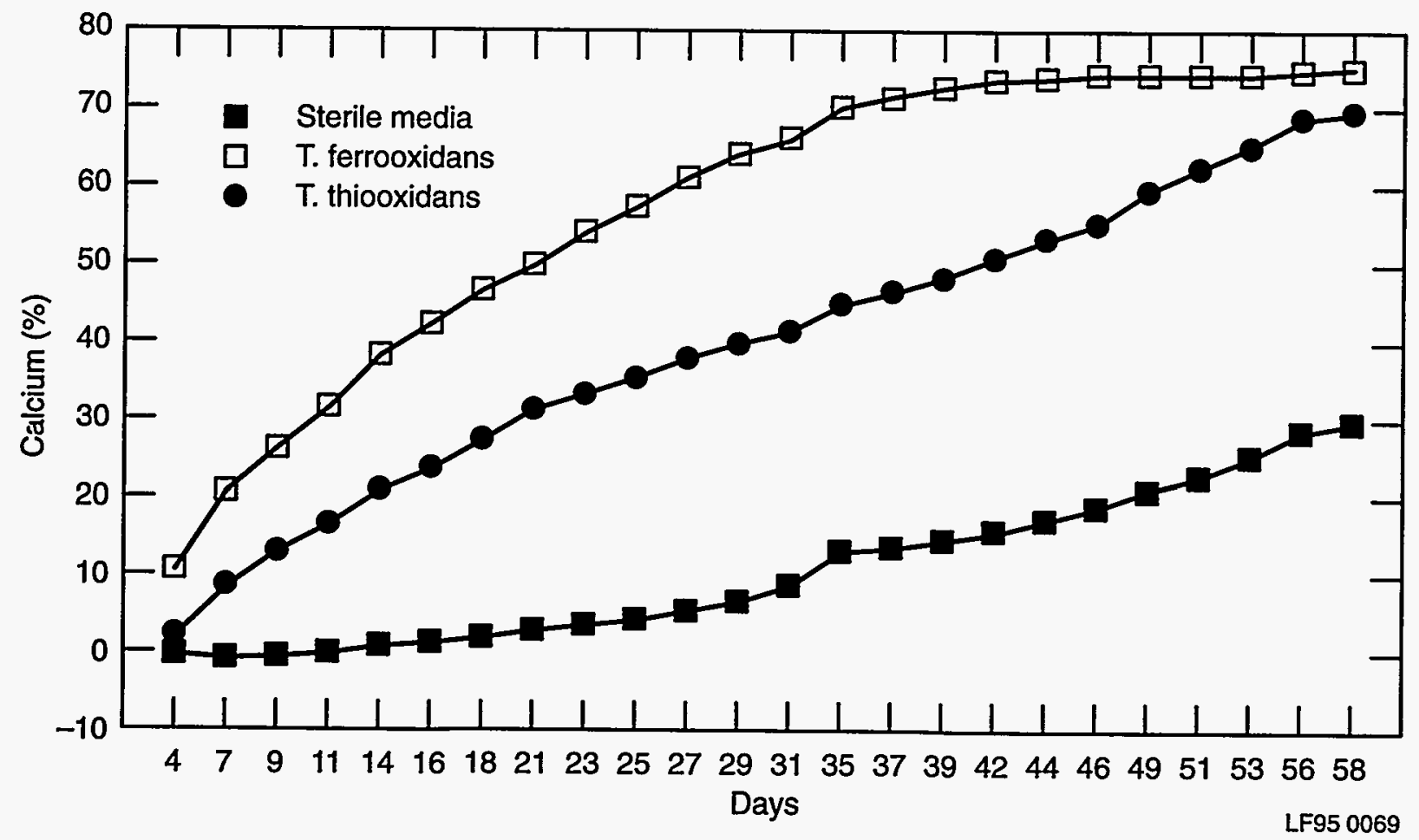

Figure 58. Cumulative quantities of $\mathrm{Ca}$ leached from vendor-supplied evaporator bottoms waste-form specimens during the intermittent-exposure study. 


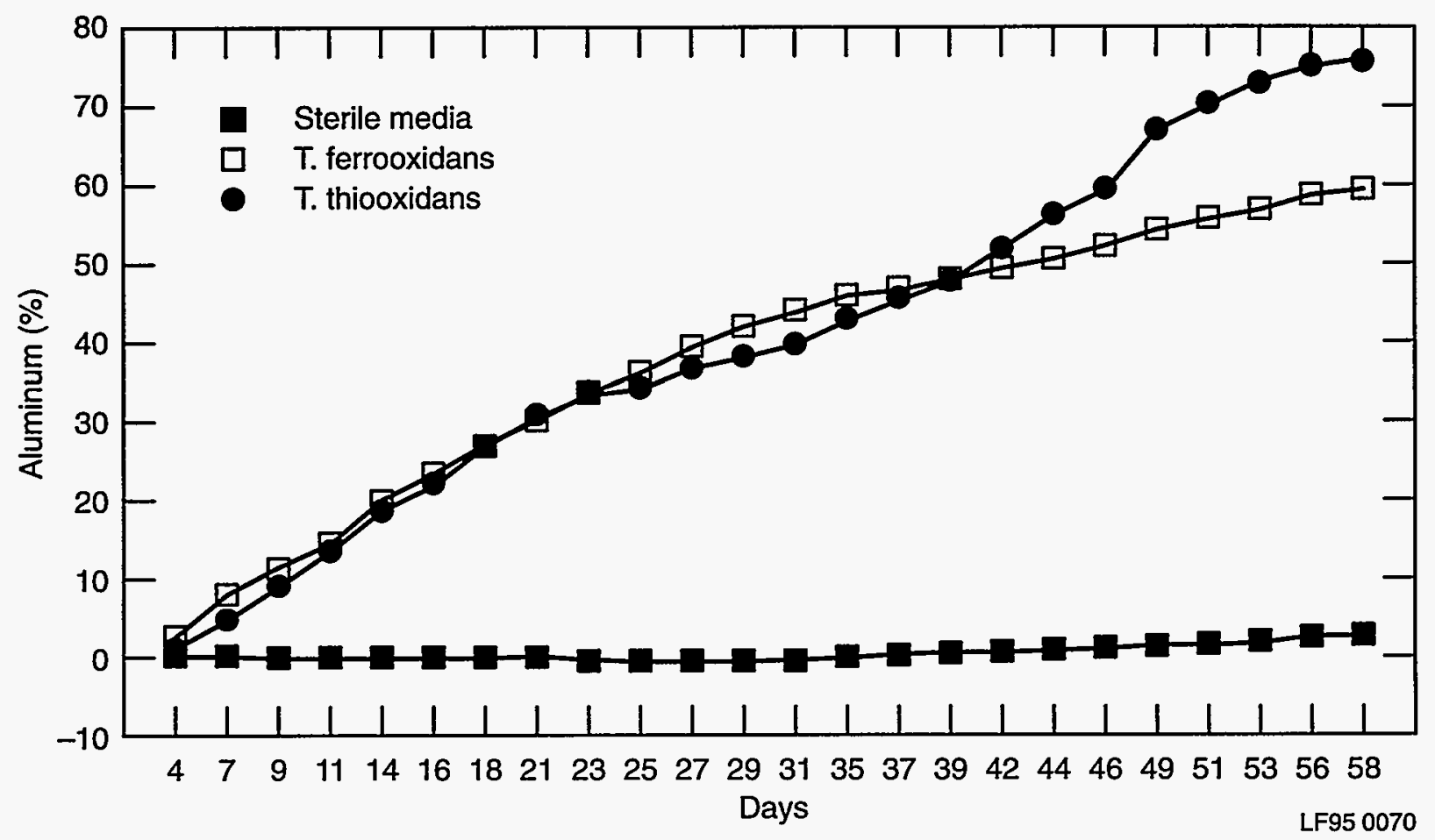

Figure 59. Cumulative quantities of $\mathrm{Al}$ leached from vendor-supplied evaporator bottoms waste-form specimens during the intermittent-exposure study.

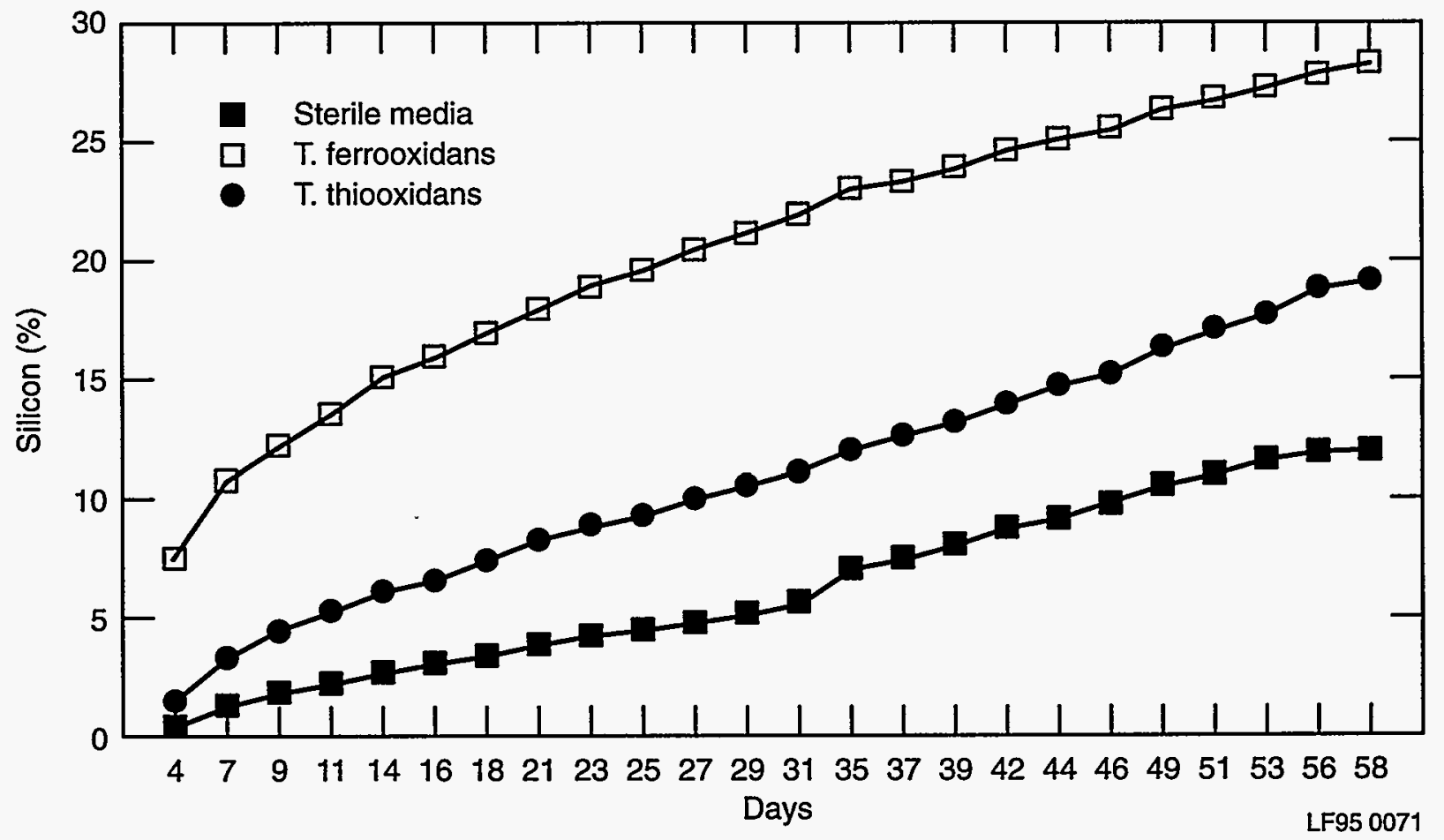

Figure 60. Cumulative quantities of Si leached from vendor-supplied evaporator bottoms waste-form specimens during the intermittent-exposure study. 


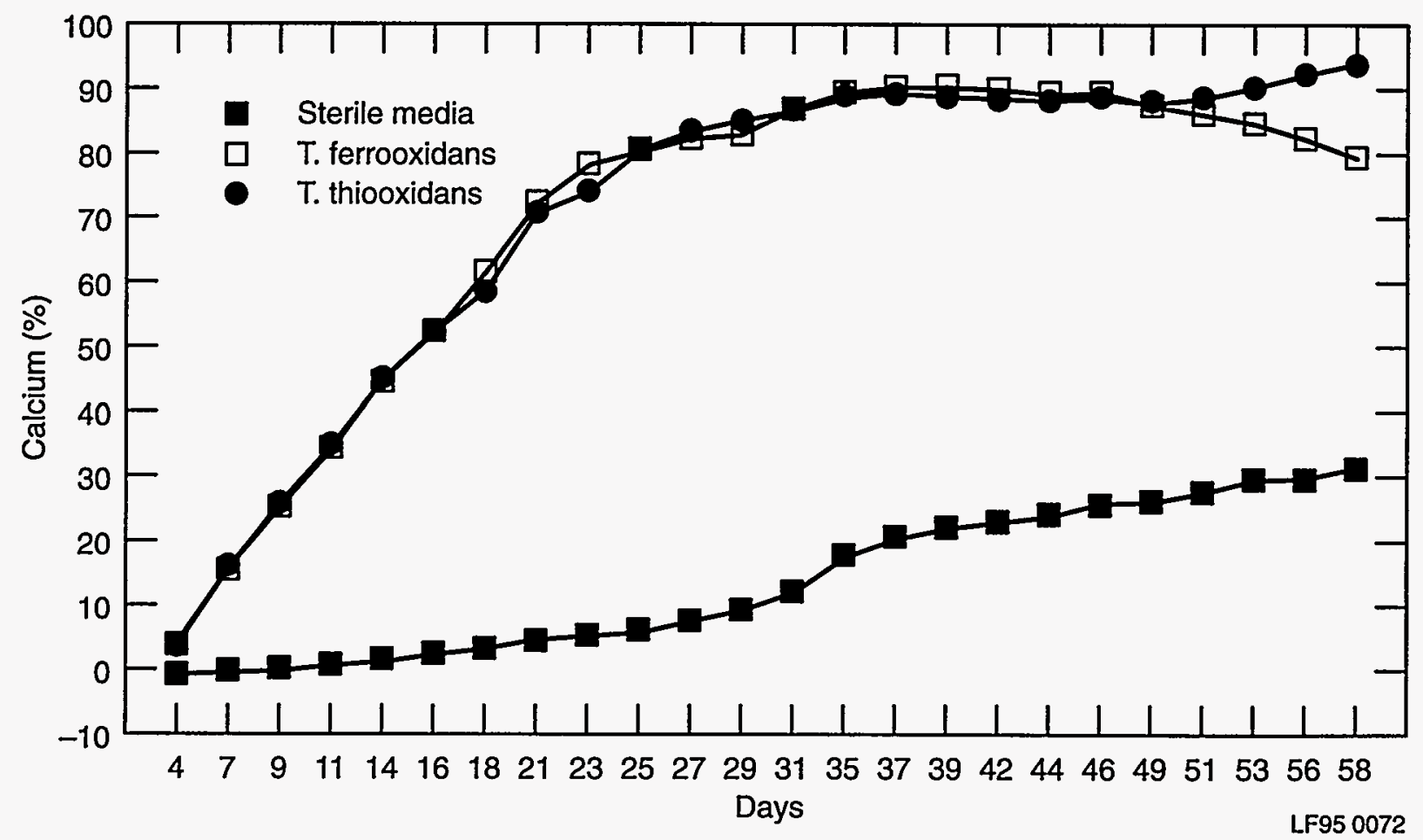

Figure 61. Cumulative quantities of Ca leached from vendor-supplied ion-exchange resin waste-form specimens during the intermittent-exposure study.

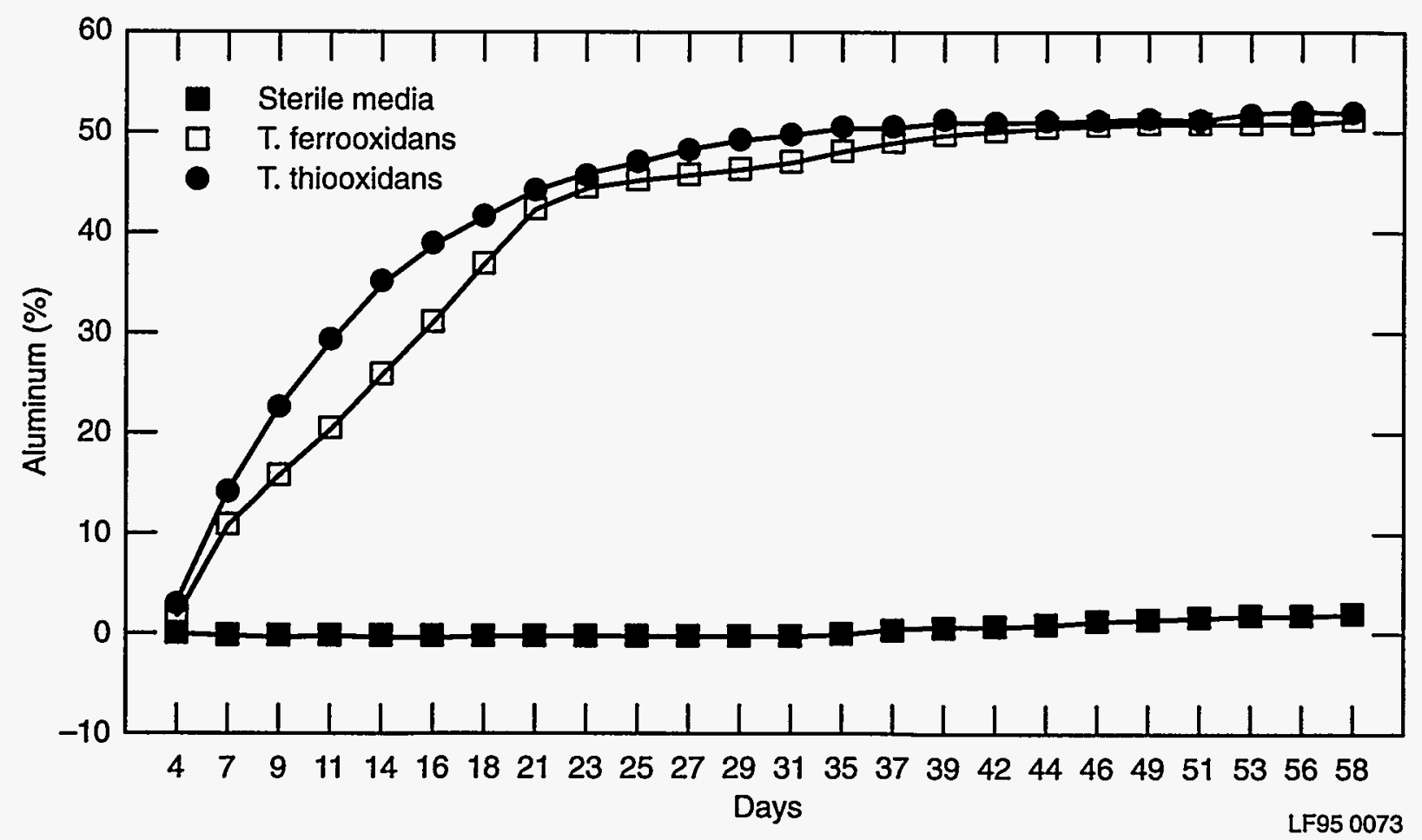

Figure 62. Cumulative quantities of $\mathrm{Al}$ leached from vendor-supplied ion-exchange resin waste-form specimens during the intermittent-exposure study. 
Experimental Results

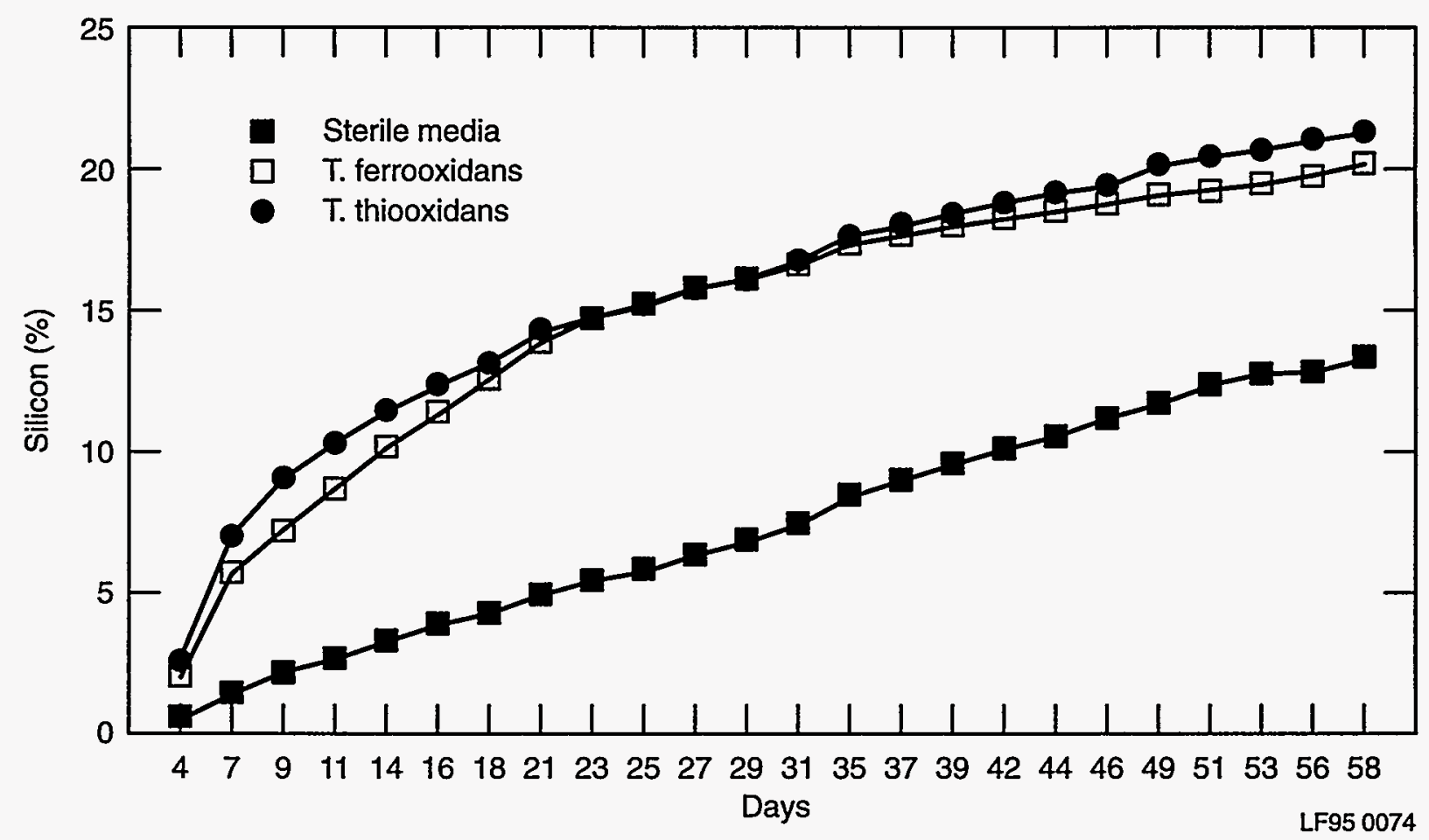

Figure 63. Cumulative quantities of Si leached from vendor-supplied ion-exchange resin waste-form specimens during the intermittent-exposure study.

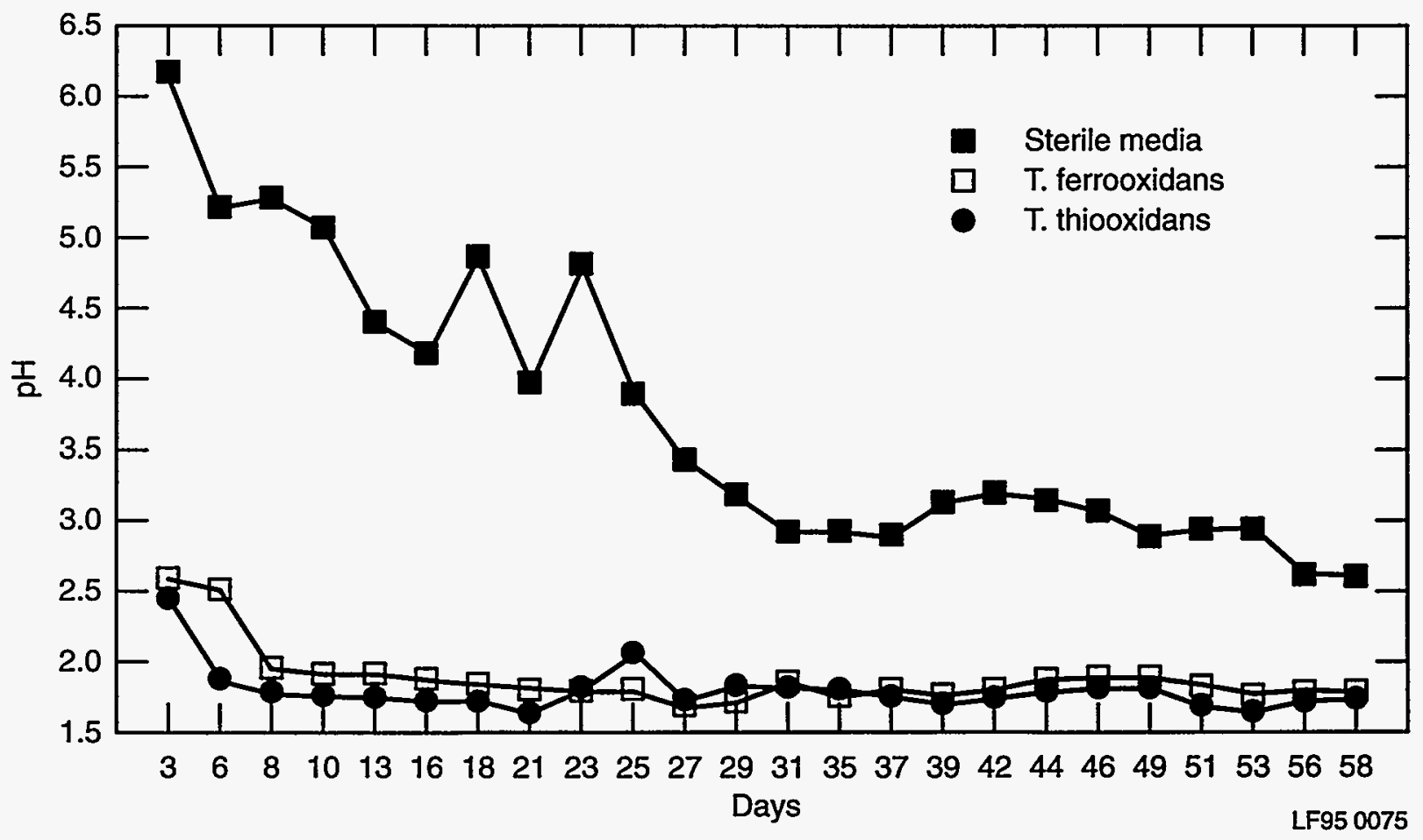

Figure 64. $\mathrm{pH}$ of lixiviants after exposure to vendor-supplied waste-form specimens during the intermittent-immersion study. 
Table 11. Surface pH of vendor-supplied waste-form specimens exposed to lixiviant during intermittent immersion.

\begin{tabular}{lcc}
\hline \multicolumn{1}{c}{ Treatment } & $\begin{array}{c}\text { Exchange resin } \\
(\mathrm{pH})\end{array}$ & $\begin{array}{c}\text { Evaporator bottoms } \\
(\mathrm{pH})\end{array}$ \\
\hline Untreated & 9 & 13 \\
Sterile medium & 5 & 4 \\
$T$. ferrooxidans & 4 & 3 \\
$T$. thiooxidans & 3 & 3 \\
\hline
\end{tabular}

Intermittent Misting. Intermittent misting was the third testing method evaluated. It was used to expose test specimens to a lixiviant mist. The design was such that liquid was drawn away from the waste-form specimens to prevent puddling. To accomplish this, exposed lixiviant (that comes in contact with specimens) was collected as it dripped from specimen surfaces. In this way, the specimen remained moist but was not at any time submersed in lixiviant.

The prototype for the misting chamber is seen in Figure 65. The body of the chamber was a 2.4-L plastic container. It came fitted with a sealtight, snap lid. The lid was modified to accommodate the motor (covered by the square perforated box shown in Figure 65) and misting generator from a "cool mist" vaporizer. Washed and sterilized glass marbles were placed in the container to reduce the volume of lixiviant necessary to maintain a requisite height. Their weight also acted to "anchor" in place a modified $100-\mathrm{mL}$ graduated cylinder (foreground; cut off at a height to allow collection of $60 \mathrm{~mL}$ of liquid). The cylinder shown in Figure 65 had a teflon pedestal placed into it to serve as a stage for placement of a simulated waste form (dark cylindrical object directly above the top of the graduated cylinder).

Two modifications were made to the prototype system before it was evaluated as a testing methodology. First, to help reduce differences due to treatment application, it was decided to use only one exposure chamber per lixiviant source. This was done so that a representative of each of the waste form types could be placed in the environment of the same chamber. Second, modified funnels were used as the physical support structure for the specimens (Figure 66). As mist collected on the specimens and eventually ran off, it was collected by the funnels into individual graduated cylinders.
Lixiviant was then recovered from the graduated cylinders by a permanently installed tube that was part of a continuous effluent withdrawal system. This system brought the effluent to collection flasks, and the contents of each collection flask were monitored daily.

The volume of lixiviant in the misting container was maintained at $300 \mathrm{~mL}$ by a continuous influent/effluent addition and withdrawal system for the main chamber and by the separate effluent systems from each of the three graduated cylinders. The misting unit was timed to operate for 5 out of every 15 minutes.

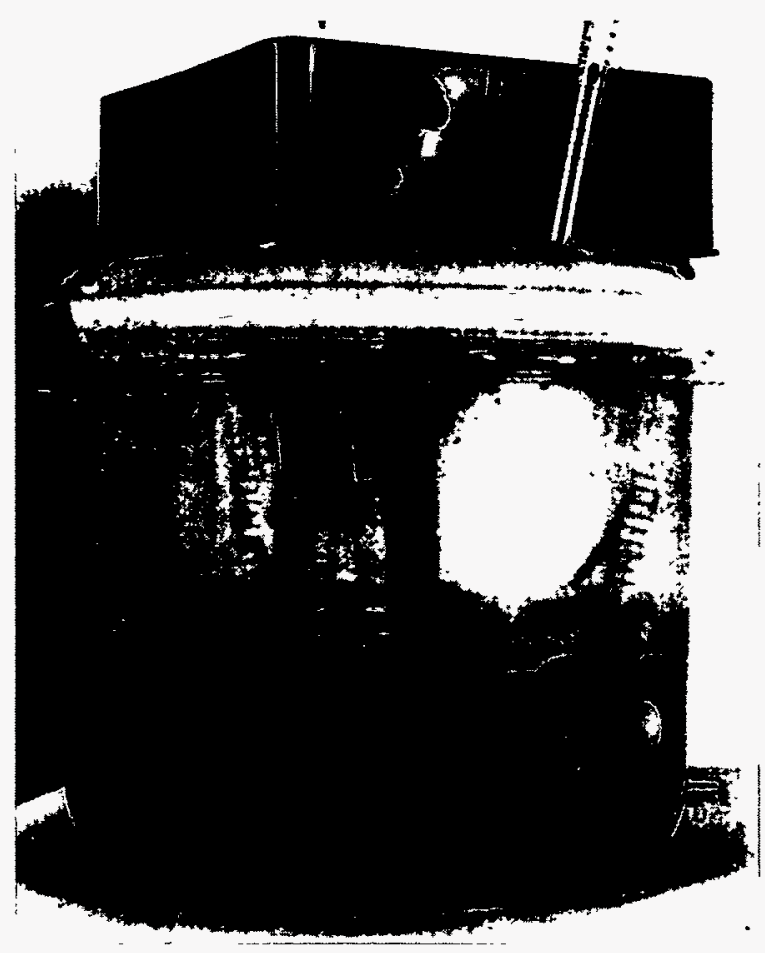

93-712-1-1

Figure 65. Prototype for intermittent-misting chamber. 


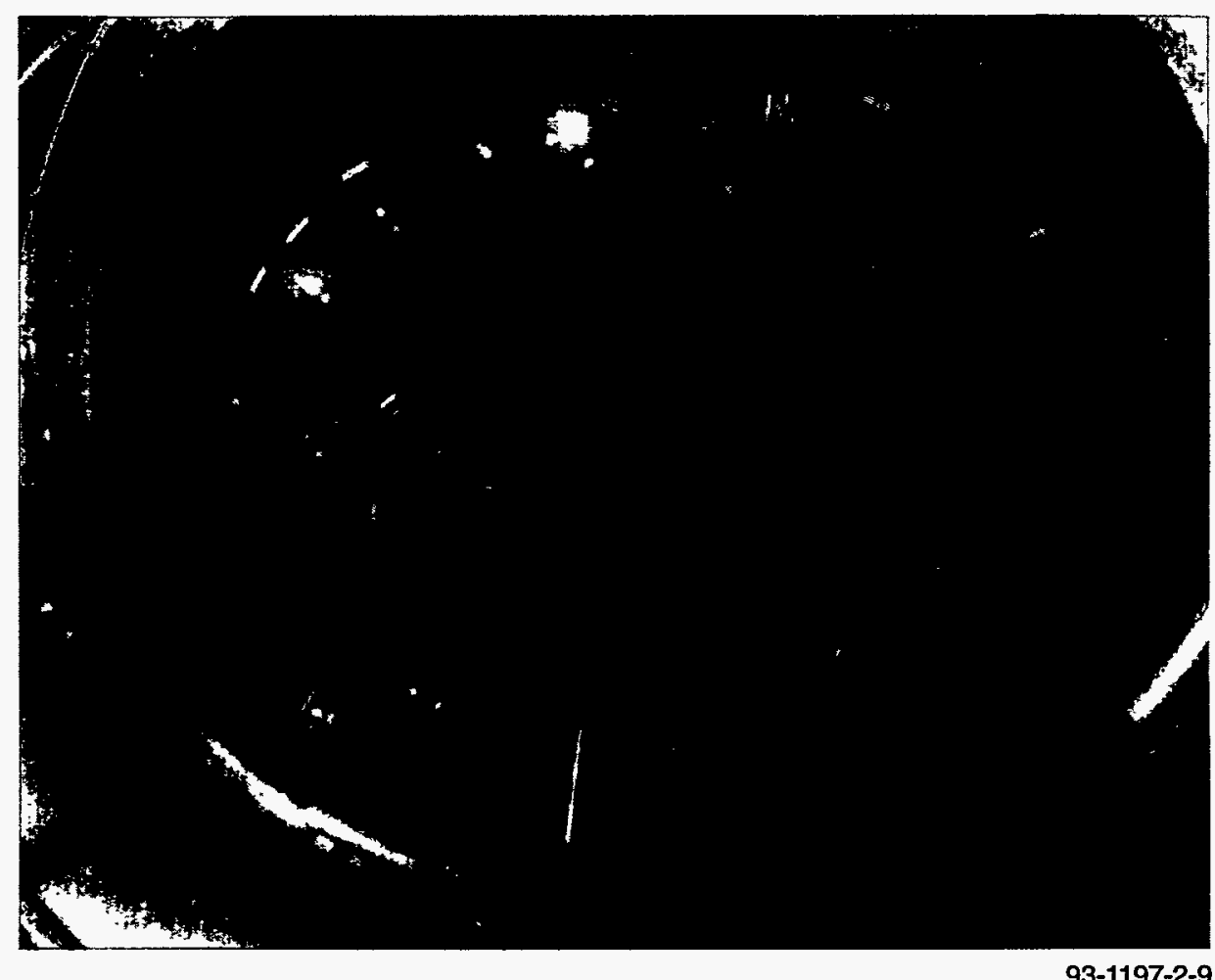

Figure 66. Waste-form specimen placement in misting chamber.

Specimens of the INEL-fabricated ASTM control, the vendor-furnished simulated evaporator bottoms (salts), and the ion-exchange resin waste form were exposed to mist generated from the $T$. ferrooxidans and the $T$. thiooxidans lixiviants and sterile growth medium. Lixiviant recovery was generally sporadic with an average range of 3 to $27 \mathrm{~mL}$ of effluent being collected from each graduated cylinder per day. Once collected, effluent from each treatment was analyzed for $\mathrm{pH}$ and the concentration of $\mathrm{Ca}, \mathrm{Al}$, and $\mathrm{Si}$. The duration of the intermittent misting test was 60 days. At the conclusion of the test, the surface $\mathrm{pH}$ of each specimen was determined. Then part of each specimen was prepared for examination by an ESEM.

The visual effect of MID on the vendor-supplied simulated waste-form specimens can be seen in Figures 67 through 69 . The surface $\mathrm{pH}$ of the specimens exposed to the lixiviant ranged from 2 to 4.5 (Table 12), while those exposed only to sterile medium were near pH 5. Figures 67a, 67b, and 67c show the ASTM control after exposure to sterile medium and the $T$. ferrooxidans and $T$. thiooxi- dans lixiviants, respectively. Figures 68 and 69 are arranged in the same sequence for the vendor-supplied simulated evaporator bottoms and ion-exchange resin specimens. As an overview, there appeared to be minimal visual effects for the ASTM control (Figure 67a) and evaporator bottoms (Figure 68a) specimens exposed only to sterile medium, while there was some deterioration of the ion-exchange resin specimen (Figure 69a). These effects were consistent with those seen for similar waste-form specimens used in the other two methods of exposure (intermittent and total immersion). While the ion-exchange resin specimen was eroded due to this treatment (Figure 69a), individual resin beads, as noted in previous work, still appeared to be firmly embedded in the cement matrix. Also comparable to past experience, ASTM specimens that were in contact with the two thiobacilli lixiviants had developed areas that were light (white) in color, which was indicative of $\mathrm{Ca}$ loss (Figures 67b and 67c). This effect was more prominent on the specimen exposed to $T$. thiooxidans (Figure 67c). Examination of the evaporator 


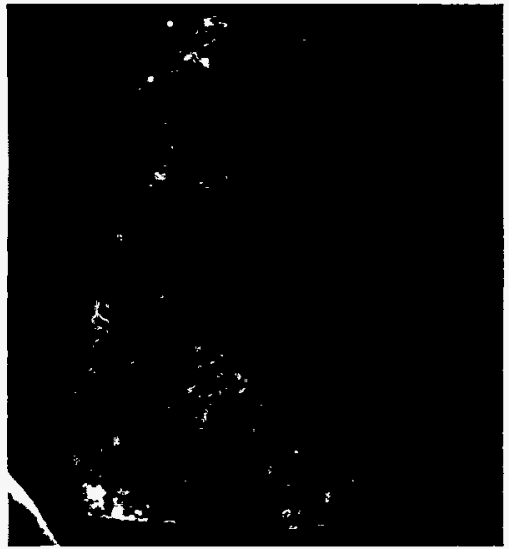

(a) $\quad 93-1197-1-10$

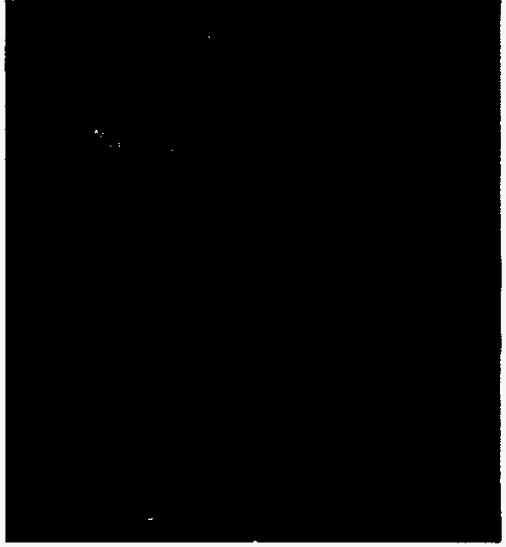

(b) 93-1197-1-18

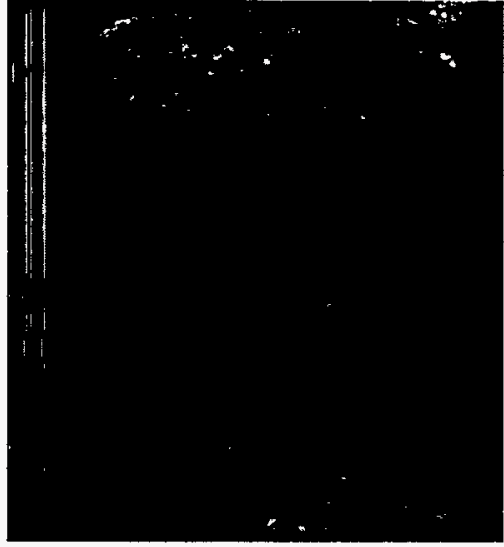

(c) $\quad 931197-1-4$

Figure 67. ASTM control waste-form specimens after being intermittently misted for 60 days with (a) sterile medium (b) $T$. ferrooxidans lixiviant (c) T. thiooxidans lixiviant.

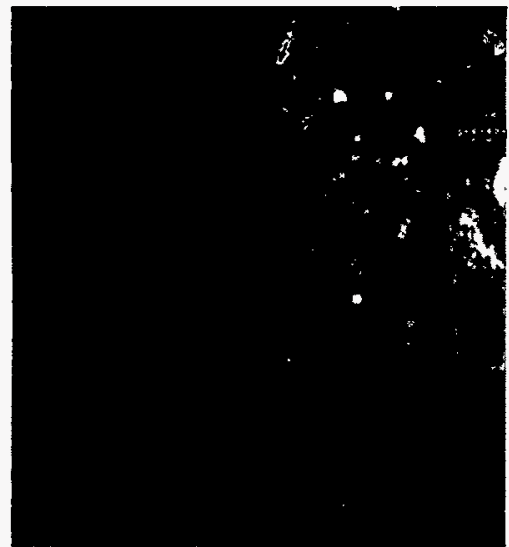

(a) 93-1197-1-12

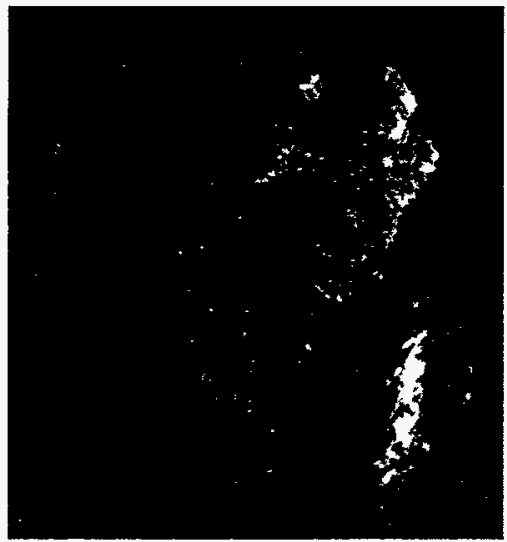

(b) $\quad 93-1197-1-17$

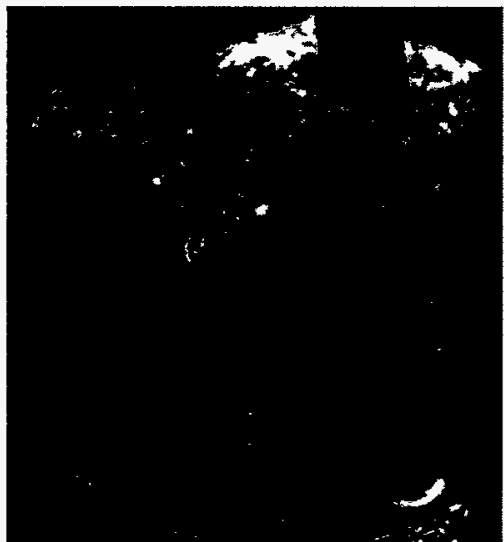

(c) $\quad 931197-1-6$

Figure 68. Vendor-supplied simulated evaporator bottoms waste-form specimens after being intermittently misted for 60 days with (a) sterile medium (b) $T$. ferrooxidans lixiviant (c) $T$. thiooxidans lixiviant.

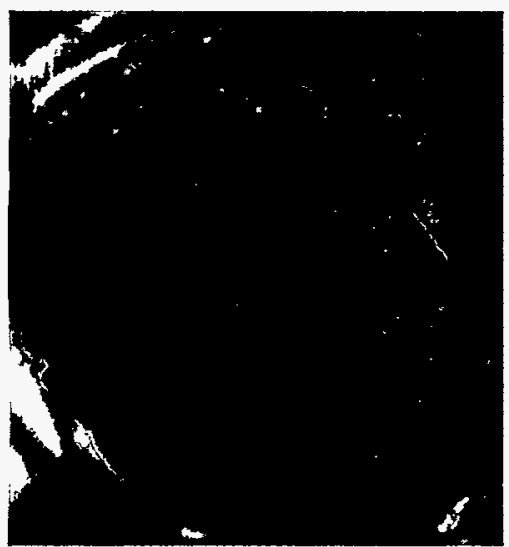

(a) $\quad 93-1197-1-11$

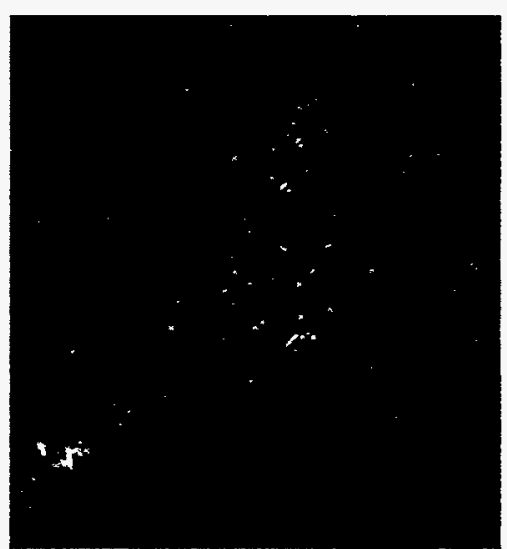

(b) 93-1197-1-19

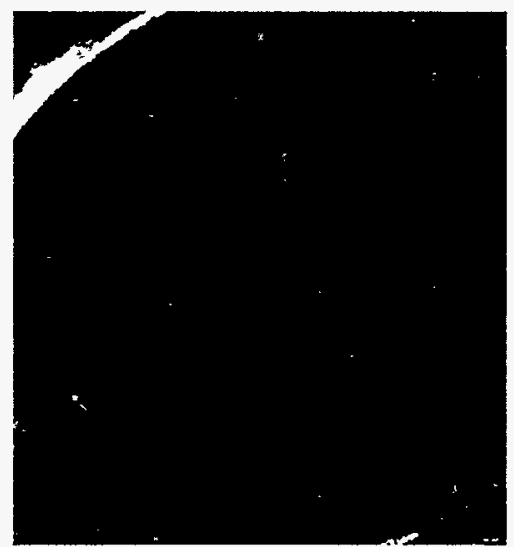

(c) $\quad 931197-1-8$

Figure 69. Vendor-supplied simulated ion-exchange resin waste-form specimens after being intermittently misted for 60 days with (a) sterile medium (b) $T$. ferrooxidans lixiviant (c) $T$. thiooxidans lixiviant. 
Table 12. Summary of data collected from waste-form specimens exposed to intermittent misting.

\begin{tabular}{llrlcccccr}
\hline $\begin{array}{c}\text { Waste } \\
\text { type }\end{array}$ & Treatment & $\begin{array}{c}\text { \% wt } \\
\text { loss }\end{array}$ & $\begin{array}{c}\text { Surface } \\
\mathrm{pH}\end{array}$ & $\begin{array}{c}\text { Bacterial } \\
\text { presence }\end{array}$ & $\begin{array}{c}\text { Visual } \\
\text { rating }\end{array}$ & $\begin{array}{c}\mathrm{Si} \\
(\% / \mathrm{mL})\end{array}$ & $\begin{array}{c}\mathrm{Ca} \\
(\% / \mathrm{mL})\end{array}$ & $\begin{array}{c}\text { Al } \\
(\% / \mathrm{mL})\end{array}$ & $\begin{array}{c}\text { Volume } \\
(\mathrm{mL})\end{array}$ \\
\hline ASTM & Medium & 8.43 & 5 & + & - & & 0.007 & & 1,339 \\
ASTM & T. ferro & 2.85 & 4.5 & + & + & & 0.007 & 694 \\
ASTM & T. thio & 7.13 & 2 & + & ++ & & 0.010 & & 1,068 \\
EB & Medium & 14.44 & 5.5 & + & - & 0.005 & 0.005 & 0.002 & 671 \\
EB & T. ferro & 23.47 & 3 & + & ++ & 0.004 & 0.010 & 0.009 & 1,647 \\
EB & T. thio & 16.33 & 4.5 & + & + & 0.002 & 0.006 & 0.003 & 1,154 \\
IER & Medium & 12.47 & 4.5 & - & + & 0.003 & 0.004 & 0.001 & 1,122 \\
IER & T. ferro & 21.16 & 3.5 & + & ++ & 0.005 & 0.020 & 0.008 & 784 \\
IER & T. thio & 10.15 & 4 & + & + & 0.009 & 0.025 & 0.009 & 181 \\
\\
EB = Evaporator bottoms.
\end{tabular}

bottoms specimens exposed to the lixiviants showed some evidence of swelling and the deposition of leached salts on the surface (Figures $68 \mathrm{~b}$ and $68 \mathrm{c}$ ). Margin definition on these wasteform specimens was not as distorted as that seen at the conclusion of other treatments. However, it would appear that they were in the initial stages of deterioration.

Physical damage to those ion-exchange resin specimens exposed to lixiviants was similar to that of the control exposed to the sterile medium (Figures 69b and 69c). However, it was significant that the treated specimens were beginning to loose their cement matrix as evidenced by the appearance of loose resin beads on the exposed surface. This is the same phenomenon seen with these waste forms when they were exposed to the other two treatments.

Results obtained from the exposure of the ASTM control and vendor-supplied simulated waste-form specimens to sterile medium and lixiviants are summarized in Table 12. This table displays the data from a variety of sources including physical, chemical, and microbial examination and analysis. A discussion of the data in Table 12 follows. In general, the effects of the intermittent misting treatment were not as pronounced as those from the other two preceding treatments. Undoubtedly, this could be attributed to the quantity of lixiviant that the waste-form specimens were exposed to during the misting procedure. After 60 days of exposure, the maximum quantity of lixiviant collected from the misting treatment was only one-sixth of that experienced in the two other test procedures $(\sim 1,000 \mathrm{~mL}$ versus $\sim 6,000$ $\mathrm{mL}$ ). In addition, it can also be seen that lixiviant exposure for the various specimens was not uniform in the misting chambers. The variability in exposure is particularly noticeable with the ionexchange specimens (range of $181 \mathrm{~mL}$ for $\mathrm{T}$. thiooxidans treatment to $1,122 \mathrm{~mL}$ for medium treatment). These data suggest why more physical damage was not seen on the treated samples (Figure 69). It appeared that the difference in lixiviant application was due to the exposure pattern of mist in the chambers.

Due to the irregularity of lixiviant deposition and subsequent recovery, it appeared advisable to normalize the loss of $\mathrm{Si}, \mathrm{Ca}$, and $\mathrm{Al}$ as percents per milliliter of collected lixiviant rather than presenting a cumulative total. When this is done, the effect of the individual treatments becomes evident (Table 12). For $\mathrm{Ca}$, it is seen in every case that the 
waste-form specimens exposed to the lixiviant treatments had a greater loss per $\mathrm{mL}$ than did the sterile controls. These data are consistent with those discussed previously in conjunction with the specimens' physical appearance. Also, the $\mathrm{Al}$ leaching from the vendor-supplied simulated waste-form specimens was increased by the lixiviant treatment. The same is true for Si loss from the ion-exchange resin waste-form specimens, but somewhat confused for the evaporator bottoms specimens. With the evaporator bottoms, the loss did not coincide with the quantity of leachate. However, based on the overall data, it was concluded that biological activity was having a deleterious effect on the treated waste-form specimens.

The percent weight loss from the waste-form specimens usually appeared to correlate with the total volume of effluent that contacted the specimens. The exception, however, was the ion-exchange resin waste-form specimen exposed to $T$. ferrooxidans lixiviant. These data appear reasonable since this specimen was beginning to deteriorate (Figure $68 \mathrm{~b}$ ).

Another aspect pursued in the examination of the subject waste forms was to determine if thiobacilli were present on the waste form surfaces.

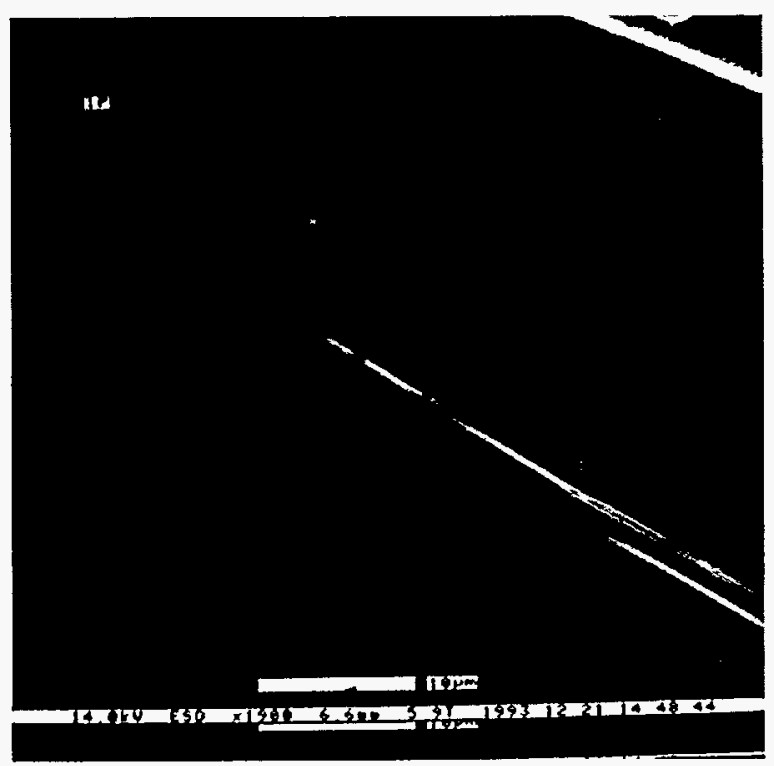

(a)
When scrapings from each of the waste-form specimens were incubated in the appropriate medium, all were positive for the presence of thiobacilli, except the ion-exchange resin specimen exposed to sterile medium. That meant that the specimens of evaporator bottoms and ASTM controls exposed to sterile medium had become contaminated with bacteria that were growing on the specimen surfaces. To confirm this finding, fragments of each waste-form specimen were submitted for ESEM analysis. This examination complemented the microbial isolation work. It showed what appeared to be a biofilm formation on the evaporator bottoms and ion-exchange resin waste-form specimens, including the evaporator bottoms specimen exposed to sterile medium (Figures 70 through 72). The same formation was not seen on fragments of the other waste-form specimens. In Figures 70a, 71, and 72, the biofilm appears as grape-like clumps. The view presented in Figure $70 \mathrm{~b}$ is probably the same physically dimensioned material, which has become dehydrated. The data demonstrate that microorganisms were colonizing the surface of the waste-form specimens. Consequently, staining with alcian blue and acridine orange was not performed on these specimens.

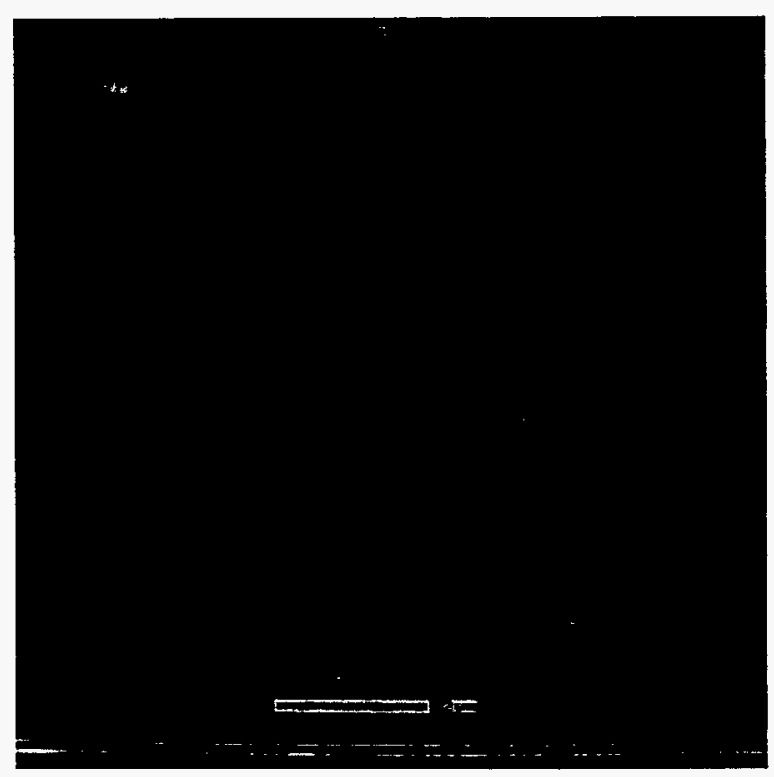

(b)

Figure 70. ESEM photograph of vendor-supplied simulated evaporator bottoms waste-form specimens after exposure to (a) $T$. ferrooxidans (b) $T$. thiooxidans. 


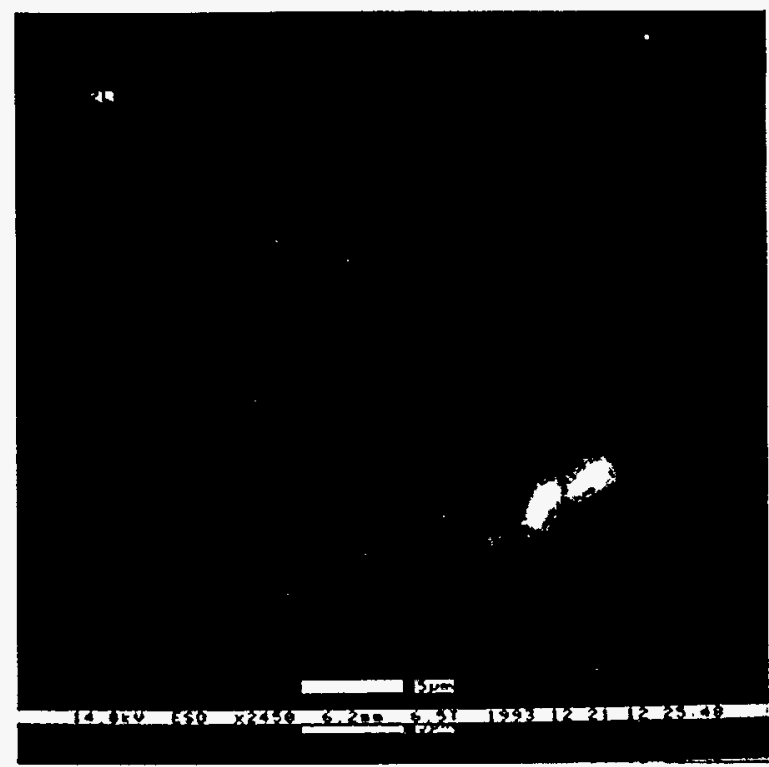

Figure 71. ESEM photograph of vendorsupplied simulated ion-exchange resin wasteform specimen after exposure to $T$. thiooxidans.

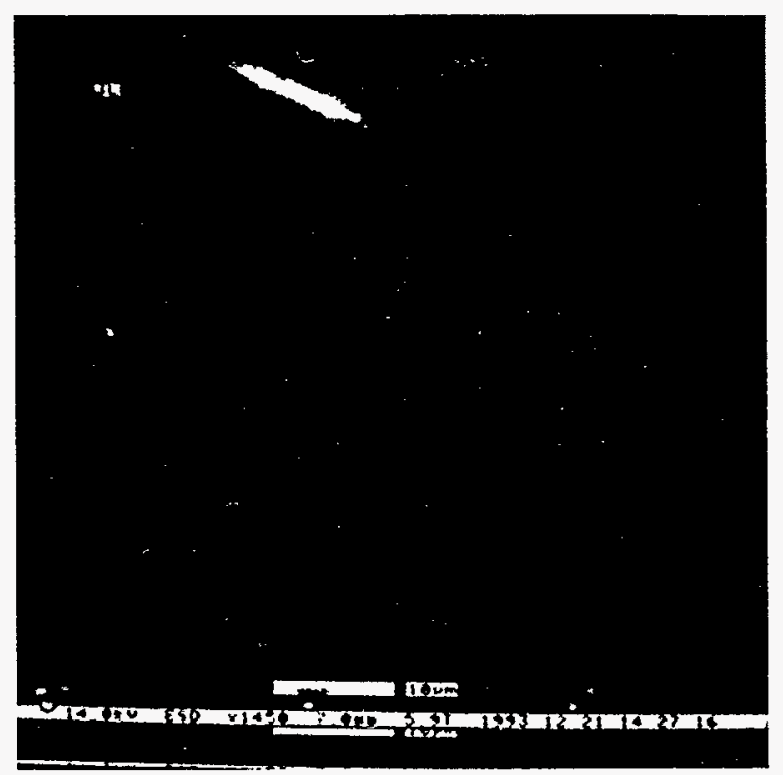

Figure 72. ESEM photograph of vendorsupplied simulated ion-exchange resin wasteform specimen after exposure to sterile medium.

\section{Testing of Actual Waste Forms}

Based on the stability of operational conditions and the consistency of data, the intermittent immersion exposure system was selected for testing of actual LLW. This selection was made because, under present operating conditions, the intermittent immersion system was less likely to have loss of lixiviant through leakage or spills, and therefore was considered more effective in controlling the spread of solubilized radioactive contaminants. Also, because the actual radioactive waste forms represented a new, untested material, it was suggested that conservative test conditions be used. For this reason, the test was conducted for 60 days and thiobacilli was used. Based on our data, both species of thiobacilli were appropriate; however, T. thiooxidans was selected because it was the microorganism most often cited in the literature as being associated with MID of cement.

For this work, the method employed was similar to the one used for intermittent immersion of simulated waste-form specimens using $T$. thiooxidans (Rogers et al. 1995). The test procedure is given in Appendix A. Specimens used in this study were taken from two varieties of actual cement-solidified low-level waste forms $(5.1 \mathrm{~cm}$ $\times 10.2 \mathrm{~cm}$ ) made from power reactor wastes. One contained ion-exchange resin waste from Peach Bottom Atomic Power Station Unit 3, and the other contained filter sludge from Nine Mile Point Nuclear Plant Unit 1 (see Table 13 for waste stream analysis). In addition to these waste forms, an ASTM standard cement formulation (the same as used in all other studies) was used for comparison purposes. All treatments were replicated.

This test differed from total immersion in that test specimens were fully immersed in the respective treatment liquid for only 6 hours out of every 12 hours. This was accomplished by using six 125-mL Soxhlet extraction columns (Figure 73). Each specimen was placed on top of a plastic pedestal inside an individual Soxhlet column. The filling of the columns with sterile media and lixiviant was controlled by the rate of the pumped influent flow. It required 6 hours for a specimen to become immersed. After the liquid level rose to a predetermined height, the column was emptied into a collection flask by activation of a syphon. Approximately $100 \mathrm{~mL}$ of liquid passed through each column per day. Effluent from each Soxhlet was collected over a period of 24 hours. A 
Table 13. Peach Bottom and Nine Mile Point waste stream analysis.

\begin{tabular}{|c|c|c|}
\hline $\begin{array}{l}\text { Radionuclide } \\
\text { (m) }\end{array}$ & $\begin{array}{l}\text { Peach Bottom resin } \\
(\mu \mathrm{Ci} / \mathrm{g} \text { on } 10 / 24 / 89)\end{array}$ & $\begin{array}{l}\text { Nine Mile Point sludge } \\
(\mu \mathrm{Ci} / \mathrm{g} \text { on } 3 / 14 / 91)\end{array}$ \\
\hline $\mathrm{Mn}-54$ & $4.35 \mathrm{E}-2 \pm 2.66 \mathrm{E}-3$ & $7.16 \mathrm{E}-3 \pm 6.67 \mathrm{~W}-5$ \\
\hline $\mathrm{Fe}-55$ & $1.35 \mathrm{E}+0 \pm 5.53 \mathrm{E}-2$ & $4.50 \mathrm{E}-4 \pm 8 \mathrm{E}-6$ \\
\hline $\mathrm{Co}-58$ & --- & $2.65 \mathrm{E}-3 \pm 2.20 \mathrm{E}-4$ \\
\hline Co-60 & $4.64 \mathrm{E}+0 \pm 1.16 \mathrm{E}-2$ & $4.59 \mathrm{E}-1 \pm 1.33 \mathrm{E}-3$ \\
\hline $\mathrm{Ni}-63$ & $7.62 \mathrm{E}-2 \pm 6.85 \mathrm{E}-3$ & $9.40 \mathrm{E}-2 \pm 5 \mathrm{E}-3$ \\
\hline $\mathrm{Zn}-65$ & $5.92 \mathrm{E}-1 \pm 1.13 \mathrm{E}-2$ & --- \\
\hline Sb-125 & $1.73 \mathrm{E}-2 \pm 9.66 \mathrm{E}-4$ & $3.66 \mathrm{E}-3 \pm 3.84 \mathrm{E}-5$ \\
\hline Cs-134 & --- & $3.46 \mathrm{E}-3 \pm 3.03 \mathrm{E}-5$ \\
\hline Cs-137 & $3.53 \mathrm{E}-3 \pm 5.15 \mathrm{E}-4$ & $4.20 \mathrm{E}-1 \pm 1.92 \mathrm{E}-3$ \\
\hline Eu-154 & --- & $2.15 \mathrm{E}-4 \pm 2.08 \mathrm{E}-5$ \\
\hline Sr-89 & --- & $4.03 \mathrm{E}-2 \pm 3.67 \mathrm{E}-3$ \\
\hline Sr-90 & $2.16 \mathrm{E}-5 \pm 2.3 \mathrm{E}-6$ & $3.03 \mathrm{E}-3 \pm 2 \mathrm{E}-4$ \\
\hline $\mathrm{Pu}-238$ & $6.61 \mathrm{E}-5 \pm 1.66 \mathrm{E}-6$ & $<1.0 \mathrm{E}-7$ \\
\hline $\mathrm{Pu}-239$ & $2.17 \mathrm{E}-5 \pm 7.50 \mathrm{E}-7$ & $<1.0 \mathrm{E}-7$ \\
\hline $\mathrm{Pu}-241$ & $1.75 \mathrm{E}-2 \pm 4.24 \mathrm{E}-4$ & $<1.0 \mathrm{E}-7$ \\
\hline Am-241 & $5.18 \mathrm{e}-5 \pm 1.40 \mathrm{E}-6$ & $<1.0 \mathrm{E}-7$ \\
\hline $\mathrm{Cm}-242$ & $9.46 \mathrm{E}-6 \pm 9.43 \mathrm{E}-7$ & $<1.0 \mathrm{E}-7$ \\
\hline $\mathrm{Cm}-244$ & $1.30 \mathrm{E}-4 \pm 1.59 \mathrm{E}-4$ & $<1.0 \mathrm{E}-7$ \\
\hline C-14 & $8.74 \mathrm{E}+0 \pm 8.7 \mathrm{E}-2$ & $1.05 \mathrm{E}+0 \pm 1.1 \mathrm{E}-1$ \\
\hline Tc-99 & $3.71 \mathrm{E}-2 \pm 8.61 \mathrm{E}-4$ & $8.11 \mathrm{E}-3 \pm 1.63 \mathrm{E}-4$ \\
\hline $\mathrm{I}-129$ & $<5 \mathrm{E}-6$ & $<5 \mathrm{E}-6$ \\
\hline Chromium $^{\mathrm{a}}$ & $650 \mathrm{ppm} \pm 20 \mathrm{ppm}$ & $64 \mathrm{ppm} \pm 66 \mathrm{ppm}$ \\
\hline Iron $^{\mathrm{a}}$ & $3,000 \mathrm{ppm} \pm 160 \mathrm{ppm}$ & $2,430 \mathrm{ppm} \pm 130 \mathrm{ppm}$ \\
\hline Zinc $^{a}$ & $158 \mathrm{ppm} \pm 12 \mathrm{ppm}$ & $98 \mathrm{ppm} \pm 42 \mathrm{ppm}$ \\
\hline Nickel $^{\mathrm{a}}$ & $730 \mathrm{ppm} \pm 30 \mathrm{ppm}$ & $20 \mathrm{ppm} \pm 4 \mathrm{ppm}$ \\
\hline Borate $b$ & $\cdots$ & $9 \mathrm{ppm} \pm 4 \mathrm{ppm}$ \\
\hline Phosphate ${ }^{b}$ & ---- & None detected \\
\hline Sulfate ${ }^{b}$ & $-\cdots$ & $18.4 \mathrm{ppm} \pm 1.8 \mathrm{ppm}$ \\
\hline Picolinic acidc & $<5 E-6$ & $-\cdots$ \\
\hline
\end{tabular}

a. Analyses were performed using inductively coupled plasma spectroscopy elemental analysis methods.

b. Analyses were performed using ion chromatography.

c. Analysis was performed using picolinic acid titration. 


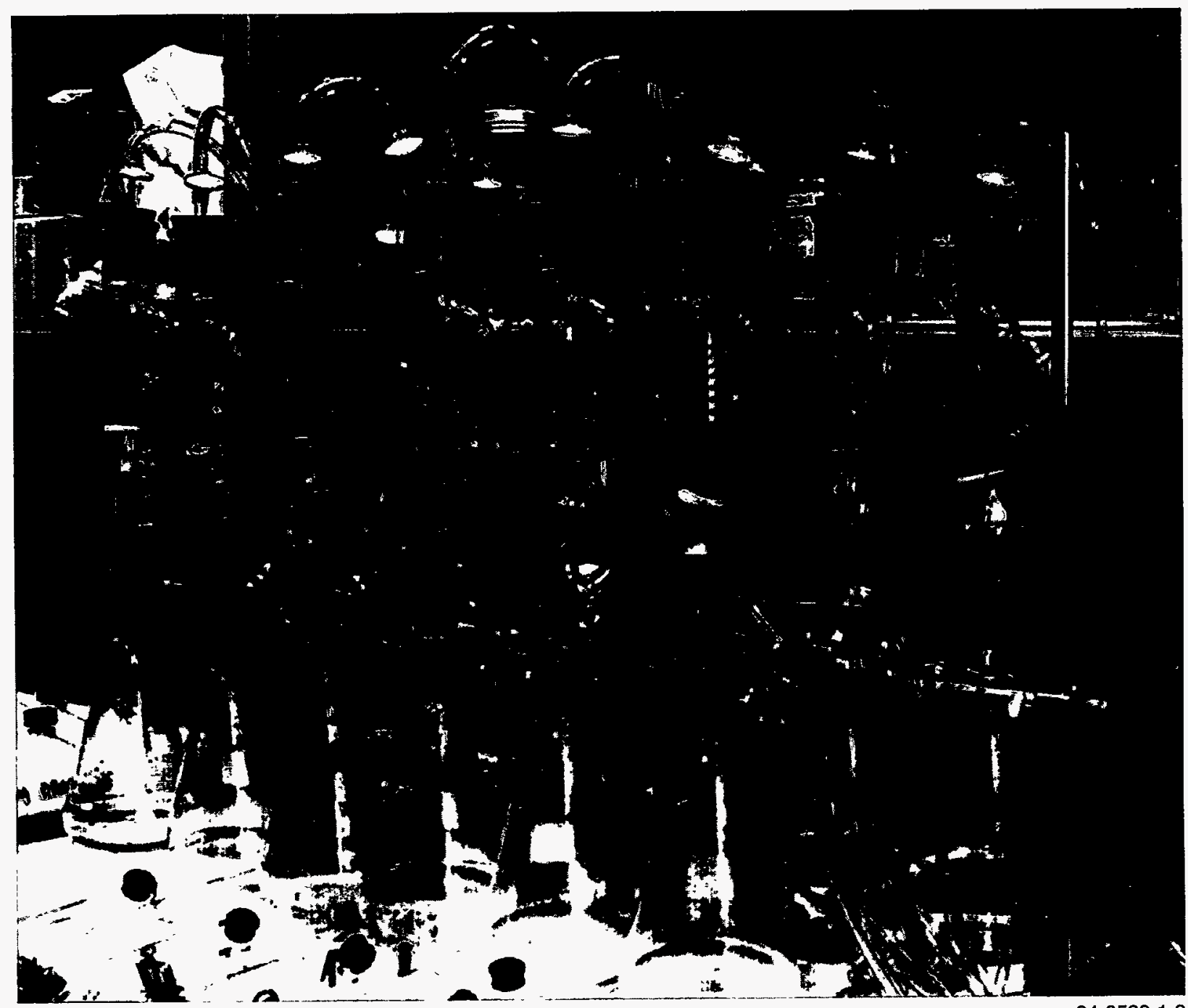

Figure 73. Setup for intermittent-immersion testing of actual vendor-supplied waste-form specimens.

subsample of this effluent was obtained each day from a sampling port installed on the collection flask connected to each individual Soxhlet. Portions of these individual, daily samples were combined with previous samples from the same source to make two sets of composite samples. Effluent not used for the composite samples was discarded. The first composite consisted of samples collected over a period of 7 days. The second composite was made up of samplespecific, individual daily samples that were collected over the entire period of the study ( 60 days). All samples were stored in glass bottles to await radiochemical analysis.
The weekly composites were analyzed for gross beta- and gamma-emitting isotopes. Those of the 60-day composite were analyzed specifically for Sr-90, Tc-99, and C-14. The sample collection is detailed in Appendix A. None of the specimens were examined for the presence of EPS or bacteria. Also, no nonradiochemical analyses ( $\mathrm{Ca}, \mathrm{Al}$, etc.) were conducted on the lixiviant from these specimens. However, $\mathrm{Ca}$ concentration in the effluent from the ASTM specimens was determined. The specimens were photographed midway through the test (days 20 and 30 ) and at the conclusion (60 days). Evaluation criteria are discussed in Appendix B. 
The physical effect of MID on the radioactive waste-form specimens can be seen in Figures 74 through 79. Figures 74 a through 74 f show the ASTM control specimens after exposure to sterile medium for 20, 30, and 60 days, while Figures 75a through 75f show the ASTM control specimens after exposure to $T$. thiooxidans lixiviant for 20,30 , and 60 days. Figures 76 through 79 are arranged in the same sequence for the Peach Bottom (PB) and Nine Mile Point (NMP) waste-form specimens. As can be seen, there is a gradation of effects for those specimens exposed only to sterile medium (Figures 74, 76, and 78). Medium exposure had no visible effect on the ASTM control specimens (Figure 74), while there was minor swelling of the NMP specimens (the waste form shape is still well defined) (Figure 78). Unlike studies with other waste forms containing ionexchange resin, the PB specimens were not totally disintegrated, and the exposed individual resin beads appeared to be firmly embedded in the cement matrix (Figure 76). The ASTM specimens that were in contact with the thiobacilli lixiviant were light (white) in color, indicating that extensive leaching of $\mathrm{Ca}$ had taken place (Figure 75). The NMP evaporator bottoms specimens exposed to the lixiviants gradually crumbled, and material loss was evident (Figure 79). Physical damage was also seen in the PB ion-exchange resin specimens exposed to lixiviant (Figure 77). As discussed previously (Rogers et al. 1995), these specimens lost their cement matrix as indicated by the appearance of loose resin beads.

A comparison between the waste forms before and after exposure to the sterile medium and thiobacilli lixiviant can be seen in Figures 80 and 81 for PB and NMP materials, respectively. Figures $80 \mathrm{a}$ and $81 \mathrm{a}$ show unexposed $\mathrm{PB}$ and NMP specimens. They appear to have well-defined margins and smooth surfaces, and where resin beads are evident ( $P B$ sample), they are firmly imbedded in the waste form matrix. It was found that specimens of both waste form types exposed to the sterile medium retained their physical integrity during the duration of the study. It was noted that the PB specimens appeared to have some exposure of their ion-exchange resin beads (Figures $80 \mathrm{~b}$ and $80 \mathrm{c}$ ), but the NMP speci- mens did not appear to be physically degraded in any way (Figures $81 \mathrm{~b}$ and $81 \mathrm{c}$ ). In general, both types of specimens were lighter in color than the originals, suggesting some leaching action. In sharp contrast, the specimens that were exposed to the lixiviant had even more extensive damage than was noticed before they were removed from the Soxhlet columns. The PB specimens crumbled, with evidence of unattached resin beads (Figures $80 \mathrm{~d}$ and $80 \mathrm{e}$ ), while the NMP specimens were completely disintegrated (Figures $81 \mathrm{~d}$ and $81 \mathrm{e}$ ).

In general, when effluent from the power reactor samples was analyzed for the presence of gross beta- and gamma-emitting nuclides, the $\mathrm{PB}$ effluents were found to have Co-60 and Cs-137, while those effluents from the NMP samples contained these nuclides and Cs-134. In addition, $\mathrm{C}-14$, Tc-99, and Sr-90 were found in the composited effluents from both waste form types. Total quantities of leached nuclides are tabulated in Tables 14, 15, and 16. The data show that the waste forms exposed to the thiobacilli lixiviant had a greater loss of Cs-137, Cs-134, Co-60, C-14, Tc-99, and Sr-90 than did the mediumtreated controls (Tables 14, 15, and 16).

The quantity of Co-60 lost from both wasteform specimen types exposed to the thiobacilli lixiviant was an order of magnitude greater than that of the sterile medium treatment (Tables 14 and 15). Comparable amounts of Co-60 ( 1 to 3 million $\mathrm{pCi}$ ) were released from both types of specimens, although the quantity recovered from the PB specimens was about twice that of the NMP types. Further, the data show that there was a considerable release (over 3 million $\mathrm{pCi}$ ) of Cs-137 from the NMP specimens. This release appeared to be independent of treatment type, although the thiobacilli treatment did have nearly a $10 \%$ greater release. The same was also true for Cs-134, although the difference between treatment and control appear indistinguishable. On the other hand, the quantity of Cs-137 leached from the PB specimens was not as consistent. Total Cs-137 removed from the duplicated PB samples due to the thiobacilli lixiviant was 51,196 and $25,000 \mathrm{pCi}$, while that of the medium was 18,849 and $36,035 \mathrm{pCi}$ (Table 14). However, when these 


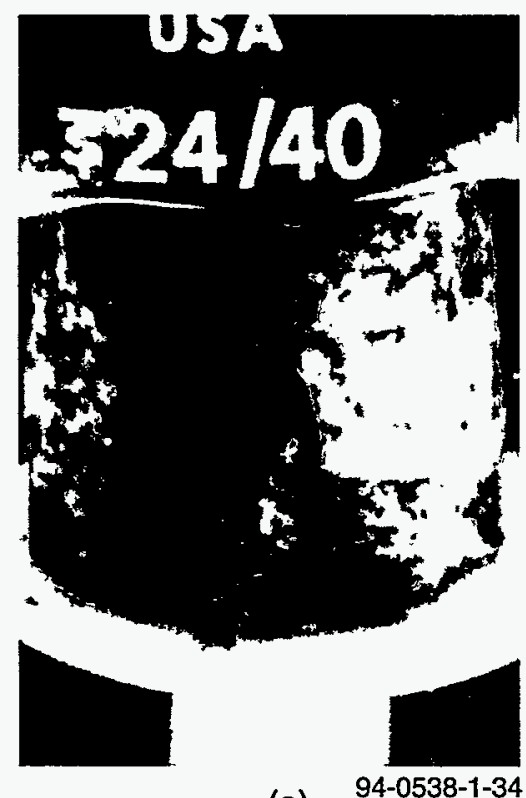

(a)

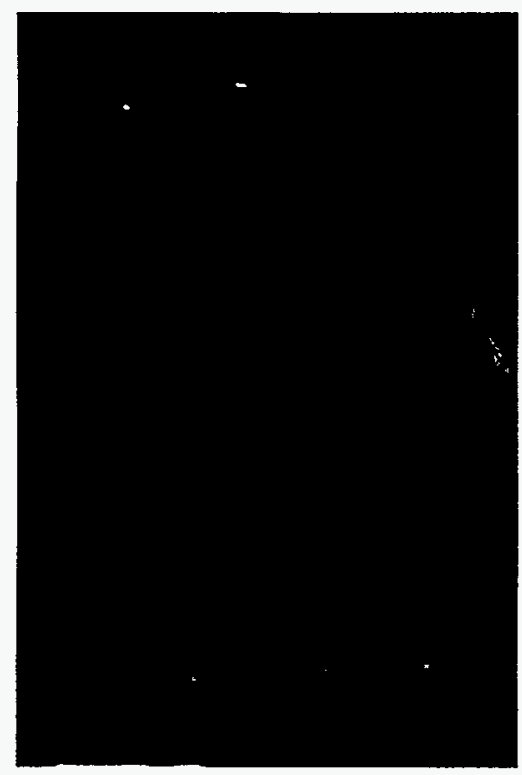

(d)

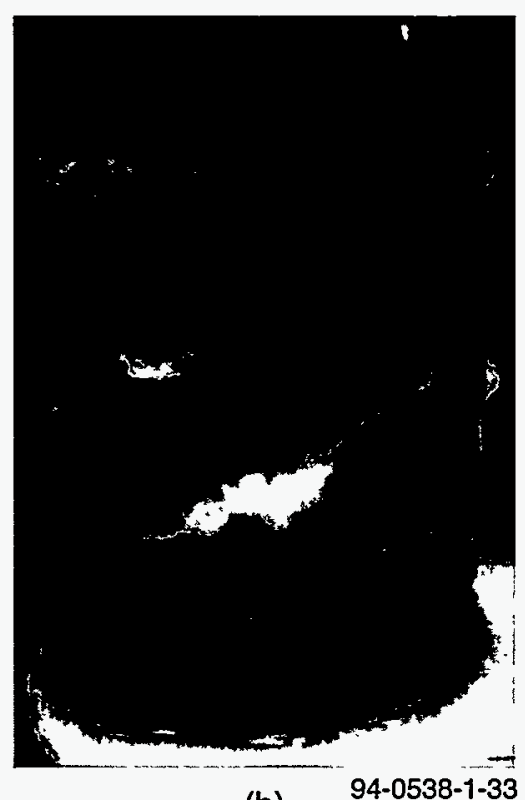

(b)

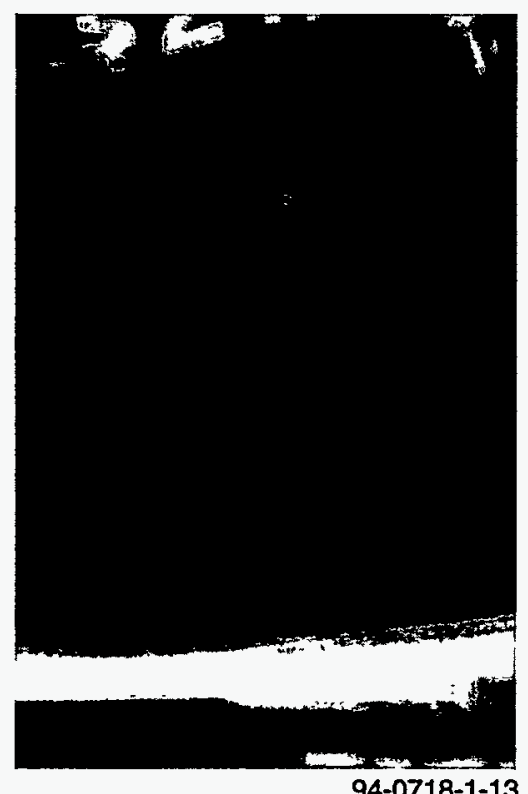

(e)

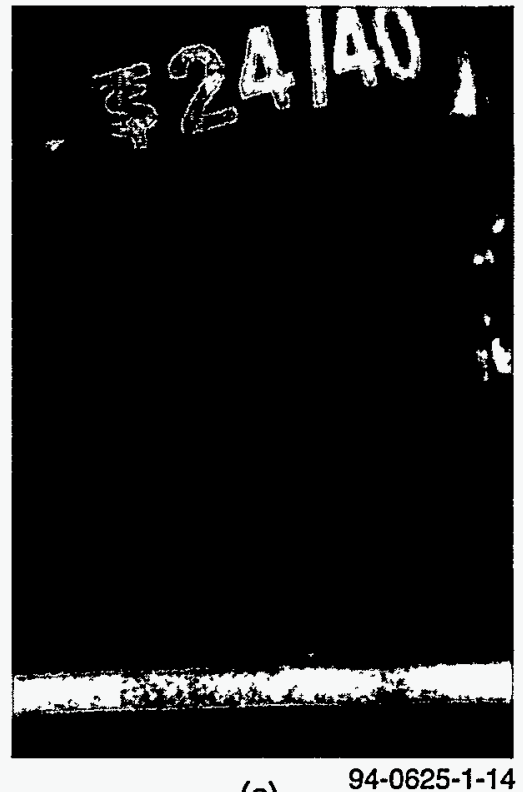

(c)

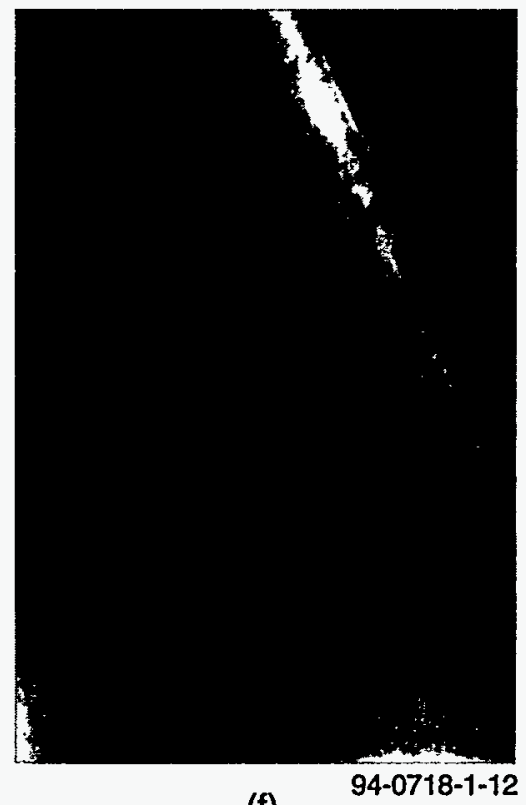

(f)

Figure 74. ASTM control waste-form specimens exposed over time to sterile medium (a) ASTM duplicate 1 at day 20 (b) ASTM duplicate 2 at day 20 (c) ASTM duplicate 1 at day 30 (d) ASTM duplicate 2 at day 30 (e) ASTM duplicate 1 at day 60 (f) ASTM duplicate 2 at day 60. 


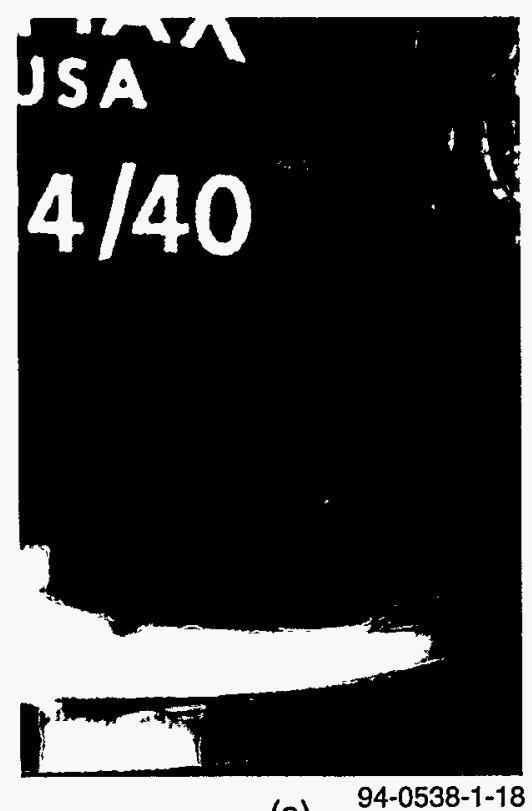

(a)

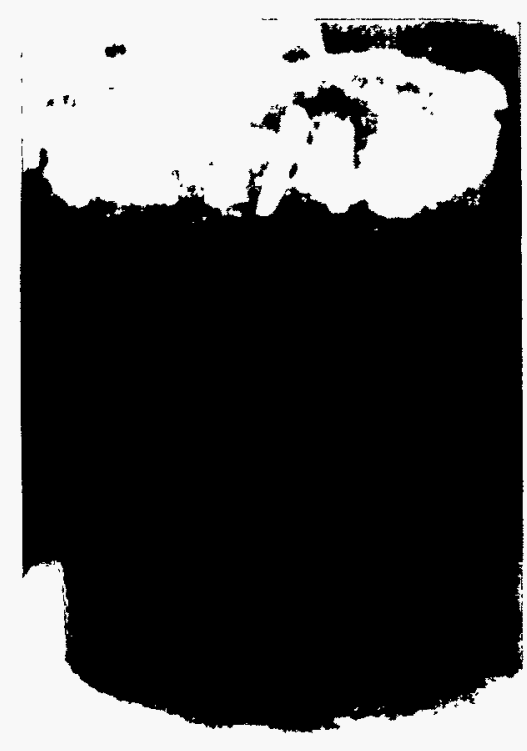

(d)

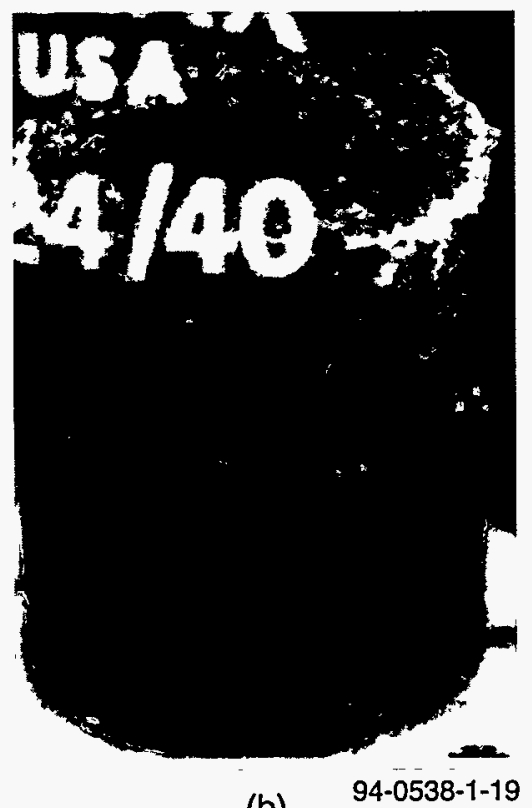

(b)

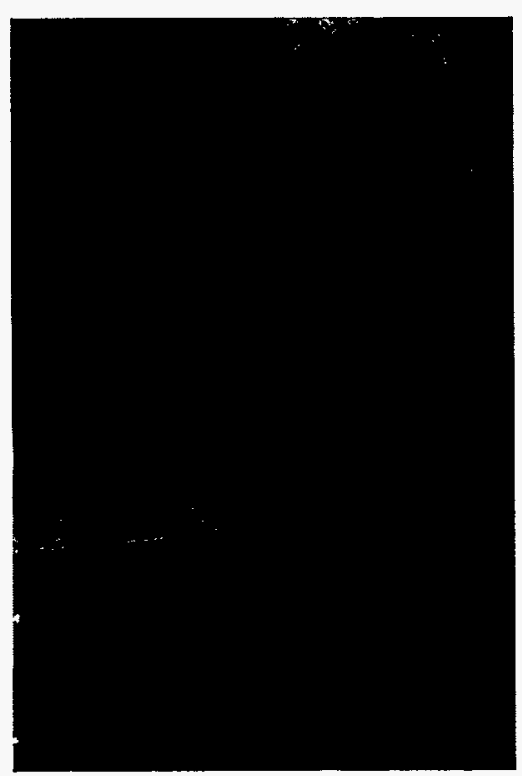

(e)
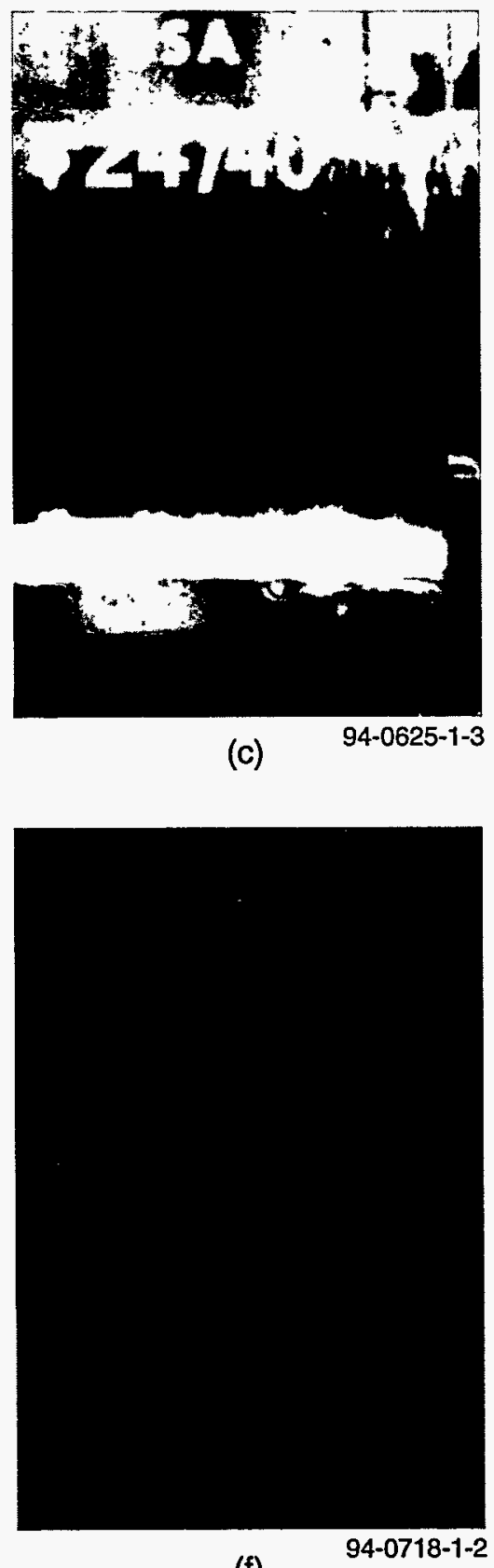

(f)

Figure 75. ASTM control waste-form specimens exposed over time to thiobacilli lixiviant (a) ASTM duplicate 1 at day 20 (b) ASTM duplicate 2 at day 20 (c) ASTM duplicate 1 at day 30 (d) ASTM duplicate 2 at day 30 (e) ASTM duplicate 1 at day 60 (f) ASTM duplicate 2 at day 60 . 
Experimental Results

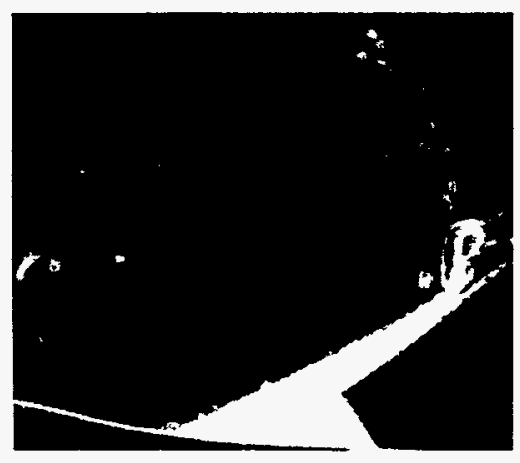

(a)

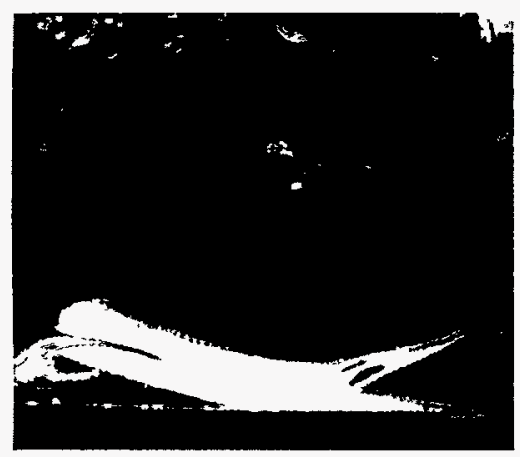

(d)

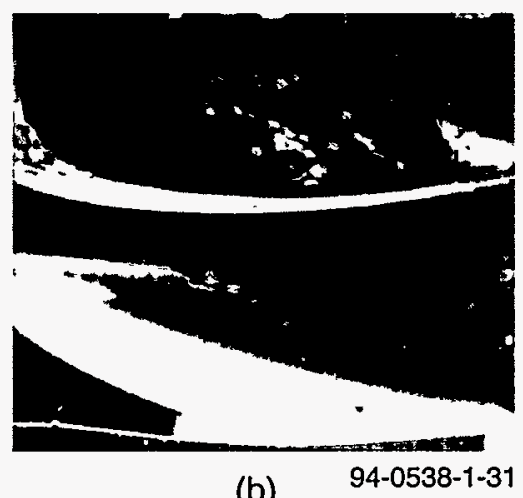

(b)

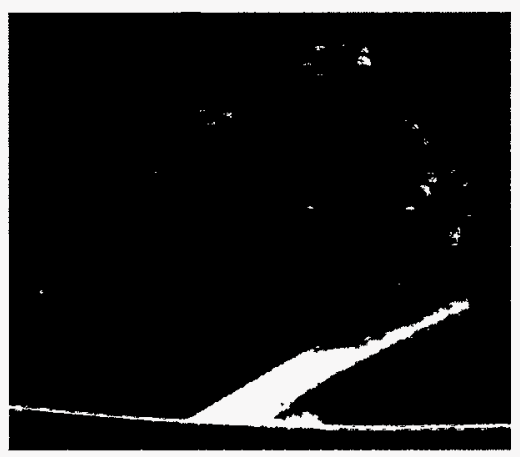

(e)

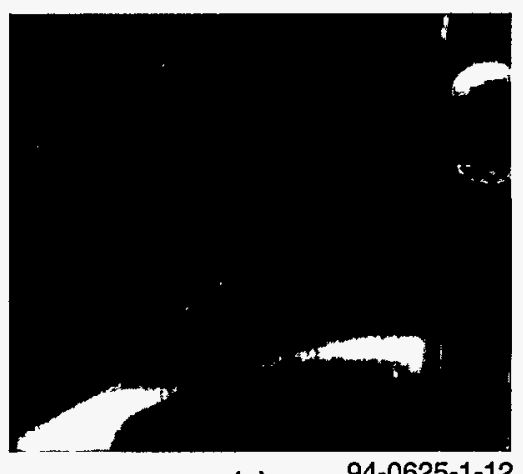

(c)

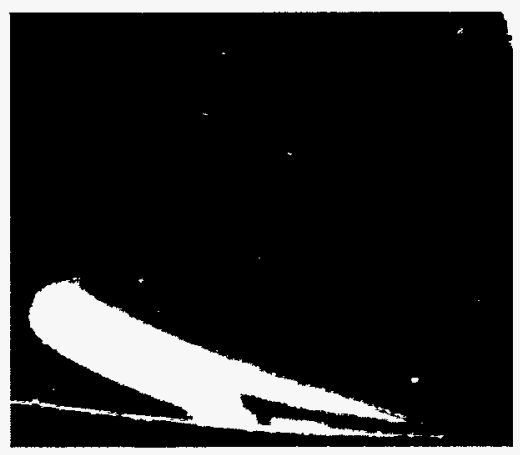

(f)

Figure 76. Vendor-supplied waste-form specimens exposed over time to sterile medium (a) Peach Bottom duplicate 1 at day 20 (b) Peach Bottom duplicate 2 at day 20 (c) Peach Bottom duplicate 1 at day 30 (d) Peach Bottom duplicate 2 at day 30 (e) Peach Bottom duplicate 1 at day 60 (f) Peach Bottom duplicate 2 at day 60 . 


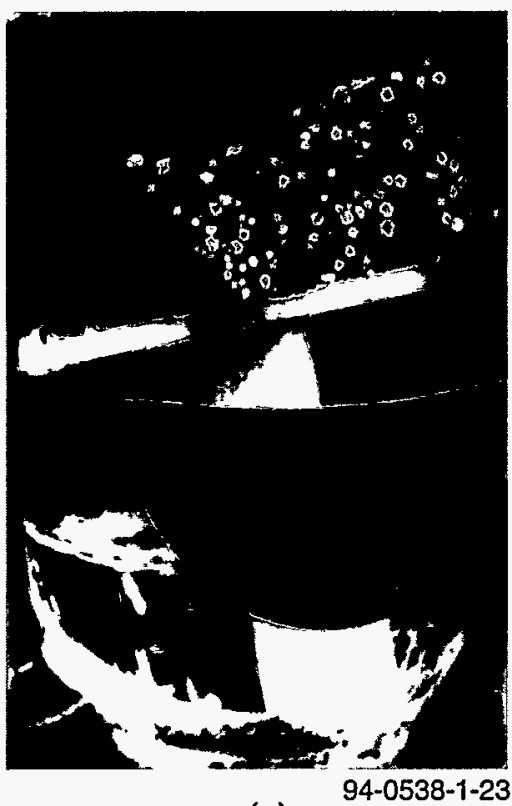

(a)

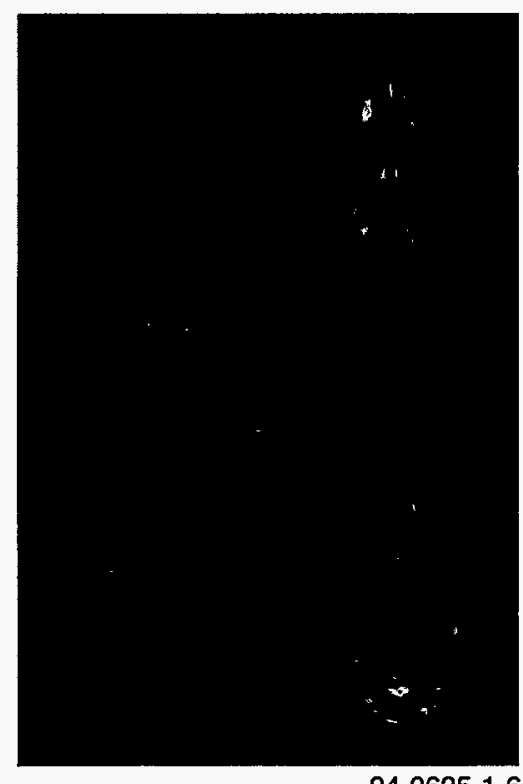

(d)

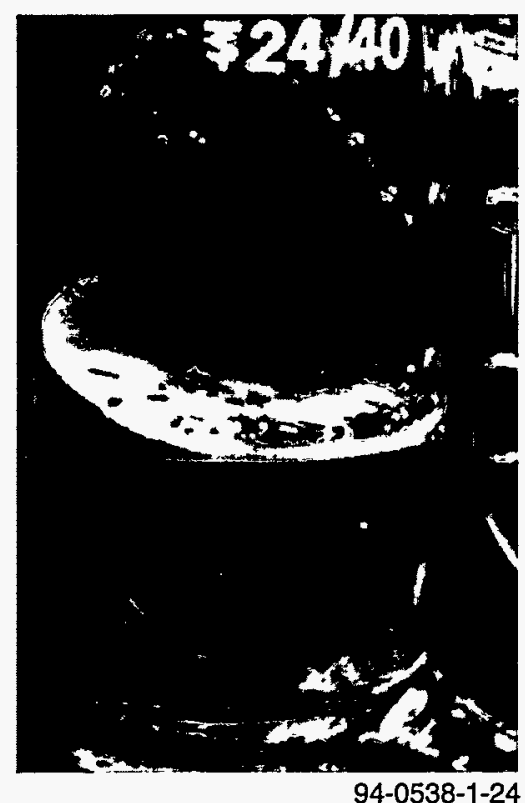

(b)

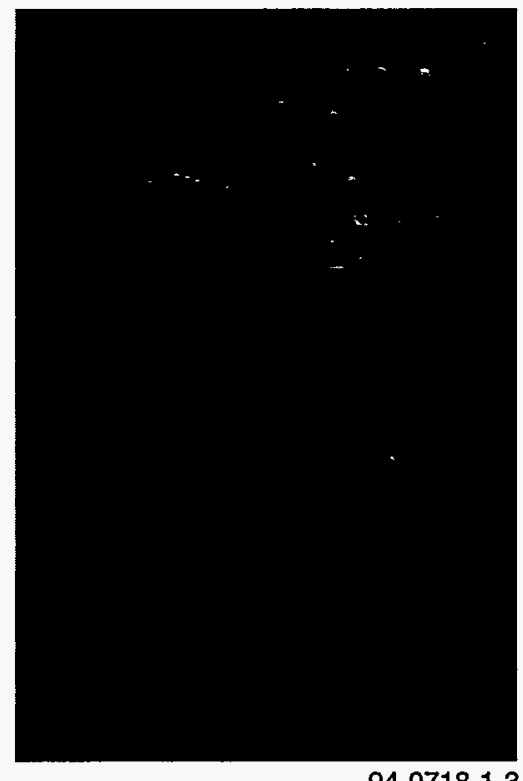

(e)

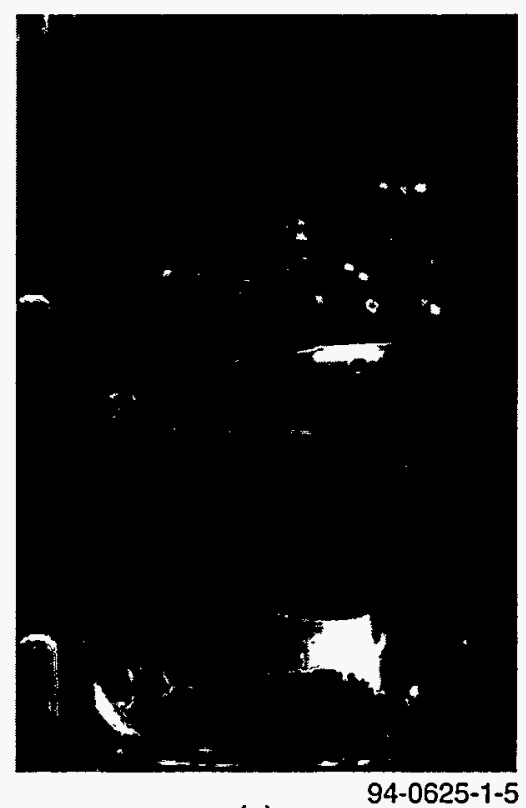

(c)

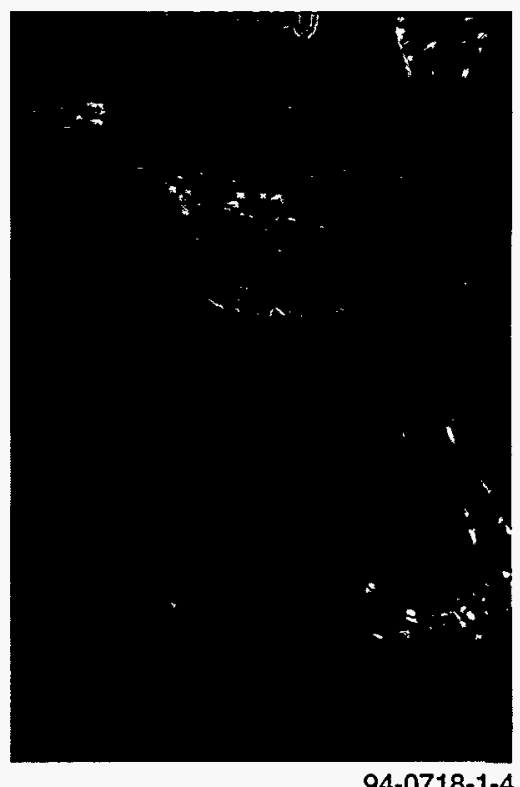

(f)

Figure 77. Vendor-supplied waste-form specimens exposed over time to thiobacilli lixiviant (a) Peach Bottom duplicate 1 at day 20 (b) Peach Bottom duplicate 2 at day 20 (c) Peach Bottom duplicate 1 at day 30 (d) Peach Bottom duplicate 2 at day 30 (e) Peach Bottom duplicate 1 at day 60 (f) Peach Bottom duplicate 2 at day 60 . 


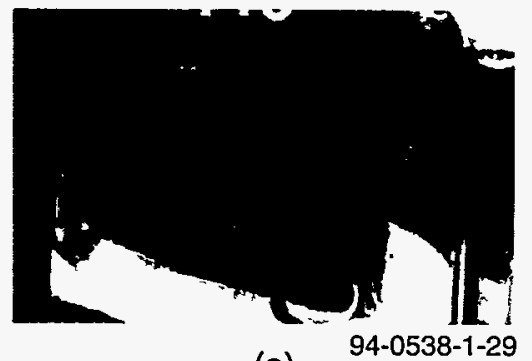

(a)

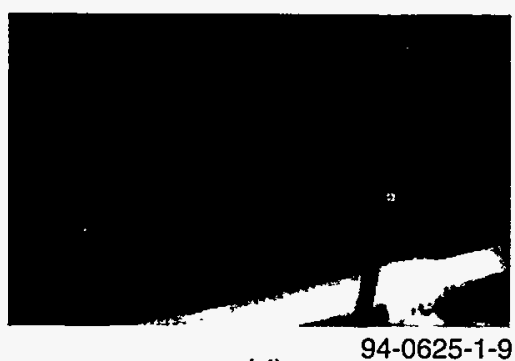

(d)

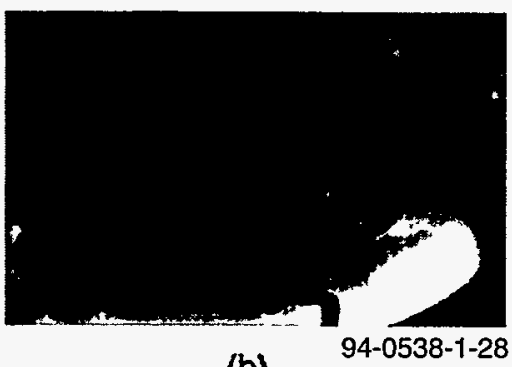

(b)

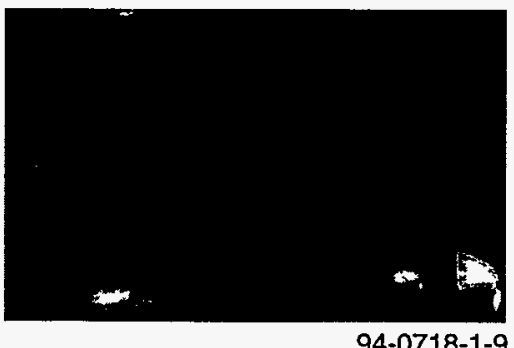

(e)

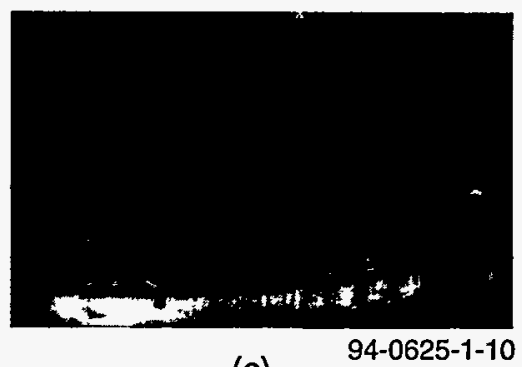

(c)

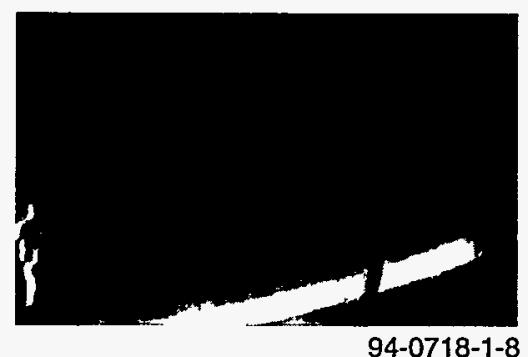

(f)

Figure 78. Vendor-supplied waste-form specimens exposed over time to sterile medium (a) Nine Mile Point duplicate 1 at day 20 (b) Nine Mile Point duplicate 2 at day 20 (c) Nine Mile Point duplicate 1 at day 30 (d) Nine Mile Point duplicate 2 at day 30 (e) Nine Mile Point duplicate 1 at day 60 (f) Nine Mile Point duplicate 2 at day 60 .

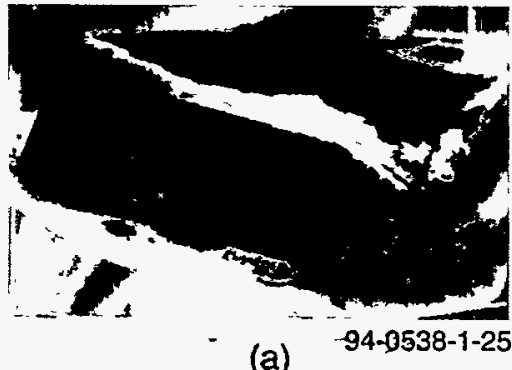

(a)

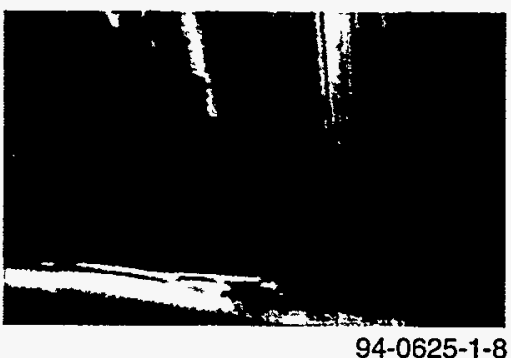

(d)

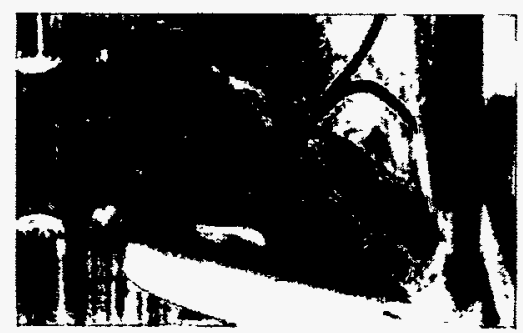

(b)

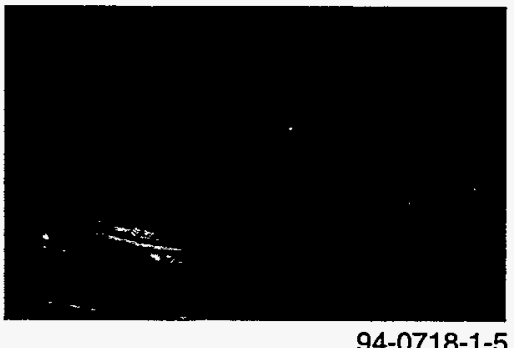

(e)

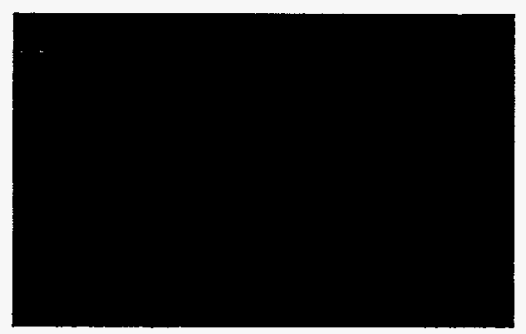

(c)

94-0625-1-7

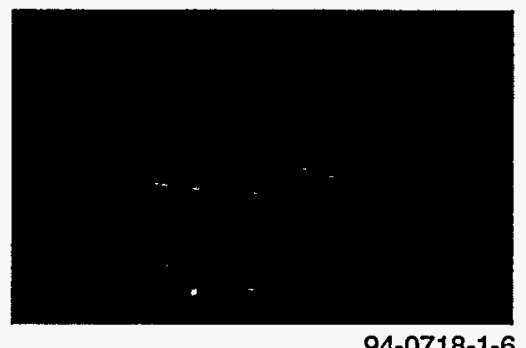

(f)

Figure 79. Vendor-supplied waste-form specimens exposed over time to thiobacilli lixiviant (a) Nine Mile Point duplicate 1 at day 20 (b) Nine Mile Point duplicate 2 at day 20 (c) Nine Mile Point duplicate 1 at day 30 (d) Nine Mile Point duplicate 2 at day 30 (e) Nine Mile Point duplicate 1 at day 60 (f) Nine Mile Point duplicate 2 at day 60 . 


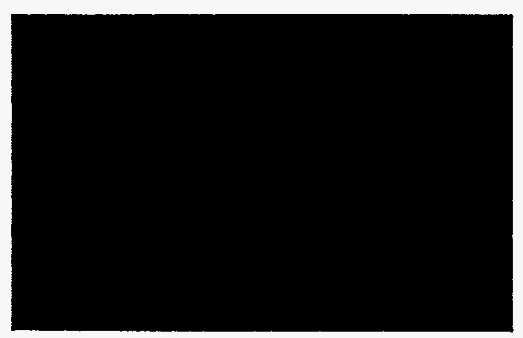

(a)

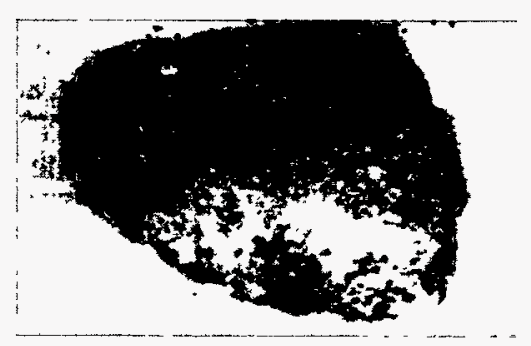

(b)

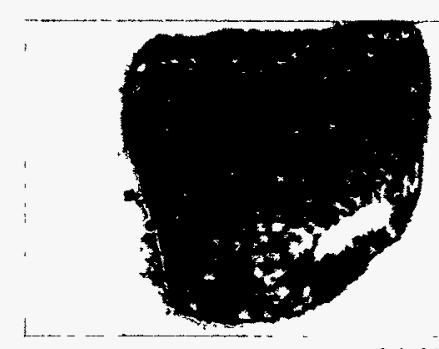

(c)

$94-0926-1-9$

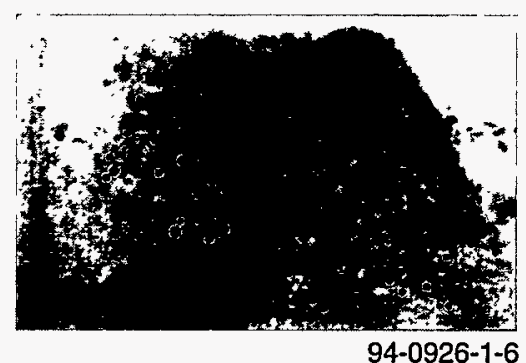

(d)

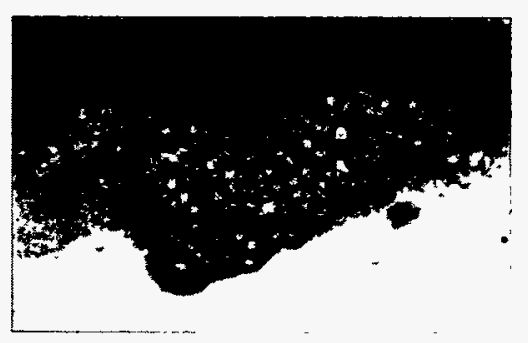

(e)

94-0926-1-7

Figure 80. Recovered vendor-supplied Peach Bottom waste-form specimens (a) before exposure (b) duplicate 1 after 60-day exposure to sterile medium (c) duplicate 2 after 60-day exposure to sterile medium (d) duplicate 1 after 60-day exposure to thiobacilli lixiviant (e) duplicate 2 after 60-day exposure to thiobacilli lixiviant.

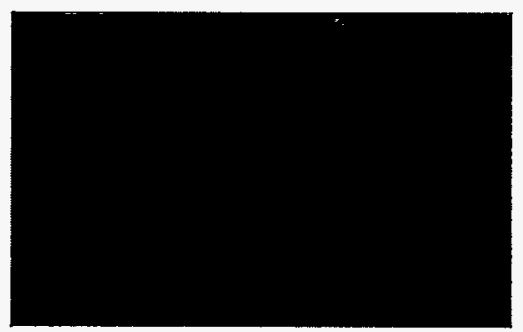

(a)

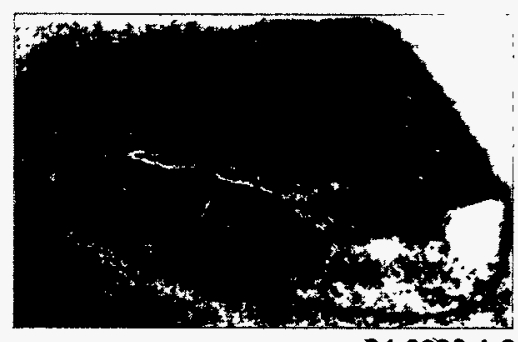

(b)

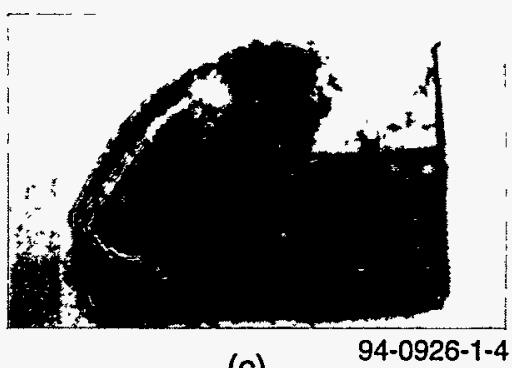

(c)

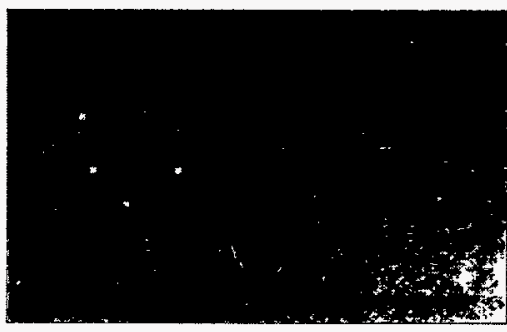

(d)

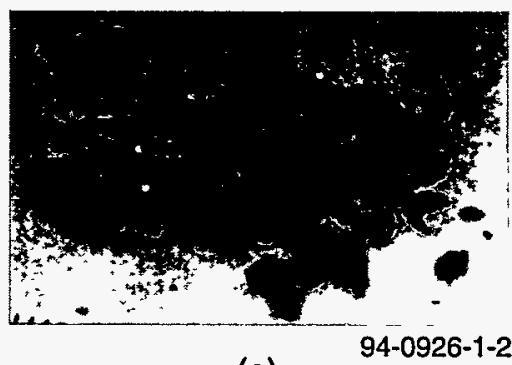

(e)

Figure 81. Recovered vendor-supplied Nine Mile Point waste-form specimens (a) before exposure (b) duplicate 1 after 60-day exposure to sterile medium (c) duplicate 2 after 60-day exposure to sterile medium (d) duplicate 1 after 60-day exposure to thiobacilli lixiviant (e) duplicate 2 after 60-day exposure to thiobacilli lixiviant. 
Experimental Results

Table 14. Quantities of Co-60, Cs-137, and Cs-134 leached over time from Peach Bottom cement-solidified low-level waste-form specimens as a result of the accelerated biotest.

\begin{tabular}{|c|c|c|c|c|c|c|c|}
\hline \multirow[b]{3}{*}{ Treatment } & \multicolumn{7}{|c|}{ Total pCi nuclide } \\
\hline & \multirow[b]{2}{*}{ Week } & \multicolumn{2}{|c|}{ Co-60 } & \multicolumn{2}{|c|}{ Cs-137 } & \multicolumn{2}{|c|}{ Cs-134 } \\
\hline & & $\operatorname{Rep} 1$ & Rep 2 & $\operatorname{Rep} 1$ & $\operatorname{Rep} 2$ & $\operatorname{Rep} 1$ & Rep 2 \\
\hline \multirow[t]{8}{*}{ Medium } & 1 & 60372.0 & 54470.0 & 15652.0 & 31980.0 & 0.0 & 0.0 \\
\hline & 2 & 25882.5 & 22620.0 & 362.3 & 1566.5 & 0.0 & 0.0 \\
\hline & 3 & 126000.0 & 26180.0 & 1351.0 & 840.0 & 0.0 & 0.0 \\
\hline & 4 & 13370.0 & 11550.0 & 171.5 & 371.0 & 0.0 & 0.0 \\
\hline & 5 & 15960.0 & 13140.0 & 503.5 & 234.0 & 0.0 & 0.0 \\
\hline & 6 & 6040.0 & 5200.0 & 240.0 & 244.0 & 0.0 & 0.0 \\
\hline & 7 & 7150.0 & 7975.0 & 250.0 & 253.0 & 0.0 & 0.0 \\
\hline & 8 & 166750.0 & 135000.0 & 355.3 & 546.8 & 0.0 & 0.0 \\
\hline \multirow[t]{8}{*}{ Lixiviant } & 1 & 374000.0 & 777150.0 & 20000.0 & 45193.5 & 0.0 & 0.0 \\
\hline & 2 & 265500.0 & 287500.0 & 2955.0 & 1717.5 & 0.0 & 0.0 \\
\hline & 3 & 373500.0 & 242250.0 & 1183.5 & 641.3 & 0.0 & 0.0 \\
\hline & 4 & 165000.0 & 174000.0 & 0.0 & 632.0 & 0.0 & 0.0 \\
\hline & 5 & 525000.0 & 434000.0 & 0.0 & 917.0 & 0.0 & 0.0 \\
\hline & 6 & 303000.0 & 364000.0 & 0.0 & 1361.8 & 0.0 & 0.0 \\
\hline & 7 & 323000.0 & 273750.0 & 952.0 & 0.0 & 0.0 & 0.0 \\
\hline & 8 & 225000.0 & 391500.0 & 0.0 & 733.5 & 0.0 & 0.0 \\
\hline
\end{tabular}


Table 15. Quantities of Co-60, Cs-137, and Cs-134 leached over time from Nine Mile Point cement-solidified low-level waste-form specimens as a result of the accelerated biotest.

\begin{tabular}{|c|c|c|c|c|c|c|c|}
\hline \multirow[b]{3}{*}{ Treatment } & \multicolumn{7}{|c|}{ Total pCi nuclide } \\
\hline & \multirow[b]{2}{*}{ Week } & \multicolumn{2}{|c|}{$\mathrm{Co}-60$} & \multicolumn{2}{|c|}{ Cs-137 } & \multicolumn{2}{|c|}{ Cs-134 } \\
\hline & & Rep 1 & $\operatorname{Rep} 2$ & $\operatorname{Rep} 1$ & $\operatorname{Rep} 2$ & $\operatorname{Rep} 1$ & $\operatorname{Rep} 2$ \\
\hline \multirow[t]{8}{*}{ Medium } & 1 & 8100.0 & 7725.0 & 1507500.0 & 1582500.0 & 4005.0 & 3840.0 \\
\hline & 2 & 4277.0 & 4550.0 & 338000.0 & 351000.0 & 845.0 & 877.5 \\
\hline & 3 & 6221.6 & 5075.0 & 532000.0 & 469000.0 & 1414.0 & 1176.0 \\
\hline & 4 & 3206.0 & 3451.0 & 150500.0 & 175000.0 & 402.5 & 465.5 \\
\hline & 5 & 5814.0 & 3543.0 & 266000.0 & 183750.0 & 725.8 & 418.3 \\
\hline & 6 & 2907.0 & 3701.8 & 165325.0 & 187000.0 & 412.3 & 501.5 \\
\hline & 7 & 2667.5 & 2392.5 & 187000.0 & 165000.0 & 555.5 & 380.6 \\
\hline & 8 & 47385.0 & 56980.0 & 188500.0 & 238000.0 & 531.1 & 588.0 \\
\hline \multirow[t]{8}{*}{ Lixiviant } & 1 & 169000.0 & 238000.0 & 2080000.0 & 2401250.0 & 5330.0 & 5992.5 \\
\hline & 2 & 69000.0 & 75000.0 & 325500.0 & 379500.0 & 837.0 & 958.5 \\
\hline & 3 & 175500.0 & 114750.0 & 643500.0 & 429250.0 & 1390.5 & 935.0 \\
\hline & 4 & 31500.0 & 67500.0 & 117000.0 & 193500.0 & 272.3 & 483.8 \\
\hline & 5 & 227500.0 & 53625.0 & 234000.0 & 46540.0 & 0.0 & 0.0 \\
\hline & 6 & 168000.0 & 153000.0 & 105000.0 & 99000.0 & 257.4 & 345.0 \\
\hline & 7 & 150000.0 & 165000.0 & 81000.0 & 82500.0 & 0.0 & 0.0 \\
\hline & 8 & 187000.0 & 96000.0 & 89250.0 & 80000.0 & 0.0 & 0.0 \\
\hline
\end{tabular}


Table 16. Total quantity of C-14, Tc-99, and Sr-90 leached over 8 weeks from Peach Bottom and Nine Mile Point cement-solidified low-level waste-form specimens as a result of the accelerated biotest.

\begin{tabular}{|c|c|c|c|c|c|c|c|}
\hline \multirow[b]{3}{*}{ Treatment } & \multirow[b]{3}{*}{ Rep } & \multicolumn{6}{|c|}{ Total pCi nuclide } \\
\hline & & \multicolumn{2}{|c|}{$\mathrm{C}-14$} & \multicolumn{2}{|c|}{ Tc-99 } & \multicolumn{2}{|c|}{ Sr-90 } \\
\hline & & $\mathrm{PB}$ & NMP & $\mathrm{PB}$ & NMP & $\mathrm{PB}$ & NMP \\
\hline \multirow[t]{2}{*}{ Medium } & 1 & 202 & 59 & 84 & 238 & 2,423 & 51,480 \\
\hline & 2 & 243 & 66 & 124 & 147 & 4,969 & 33,191 \\
\hline \multirow[t]{2}{*}{ Lixiviant } & 1 & 313 & 773 & 745 & 853 & 15,283 & 90,860 \\
\hline & 2 & 358 & 452 & 1,024 & 1,302 & 29,804 & 92,660 \\
\hline
\end{tabular}

data are averaged based on treatment, the thiobacilli treatment appears to have released more $\mathrm{Cs}-137$ than the medium $(38,143 \mathrm{pCi}$ versus $27,442 \mathrm{pCi})$. While there may not be a significant difference between these averaged data, they do follow the trend in which more nuclides were leached due to the thiobacilli treatment.

Data for the cumulative removal of Co-60, Cs-137, and Cs-134 over time from each treatment and waste-form specimen type is also presented (Figures 82 through 86 ). These data (Figures 82 and 84 ) show that release of Co-60 from both waste-form specimen types was dependant on the thiobacilli treatment. The rates of Co-60 released from the two types of waste-form specimens appeared to be very similar. Action by the sterile medium occurred at almost a negligible rate when-compared with that of the treatment. The release of Co-60 from all the specimens was being maintained at a constant rate by the end of the eighth week. There was a distinctly different pattern of $\mathrm{Cs}$ release compared to that of the Co-60, as seen in Figures 83, 85, and 86. First, it is noted that Cs release was not entirely dependent on the treatment. There was a parallel Cs release for treatments exposed to lixiviant and sterile medium. Next, for the PB specimens (Figure 83), the majority of Cs-137 loss occurred within the first week, while for the NMP specimens exposed to the biotreatment, the rate of Cs-137 and Cs-134 leaching decreased after the third week (Figures 85 and 86). The total amount of Cs leached due to both treatments stabilized by the end of the eighth week. The figures, however, show that the rate of the leaching process was greater in the thiobacilli treatments.

Analyses of the composited effluent samples showed that more total quantities of $\mathrm{C}-14$ and $\mathrm{Sr}-90$ were removed from the treated NMP specimens than from the treated $\mathrm{PB}$ specimens (Table 16). The amount of liberated Tc-99 was comparable for both waste form types (Table 16). Again, those waste forms exposed to the thiobacilli lixiviant had more nuclides removed than the controls. On average, there was approximately $1.5,8.5$, and 6.1 times more C-14, Tc-99, and Sr-90, respectively, leached from the PB specimens treated with the thiobacilli lixiviant than from the samples treated with the control medium. For the NMP specimens, these values were $9.9,5.6$, and 2.2 , respectively. 


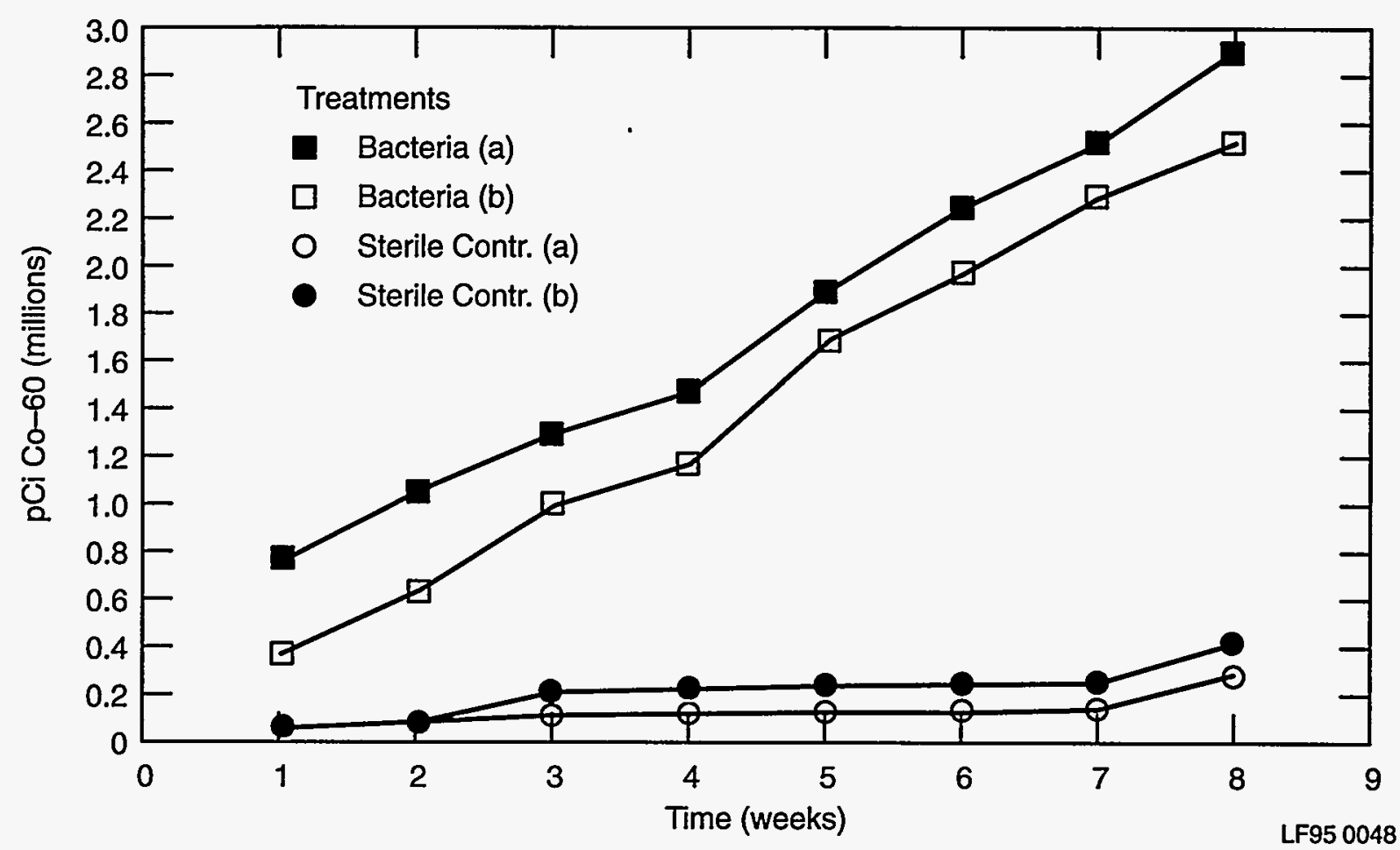

Figure 82. Cumulative Co-60 leached over time from Peach Bottom waste-form specimens exposed to either sterile medium or thiobacilli lixiviant.

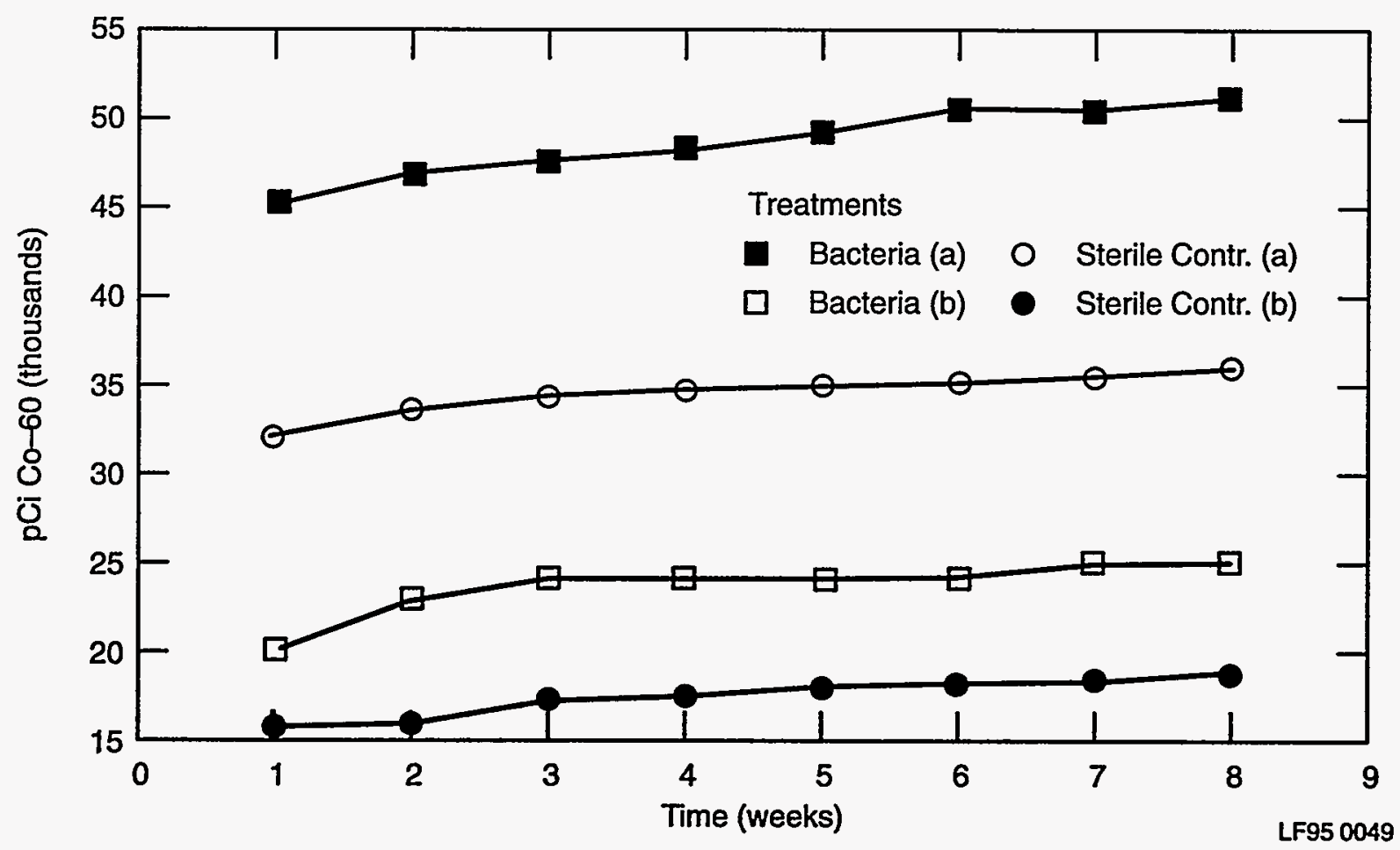

Figure 83. Cumulative Cs-137 leached over time from Peach Bottom waste-form specimens exposed to either sterile medium or thiobacilli lixiviant. 
Experimental Results

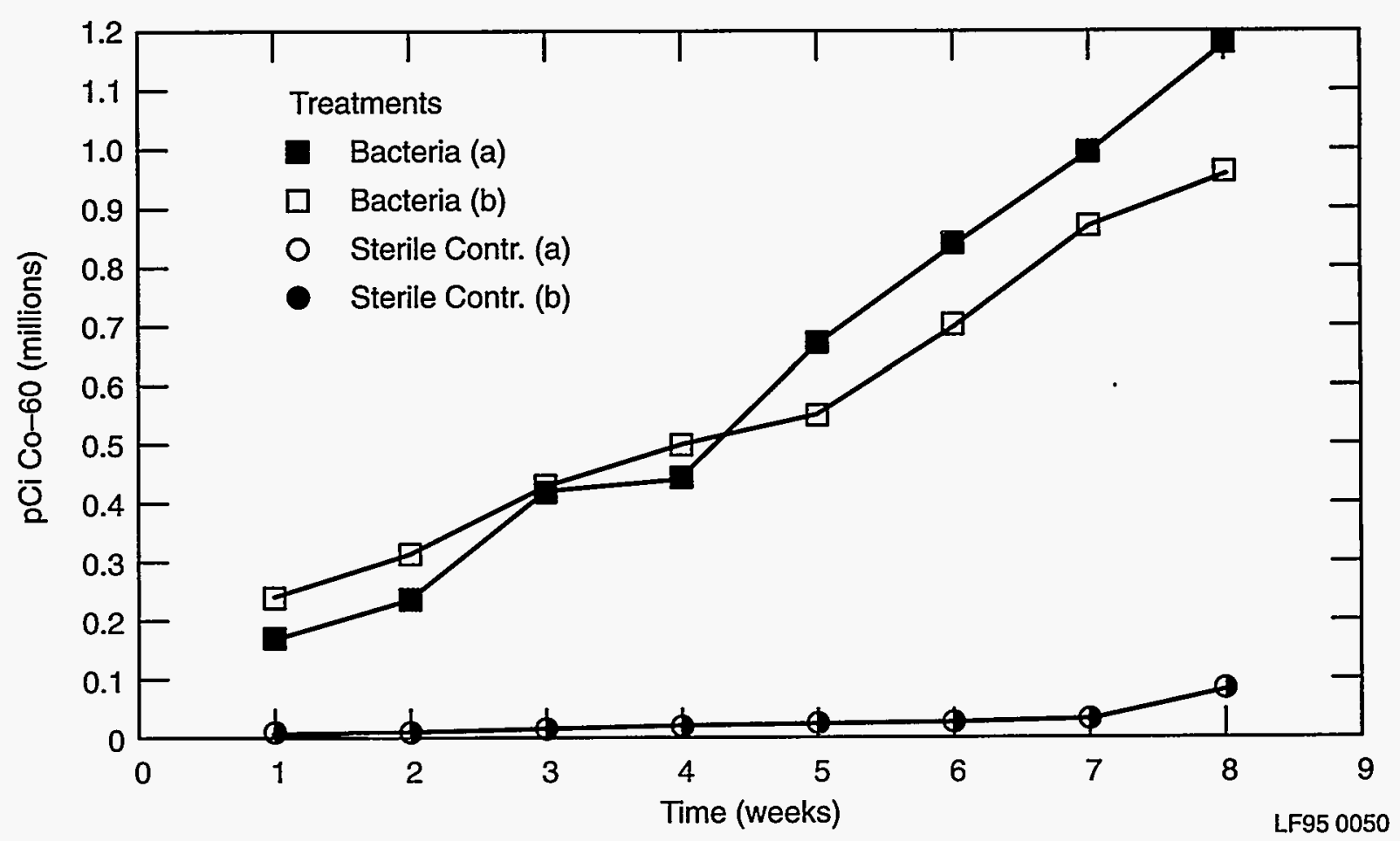

Figure 84. Cumulative Co-60 leached over time from Nine Mile Point waste-form specimens exposed to either sterile medium or thiobacilli lixiviant.

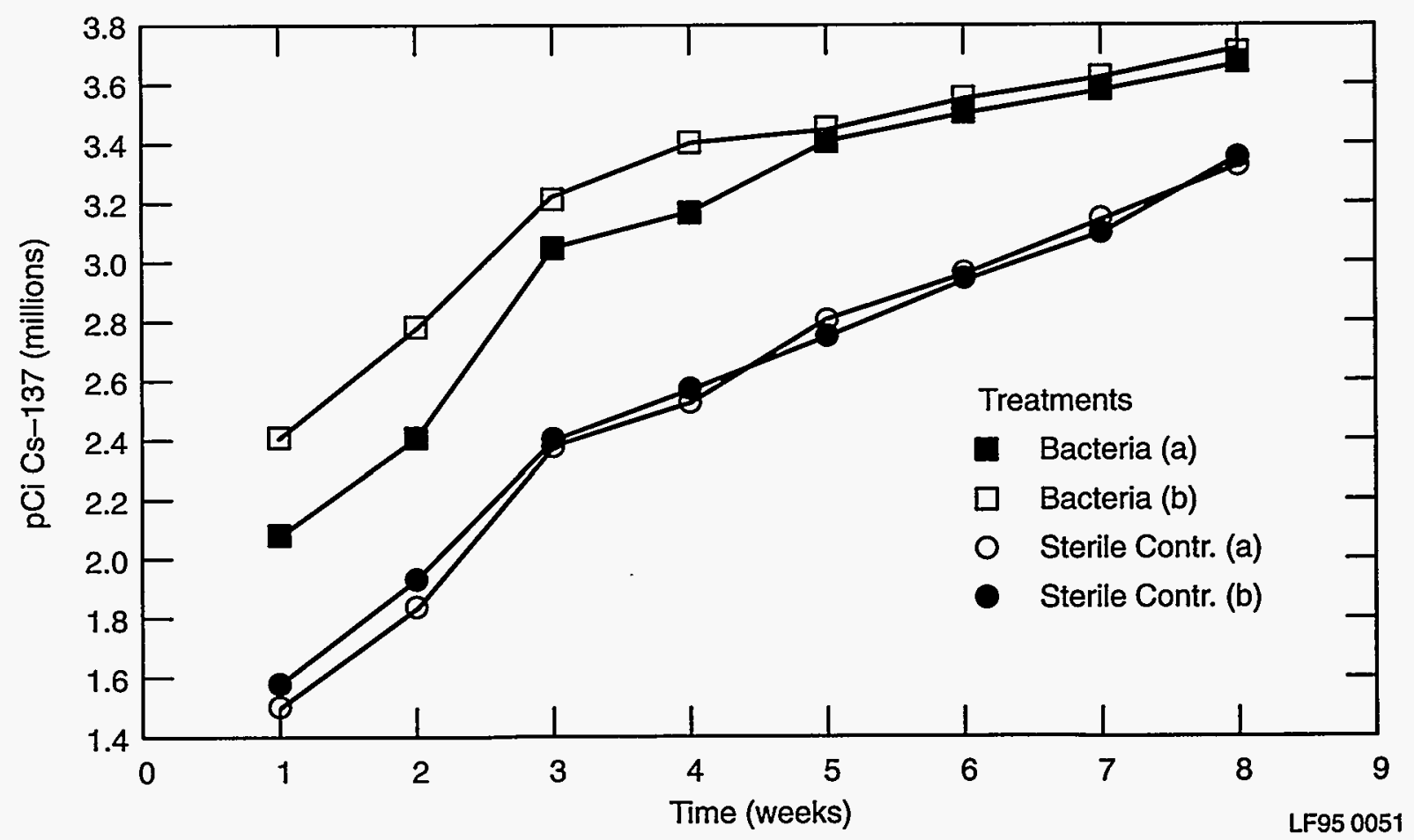

Figure 85. Cumulative Cs-137 leached over time from Nine Mile Point waste-form specimens exposed to either sterile medium or thiobacilli lixiviant. 


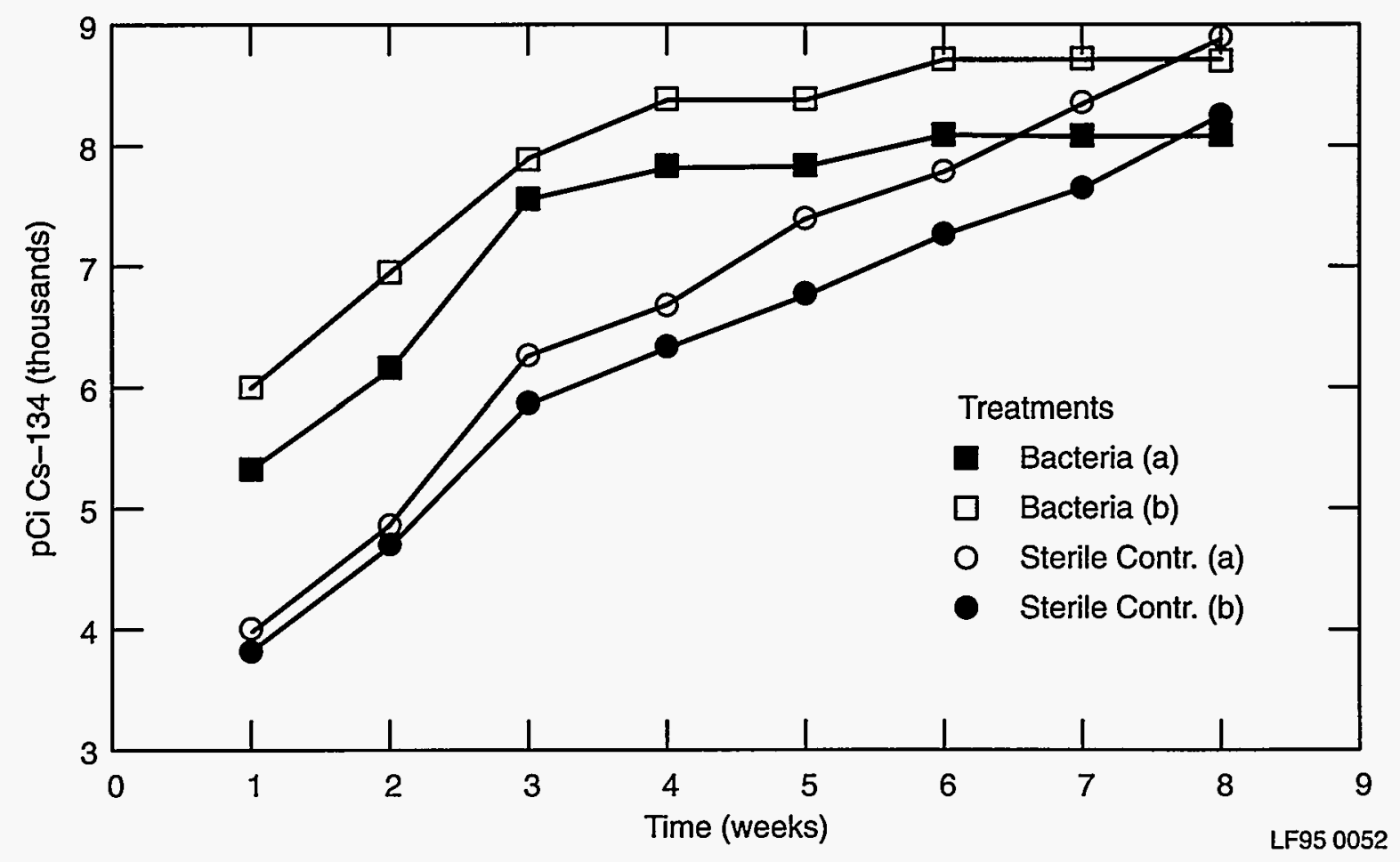

Figure 86. Cumulative Cs-134 leached over time from Nine Mile Point waste-form specimens exposed to either sterile medium or thiobacilli lixiviant. 


\section{SUMMARY}

The literature provides data showing that there are microorganisms that can influence the degradation of cement. Three groups have been identified as principals in the creation of conditions conducive to the degradation of concrete integrity. They include representatives of heterotrophic, nitrifying, and sulfur-oxidizing bacteria. These microbes appear to be ubiquitous in the environment. Work conducted on this program has demonstrated that it is possible to isolate these species of microbes and grow them under laboratory conditions. Representatives of the three genera of MID bacteria have been used in the development of prototype testing methodologies for exposing waste-form specimens to microbial effects. The evaluated methods include exposure of wasteform specimens in constant flow solutions containing microbial biomass and metabolic products (lixiviant). For nitrifying bacteria, a fed-batch system was used. Systems tested using sulfur-oxidizing bacteria included total immersion, intermittent immersion, and intermittent lixiviant mist.

It was shown that exposure to heterotrophic bacteria did not have the same effect as the thiobacilli. Effects similar to those described above were not seen after 60 days of total immersion of specimens in heterotrophic lixiviant. In addition, initial work with the nitrifying bacteria using the fed batch method showed that exposure periods over 60 days were suggested before effects comparable to the thiobacilli are obtained.

Demonstration of the three methods for the sulfur-oxidizing bacteria has been completed using T. thiooxidans and T. ferrooxidans. When used with these microorganisms, the exposure methods appear to be very conservative in nature because they expose simulated waste-form specimens to an environment that promotes active microbially influenced degradation (MID). Extensive damage to tested, simulated wasteform specimens occurred from each exposure methodology by the end of 60 days. Based on test results, it was determined that the intermittent immersion method, using Soxhlet columns for exposure cells, provided more control of lixiviant delivery to the test specimen and subsequent effluent recovery.

It was found with both the nitrifier and thiobacilli that the presence of the cement-solidified waste did not hinder the active growth of planktonic microbes. Further, it was established that the microbes could colonize the cement waste-form specimen surface and initiate the formation of a biofilm. This information was confirmed by both selective staining and SEM. These data were considered important since the presence of biofilm EPS on a waste form surface indicates that the microorganisms are not only tolerating the chemical conditions of the surface, but they are also able to proliferate. The implication of these findings is that biofilm formation with accompanying microbial activity would contribute to degradation of infected waste forms. This is an important finding because MID microorganisms have been shown to exist at actual and proposed LLW disposal sites (Rogers et al. 1994), and it indicates that in a natural, low-level waste disposal setting, microbes could proliferate at the soil/waste form interface or waste form surface. Under such intimate conditions, the MID microorganisms would be protected from the environment while challenging the integrity of the waste form.

In general, this work has shown that production of acid as a function of obtaining energy for metabolism can cause a significant decrease in the $\mathrm{pH}$ of both waste form surfaces and solutions. This is obvious from the strong inverse correlation between oxidation of reduced forms of nitrogen and sulfur and the $\mathrm{pH}$ decrease observed in inoculated treatments and uninoculated controls. The increase in solubilized $\mathrm{Ca}$ associated with the biological treatments shows that the presence of MID bacteria contributed to an increase in degradation of the cement matrix of both INEL and vendor-supplied waste-form specimens and the ASTM control formulation.

For the nitrifying bacteria, most-probablenumber enumeration of treated waste form types and the ASTM control demonstrates the presence of a generally stable population of Nitrosomonas 
europea on the respective pellet surfaces. SEM imaging of the inoculated pellet surfaces corroborates bacterial colonization.

Work with the thiobacilli has shown that the effects of MID on treated waste forms can be ascertained by physical, chemical, and biological examination. Physically, exposed waste forms appear to be in various degrees of degradation ranging from eroded surfaces to complete disintegration. The extent of damage appears to depend on the specimen composition and the time of lixiviant exposure. Chemical evidence of MID includes a decrease in exposed lixiviant $\mathrm{pH}$ and a decreased surface $\mathrm{pH}$ of the test specimen. Final $\mathrm{pH}$ of both solutions and surfaces can range from 1 to $\sim 3$. Also, it was found that a substantial number of elements composing the cement matrix of the specimen were solubilized, indicating a loss of waste form integrity.

Based on the stability of operational conditions and the consistency of data, the intermittent immersion exposure system using $T$. thiooxidans was selected for testing waste-form specimens containing radionuclides. The conservative test conditions were used because these waste forms represented a new, untested material. Waste forms used in this study were two varieties of actual cement-solidified low-level waste forms made from power reactor wastes. One contained ionexchange resin waste from the Peach Bottom (PB) Atomic Power Station Unit 3, and the other contained sludge from the Nine Mile Point (NMP) Nuclear Plant Unit 1. Effluents derived from the testing of these specimens were analyzed for gross beta- and gamma-emitting isotopes. In addition, final composite samples were analyzed for Sr-90, Tc-99, and C-14.

Medium exposure had no visible effect on the ASTM control, while there was minor swelling of the NMP specimens (the waste form shape is still well defined). Unlike some INEL studies with other waste-form specimens containing ion-exchange resin, the PB samples were not totally disintegrated, and the exposed individual resin beads appeared to be firmly embedded in the cement matrix. The NMP evaporator bottoms waste-form specimens that were exposed to the thiobacilli lixiviants gradually crumbled, and material loss was evident. Similar physical damage was seen in the $\mathrm{PB}$ ion-exchange resin specimens exposed to sterile lixiviant. Upon close examination, however, there was more extensive damage to all specimens in contact with the lixiviant than was first observed. The NMP specimens were completely disintegrated, and the PB waste-form specimens had crumbled, with evidence of unattached resin beads.

When effluent from the power reactor samples was analyzed for the presence of gross beta- and gamma-emitting nuclides, the PB effluents, generally, were found to have Co-60 and Cs-137; the effluents from the NMP samples contained these nuclides and Cs-134. In addition, C-14, Tc-99, and $\mathrm{Sr}-90$ were found in the composite effluents from both types of waste-form specimens. The data show that the specimens exposed to the thiobacilli lixiviant had a greater loss of Co-60, C-14, Tc-99, and Sr-90 when compared to the controls treated with the sterile medium, while those effects on Cs-137 and -134 were less noticeable. Analysis of the composite effluent samples showed that more total quantities of C-14 and Sr-90 were removed from the treated NMP specimens than from the PB specimens, while the amount of liberated Tc-99 was comparable for both waste form types. Again, those specimens exposed to the thiobacilli lixiviant had more nuclides removed than did the controls. On average, the PB waste forms leached approximately 1.5, 8.5, and 6.1 times more C-14, Tc-99, and Sr-90, respectively, when treated with the thiobacilli lixiviant than they did when treated with the control medium. For the NMP specimens, these values were $9.9,5.6$, and 2.2 , respectively.

These data support the continued development of appropriate tests necessary to determine the resistance of cement-solidified LLW to microbially induced degradation that could impact the stability of the waste form. They also justify the continued effort to define the conditions necessary to support the microbiological growth and population expansion. 


\section{CONCLUSIONS}

This project has been responsible for documenting that microbially influenced degradation (MID) of concrete does occur and that it has direct relevance to the disposal of cement-solidified LLW. In addition, field work showed that MID bacteria are present in soils at LLW sites. Also, it was demonstrated that selected species of microorganisms are capable of degrading cementitious material. Based on these data, a testing methodology was developed to evaluate the effects of MID on cement-solidified LLW waste forms.

This report provides data from three developed biodegradation test methodologies that are suitable for testing cement-solidified low-level waste. Data from several testing scenarios have demonstrated conclusively that cementatious materials can be substantially damaged by the aggressive environment promoted by the activity of specific microorganisms. Of the three genera of bacteria used for testing, the two species of sulfur-oxidizing thiobacilli bacteria were the most aggressive. Use of these bacteria in three different waste form exposure scenarios (total immersion, intermittent immersion, and intermittent misting) has demonstrated that their presence can promote physical damage to simulated waste forms (those containing exchange resin or evaporator bottoms). This work has shown that, under conditions of total immersion (the only exposure method used on these genera), the heterotrophic bacteria can initiate cement degradation. This action occurs over an extended period and is much less effective than the thiobacilli. It was also demonstrated that the nitrifying bacterium used in a fed batch system can initiate cement degradation.

It was shown that both the thiobacilli and the nitrifying bacteria $N$. europea can form biofilms on exposed surfaces of waste forms. (The surface activity of the heterotrophic bacteria was not evaluated.) The active colonization of the waste form surface and resulting formation of a biofilm showed that the bacteria were not adversely affected by cement chemistry. These data indicate that the colonization of the surfaces of cementatious waste forms could occur under natural conditions. It is therefore concluded that prolonged exposure to microbial activity could compromise the integrity of cement-based waste forms. Furthermore, work with specimens of actual waste forms has demonstrated the accelerated release of radionuclides due to microbial action. In an accelerated test, thiobacilli would be the candidate organism of choice. Testing conducted with the developed biodegradation test has convincingly demontrated that cement-solidified LLW waste forms can be attacked and degraded by the action of ubiquitous microorganisms that are present at LLW disposal sites. It was shown that during the degradation process, large percentages of those elements composing the cement matrix of waste forms were removed. In addition, it was conclusively shown that the ability of cement-based waste forms to retain or retard the loss of encapsulated radionuclides was compromised due to the action of microorganisms.

Based on stability of operational conditions and consistency of data, the intermittent immersion exposure system should be used for testing of actual LLW. Also, under present operating conditions, the intermittent immersion system is less likely to have loss of lixiviant through leakage or spills, and therefore will be most effective in controlling the spread of solubilized radioactive contaminants. Because samples of actual radioactive waste forms will represent new, untested material, it is suggested that the conservative test conditions be used for the purposes of the Branch Technical Position testing. This will necessitate that the tests be conducted for at least 60 days and that a thiobacilli be used. While both species of thiobacilli would be appropriate, $T$. thiooxidans has been selected because it is the microorganism most often cited in the literature associated with MID of cement. 


\section{REFERENCES}

Alexander, M., 1982, "Most Probable Number Method for Microbial Populations," Methods of Soil Analysis, Part 2, Chemical and Microbiological Properties, Chapter 39, p. 815-820, Agronomy Monograph No. 9, ASA-SSSA, Madison, WI.

ANS (American Nuclear Society), 1992, World Directory of Radwaste Managers, First Edition, American Nuclear Society, La Grange Park, IL, pp. 226.

ASTM (American Society for Testing and Materials), 1981a, "Standard Practice for Determining Resistance of Synthetic Polymeric Materials to Fungi," ASTM G21-70, 1981 Annual Book of Standards, Part 35.

ASTM, 1981b, "Standard Practice for Determining Resistance of Plastic to Bacteria," ASTM G22-76, 1981 Annual Book of Standards, Part 35.

ASTM, 1990, "Standard Test Methods of Compressive Strength of Hydraulic Cement Mortar," ASTM C109-90, 1990 Annual Book of ASTM Standards.

Bailey, J. E. and D. F. Ollis, 1986, Biochemical Engineering Fundamentals, McGraw-Hill, Inc., New York.

Colombo, P. and R. M. Neilson, Jr., 1979, Properties of Radioactive Wastes and Waste Containers, NUREG/CR-0619, BNL-NUREG-50591, Brookhaven National Laboratory.

Diercks, M., W. Sand, and E. Bock, 1991, "Microbial Corrosion of Concrete," Experientia 47, pp. 514-516.

Dunk, M., 1991, Influences of Microbiology on Nuclear Waste Disposal, DOE/HMIP/RR/91/033, HMIP Department of the Environment.

Francis, A. J., S. Dobbs, and R. J. Nine, 1980, "Microbial Activity of Trench Leachates from Shallow-land Low-level Radioactive Waste Disposal Sites," Applications of Environmental Microbiology, 40, pp. 108-113.

Garret, R. H. and A. Nason, 1969, "Further Purification and Properties of Neurospora Nitrate Reductase," Journal of Biological Chemistry, 244, pp. 2870-2882.

Grady, C. P. L., Jr. and H. C. Lim, 1980, Biological Wastewater Treatment: Theory and Applications, Marcel Dekker, Inc., New York.

Islander, R. L., J. S. Devinny, R. Mansfeld, A. Postyn, and H. Shih, 1991, "Microbial Ecology of Crown Corrosion in Sewers," Journal of Environmental Engineering, 177, pp. 751-770.

Katznelson, H. and B. Bose, 1959, "Metabolic Activity and Phosphate-dissolving Capability of Bacterial Isolates from Wheat Roots, Rhizosphere, and Non-rhizosphere Soil," Canadian Journal of Microbiology, 5, pp. 79-85.

Libert, M. F., R. Sellier, G. Jouquet, M. Trescinski, and H. Spor, 1993, "Effects of Microorganisms Growth on the Long-term Stability of Cement and Bitumen," Proceedings of the Materials Research Society: Scientific Basis for Nuclear Waste Management XVI Symposium: Boston MA, Volume 294, C. G. Interrante and R. T. Pabalan (eds.), p. 267-272. 
Mansch, R. and E. Bock, 1992, "Simulation of Microbiologically and Chemically Influenced Corrosion of Natural Sandstone," Proceedings of the International Symposium on Microbiologically Influenced Corrosion (MIC) Testing, Miami, FL, November 1992, Special Technical Publication (STP) "MIC Testing."

Mayfield, C. I. and J. F. Barker, 1982, An Evaluation of the Microbiological Activities and Possible Consequences in a Fuel Waste Disposal Vault: A Literature Review, Atomic Energy of Canada Ltd. Report No. TR-139.

Mori, T., T. Nonada, K. Tazake, M. Koga, Y. Hikosaka, and S. Hoda, 1992, "Interactions of Nutrients, Moisture, and pH on Microbial Corrosion of Concrete Sewer Pipes," Water Resources, 26, pp. 29-37.

NRC (U.S. Nuclear Regulatory Commission), 1987, Licensing Requirements for Land Disposal of Radioactive Waste, Title 10, Code of Federal Regulations, Part 61, U.S. Federal Register, Vol. 46, No. 142, July 24, 1987.

NRC, 1991, Technical Position on Waste Form, Revision 1, Low-Level Waste Management Branch, Washington, D.C., January 1991.

Rogers, R. D. and J. W. McConnell, Jr., 1988, Biodegradation Testing of TMI-2 EPICOR-II Waste Forms, NUREG/CR-5137, EGG-2540, Idaho National Engineering Laboratory, June.

Rogers, R. D. and J. H. Wolfram, 1992, "Biological Separation of Phosphate Ore," Mineral Bioprocessing, 1992.

Rogers, R. D., M. A. Hamilton, and J. W. McConnell, Jr., 1993, Microbial-Influenced Cement Degradation - Literature Review, NUREG/CR-5987, EGG-2695, Idaho National Engineering Laboratory, March.

Rogers, R. D., M. A. Hamilton, R. H. Veeh, and J. W. McConnell, Jr., 1994, Microbial Degradation of LowLevel Radioactive Waste, Annual Report for FY 1993, NUREG/CR-6188, Vol. 1, EGG-2730, Idaho National Engineering Laboratory, April.

Rogers, R. D., M. A. Hamilton, R. H. Veeh, and J. W. McConnell, Jr., 1995, Microbial Degradation of LowLevel Radioactive Waste, Annual Report for FY 1994, NUREG/CR-6188, Vol. 2, INEL-95/0153, Idaho National Engineering Laboratory, May.

Sand, W. and E. Bock, 1988, "Biogenic Sulfuric Acid Attack in Sewage Systems," 7th International Biodeterioration Symposium: Cambridge England, D. R. Houghton, R. N. Smith, and H. O. W. Eggins (eds.), pp. 113-117.

Schmidt, E. L. and L. W. Belser, 1982, "Nitrifying Bacteria," Methods of Soil Analysis, Part 2, Chemical and Microbiological Properties, Chapter 48, pp. 1027-1042, Agronomy Monograph No. 9, ASASSSA, Madison, WI.

Tokar, M., 1989, Workshop on Cement Stabilization of Low-Level Radioactive Waste, NUREG/CR-0103, NISTIR 89-4178, October. 


\section{Appendix A \\ Task 8: Intermittent Emersion Test Procedure}




\title{
Microbial Degradation of Cement Waste Forms Letter Report Task 8: Intermittent Emersion Test Procedure
}

\author{
R. D. Rogers \\ M. A. Hamilton \\ R. H. Veeh \\ J. W. McConnell, Jr. \\ Idaho National Engineering Laboratory \\ Managed by the U.S. Department of Energy \\ EG\&G Idaho, Inc. \\ Idaho Falls, ID 83415 \\ Prepared for the \\ Division of Regulatory Applications \\ Office of Nuclear Regulatory Research \\ U.S. Nuclear Regulatory Commission \\ Washington, D.C. 20555 \\ NRC FIN L1807 \\ Under DOE Contract No. DE-AC07-76ID01570
}




\section{Microbial Degradation of Cement Waste Forms Letter Report Task 8: Intermittent Emersion Test Procedure}

\section{INTRODUCTION}

The bacteria Thiobacillus thiooxidans will be used to determine the extent of microbially induced degradation (MID) on actual cement solidified low-level radioactive waste form specimens. Peach Bottom resin and Nine Mile Point sludge wastes, solidified in cement and an American Society for Testing and Materials (ASTM) standard cement formulation will be evaluated under conditions of intermittent immersion in T. thiooxidans lixiviant and compared to waste form specimen under intermittent immersion in sterile growth media. All treatments will be replicated.

The bacteria $\mathrm{T}$. thiooxidans will be grown in a one-liter, continuous flow bioreactor and lixiviant will be pumped to the contact cells at a rate of approximately $100 \mathrm{ml} /$ day/cell. Sterile growth media will be pumped to other contact cells at the same rate. The system has been designed for complete containment of the radioactive waste. Each contact cell will consist of a Soxhlet apparatus containing the waste form or ASTM standard specimen attached to a $500 \mathrm{ml}$ Erlenmeyer flask with a stopcock valve at the base to allow sampling and draining to the appropriate collection carboy (see attached figure).

Effluent samples will be collected daily with a syringe from a sample port at the base of the Erlenmeyer collection flask. Daily liquid samples will be combined to form a weekly composite sample to be analyzed for gamma emitters, and a total composite sample will be collected for analysis of beta emitters for each waste form.

\section{DESCRIPTION}

The experiment is a closed system which was developed to contain radioactive waste produced by the process while exposing the low-level radioactive waste to microbial attack and under intermittent immersion conditions. A one-liter bioreactor (self-contained) will be set up and operated, growing the bacteria T. thiooxidans, with a sterile growth mineral salts and potassium tetrathionate media. Neither the constituents of the growth media nor the bacteria themselves, pose any safety or health hazards. Carboys containing sterile growth media consisting of the formulation given in the table will be brought into the lab periodically to supply feed for the bioreactor. Empty carboys will be monitored for radiation when removed from the lab.

Sterile growth media will be pumped directly into the bioreactor from a carboy as shown in the attached figure. Effluent from the bioreactor will be pumped to contact cells. Any excess effluent (not going directly to the contact cells) will be drained via an overflow tube into a waste carboy: The experiment setup will consists of 12 Soxhlet contact cells. The bioreactor effluent will be distributed to six of the contact cells. Sterile growth media will be pumped from a carboy and distributed to the other contact cells. Eight of the twelve cells will contain a cement solidified, low-level waste form specimen (Peach Bottom Resin solidified in cement or Nine Mile Point Sludge solidified in cement). Four of the cells will contain a waste form specimen fabricated to an ASTM control cement formulation (nonradioactive). $\mathrm{T}$. thiooxidans lixiviant will be directed to four radioactive and two ASTM standard specimens while sterile media will flow to the remaining four radioactive and two ASTM standard form specimens. After effluent (or media) is distributed to the Soxhlets, it will pass over the waste form 


\section{Appendix A}

specimens and accumulate in the Soxhlets. It then will be drained on a periodic basis, every 6 hours, into flasks attached to the Soxhlet tubes and then collected through drain tubes at the base of each flask, into a waste carboy. It will be disposed of as necessary (into hot sinks, warm sinks, or stored for disposal at another facility, whatever is determined appropriate).

A sample port in each flask drain tube will be used to sample the effluent daily with a syringe. These samples will be stored in glass wheaton bottles for radiochemical analysis. Addition of acid for sample preservation will not be necessary because the effluent will have a pH less than 5 . Daily sampling will be in accordance with the attached Daily Sampling Procedure and Checklist.

The experiment is expected to be operating approximately 60 days. At the conclusion of the experiment, all waste will be properly disposed of and the experiment will be dismantled and removed from the laboratory.

\begin{tabular}{ll}
\multicolumn{1}{c}{$\begin{array}{c}\text { Sterile growth } \\
\text { media formulation }\end{array}$} & $\begin{array}{c}\text { Quantity } \\
(\mathrm{g})\end{array}$ \\
\hline $\mathrm{Mg} \mathrm{SO}_{4} \cdot 7 \mathrm{H}_{2} \mathrm{O}$ & 0.4 \\
$\left(\mathrm{NH}_{4}\right)_{2} \mathrm{SO}_{4}$ & 0.5 \\
$\mathrm{CaCL}_{2}$ & 0.25 \\
$\mathrm{KH}_{2} \mathrm{PO}_{4}$ & 3.0 \\
$\mathrm{FeSO}_{4} 0.01 \mathrm{~g}$ & 0.01 \\
$\mathrm{~K}_{2} \mathrm{~S}_{4} \mathrm{O}_{6}$ & 3.0 \\
& \\
& \\
& All in 1 L of doubly deionized water. \\
\hline
\end{tabular}




\section{DAILY OPERATING AND SAMPLING PROCEDURE}

Date:

Operating Procedure

Verify

Check operation per checklist

Record volume in contact cells

Open stopcocks

Draw samples $(45-50 \mathrm{ml})$

Distribute samples in bottles

$20 \mathrm{ml}$ to weekly samples

$25 \mathrm{ml}$ to composite samples

Open clamps and drain contact cells

Close clamps

Close stopcocks

Double check everything

\section{CHECKLIST}

Bioreactor

Mixer condition OK

Temperature: $26-30 \mathrm{C}$

Air flow ON

Culture level OK

Culture turbid OK

$\underline{\text { Lines }}$

No leaks

Pump working OK

Level OK in distribution flask

Level OK in feed carboys

\section{Specimens}

Draining OK

Level OK in collection flasks

Verify drips in each contact cell 


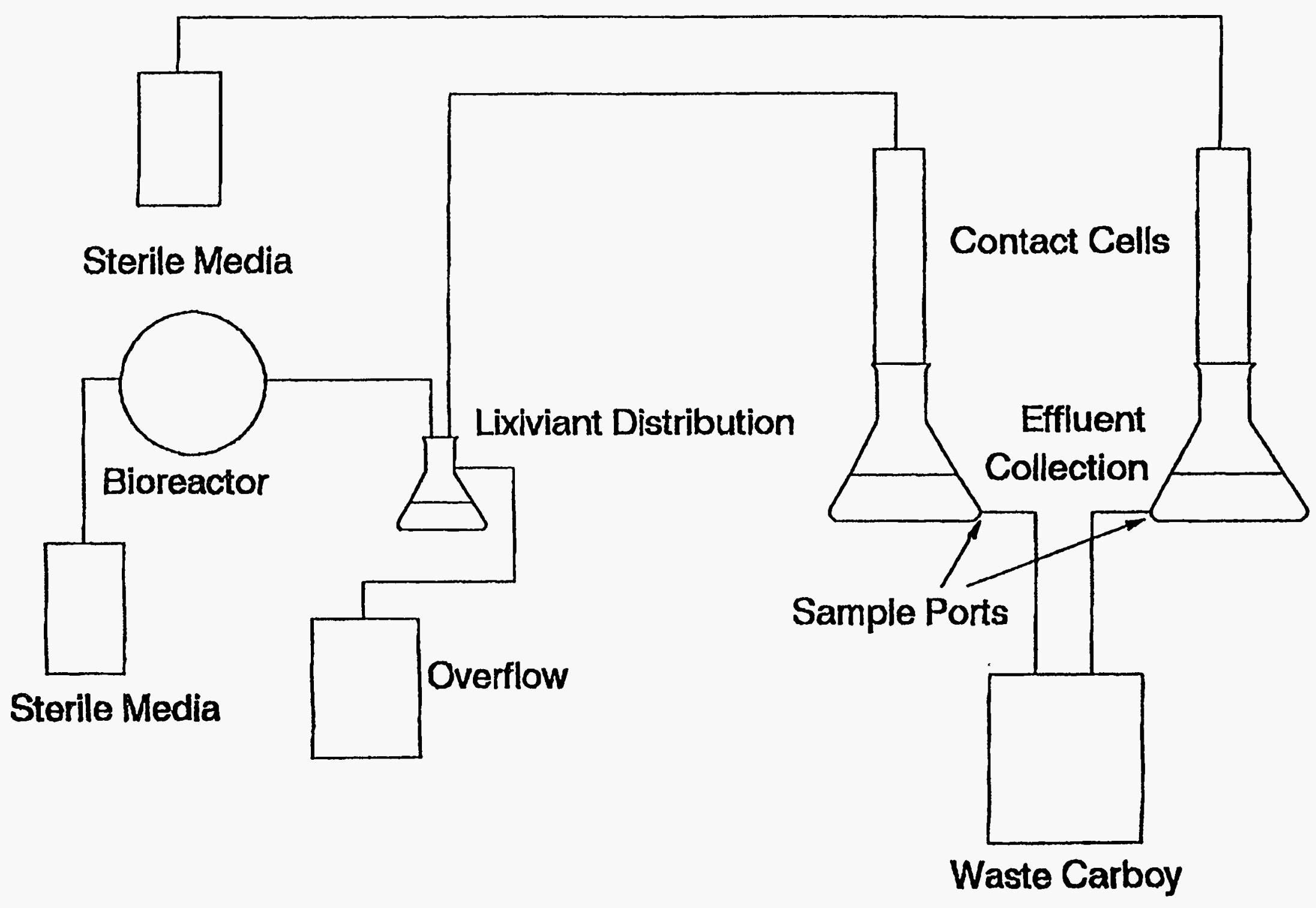




\section{Appendix B \\ Task 7: Development of Criteria for \\ Evaluation of Test Effects}




\title{
Microbial Degradation of Low-Level Radioactive Waste Letter Report Task 7: Development of Criteria for Evaluation of Test Effects
}

\author{
R. D. Rogers \\ M. A. Hamilton \\ R. H. Veeh \\ J. W. McConnell, Jr. \\ Idaho National Engineering Laboratory \\ Managed by the U.S. Department of Energy
}

EG\&G Idaho, Inc.

Idaho Falls, ID 83415

Prepared for the

Division of Regulatory Applications

Office of Nuclear Regulatory Research

U.S. Nuclear Regulatory Commission

Washington, D.C. 20555

NRC FIN L1807

Under DOE Contract No. DE-AC07-76ID01570 


\section{Microbial Degradation of Low-level Radioactive Waste Letter Report Task 7: Development of Criteria for Evaluation of Test Effects}

\section{INTRODUCTION}

\section{Regulatory Background}

Evidence that microorganisms have been isolated in samples taken from low-level radioactive waste (LLW) environments (Francis et al., 1980), combined with scientific data that demonstrate the existence of microorganisms under hostile conditions once thought to exclude them, have raised the concerns that microbial activity at LLW disposal sites could affect the long term stability of the disposed waste. Because of apprehension over possible microbial effects, the United States Nuclear Regulatory Commission (NRC) requires that microbial activity be addressed as one of the requirements for determining the stability of solidified Class B and C LLW [10 CFR 61.56(b)(1)]. This is to ensure that these radioactive wastes will remain immobilized for 300 to 500 years. To provide guidance to disposal vendors and nuclear station waste generators for implementing the stability requirements of 10 CFR 61 (NRC 1982), the NRC developed the Technical Position on Waste Form (TPWF) (NRC 1991).

Concerns over the appropriateness of the TPWF tests for microbial degradation of cement containing LLW were voiced in the NRC sponsored "Proceedings of the Workshop on Cement Stabilization of Low-Level Radioactive Waste" (Tokar, 1989). It became apparent during the deliberations that improved tests would be required if meaningful information were to be obtained from biodegradation studies on cement wastes. A major difficulty identified was that current testing procedures did not adequately provide the necessary test methodology to determine bioeffects on cementitious materials since the microorganisms used for the accelerated testing were note associated with cement degradation. Further, it was pointed out that there were literature references which identified specific microorganisms as the causative agents of cement degradation. The conclusion of the workshop was that "There appeared to be a clear need to specify more appropriate microbes for such (TPWF) test" and that "This [need] might require a substantial research effort." (Tokar, 1989).

Researchers familiar with the required TPWF biodegradation tests, American Society of Testing Materials (ASTM) G21 and G22 (ASTM $1981 \mathrm{a} \& \mathrm{~b}$ ) have found them to be not applicable for use with cement solidified LLW. Doubts raised concerning the tests included the lack of demonstrable evidence that specific microorganisms required by the ASTM standard tests could promote degradation of cement waste forms under any test condition, lack of flexibility in determining the duration of time required for test completion, and lack of flexibility in determining test specimen size and preparation (Rogers and McConnell, 1988).

The NRC's Advisory Committee on Nuclear Waste (ACNW) also has raised concerns about biodegradation testing of $L L W$. In a letter to the Commission dated September 6, 1990, the ACNW indicated that biodegradation testing should be specified for cementitious waste matrices using bacteria that are likely to affect cement as well as any organic component exposed during the degradative process.

Based on the NRC needs, the objective of Task 7 is to identify what significant occurrence or 
change would best be applied as failure criteria for the cement solidified waste form testing.

\section{Technical Background}

Microbially influenced degradation (MID) of concrete has been reviewed elsewhere (Rogers et al., 1993 and 1994). MID of concrete is thought to occur when microorganisms present in the environment produce mineral and organic acids on the surface of the solid that dissolve or disintegrate the cement matrix. Because the microorganisms are not metabolizing the cement matrix, the rate of degradation cannot be determined by measuring the generation of metabolically produced gases. The particular mechanism of biological acid attack on concrete are consistent with those that have been associated with chemical attack (Rogers et al., 1993).

Development of a testing protocol for the determination of the effect of MID on cement solidified waste forms has been based on selection of a microorganism, testing methodology, and degradation evaluation criteria. A knowledge of the types of microorganisms that promote cement degradation can be helpful when evaluating test effects. Preliminary data (Rogers et al., 1993) suggest that the activity of three different genera of bacteria must be understood to provide a comprehensive evaluation of microbial degradation of selected cement-solidified waste materials. These include organic acid-producing heterotrophic bacteria, nitrifying bacteria, and sulfur oxidizing bacteria. The sources of microorganisms together with steps for confirming their viability in selective environments and under various testing schemes have been discussed previously (Rogers et al., 1994); however, it has been shown that the microorganisms associated with MID have been shown to be present in disposal site environments.

The test scheme that was suggested for conducting the testing protocol was the intermittent immersion exposure system (see Task 6 letter report). This selection was made based on stability of operational conditions and consistency of data. Also, under operational conditions, the intermittent immersion system was less likely to have loss of lixiviant through leakage or spills and, therefore, was considered more effective in controlling the spread of solubilized radioactive contaminants.

As a final step in test development, it was necessary to designate some occurrence or change as the indicator of failure for the tested cement specimen. Chemical, physical, and biological parameters were all considered. For example, it has been suggested that defects be determined directly by measuring a metabolic activity such as by-product production (acid etc.) or by use of consumables (oxygen, carbon, inorganic materials, etc.). Others suggested using specimen weight loss, porosity, permeability, or visual deterioration as parameters to evaluate waste form failure. These possibilities are considered below.

\section{Discussion}

It has been our conclusion that criteria for selection of an indicator of waste form failure should be based on a characterization scheme in which the process of degradation is readily apparent, there is inherent reliability, the method provides rapid results, and it is cost effective. During test development it became apparent that physical, chemical, and biological parameters could be used to evaluate waste form performance. The selection of which of these parameters to use for evaluation was made in light of the above criteria. With these criteria in mind, measurements were made before, during, and after each test to gather data to aid in the decision process.

Before testing specimens, their dry weight and physical dimensions were determined for the purpose of establishing a physical baseline. There was also a total chemical analysis performed on selected INEL-fabricated and vendor-supplied, simulated waste forms. Chemical parameters that were evaluated included $\mathrm{pH}$ and elemental determinations. For example, the $\mathrm{pH}$ of leachate solutions has been determined over time as well as a final measurement specimen surface $\mathrm{pH}$. Also, the total quantities of $\mathrm{Ca}, \mathrm{Al}$, and $\mathrm{Si}$ in selected specimens have been determined so that the percentages of elements leached during testing could 
be determined. Based on the results of this activity, there is now a record of the quantity of select elements that are routinely leached from simulated waste forms. As mentioned, physical effects (i.e., color change, swelling, spalling, crumbling, etc.) have been documented with photographs. In addition, evidence of microbial activity has been obtained from efforts to collect microbial isolations and conduct microscopic examination of treated waste form surfaces.

It is apparent that any of the above characteristics could be used as an indication of waste form failure. The question is which one is relevant to the needs of the program. Chemical analysis of the leachate does provide an early indication of MID activity. If there is routine analysis of leachate samples these data can be obtained before there are overt physical signs of deterioration. These data are easy to quantify and lend themselves to intercomparisons between one test and another. However, there is a cost affixed in the collection, storage, analysis, and interpretation of results (i.e., what quantity of a selected element indicates deterioration). As mentioned, the surface $\mathrm{pH}$ of the specimen could serve as an indicator of MID since it has been established that surface $\mathrm{pH}$ is correlated with deterioration (i.e., decreasing surface $\mathrm{pH}$ indicates the increase of surface deterioration). Use of this method would require that the specimen be retrieved and tested at given intervals. A loss of time together with the need for frequent handling of the specimens are the downside of this method. Microbial analysis would require the services of trained technical staff and specialized supplies and equipment. Measurements of weight loss and compressive strength could be made which would involve the handling of treated specimens and the use of some specialized equipment (e.g., compressive testing equipment, etc.).

Based on the selection criteria, the characteristic that is apparent, reliable, rapid, and cheap involves detection of physical signs of deterioration by visual observation. If unspecialized, plant personnel will be required to make a judgement on waste form deterioration, direct visual observation seems to be the most reasonable method for assessing accelerated test effects. However, a more quantitative measurement can be obtained if the loss of radionuclides is measured at specified times during the test, and these data used to calculate a cumulative fractional release (CFR). This CFR would then be comparable to the CFR determined under ANS leach testing (ANS, 1986). In this way, any effects due to microbiological activity would be documented. The use of the CFR method will require that the inventory or initial amount of several constituents of the cement binder in the waste form be determined chemically before the start of the biotest. In addition, the beginning concentration of radionuclides in the waste form will need to be determined. Then, after initiation of the biotest, samples of effluent from the test cells would be collected on a regular basis. These samples would then be analyzed for chemical and radiochemical content and the results compared to the total initial inventory so that the CFR calculation can be made. Lastly, to improve the accountability, credibility, and consistency of results coming from a testing program, it is strongly recommended that certified testing facilities be created and only they be used to perform the testing. 
Appendix B

\section{LITERATURE CITED}

ANS (American National Standard), 1986, "Measurement of the Leachability of Solidified Low-Level Radioactive Wastes by a Short-Term Test Procedure," ANS-16.1, 1986.

ASTM (American Society for Testing and Materials), 1981a, "Standard Practice for Determining Resistance of Synthetic Polymeric Materials to Fungi," ASTM G21-70, 1981 Annual Book of Standards, Part 35.

ASTM, 1981b, "Standard Practice for Determining Resistance of Plastic to Bacteria," ASTM G22-76, 1981 Annual Book of Standards, Part 35.

Francis, A. J., S. Dobbs, and R. J. Nine, 1980, "Microbial Activity of Trench Leachates from Shallow-Land Low-Level Radioactive Waste Disposal Sites," Applications of Environmental Microbiology, 40, pp. 108-113.

NRC (U.S. Nuclear Regulatory Commission), 1987, Licensing Requirements for Land Disposal of Radioactive Waste, Title 10, CFR, Part 61, U.S. Federal Register, Vol. 46, No. 142, July 24, 1987.

NRC, Technical Position on Waste Form, Revision 1, Low-Level Waste Management Branch, Washington, D.C., January 1991.

Rogers, R. D. and J. W. McConnell, Jr., Biodegradation Testing of TMI-2 EPICOR-II Waste Forms, NUREG/CR-5137, June 1988.

Rogers, R. D., M. A. Hamilton, and J. W. McConnell, Jr., 1993, Microbial-Influenced Cement Degradation - Literature Review, NUREG/CR-5987, March 1993.

Rogers, R. D., M. A. Hamilton, and J. W. McConnell, Jr., 1994, Microbial Degradation of Low-Level Radioactive Waste - Annual Report for FY 1993, NUREG/CR-6188, Vol. 1, April 1994.

Tokar, M., Workshop on Cement Stabilization of Low-Level Radioactive Waste, NUREG/CK-0103, NISTIR 89-4178, October 1989. 


\begin{tabular}{|c|c|}
\hline $\begin{array}{l}\text { U.S. NUCLEAR REGULATORY COMMISSION } \\
\text { BIBLIOGRAPHIC DATA SHEET } \\
\text { (SSE instrut:ions on the reversel }\end{array}$ & $\begin{array}{l}\text { 1. REPORT NUMBER } \\
\text { NUREG/CR-6341 }\end{array}$ \\
\hline 2. TITLE AND SUBTITLE & INEL-95/0215 \\
\hline Microbial Degradation of Low-Level Radioactive Waste & 3. DATE REPORT PUBLISHEO \\
\hline Final Report & \begin{tabular}{|l|l} 
MONTH & YEAR \\
June & 1996 \\
\end{tabular} \\
\hline & $\begin{array}{l}\text { A. FIN OR GRANT NUMBER } \\
\text { L1807 }\end{array}$ \\
\hline R. D. Rogers, M. A. Hamilton, R. H. Veeh, J. W. McConnell, Jr. & $\begin{array}{l}\text { 6. TYPE OF AEPOAT } \\
\text { Technical }\end{array}$ \\
\hline & 7. PERIOD COVERED (InCluUtue Doses) \\
\hline \multicolumn{2}{|c|}{ 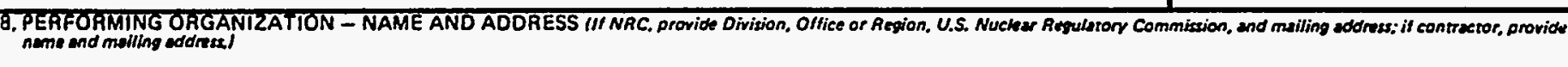 } \\
\hline $\begin{array}{l}\text { Idaho National Engineering Laboratory } \\
\text { Lockheed Idaho Technologies Company } \\
\text { P.O. Box } 1625 \\
\text { Idaho Falls, Idaho } 83415\end{array}$ & \\
\hline
\end{tabular}

Division of Regulatory Applications

Office of Nuclear Regulatory Research

U.S. Nuclear Regulatory Commission

Washington, D.C. 20555-0001

10. SUPPLEMENTARY NOTES

$\therefore$ Reed, NRC Project Ilanager

11. ABSTRACT 1200 words or lessi

The Nuclear Regulatory Commission stipulates in 10 CFR 61 that disposed low-level radioactive waste (LLW) be stabilized. To provide guidance to disposal vendors and nuclear station waste generators for implementing those requirements, the NRC developed the Technical Position on Waste Form, Revision 1. That document details a specified set of recommended testing procedures and criteria, including several tests for determining the biodegradation properties of waste forms. Information has been presented by a number of researchers, which indicated that those tests may be inappropriate for examining microbial degradation of cement-solidified LLW. Cement has been widely used to solidify LLW; however, the resulting waste forms are sometimes susceptible to failure due to the actions of waste constituents, stress, and environment. The purpose of this research program was to develop modified microbial degradation test procedures that would be more appropriate than the existing procedures for evaluation of the effects of microbiologically influenced chemical attack on cement-solidified LLW. The procedures that have been developed in this work are presented and discussed. Groups of microorganisms indigenous to LLW disposal sites were employed that can metabolically convert organic and inorganic substrates into organic and mineral acids. Such acids aggressively react with cement and can ultimately lead to structural failure. Results on the application of mechanisms inherent in microbially influenced degradation of cement-based material are the focus of this final report. Data-validated evidence of the potential for microbially influenced deterioration of cement-solidified LLW and subsequent release of radionuclides developed during this study are presented.

12. KEY WORDS/DESCR!PTORS (List words or phrases thal will essist resesrchers in locating the report.)

Concrete, Cement, Low-Level Radioactive Waste, Microbial Degradation

13. AVAILABILITY STATEMENT
Unlimited
14. SECURITY CLASSIFICATION
TTh/S PAgEI
Unclassified
This REPOOI
Unclassified
15. NUMBER OF PAGES
16. PRICE




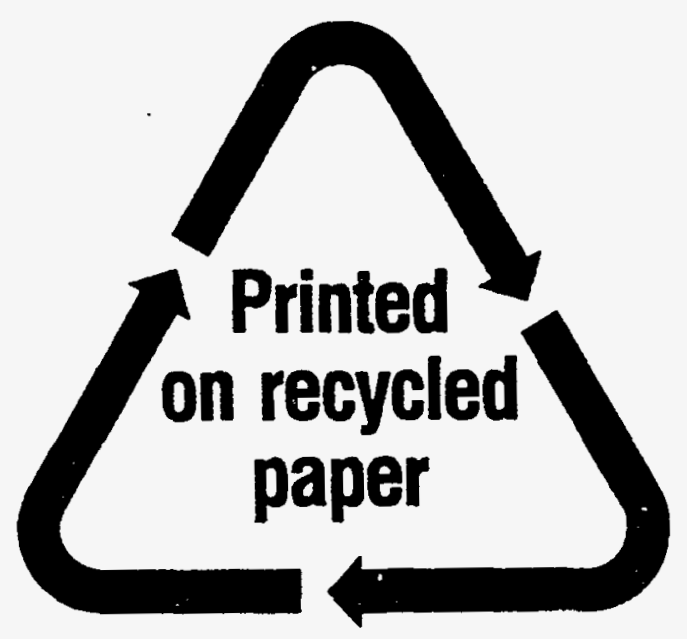

Federal Recycling Program 
NUREG/CR-6341 has been reproduced from the best available copy. 

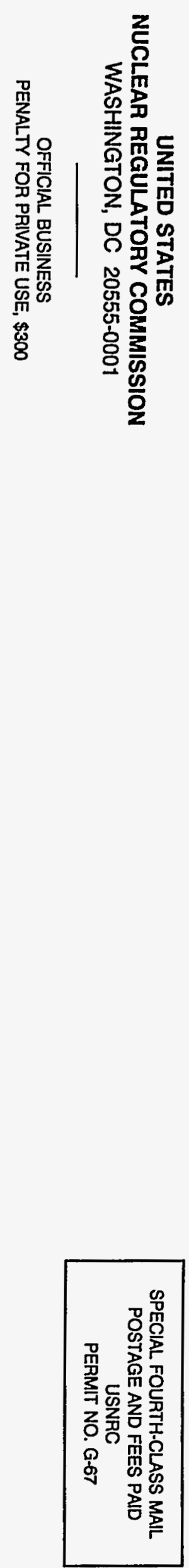